


\section{Propositions}

1. Decisions based on aggregated data further marginalise the marginalised people.

(this thesis)

2. Resource limitation results in reactive strategies of dealing with shocks. (this thesis)

3. Researchers should spend more time listening to farmers and less time asking questions.

4. The hype of big data can divert attention from the problems of poor quality data.

5. Conducting complex analyses helps us to appreciate the power of simple analyses.

6. Developing skills to convey results to society should be equally important in a $\mathrm{PhD}$ candidate's curriculum as developing skills to write scientific papers.

7. Doing a $\mathrm{PhD}$ as a young parent is a family project.

Propositions belonging to the thesis, entitled

'Food security in a changing world: Disentangling the diversity of rural livelihood strategies across Uganda'

Jannike Wichern

Wageningen, 28 May 2019 



\section{Food security in a changing world}

Disentangling the diversity of rural livelihood strategies across

Uganda 


\section{Thesis committee}

\section{Promotor}

Prof. Dr Ken E. Giller

Professor of Plant Production Systems

Wageningen University \& Research

\section{Co-promotors}

Dr Katrien K. E. Descheemaeker

Associate professor, Plant Production Systems Group

Wageningen University \& Research

Dr Mark T. van Wijk

Senior Scientist

International Livestock Research Institute (ILRI), Quito, Ecuador

\section{Other members}

Prof. Dr Fulco Ludwig, Wageningen University \& Research

Dr Fred Kizito, International Institute of Tropical Agriculture (IITA), Tamale, Ghana

Dr Philip K. Thornton, CGIAR Research Program on Climate Change, Agriculture and Food Security (CCAFS), Nairobi, Kenya

Dr Marrit M. van den Berg, Wageningen University \& Research

This research was conducted under the auspices of the C. T. de Wit Graduate school of Production Ecology and Resource Conservation 


\title{
Food security in a changing world \\ Disentangling the diversity of rural livelihood strategies across \\ Uganda
}

\author{
Jannike Wichern
}

Thesis

Submitted in fulfilment of the requirements for the degree of doctor

at Wageningen University

by the authority of the Rector Magnificus,

Prof. Dr A.P.J. Mol,

in the presence of the

Thesis Committee appointed by the Academic Board

to be defended in public

on Tuesday 28 May 2019

at 4.00 p.m. in the Aula. 
Jannike Wichern

Food security in a changing world: Disentangling the diversity of rural livelihood strategies across Uganda, $v i+226$ pages.

$\mathrm{PhD}$ thesis, Wageningen University, Wageningen, The Netherlands (2019).

With references, with summaries in English and German.

ISBN: 978-94-6343-941-1

DOI: https://doi.org/10.18174/475220 
Climate change increasingly challenges smallholder farming and our ability to achieve Sustainable Development Goal 2 (Zero Hunger) in sub-Saharan Africa. Agricultural interventions are needed that aim at improving the food insecurity of the most vulnerable rural households. Interventions must fit the local context of a diverse population of rural households, and a key challenge is to identify which kinds of interventions work in which regions and for which households. Micro-level information can account for this diversity, but is an underused source of information for planning of interventions at national and sub-national levels.

In this thesis, I explored how micro-level information from cross-country household survey data can be used for effective planning of interventions. A further research aim was to understand within-country patterns of livelihood strategies in relation to food security and vulnerability to climate change of rural households in Uganda. Cross-country household data from the World Bank Living Standard Measurement Survey - Integrated Surveys on Agriculture (LSMS-ISA) were used to 1) aggregate household level information to higher levels (e.g. districts, regions, livelihood zones), 2) spatially interpolate household level information and 3) identify hotspot areas of household vulnerability. I used data that I collected from two sites in Uganda for an in-depth analysis on current coping strategies of households for climate and price variability. Household food security was approximated using a food availability indicator that quantified the contribution of livelihood activities to household food availability.

Livelihood strategies of rural households across Uganda varied with household food availability. They changed from subsistence-oriented on-farm activities to market-oriented onfarm and off-farm activities as household food availability increased. Aggregation revealed spatial differences in food availability and livelihood activities. However, a geostatistical interpolation approach showed that local variability in food availability and livelihood activities was often larger than variability across larger areas. These findings stress that the large diversity in livelihood activities within any given area must be recognised in decision making at higher levels.

Climate change scenarios were linked to the household livelihood activities to identify hotspot areas of vulnerable households in a country-wide assessment of climate change impacts on crop suitability. Groups of crop-related adaptation options were determined per hotspot area. Adaptation options related to temperature were suitable in the north, while drought-related adaptation options were more suitable in the southwest of Uganda. An in-depth analysis 
indicated that few ex-ante coping strategies were applied under current climate and price variability. Such coping strategies mostly required little financial investment such as switching crops, which was common for households with more land available. Households tended to react to shocks rather than taking preventive action. Better-off households compensated for crop losses by selling livestock or relying more on off-farm income, while the poor and food insecure lacked the resources to do so. These findings suggest that lack of resources can prevent households from adapting to climate change, even when adaptation options are useful from an agronomic perspective. Therefore, contextualised research is needed to understand local barriers to adoption, so that adaptation options can be tailored to local contexts and underpinned by enabling policies and institutional arrangements.

Current top-down approaches to planning interventions ignore local diversity of livelihood strategies and food security. However, my results demonstrate that food security and vulnerability tend to be locally driven with large variability at small scale. Therefore, I propose a three-step approach for using micro-level information for multi-level planning. Step 1 disentangles livelihood diversity using cross-country household surveys. Step 2 locates important production activities (Pathway 2a) or vulnerable households and suitable adaptation options (Pathway 2b). Step 3 uses site-specific household surveys to assess which interventions work for which groups of households in the local context. This approach adds to existing approaches by generating spatially-explicit and quantitative information on livelihood activities for food availability and on household vulnerability, while accounting for the diversity of households within and across areas. It enables the exploration and tailoring of intervention options under different future scenarios. In this way, my work contributes to identifying pathways to achieve zero hunger by 2030 in sub-Saharan Africa. 


\section{Contents}

Chapter 1 General introduction 1

Chapter 2 Food availability and livelihood strategies among rural households 15 across Uganda

Chapter $3 \quad$ Using household survey data to identify large-scale food security 51 patterns across Uganda

Chapter 4 Vulnerability and adaptation options to climate change for rural livelihoods - a country-wide analysis for Uganda

Chapter 5 Production variability and coping strategies of Ugandan smallholders in the face of climate variability and market shocks

Chapter 6 General discussion

Bibliography 185

Summary

Zusammenfassung

Acknowledgements

About the author

PE\&RC Education and Training Statement

Financial support 


\section{List of abbreviations}

AIC

ASSP

BL

CFSVA

EV

EVHR

FA

FEWS NET

GDP

GIEWS

GPS

HDDS

HFIAS

HHCropSuit

HHCropSuitChange

HHSuit

HHSuitChange

LSMS

LSMS-ISA

MAE

MAUP

MIBR

MIBR-0

MLR

PI

PHL

RCP

RHoMIS

SDG

TLU

USD

VIF
Akaike information criterion

Agriculture Sector Strategic Plan of Uganda

Baseline

Comprehensive Food Security and Vulnerability Analysis

Environmental explanatory variables

Environmental and household resource variables

Household food availability indicator

Famine Early Warning Systems Network

Gross domestic product

Global Information and Early Warning System

Global positioning system

Household dietary diversity score

Household Food Insecurity Access Scale

Household level crop suitability

Change of household level crop suitability

Household level suitability

Change of household level suitability

see LSMS-ISA

Living Standard Measurement Study - Integrated Surveys on Agriculture

Male adult equivalents

Modifiable Areal Unit Problem

Multiple zero-and-one inflated beta regression

Multiple zero-inflated beta regression

Multiple linear regression

Prediction interval

post-harvest losses

Representive concentration pathway

Rural Household Multi-Indicator Survey

Sustainable Development Goal

herd size in tropical livestock unit

US Dollar

Variance inflation factor 
A little drum makes a thousand feet dance.

African proverb 
Chapter 1

General introduction 


\subsection{Aspiring for a world without hunger}

In 2015 the United Nations General Assembly set the Sustainable Development Goals (SDGs) with one of the goals, SDG 2: Zero Hunger, aiming at globally ending hunger and malnutrition and achieving food security by 2030 (UNGA 2015). Meanwhile, recent trends on hunger and food security are sobering: After a prolonged decline in world hunger, a rising trend has been observed in the past years. Estimates of the absolute number of people suffering hunger globally resemble levels from a decade ago. Undernourishment is particularly prevalent and on the rise in sub-Saharan Africa affecting an estimate of $23 \%$ of the population. Partly because of the rapid population growth in sub-Saharan Africa, the total number of undernourished people has increased by more than $22 \%$ within six years (FAO et al. 2018). Also 'hidden hunger', the shortage of micronutrients, shows high prevalence in sub-Saharan Africa (Joy et al. 2014; RuelBergeron et al. 2015). Despite the fact that most rural households produce food themselves, they are often more affected by food insecurity than their urban counterparts (von Grember et al. 2018). This has also to do with the importance of agriculture for these rural households and the sensitivity of farming systems to climate and market variability (Kotir 2011; Wossen et al. 2018).

Box 1.1 Some concepts around food security

Food security exists when all people, at all times, have physical and economic access to sufficient safe and nutritious food that meets their dietary needs and food preferences for an active and healthy life. The four dimensions of food security are availability, access, utilisation and stability. Availability refers to the physical supply of food products. Access refers to the economic and physical access to food through markets and income. Utilisation addresses the nutritional status of individuals. Stability identifies the availability, access and utilisation of food over time (FAO 2009).

Hunger is referred to as food deprivation by FAO (2008).

Undernourishment refers to the proportion of the population whose dietary energy consumption is below a defined threshold of required energy. Information on food available to a population is obtained at the national level. Undernourishment is understood as a measure of hunger (FAO 2008; Carletto et al. 2013).

Malnutrition is related to deficient, excessive or imbalanced consumption of macro- and/or micronutrients (FAO 2008). 


\subsection{Food security among rural households in sub-Saharan Africa}

Although approximately 35\% of rural income in sub-Saharan Africa comes from off-farm sources (Haggblade et al. 2010), agriculture remains an important component in the rural economy and plays an important role in the livelihoods of rural households. These rural households commonly manage mixed crop-livestock systems (Thornton and Herrero 2015) and have only a few $(<15)$ hectares of land available (Samberg et al. 2016). Yet, they often produce m ost of their country's food (Herrero et al. 2017). In this way rural households play a double role in food security: They are important for national level food security by producing food for domestic markets, while they tend to be the most food insecure themselves (von Grember et al. 2018).

Most rural households in sub-Saharan Africa farm under rain-fed conditions putting them at large risk to climate variability and future climate change (The World Bank 2009; Kotir 2011). Furthermore, these rural households face challenges related to low soil fertility and stagnating low crop yields (Tittonell and Giller 2013), limited access to land and weak market structures (Kristjanson et al. 2012; Jayne et al. 2006; Vermeulen et al. 2012). Additionally, the lack of supporting policies to access knowledge, financial means and functioning markets often results in poor agricultural performance (Cooper and Coe 2011) and high sensitivity to both climate and market variability. Entry barriers to alternative, remunerative off-farm income opportunities are often high for the poorest in a community (Loison 2015), particularly exposing them to the risks around agricultural production.

\subsection{Characteristics of food (in)secure rural households in sub-Saharan Africa}

Despite these overall challenges that rural households face, some households in a community are more food secure than others. This seems to be particularly related to household characteristics, their asset base and their livelihood strategies. For example, food security is often associated with higher education of the household head, smaller household size, larger land and herd sizes, and with better access to remittances, to markets and to market information (Mango et al. 2014; Bashir and Schilizzi 2013; Fisher and Lewin 2013). More food secure households tend to have a wider range of crops, more diversified livelihood activities, stronger market orientation, higher dependence on off-farm income and lower dependence on crop production for own consumption (Frelat et al. 2016; Silvestri et al. 2015). However, despite these identified relationships, our understanding of which drivers and strategies influence household food security and how these differ across regions and among households remain rudimentary (Silvestri et al. 2015). Better understanding of household food security patterns 
and their relation to livelihood strategies is particularly important in the light of future trends in population growth and climate change. The population in Africa is expected to double from 2017 to 2050 (United Nations DESA 2017) and climate change has been recognised as one of the most pressing challenges for achieving future food security (Godfray et al. 2010).

Box 1.2 Livelihood, livelihood strategies and livelihood activities

A livelihood is understood as the way an individual or social group (in this thesis a household) uses income and other resources to satisfy its needs and achieve well-being (Wisner et al. 1994).

In this thesis I distinguish between livelihood strategies and livelihood activities:

Livelihood strategies are followed by households to achieve well-being (i.e. here: food security) and are relate to their livelihood activities. Examples of livelihood strategies are to focus on food self-sufficiency, on cash crop production, on diversifying crop or livestock production, on off-farm income generation or to focus on more than one activity.

Livelihood activities refer to the on- and off-farm activities of households to achieve well-being (in this study linked to food security), such as the production of (specific) food crops and livestock products for food consumption or the production of e.g. coffee as a cash crop.

\subsection{Climate change as emerging threat to food security in sub-Saharan Africa}

Climate change models project temperature increases across sub-Saharan Africa, changes in rainfall patterns and increases in extreme events such as heatwaves, droughts and extremely wet days, although with varying confidence (Niang et al. 2014). These future changes will negatively affect agricultural production and increase the risk for food insecurity (Ongoma et al. 2018; FAO et al. 2018). Expected impacts on agricultural production include shorter and disrupted growing seasons, changes in the presence and abundance of pests and diseases, and in available suitable agricultural areas (Loison 2015; Thornton et al. 2011; Niang et al. 2014; Müller et al. 2011). Climate change also influences food price dynamics (Wossen et al. 2018) bearing additional risks for farming households. The effect and magnitude of climate change impacts will differ between regions and farming systems (Niang et al. 2014). Yet, it is expected that particularly those households that are already susceptible to food insecurity will also be most vulnerable to climate change (Vermeulen et al. 2012; Müller et al. 2011). 


\subsection{Vulnerability and adaptation to climate change}

Vulnerability can be understood as a function of exposure, sensitivity and adaptive capacity (Schneider et al., 2007). Exposure to a climate shock can be similar for households in an area. However, the sensitivity (resulting from e.g. the dependence of a household on a particular crop) and the adaptive capacity of a household (i.e. the ability to respond or adapt to the exposure) also depends on the household's characteristics and farm structure (Berm an et al. 2015; Cooper and Wheeler 2017; Cooper et al. 2008). Reducing the sensitivity and increasing the adaptive capacity are essential for adapting to climate change and achieving food security under future climate conditions. Sensitivity can be reduced by decreasing the dependence of households on crops that are negatively affected by an exposure or by reducing the sensitivity of the crops to the exposure. Dependence of households can be decreased through diversification of livelihood activities (Waha et al. 2018). Sensitivity of the crops can be reduced by switching to, for example, drought-resistant or short-maturing varieties (Niang et al. 2014). Adaptive capacity is linked to household assets and entitlements (Cooper and Wheeler 2017), to knowledge and information, to innovation, and also to a forward looking governance (Jones et al. 2010). Examples of effective strategies to increase adaptive capacity include strengthening a household's asset base, enabling access to weather forecast system s or providing crop insurance systems (e.g. Panda et al. 2013; Valdivia et al. 2010; Kalanda-Joshua et al. 2011).

Adaptation options need to address both, extreme events and climate variability as well as progressive climate change, which is the long-term change in the baseline climate (Vermeulen et al. 2012). Effective and feasible adaptation options can be identified through assessing current strategies of households to cope with variable weather conditions and extreme events (Below et al. 2010; Helgeson et al. 2013; Cooper et al. 2008). Furthermore, crop models, national statistics, or long-term trials are commonly used to identify promising crop-related options to adapt to progressive climate change (Thornton et al. 2009a; Traore et al. 2015; Alemayehu and Bewket 2016; Rowhani et al. 2011). In systems where livestock depend on crop residues and cultivated forages, assessments of climate change impacts on crops used as feed sources can also shed light on the vulnerability of the livestock systems (Descheemaeker et al. 2018). While many of these studies focussed on system components (e.g. individual crops), a household's vulnerability depends on the im portance of the different livelihood activities for its food security and income. Therefore, assessments need to identify impacts and adaptation options at the household level, while accounting for the different livelihood activities (Descheemaeker et al. 2016a). Holistic household level analyses that are integrated in assessments at multiple levels are particularly important given the growing evidence that 
transformative change of farming and food systems is needed for climate change adaptation (Biermann et al. 2012; Vermeulen et al. 2018; Kates et al. 2012).

\subsection{Targeting interventions for food security and climate change adaptation}

To achieve the goal of zero hunger in an environment where climate change becomes an increasing challenge requires interventions that target the rural households that are most vulnerable to food insecurity and climate change. Decision makers at national and sub-national levels need spatially-explicit, quantitative information to assess vulnerability and target such interventions. A key challenge remains to identify what kinds of interventions can work in which regions and for which households. Silver bullets for agricultural interventions for subSaharan African rural households do not exist (Giller 2012; Giller et al. 2011). Indeed, blanket recommendations are often ineffective and result in low adoption (Ojiem et a. 2006; Wairegi and van Asten 2010; Descheemaeker et al. 2016b). Instead, the large diversity of households that exists across and within regions requires interventions to be context specific (Descheemaeker et al. 2016b; Giller et al. 2011). Therefore, the diversity of households must be taken into account in assessments of food security and climate change adaptation from local to (sub-)national levels and approaches are needed to guide this (Franke et al. 2014; Descheemaeker et al. 2016b).

Many models that are currently used to identify options for agricultural development for food security at (sub-)national level are top-down approaches ${ }^{1}$, for example using macro-economic models or large-scale land use models (van Wijk 2014). These models may insufficiently account for the diverse contexts of households risking ineffective interventions. Bottom-up approaches that use micro-level information such as household survey data can account for the local diversity but often only go up to the community or landscape level (van Wijk 2014; AsareKyei et al. 2017; Oluoko-Odingo 2011; Herrero et al. 2014). They also often do not preserve the variability at the local level in the assessments at broader scales. Since food security and related vulnerability to climate change tend to be locally driven, approaches are needed that can analyse country-wide patterns while preserving information on the local diversity of households. Geo-referenced household survey data that are nationally representative are a promising source of micro-level information for such an approach. In the field of poverty research, such survey datasets have shown to be useful when linked to census data using simple explanatory variables to determine areas or communities with larger prevalence of poverty

\footnotetext{
${ }^{1}$ Here top-down approaches are approaches that use large-scale information breaking them down into smaller units to understand system processes at smaller scales. By contrast, bottom-up approaches use detailed information on small scale (here the household level) to understand system processes at broader scales.
} 
(Hyman et al. 2005; Farrow et al. 2005; Elbers et al. 2003; Pokhriyal and Jacques 2017). However, this approach is limited to the data available in the census dataset, while detailed information on livelihood activities is usually missing. Despite the potential added value of these approaches there exists currently no framework on how such micro-level information could be used for interventions planning at sub-national and national levels while preserving information on the local diversity of households.

\subsection{Research aim and study objectives}

In this thesis I assessed how micro-level information from household survey data collected across the country could be used to improve advice to policy and other decision makers for planning of interventions. The corresponding research aim was to understand within-country patterns of livelihood strategies in relation to food security and vulnerability to climate change of rural households in sub-Saharan Africa, using micro-level information from cross-country household survey data.

Two research questions and hypotheses addressed the research aim:

1. How can micro-level information be used for planning interventions for food security and reducing vulnerability of rural households at national and sub-national level?

(I) By preserving information on the local heterogeneity of households at broader scales, micro-level information can enhance the identification of interventions at national and sub-national levels.

2. How do livelihood activities for food security and vulnerability to climate change differ across a country and what are the implications for interventions planning?

(II) Livelihood activities for food security differ across a country related to agroecological conditions allowing us to identify target areas for groups of interventions and assess for which households what kinds of interventions are suitable in these target areas.

To answer the research questions and test the hypotheses, four research objectives were assessed in the research chapters (Chapters 2 to 5):

1. Quantify how livelihood strategies and related activities of rural households contribute to household food security and assess how these vary across the country (Chapter 2).

2. Develop an approach that translates micro-level information on welfare and livelihood strategies into spatially-explicit, country-wide patterns (Chapter 3).

3. Assess how vulnerability of households to climate change varies across the country and identify suitable adaptation options (Chapter 4). 
4. Explore suitable strategies of rural households to cope with current climate and market price variability (Chapter 5).

Research objectives 1 and 2 looked at the current situation of households in relation to their food security and the contributing livelihood strategies. Research objective 3 aimed at assessing how the current livelihood strategies of households might buffer or affect a household's vulnerability to future climate change. Research objective 4 aimed at understanding how the households currently deal with climate and market price variability, which can influence their vulnerability to future climate change.

For research objective 3, I analysed household vulnerability in relation to exposure (changes in climate conditions that affect crop production) and sensitivity of households through dependencies on different crops for household food security. These dependencies were derived from survey-reported production data. For research objective 4, I identified vulnerability by quantifying sensitivity based on farmer-reported production variability between years and determining adaptive capacity as the capacity to adapt or respond to an exposure. Adaptive capacity was assessed based on farmer-reported experiences from past climate shocks and 'what-if's' of potential climate or price variability. To address the research aim and the related objectives I used Uganda as a case study country.

\subsection{Case study country: Uganda}

Uganda is located in eastern Africa (Fig 1.1) and considered one of the fastest growing economies in sub-Saharan Africa with an annual Gross Domestic Product (GDP) growth rate of 5\% (Kuteesa et al. 2010; The World Bank 2016b). Despite of the national economic growth in the recent past, poverty and food insecurity rem ain a reality for $\mathrm{m}$ uch of Uganda's population. While poverty rates more than halved from $56 \%$ in the 1990 s to $24 \%$ in 2010 , the standard of living has not improved uniformly across Uganda (Daniels and Minot 2015; Kakande 2010). The FAO Hunger Map 2015 identified 24.8\% of the population being undernourished between 2010 and 2012, while FAOSTATS estimated the prevalence of undernourishment to be $31.6 \%$ in the same period and to have increased to $>40 \%$ in 2017 (FAO 2018, 2016).

The total num ber of poor and food insecure people is expected to continue to increase: Uganda's population is growing rapidly at an annual growth rate of $3.3 \%$ in 2016 and is expected to continue since almost half of the population is $<15$ years old (World Population Review 2018). Thus, poverty and food insecurity will remain an urgent topic on the political agenda. 


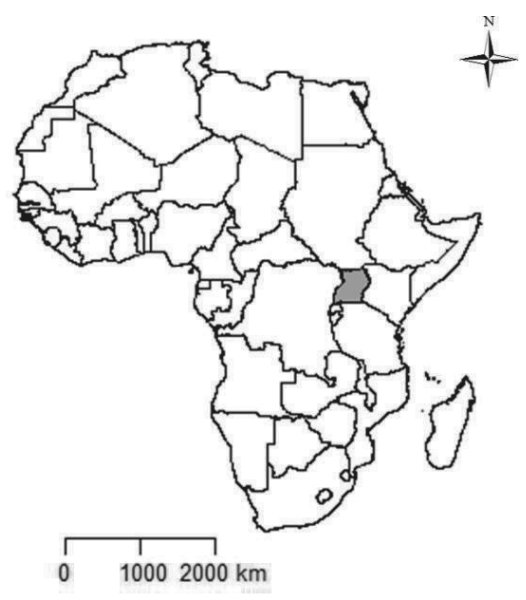

Fig 1.1 Location of Uganda (grey) (Source: Map Library 2019)

Agriculture contributes almost a quarter of the country's GDP with food crops having the largest contribution, followed by livestock, forestry and cash crops. Major agricultural commodities for export (in USD earnings) are coffee, fish (products), animal fats and vegetable oils, tea, hides and skins and sugar. Major crops for the domestic markets are highland banana (Musa acuminata Colla), maize (Zea mays L.), cassava (Manihot esculenta Crantz) and beans (Phaseolus vulgaris L.). Most of Uganda's agricultural production is based on sm allholder farming. More than $80 \%$ of Ugandans are living in rural areas with rain-fed agriculture constituting an important part of their livelihoods (FAO 2018; Government of Uganda 2016).

Uganda has a diverse climate with average annual temperatures ranging from $15^{\circ} \mathrm{C}$ in the mountains in the east and west to $>26^{\circ} \mathrm{C}$ in the northwestern lowlands, depending on elevation rather than on latitude. Annual rainfall varies between $<750 \mathrm{~mm}$ in the northeast and $>2,000$ $\mathrm{mm}$ on the Ssese Islands (Hijmans et al. 2005). Most of the country has two rainy seasons, while rainfall distribution is unimodal towards the northeast with an extended dry season (Mwebaze 1999). These diverse climatic patterns together with topographic and soil characteristics result in a large diversity of farming systems from perennial banana-coffee systems in the humid highlands to dryland pastoral savannah systems in the northeast (Pender et al. 2004; Wortmann and Eledu 1999).

Climate change is threatening these diverse farming systems. It is becoming a reality in Uganda with rising minimum and maximum temperatures (Kikoyo and Nobert 2016; Mubiru et al. 2012; Nsubuga et al. 2014). Depending on the location and time of the year, both decreasing and increasing trends in rainfall patterns were observed in the recent past (Lyon and DeWitt 2012; Maidment et al. 2015; Funk et al. 2008; Muthoni et al. 2018). Projections of future climate 
change entail large uncertainties, particularly for rainfall trends (Shongwe et al. 2011; Patricola and Cook 2011; Niang et al. 2014). Yet, projections of im pacts on Uganda's crop production are mostly negative (Adhikari et al. 2015; Thornton et al. 2010; Thornton et al. 2011) jeopardising future rural livelihoods. Uganda has been selected as a case study for this thesis because of the importance of agriculture for national food security and for rural livelihood, and because of the diverse farming systems, which will be affected by climate change in different ways.

\subsection{Methodological assumptions, corresponding data and approaches}

My study is based on two underlying methodological assumptions: 1) Existing (cross-country) household survey data can be used to identify food security and livelihood patterns and to assess household vulnerability to climate change. 2) To determine the importance of livelihood strategies for food security of rural households, food security can be approximated by household food availability. The validity of these assumptions is discussed in Chapter 6, while below I introduce the household survey datasets and the food security approach that were used in this thesis.

Household survey data were the source of micro-level information and are at the core of this thesis to address the study objectives. For Chapter 2 to 4 I analysed patterns at household, subnational and national levels using the country-wide household survey data from the World Bank Living Standard Measurement Survey - Integrated Surveys on Agriculture (LSMS-ISA) for Uganda from 2010/11 (Kilic et al. 2015; UBOS 2011). The LSMS-ISA is representative at the national, regional and urban/rural level. In total 2,671 geo-referenced households were sampled across the country over a 12-month period from 2010 to 2011. Households were sampled per enumeration area, based on random selection of enumeration areas per region (Kampala, Eastern, Central, Northern and Western, The World Bank (2012)). From this dataset we used information on household characteristics, farm and herd sizes, crop and livestock production, and off-farm income. For Chapter 5 I collected own household survey data in two rounds in 2016 and 2017 at two sites in Uganda that were contrasting in their agroecological settings and representative for larger regions within Uganda. In total 106 households were interviewed on on- and off-farm livelihood activities, production variability of major crops, coping strategies to climate and market price variability, and food security. For the 2017 round the Rural Household Multi-Indicator Survey (RHoMIS) was used, which was designed to rapidly characterise households based on a series of standardised indicators, including indicators on agricultural production, nutrition, food security and poverty (Hammond et al. 2016). 
Food security is a multidimensional concept with numerous definitions (Jones et al. 2013). The most commonly used definition acknowledges four dimensions of food security (see Box 1.1). Many food security metrics exist addressing food security and its four dimensions from the national to individual level (for an overview see Jones et al. 2013). No single indicator can capture all dimensions of food security (Carletto et al. 2013) and the selection of indicators depends on the purpose of the study. Moreover, studies have identified discrepancies between different indicators such as the FAO undernourishment indicator and survey-based household consumption or anthropometric indicators (de Haen et al. 2011; Smith et al. 2006). Therefore, choosing an adequate indicator and deciding between composite or one-dimensional indicators is a challenge when measuring a complex concept such as food security (Carletto et al. 2013).

In this thesis food security was approximated using a food availability indicator. I choose a simple, one-dimensional indicator to assess food availability at the household level using information from household surveys on on- and off-farm activities (Frelat et al. 2016). Major underlying assumptions of this food availability indicator (henceforth FA) were: a) food access is equal within the household, b) dietary requirements of households can be approximated using male adult equivalents identified with age and gender classes, c) all agricultural products that are not sold are consumed by the household members (i.e. no losses), d) the income available to the household is used to buy staple food. Particularly c) and d) may have resulted in an overestimation of food available to a household. At the same time underreporting of crop and livestock production or of on- or off-farm income in the survey can result in underestimation of food availability. FA is a simplification of the common household consumption indicators as it does not use reported consumption or expenditure information (Carletto et al. 2013). The main advantage of this indicator over other household consumption indicators is that it quantifies the contributions of different livelihood activities to household food availability through the direct link of production data and available kilocalories. In this way it provides a good basis for addressing the overall research aim of this thesis. FA closely correlates with well-established food security indicators, such as the Household Dietary Diversity Score (HDDS) and the Household Food Insecurity Access Scale (HFIAS) (Hammond et al. 2016) providing confidence to use it as proxy to food security.

\subsection{Thesis outline}

An overview on how the four research chapters (Chapters 2 to 5) are inter-related is provided in Fig 1.2. While Chapters 2, 3 and 5 assess patterns of livelihood strategies under current climatic conditions, Chapter 4 identifies the role of livelihood strategies under future climate scenarios. Chapters 2 to 4 analyse livelihood strategies and food security from household to 
national level. Chapter 5 is an in-depth analysis at two sites in northern and southwestern Uganda with the analysis focusing on household and site levels. Household level information from Chapter 2 feed into all three subsequent chapters through interpolation, scenario analyses and zoomed-in assessments. Chapters 4 and 5 inform each other with respect to potentially suitable adaptation options of households.

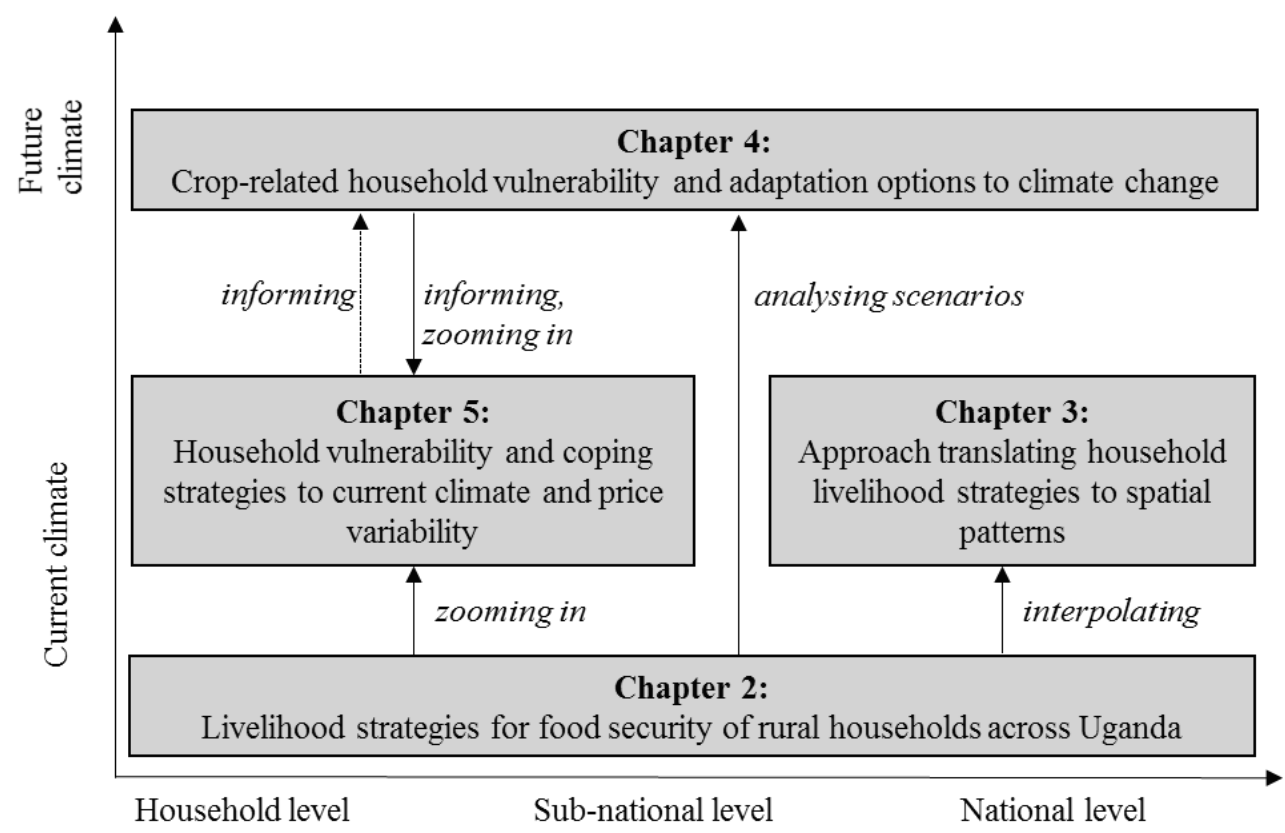

Fig 1.2 Outline of the thesis and how the research chapters are connected

Chapter 2 quantifies the contribution of current livelihood strategies and activities for household food availability across Uganda using the food availability framework of Frelat et al. (2016). It identifies large-scale patterns by aggregation to district, livelihood zone and regional levels (Research objective 1). In Chapter 3 an approach was developed to interpolate the livelihood activities contributing to food availability, which were identified in Chapter 2, to the national level. For the interpolation spatially-explicit biophysical and socio-economic explanatory variables are used in a regression kriging approach (Research objective 2). Chapter 4 assesses country-wide patterns of household vulnerability to climate change and corresponding crop performance using a crop suitability model and the food availability framework of Chapter 1 (Research objective 3). It zooms into four hotspot areas of large household vulnerability to identify how more and less vulnerable households differed in their livelihood activities and explored possible adaptation options. Chapter $\mathbf{5}$ determines how households differed in their sensitivity to current climate variability and identify coping strategies to annual and seasonal variability in climate and market prices (Research objective 
4). Household survey data were used from two sites in Uganda that are contrasting in their agroecological settings. We distinguished between ex-ante, within-season and ex-post coping strategies for households of different wealth classes using indicators on food availability, income and household assets. Chapter 6 synthesises the findings from Chapters 2 to 5 and critically reflects upon the underlying methodological assumptions. It discusses how the main findings can improve our understanding on livelihoods and food security in sub-Saharan Africa on the example of Uganda and in how far the tools and approaches developed in Chapters 2 to 5 can help to better target interventions. A stepwise approach is presented for using micro-level information for interventions planning for food security and vulnerability of rural households at national and sub-national levels. 


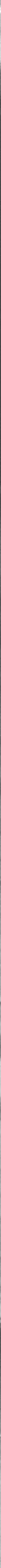


Chapter 2

\section{Food availability and livelihood strategies among rural households across Uganda}

This chapter is based on the publication:

Wichern, J., van Wijk, M. T., Descheemaeker, K., Frelat, R., van Asten, P. J. A., Giller, K. E. (2017). Food availability and livelihood strategies among rural households across Uganda. Food Security 9 (6), 1385-1403. 


\begin{abstract}
Despite continuing economic growth, Uganda faces persistent challenges to achieve food security. The effectiveness of policy and development strategies to help rural households achieve food security must improve. We present a novel approach to relate spatial patterns of food security to livelihood strategies, including the contribution of on- and offfarm activities to household food availability. Data from 1,927 households from the World Bank Living Standards Measurement Study were used to estimate the calorific contribution of livelihood activities to food availability. Consumption of crops produced on-farm contributed most to food availability for households with limited food availability, yet the majority of these households were not food self-sufficient. Off-farm and market-oriented on-farm activities were more important for households with greater food availability. Overall, off-farm income was important in the north, while market-oriented on-farm activities were important in western and central Uganda. Food availability patterns largely matched patterns of agroecological conditions and $m$ arket access, with households doing worst in Uganda's drier and rem ote northeast. Less food secure households depended more on short-cycle food crops as compared with better-off households, who focused more on plantation (cash) crops, although this varied among regions. Targeting interventions to improve food security should consider such differences in enterprise choice and include options to improve household market access and off-farm income opportunities.
\end{abstract}

Keywords: Smallholder farms, household level, food security, East Africa, district, crop choice 


\subsection{Introduction}

The majority of rural households in East Africa derive much of their livelihood from agriculture. They face challenges related to declining soil fertility and stagnating crop yields, declining farm size as a result of population growth, poor market access, insecure land rights and climate change (Kristjanson et al. 2012; Jayne et al. 2006; Rufino et al. 2013b). Household food security has decreased in East Africa (Kristjanson et al. 2012) with a steady decline in calorie availability per capita over the past 50 years (Leliveld et al. 2013). By contrast the poverty rate is reducing, particularly in Uganda, as a consequence of national economic growth $(\mathrm{UBOS} 2010 \mathrm{a})^{2}$. Yet, researchers disagree whether economic growth has contributed to poverty decline across the whole population (Daniels and Minot 2015). For example, Daniels and Minot (2015) observed that the poverty decline from 1995 to 2010 was much greater in the eastern and western parts of the country, while UBOS (2013) identified northern Uganda as the most food insecure region. What remains clear is that both poverty and food insecurity are challenges in East Africa now and for the future. East Africa's rural households play an im portant role in agricultural production and make a major contribution to national food security and the economy. Poor agricultural performance has been related to a lack of supporting policies (e.g. Cooper and Coe 2011) to assist farmers to access knowledge, credit and functioning inputoutput markets. To identify suitable and effective policy interventions, the determinants of household food security need to be better understood.

Several studies have analysed the relationships between household food security and underlying (household level) drivers: larger cultivated land per capita, better education of the household head, a wider variety of crops, and access to market information are all positively related to food security (Fisher and Lewin 2013; Mango et al. 2014; Silvestri et al. 2015). Yet our understanding of what affects household food security in East Africa remains rudimentary (Silvestri et al. 2015) and strategies to achieve household food security vary widely across regions and among households. One challenge lies in the complexity of the food security concept itself, which consists of four pillars: Availability, access, utilisation, and stability (FAO 2009). No single indicator can capture all four dimensions of food security (Carletto et al. 2013). Frelat et al. (2016) developed a simple food availability indicator using information on household on- and off-farm activities of smallholders. This food availability indicator closely correlates to well-established indicators such as the Household Dietary Diversity Score (HDDS) and the Household Food Insecurity Access Scale (HFIAS) (Hammond et al. 2016). Frelat et al. (2016) observed that household food availability improved with increasing dependency on off-

\footnotetext{
${ }^{2}$ The Uganda Bureau of Statistics (UBOS) measures poverty as 'the cost of meeting caloric needs, given the food basket of the poorest half of the population and some allowance for non-food needs' (UBOS 2010a), which allows us to compare trends in poverty and food security
} 
farm activities, suggesting diverse strategies among rural households. Frelat et al. (2016) analysed cross-sectional household data from more than 13,000 households across 97 locations in 17 countries across sub-Saharan Africa, yet their spatial coverage across the continent in general and Uganda in particular was poor; e.g. no data from northern and eastern Uganda were included. National policy makers need disaggregated regional analyses at more local levels, such as the district to target interventions on food security.

We aim to understand how spatial patterns in food availability and the related livelihood strategies vary within a single country. We chose Uganda because of its variety in agroecological conditions and farming systems ranging from perennial banana-coffee systems in the humid highlands and around Lake Victoria to dryland pastoral savanna systems in the northeast (Pender et al. 2004; Wortmann and Eledu 1999). Using household survey data, our analysis quantifies the contribution of diverse livelihood strategies to household food availability and reveals how these strategies differ in their importance across the country.

Country-wide assessments of food security for Uganda and other countries in sub-Saharan Africa have been conducted before; for example the Comprehensive Food Security and Vulnerability Analyses of the World Food Programme (UBOS 2013) and the Famine Early Warning Systems Network (FEWS NET) (www.fews.net). FEWS NET uses livelihood zones as an aggregation level to project food insecurity across a country. Its main purpose is to provide early warning of acute risks of food insecurity and famine. FEWS NET stratifies countries into zones of similar livelihood activities and uses household information to identify wealth groups and related key sources of food and income per zone (Grillo and Holt 2009). Our study adds to the existing approaches by quantitatively linking food availability and contributing livelihood activities, using household level data thereby identifying the diversity and patterns of income and food sources using a 'bottom-up' approach. We investigated differences am ong regions and districts, aiming to make the targeting of interventions more location specific.

Our key objectives were: (i) to quantify and understand how on- and off-farm activities of Uganda's rural households contribute to their food availability, contrasting m ore food secure with food insecure households, and (ii) to assess how food availability and its relationship with different household activities vary across Uganda.

The following questions and related hypotheses were addressed:

1. What proportion of Ugandan households has insufficient food available and how does food availability differ across the country?

Hypothesis I: The Northern region is characterised by less food availability compared to the Central, Western and Eastern region. 
2. What livelihood strategies and household activities contribute to household food availability and how much, and how do these differ with food availability across the country?

Hypothesis II: For the more food secure households, marketoriented on-farm activities and off-farm income, and not on-farm food production, are the major contributors to household food availability and this is similar across the country.

3. How do cropping patterns relate to household food availability and how do they differ across the country?

Hypothesis III: Staple crops (particularly banana, cassava, maize and sorghum) are more important for food insecure households.

We used cross-sectional household survey data from the World Bank Living Standard Measurement Study - Integrated Surveys on Agriculture (LSMS-ISA) for the period 2010/11 (Kilic et al. 2015). The LSMS-ISA data of Uganda have been used in a wide range of livelihood studies both on food security, for example on effects of physical activities on food consumption and on the use of complementary indices for food security (Mathiassen and Hollema 2014; Hjelm et al. 2016) and on agriculture (e.g. Sheahan and Barrett 2017; Gilbert et al. 2017; Palacios-Lopez et al. 2017). The comprehensive cross-country coverage and the detailed agricultural survey of the LSMS provided an adequate dataset for the purpose of our study.

\subsection{Material and methods}

\subsubsection{Background of Uganda}

Uganda is one of the fastest growing economies in Africa (Kuteesa et al. 2010) with an annual GDP growth rate of 5\% (The World Bank 2016b). Agricultural value added ranges from 23 to $25 \%$ of the GDP and major agricultural commodities for export are coffee, cotton, sugar and tea (FAO 2015). More than $80 \%$ of Ugandans live in rural areas (FAO 2016b) and are involved in agriculture. Uganda's poverty rates reduced from $56 \%$ in the 1990 s to $24 \%$ in 2010 , but the standard of living did not improve uniformly across the country (Daniels and Minot 2015; Kakande 2010). Population densities are highest in the western, central and eastern parts of Uganda and most sparse in the northeast (WorldPop 2016). Similarly, the most dense road networks are found in the central and southwest of the country where the major towns and cities are located (Nelson 2008). The poorer infrastructure in the north of Uganda is partly related to the conflict that started in 1987 and lasted for more than 20 years. The conflict displaced millions of people and caused agricultural production and market structures to collapse 
(Tusiime et al. 2013). Today, roughly five years after the end of the conflict, the region is still recovering.

Temperatures in Uganda are in the range of 15 to $30{ }^{\circ} \mathrm{C}$ depending on elevation rather than on latitude with maximum temperatures in the range of 25 to $31^{\circ} \mathrm{C}$ for most areas. Annual rainfall varies from $750 \mathrm{~mm}_{\text {year }}^{-1}$ in the northeast to $>1,750 \mathrm{~mm}^{-1} \mathrm{year}^{-1}$ in the areas of high rainfall. The majority of the country receives annual rainfall between 1,000 and 1,750 mm year ${ }^{-1}(70 \%$ of the land area). Rainfall distribution is bimodal in the southern part of the country, while, towards the north (particularly the northeast), patterns gradually change to unimodal with an extended dry season (Mwebaze 1999). The diverse climatic patterns together with topographic and soil characteristics result in a large diversity of farming systems across Uganda.

\subsubsection{Data}

We used cross-sectional household survey data sampled across Uganda in the period of 2010 to 2011 covering 2,716 households (Fig 2.1). The surveys were conducted as part of the World Bank Living Standard Measurement Study - Integrated Surveys on Agriculture (LSMS-ISA) (Kilic et al. 2015). Households were visited twice over a 12-month period to capture the two cropping seasons. The households were sampled from a former survey conducted in 2005 in which a stratification on urban/rural and regional levels was used (UBOS 2007). Details about the sampling method can be found in The World Bank (2016c). We used survey data on household characteristics, farm size, crop and livestock production and off-farm income.

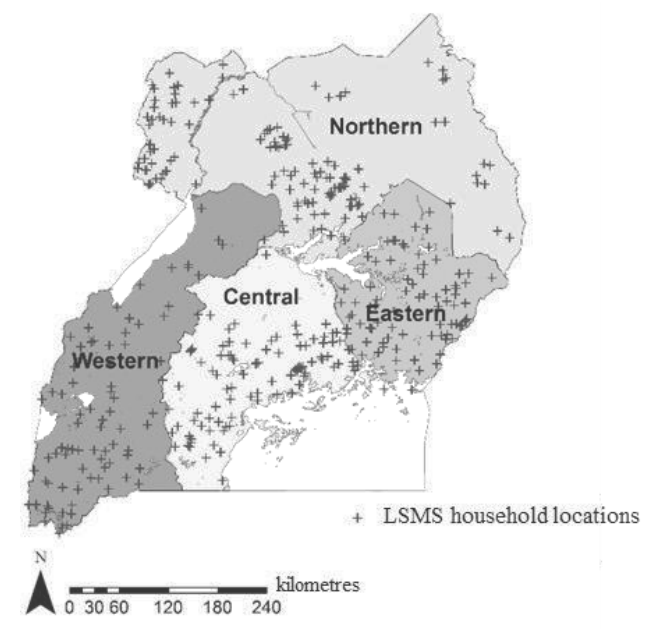

Fig 2.1 Locations of the households that were included in the analysis $(n=1,927)$ and administrative regions in Uganda (Sources: Thompson (2016), clipped from WRI (2009)). Each + represents a single household 


\subsubsection{Household food availability}

For each household a simple food availability (FA) indicator was calculated following Frelat et al. (2016). The FA estimates the average amount of potential food energy that is available to each male adult household member equivalent per day $\left(\mathrm{kcal} \mathrm{cap}^{-1} \mathrm{day}^{-1}\right)$ :

$$
F A=\frac{\left(E_{\text {consumed }}+E_{\text {income }}\right)}{365 \times n_{\text {hh-mae }}}
$$

where $E_{\text {consumed }}$ is the annual direct consumption of potential food energy from on-farm products (kcal year $\left.{ }^{-1}\right), E_{\text {income }}$ is the annual indirect consumption of potential food energy from on- and off-farm income ( $\left.\mathrm{kcal} \mathrm{year}^{-1}\right)$, and $n_{\text {hh-mae }}$ is the household size in male adult equivalents. For the estimation we used annual data on agricultural and off-farm income generating activities and on the household composition. The contribution to FA was calculated for the following activities: Consumption of on-farm food crops and livestock products, sales of on-farm food crops and cash crops, sales of on-farm livestock products and off-farm income. The crop and livestock related activities were further differentiated into key crops and livestock groups (contributing to the crop part and livestock part of the food availability, respectively). A threshold of 2,500 $\mathrm{kcal} \mathrm{cap}^{-1} \mathrm{day}^{-1}$, representing the daily energy need of a male adult (FAO 2001), was chosen to distinguish households with sufficient and insufficient food available. Kilo-caloric energy values for crops and livestock products were retrieved from the standard product list of the US Department of Agriculture (source: ndb.nal.usda.gov/ndb/search/list, accessed 02/07/16) and from the Food and Agricultural Organization of the United Nations (source: http://www.fao.org/docrep/x5557e/x5557e00.htm\#Contents, accessed 02/07/16). We converted prices from local currency to US dollar (USD) using the currency-conversion rate of the first of January 2011. We assumed that all money earned in a household was used to purchase a staple crop (in this case maize) for food consumption. With this assumption we overestimate the actual supply of energy to the household because no account is made of other household expenses (e.g. clothing, school fees, transport). The indicator thus shows the potential to obtain sufficient energy for the household, and not whether this actually occurs (Frelat et al. 2016). We also assumed that the amount of crops consumed by the household was the difference between the reported quantities harvested and sold. Hence, post-harvest losses, gifts, in-kind trading or saving of crop seeds were not considered. Cash crops were defined as crops of which more than $90 \%$ of the annual produce was sold (Frelat et al. 2016). Prices for crops and livestock products reported in the dataset varied substantially among the households. To reduce the possible effect of erroneous price reporting, we used the median of the reported prices per region per year to calculate income from sold crops and livestock products. We excluded all households from the analysis that reported both zero agricultural production and zero off-farm income in the year of sampling. We further excluded households that reported no 
area for cultivation. The final household sample for the analysis resulted in 1,927 households out of a total of 2,716 households.

\subsubsection{Food availability classes and additional indicators}

We aggregated the individual households into three food availability classes to understand how on- and off-farm activities differ according to the degree of food availability. Hammond et al. (2016) correlated the food availability indicator with other food security indicators, including the Household Dietary Diversity Score (HDDS) and the Household Food Insecurity Access Scale (HFIAS). These food security indicators improved up to a food availability indicator value of 5,000 kcal cap ${ }^{-1}$ day $^{-1}$, but not beyond (Hammond et al. 2016). Hence, we split our dataset based on the following thresholds: Class 1 included households with food availability below 2,500 $\mathrm{kcal} \mathrm{cap}^{-1} \mathrm{day}^{-1}$ (deficient food availability); Class 2 comprised households with food availability between 2,500 and 5,000 kcal cap ${ }^{-1}$ day $^{-1}$ (adequate food availability); and Class 3 included households with food availability above 5,000 $\mathrm{kcal} \mathrm{cap}^{-1}$ day $^{-1}$ (surplus food availability). Henceforth, we call Class 1 'food deficient households', Class 2 'food adequate households' and Class 3 'food surplus households'.

Besides the food availability indicator, we calculated five production and income-related indicators to provide inform ation about households' perform ance and livelihood orientation. We calculated a food self-sufficiency indicator (FSS) to assess the importance of on-farm production for household food consumption:

$$
F S S=\frac{E_{\text {consumed }}}{E_{\text {needed }}}
$$

$E_{\text {needed }}$ is the annual energy required for the household ( $\mathrm{kcal}^{-1} \mathrm{yr}^{-1}$ ), calculated from 365 (days year $\left.^{-1}\right) \times 2,500\left(\mathrm{kcal} \mathrm{day}^{-1}\right) \times$ household size in male adult equivalents $\left(n_{h h-m a e}\right)$. Gross daily income per capita (Igross) (USD cap $^{-1}$ day $^{-1}$ ) quantified the total income that a household generated per household member:

$$
I_{\text {gross }}=\frac{I_{\text {tot }}}{365 \times n_{h h}}
$$

$I_{\text {tot }}$ is the total annual household income generated from sold on-farm products and off-farm activities (USD year ${ }^{-1}$ ), $n_{h h}$ is the household size. 
Gross on-farm income per capita $\left(I_{\text {gross, }}\right.$ on-farm $)\left(\mathrm{USD}_{\mathrm{cap}}{ }^{-1}\right.$ day $\left.^{-1}\right)$ identified the income that a household generated per household member from the sold on-farm products:

$$
I_{\text {gross }, \text { on-farm }}=\frac{I_{\text {crops }}+I_{\text {livestock }}}{365 \times n_{h h}}
$$

$I_{\text {crops }}\left(\mathrm{USD}_{\mathrm{year}}{ }^{-1}\right.$ ) is the annual income from sold cash and food crops, and $I_{\text {livestock }}$ (USD year${ }^{1}$ ) is the annual income from sold livestock products. While income indicators related to the real income generated from sold products and off-farm activities, cash value indicators related to the potential income that could be generated from produced goods. The cash value of production ( $C V_{\text {production }}$ (USD cap ${ }^{-1}$ day $\left.^{-1}\right)$ identified the potential income that could have been generated if all on-farm products had been sold:

$$
C V_{\text {production }}=\frac{C V_{\text {crops }}+C V_{\text {livestock }}}{356 \times n_{h h}}
$$

$C V_{\text {crops }}$ is the cash value of crops (USD year-1), $C V_{\text {livestock }}$ is the cash value of livestock (USD year $\left.^{-1}\right)$. Market orientation $(M O)(\%)$ identified the share of agricultural products that were sold relative to the cash value of crops and livestock:

$$
M O=\frac{I_{\text {crops }}+I_{\text {livestock }}}{C V_{\text {crops }}+C V_{\text {livestock }}} \times 100
$$

\subsubsection{Spatial aggregation levels}

Results of the analyses are presented at regional level (four regions, Fig 2.1), for the three food availability groups, as well as at district level for those districts for which the dataset included at least 8 households ( 87 districts). At regional level, we used simple mean values (i.e. the means were not weighted) to identify relative differences in contributing activities and crops per class. At district level, we used the simple (unweighted) median values because of the small sample sizes per district and the large skewness in the data.

LSMS data for Uganda are representative at the national and regional levels (The World Bank 2016a). However, we use a more fine-grained aggregation of data to allow analysis at the district level, so as to visualise spatial trends in household characteristics as a function of strong socio-economic and environmental gradients within regions, agricultural production zones (MAAIF 2010) and livelihood zones (FEWS NET 2013). In addition, if insights from this analysis are to provide support to sub-national policy processes, then districts are the highest aggregation level at which policy decisions are taken, as neither policy engagement nor policy decisions take place at a zonal/regional level (an exception are the zonal agricultural research 
and development institutes that manage and apply agricultural research for specific agroecological zones, Uganda Law Reform Commission (2005)). Consequently, several ongoing agricultural research programmes for policy advice engage with policy stakeholders at the district and not zonal/ regional level (e.g. CCAFS-PACCA - www.ccafs.cgiar.org/policy-

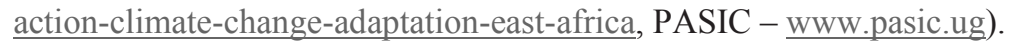

However, our approach of aggregating the data to district levels may introduce statistical bias (i.e. Modifiable Areal Unit Problem, MAUP) (Openshaw and Taylor 1979). In addition, sample numbers of households per district were small ( $n=8$ to 64 households for the districts included) as compared with the district populations (ranging from 50,000 to 2 million inhabitants) to generate accurate and representative data at the district level (UBOS 2016). To improve our understanding of, and confidence in (i.e. subject to spatial bias) spatial patterns across districts, we compared results of district level to livelihood zone level aggregation (FEWS NET 2013). If patterns observed were similar at both aggregation levels, then we considered results to be robust. All analyses were performed in R, version 3.2.3 (R Development Core R Development Core Team 2008) and maps were created in ArcMap, version 10.2.1 (ESRI 2011).

\subsubsection{Scope of the study}

The food availability indicator addresses part of what FAO (2009) defined as 'food security'. Nutritional food security, for example, is not included. Yet, Hammond et al. (2016) observed that the food availability indicator correlates with indicators of dietary diversity. Because the m ajority of Uganda's households depend on own farm productsUBOS 2013), food availability plays an important role for their food security. For that reason, the food availability indicator was considered suitable to answer our research questions. Still, areas that we identify as having large food availability can be areas having small dietary diversity. The food availability and food self-sufficiency indicators were sensitive to the threshold of minimum energy requirements, which we set at 2,500 kcal cap ${ }^{-1} \mathrm{day}^{-1}$. In our food availability analysis we compared only the proportional contribution of on- and off-farm activities, potentially obscuring differences in absolute energy values between the regions. However, as an analysis of the absolute values of the on- and off-farm activities did not provide additional insight, they were not included in the further analysis. When interpreting the results of the aggregated household data, we need to consider the MAUP and the loss of information on variability among households within an aggregation unit. In the interpretation of district level data, focus should be given to trends across districts rather than outcomes for individual districts. Household locations (in latitude/ longitude) were randomly off-set by the publisher (UBOS 2010b). When interpreting the aggregated household data to small districts or livelihood zones, the risk of 
allocation of households to wrong livelihood zones must be considered. However, large-scale patterns are not affected.

\subsection{Results}

\subsubsection{Household food availability patterns across Uganda}

Food availability varied strongly among the rural households with values ranging from well below 2,500 kcal cap ${ }^{-1}$ day $^{-1}$ to values beyond 40,000 kcal cap ${ }^{-1}$ day $^{-1}$ (Fig 2.2a). Households with insufficient food availability constituted $23 \%$ of the overall dataset. Also, at the regional level, food availability varied strongly: Mean food availability ranged from 10,000 kcal cap ${ }^{-1}$ day $^{-1}$ for eastern Uganda to 49,000 kcal cap ${ }^{-1}$ day $^{-1}$ for central Uganda (Table 2.1), but the variability of households within the regions was large (standard deviations from 20,000 kcal cap $^{-1}$ day $^{-1}$ in eastern Uganda to 491,000 kcal cap ${ }^{-1}$ day $^{-1}$ in central Uganda). Because of the large variability we used the percentage of households per class to determine regional differences in food availability. Food surplus households (Class 3, >5,000 kcal cap ${ }^{-1}$ day $^{-1}$ available) constituted the majority of households (66 and 72\%) in the Central and Western regions, respectively, while food deficient households (Class 1, $<2,500 \mathrm{kcal} \mathrm{cap}^{-1}$ day $^{-1}$ available) constituted the minority of households (15 and 10\%) respectively. In contrast, in the Eastern and Northern regions, only 48 and $40 \%$ were food surplus households, respectively, while 27 and 34\% were food deficient households, respectively. The patterns observed at district level resembled the observations at the regional level. Median food availability was largest in the western and central districts and smallest in the northeastern districts (part of the Northern region), where food insufficiency $\left(<2,500 \mathrm{kcal} \mathrm{cap}^{-1}\right.$ day $\left.^{-1}\right)$ prevailed (Fig 2.3a) and the proportion of food deficient households was largest.

Similarly, at the livelihood zone level median food availability was smallest in the Northeast and North/Northwest and largest in the southwest and central areas (Fig 2.3b). Yet, differences between the two aggregation levels were also apparent revealing aggregation bias. For example, two districts in the northwest and two districts in the Eastern region had small median food availability, while these trends were not observed at the level of the livelihood zone level. In contrast, at livelihood zone level the area in the north indicating smallest median food availability was not identified at the district level. Overall, patterns at the district level were more variable than at the livelihood zone level. 


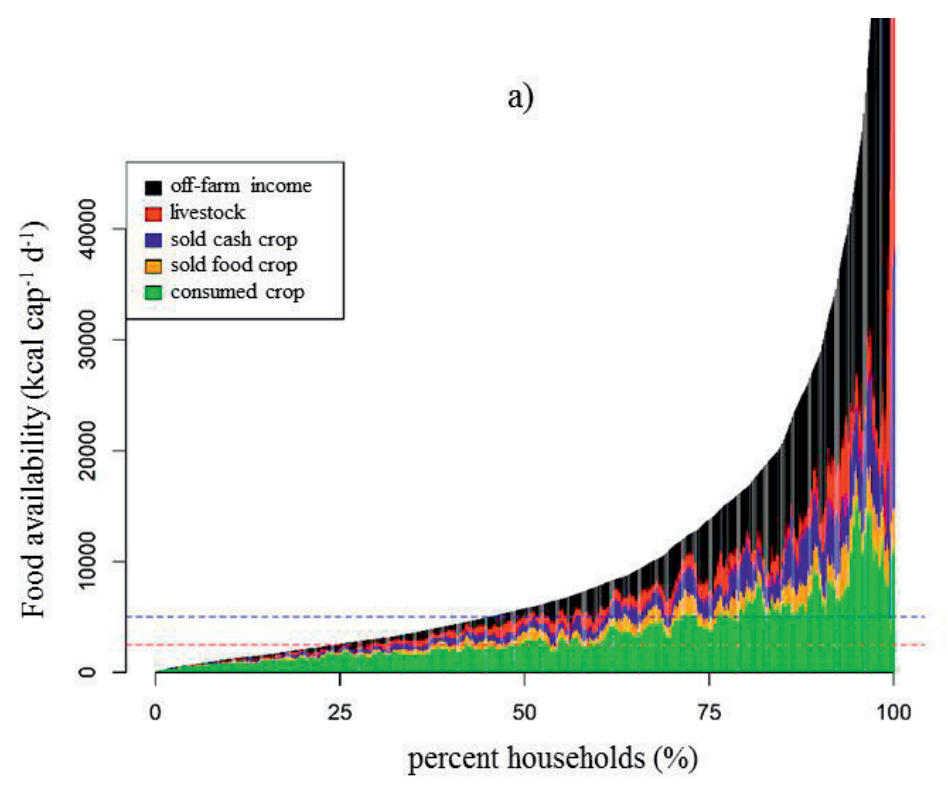

b)

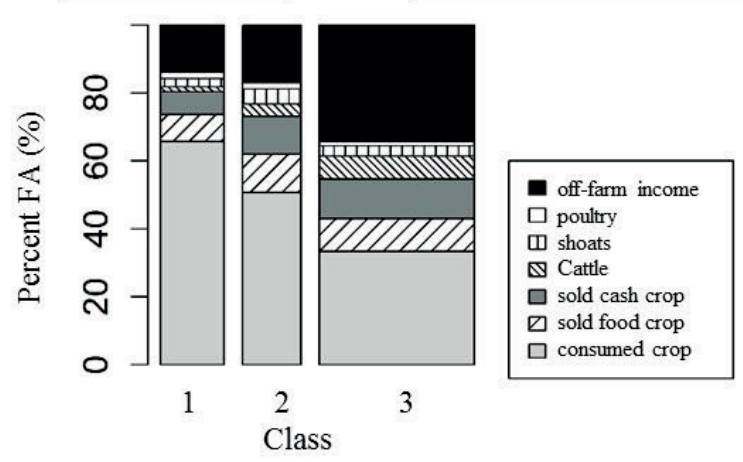

Fig 2.2 a) Household food availability for 1,927 households across Uganda. Households are ordered by increasing food availability (FA) along the $\mathrm{x}$-axis where each bar represents one household. The red dashed line represents a food availability value of 2,500 $\mathrm{kcal} \mathrm{cap}^{-1} \mathrm{day}^{-1}$, the daily energy need of a male adult (Holden et al. 2001) and the blue dashed line represents 5,000 $\mathrm{kcal} \mathrm{cap}^{-1} \mathrm{day}^{-1}$, the lower boundary of 'food surplus households'. A m oving average was applied with a window length of 10 households. The large values of consumed crop on the right side are a result of a few households that reported high amounts of consumed crops, which are expected to result from a bias in the survey rather than to reflect real consumption figures. b) Contribution of on- and off-farm activities to FA per class (Class 1, deficient FA $<2,500 \mathrm{kcal} \mathrm{cap}^{-1}$ day $^{-1}$; Class 2, adequate FA between 2,500 and 5,000 kcal cap ${ }^{-1}$ day $^{-1}$; Class 3, surplus FA $>5,000 \mathrm{kcal} \mathrm{cap}^{-1} \mathrm{day}^{-1}$ ) for $n=1,927$ households. The thickness of bars represents the number of households per class. Livestock is divided into poultry, shoats (sheep and goats), and cattle 


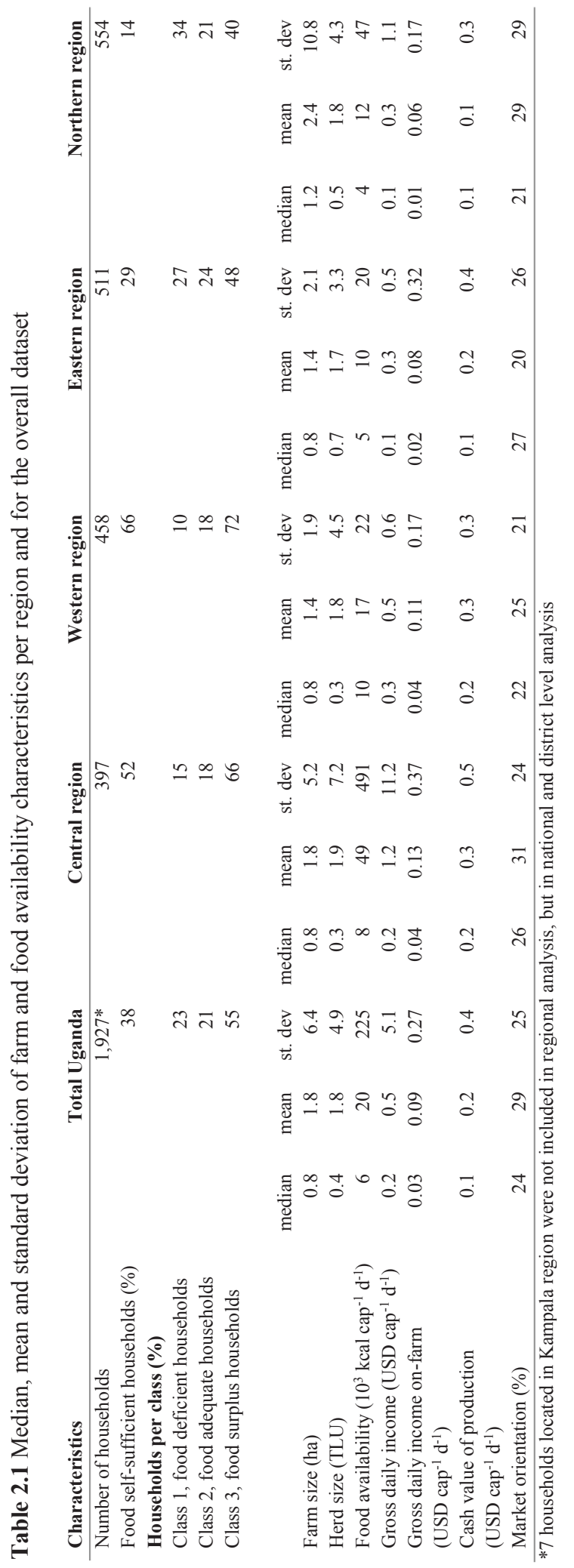


a)

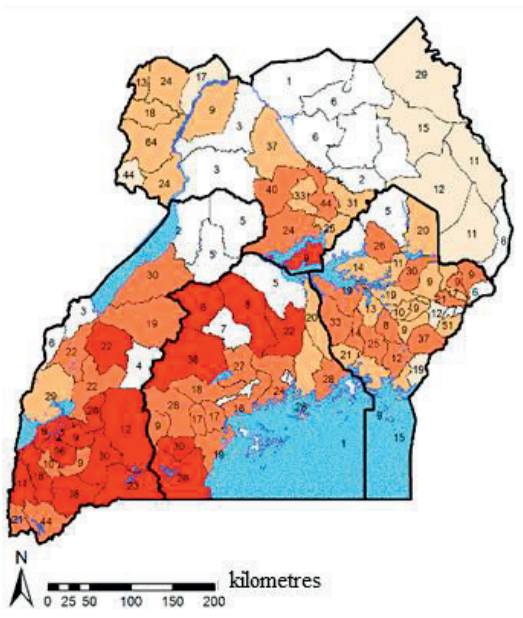

b)

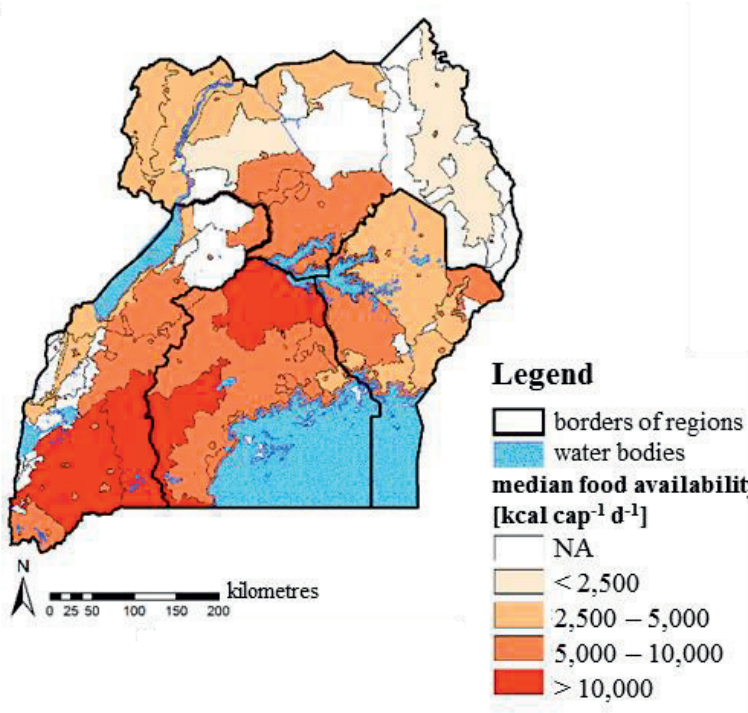

Fig 2.3 a) Median food availability at district level. All districts with at least eight households taken into account. The numbers in the figure represent the number of observations (households) per district. b) Median food availability at livelihood zone level. All zones with at least eight households taken into account. The maps reveal patterns, while individual district/ livelihood zone values must be interpreted with care as LSMS data is not representative at the district/ livelihood zone level and their location (in latitude/longitude) was randomly off-set adding uncertainty to the exact location (Sources: UBOS 2012; WRI 2009; FEWS NET 2013; Thompson 2016)

\subsubsection{Household activities and strategies}

\subsubsection{Household activities contributing to food availability}

Contributions of activities differed strongly across households with similar food availability (Supplementary materials Fig S2.1) demonstrating a large diversity in how households across Uganda acquired food. Further, the role of contributing activities changed along the FA gradient as revealed by the moving average (Fig 2.2a). Consumption of food crops produced on-farm contributed to a basic level of food availability for almost all households. However, beyond this basic level, the contribution of the other activities to food availability increased. Cash income from sale of on-farm products (food crops, cash crops and livestock products) first became more important with increasing food availability (moving to the right along the $x$-axis in Fig 2.2a), followed by an increase in off-farm income. Similarly, in food deficient households (Class 1 , $<2,500 \mathrm{kcal} \mathrm{cap}^{-1} \mathrm{day}^{-1}$ available) off-farm income contributed least to food availability (14\%), 
while in food surplus households (Class 3, >5,000 $\mathrm{kcal} \mathrm{cap}^{-1}$ day $^{-1}$ available) this contribution was largest (34\%) (Fig 2.2b). In contrast, food deficient households had the largest contribution to food availability of consumed crops produced on-farm (66\%) and food surplus households had the smallest (33\%). While the contribution to food availability of small livestock including poultry, goats and sheep ('shoats') did not show clear differences am ong classes, the contribution of cattle increased from deficient to food surplus households. However, the variability around the mean per contributing activity was large (Table 2.2), pointing again to diverse strategies of rural households within the classes.

Between regions, the contribution of on- and off-farm activities to food availability was similar with only a smaller mean contribution of consumed crops produced on-farm and an equivalent larger mean contribution of off-farm income in the Northern region (Fig 2.4). At district level, the median contribution of sold food crops to food availability amounted to less than $10 \%$ for the majority of the districts (Fig 2.5a). For some 13 districts scattered across all regions median contributions amounted to $10-20 \%$ or above. The median contribution of cash crops was zero for many districts in the Northern and the Eastern regions (Fig 2.5b). Median off-farm income contribution was large $(>20 \%)$ in four large districts in the northeast, in five districts in the northwest (Fig 2.5c), around Kampala and in a few districts in the Eastern, Central and Western regions.

Observations of the contribution of these livelihood activities to food availability were similar at livelihood zone levels. For example, the large median off-farm income contribution in the north was confirmed at livelihood zone level. Yet, particularly in areas where districts were small, district level maps showed variation at short distance while livelihood zone maps indicated larger patterns (Supplementary materials Figs S2.3-S2.5). 


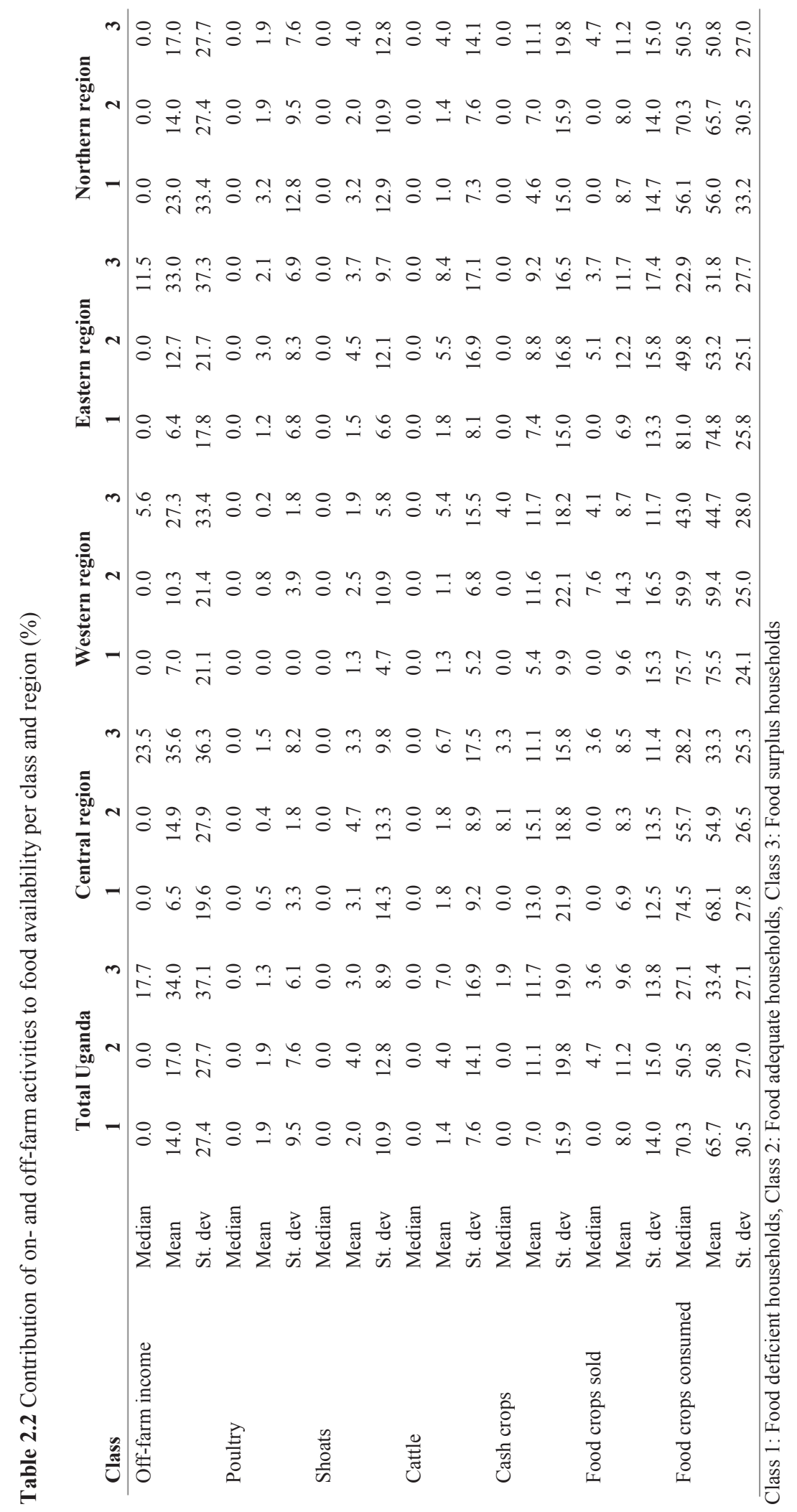



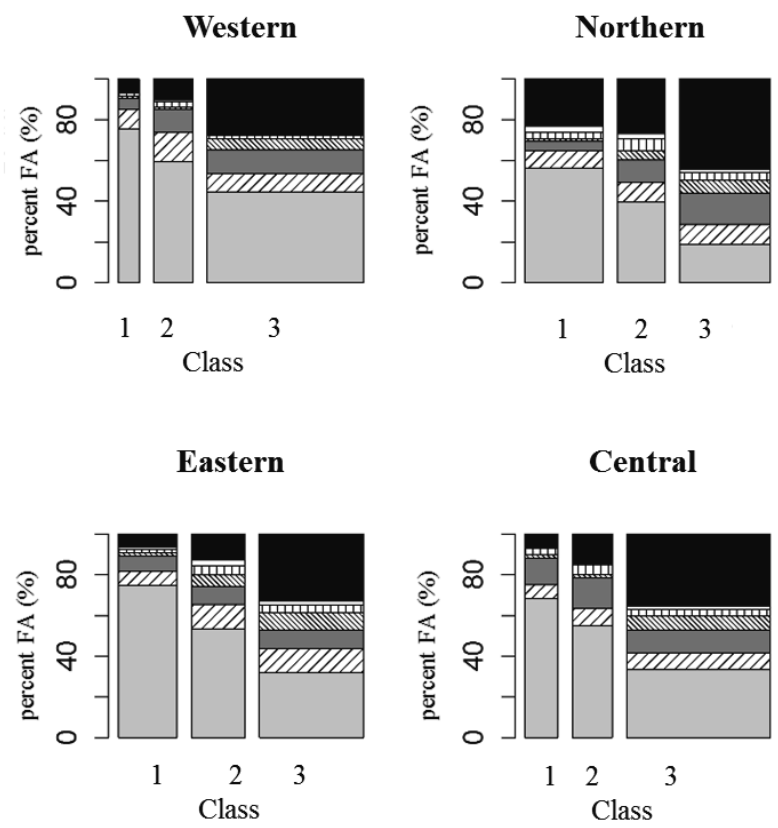

Fig 2.4 Contribution of on- and off-farm activities to rural household food availability per class (Class 1 , deficient food availability $<2,500 \mathrm{kcal} \mathrm{cap}^{-1} \mathrm{day}^{-1}$; Class 2 , adequate food availability between 2,500 and 5,000 kcal cap ${ }^{-1}$ day $^{-1}$; Class 3, surplus food availability $>5,000 \mathrm{kcal} \mathrm{cap}^{-1} \mathrm{day}^{-1}$ ) and per region. Number of households: $n_{\text {Western }}=458, n_{\text {Northern }}=554, n_{\text {Central }}=397, n_{\text {Eastern }}=511$ ( 7 households from Kampala not included in analysis). The thickness of bars represents the number of households within the class. Livestock is divided into poultry, shoats (sheep and goats), and cattle 
a)

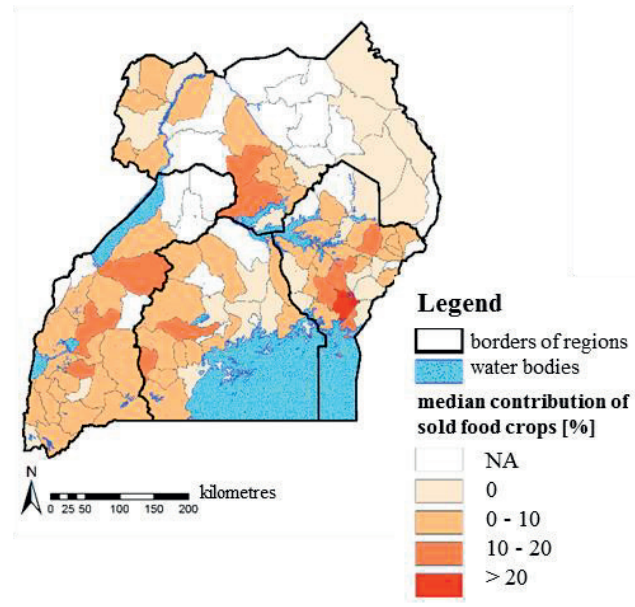

c)

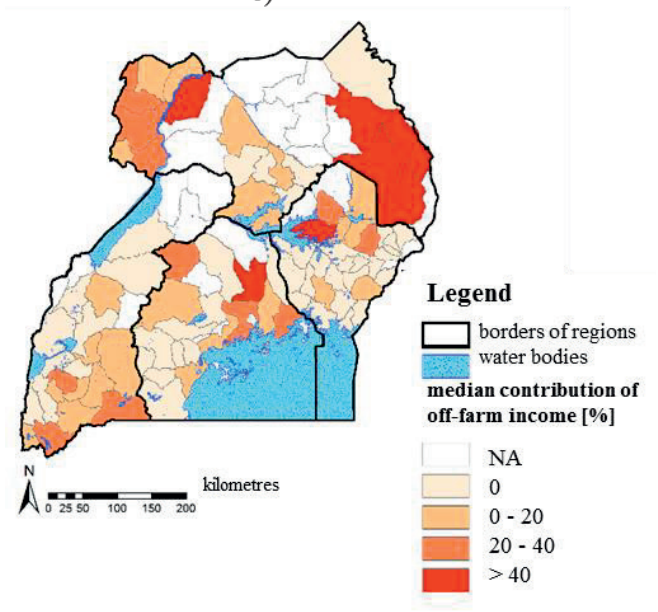

b)

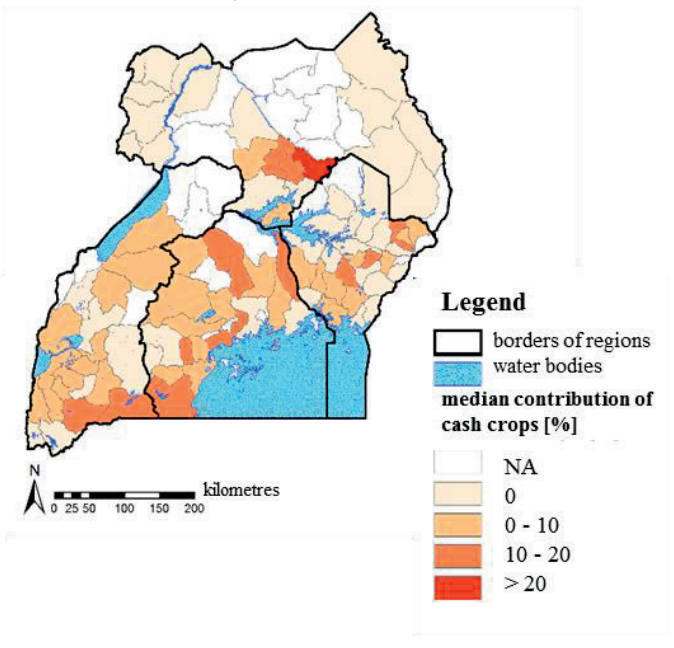

Fig 2.5 a) Median contribution of sold food crops to household food availability per district. b) Median contribution of cash crops to household food availability per district. c) Median contribution of off-farm income to household food availability per district. All districts with at least eight households were taken into account. The maps reveal patterns, while individual district values must be interpreted with care as LSMS data is not representative at the district level and their location (in latitude/longitude) was randomly off-set adding uncertainty to the exact location (Sources: UBOS 2012; WRI 2009; Thompson 2016) 


\subsubsection{Household production, income and food self-sufficiency}

Food self-sufficiency is the ratio of the household's annual direct consumption of potential food energy from on-farm products ( $\left.E_{\text {consumed }}\right)$ to the annual food energy required for the household $\left(E_{\text {need }}\right)$. $E_{\text {need }}$ was calculated from $365\left(\right.$ days year $\left.{ }^{-1}\right) \times 2,500\left(\mathrm{kcal} \mathrm{day}^{-1}\right) \times$ household size in male adult equivalents. Overall, $38 \%$ of the rural households were food self-sufficient, but patterns differed between the regions. In the Central and Western regions, 52 and 66\%, respectively, of the households were food self-sufficient as compared to 29 and 14\%, respectively, in the Eastern and Northern regions (Table 2.1). Per class, the proportions of food self-sufficient households were largest in the Western region with $83 \%$ of the food surplus households and $35 \%$ of the food adequate households. By contrast, in the Northern region, only $27 \%$ of the food surplus households and $15 \%$ of the food adequate households were food selfsufficient (Supplementary materials Table S2.2). Household income, production and production resources differed among the regions. Mean gross daily income was smallest in northern and eastern Uganda (0.3 USD cap ${ }^{-1}$ day $\left.^{-1}\right)$ and largest in central Uganda (1.2 USD cap ${ }^{1}$ day $^{-1}$ ) (Table 2.1). However, mean gross daily income in central Uganda also had the largest variability around the mean. The mean cash value of production was smallest in the Northern region (0.1 USD cap ${ }^{-1}$ day $\left.^{-1}\right)$ and largest in the Western and Central regions (0.3 USD cap ${ }^{-1}$ day $^{-}$ ${ }^{1}$ ), but also here variability around the mean was large. Mean farm size was similar (1.4 ha) for the Western and Eastern regions, but 20\% larger for the Central region and more than $40 \%$ larger in the Northern region compared with the Western and Eastern regions. For all regions except the Central region, mean farm size increased from food deficient households to food surplus households (Supplementary materials Table S2.2).

Also, at the district level, the median cash value of production was larger in the west than in the northeast and the northwest (Fig 2.6a). Median farm size was not correlated with median cash values of production (linear model, $R^{2}=1 \times 10^{-5}, p=0.98$ ). For example, the median cash value of production was small in the northeast and northwest, despite the larger median farm sizes (Fig 2.6b). Some districts in the west had smaller median farm sizes, yet their median cash value of production was larger than in areas with larger farm sizes. Median food availability and median farm size were not correlated at the district level (linear model, $R^{2}=0.006, p=0.44$ ).

Similar to the district level, the median cash value of production at the livelihood zone level was largest in the southwest and smallest in the north and east. Median farm size aggregated per livelihood zone revealed more distinct patterns than at the district level: At livelihood zone level, an area of median farm sizes $>1$ ha stretched from the northwest (West Nile) to the Eastern region, while median farm sizes $<1$ ha covered most of the Central and Western regions, parts 
of the Eastern region and Karamoja (northeast). Median farm sizes $<0.5$ ha were apparent in the mountain areas (Supplementary materials Figs S2.6 and S2.7).
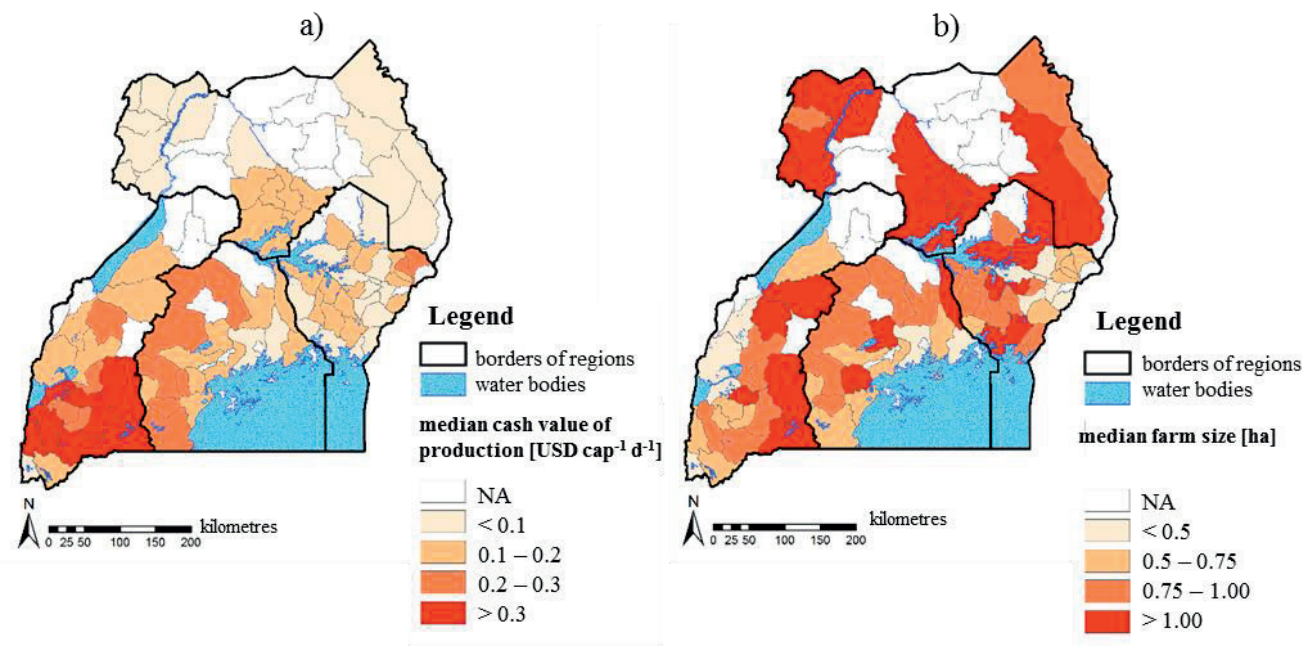

Fig 2.6 a) Median cash value of production (USD cap $^{-1}$ year $^{-1}$ ) (left). b) Median farm size (ha) of the households. All districts with at least eight households taken into account. The maps reveal patterns, while individual district values must be interpreted with care as LSMS data are not representative at the district level and their location (in latitude/longitude) was randomly off-set adding uncertainty to the exact location (Sources: UBOS 2012; WRI 2009; Thompson 2016)

\subsubsection{Cropping patterns related to food availability}

The contribution of individual crops to the household food availability differed per food availability class (Fig 2.7). The mean contribution of banana, one of the important food crops in Uganda, was largest for food surplus households (33\%) and smallest for food deficient households (14\%). In contrast, the mean contribution of the other important food crops (maize, cassava and sorghum) was least for food surplus households (14\%, $9 \%$ and $2 \%$, respectively) and most for food deficient households $(19 \%, 15 \%$ and $10 \%$, respectively). The mean contribution of coffee was relatively similar (3-5\%) for all classes, though the lowest contribution was consistently observed for the food deficient households across all regions. 


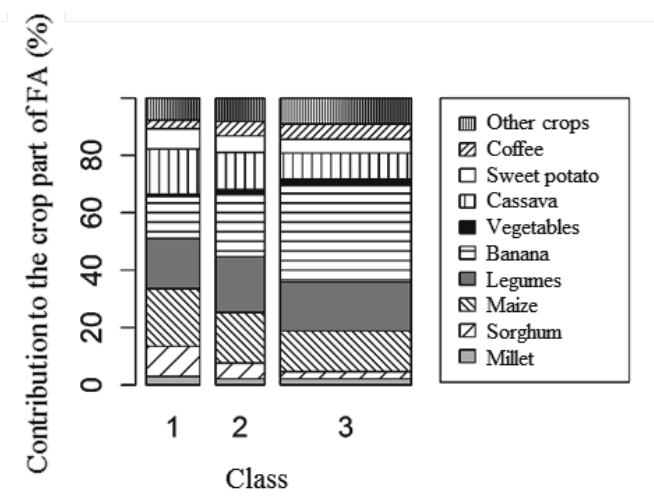

Fig 2.7 Contribution of crops to the crop part of household food availability per class (Class 1, deficient food availability $<2,500 \mathrm{kcal} \mathrm{cap}^{-1} \mathrm{day}^{-1}$; Class 2, adequate food availability between 2,500 and 5,000 $\mathrm{kcal} \mathrm{cap}^{-1} \mathrm{day}^{-1}$; Class 3 , surplus food availability $>5,000 \mathrm{kcal} \mathrm{cap}^{-1}$ day $\left.^{-1}\right)$. The crop part includes energy from food crops consumed and energy equivalent from income from food and cash crops sold (N.B. coffee). Number of households: $n=1,927$. The thickness of bars represents the number of households within the class

At the regional level, we observed differences in the importance and type of crops contributing to food availability in terms of consumption and cash generation. While banana was the most important food crop in the Western and Central regions, cassava, maize and sorghum were the most important in the Northern and Eastern regions (Fig 2.8). Coffee was an important cash crop in the Central region (and to a lesser extent in the Eastern region), while there was no single dominant cash crop in the other regions. In the Western region, banana was most important for food surplus households showing that banana was an important crop for income generation as well as food. Most of the food deficient households consumed all their produced bananas (almost 90\% of the food deficient households), while $66 \%$ of the food surplus households (comprising more than $70 \%$ of all households in the Western region) sold on average $19 \%$ of their banana production. In the Northern region, 'other crops', including rice and tobacco, contributed most for the food surplus households. Legumes contributed similarly to the crop part of food availability across all regions and classes with a mean of 14 to $20 \%$. 

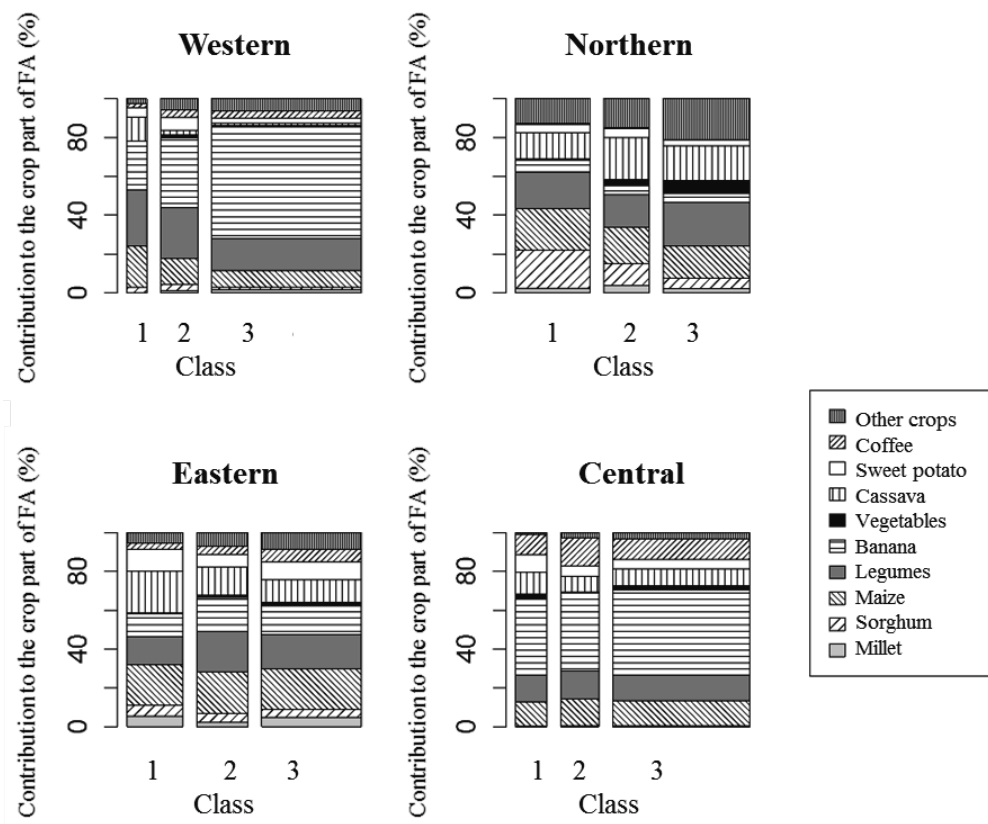

Fig 2.8 Contribution of crops to the crop part of household FA per class (Class 1, deficient food availability $<2,500 \mathrm{kcal} \mathrm{cap}^{-1} \mathrm{day}^{-1}$; Class 2 , adequate food availability between 2,500 and 5,000 kcal $\mathrm{cap}^{-1} \mathrm{day}^{-1}$; Class 3 , surplus food availability $>5,000 \mathrm{kcal} \mathrm{cap}^{-1} \mathrm{day}^{-1}$ ) and region. The crop part includes energy from food crops consumed and energy equivalent from income from food and cash crops sold (N.B. coffee). Number of households: $n_{\text {Western }}=458, n_{\text {Northern }}=554, n_{\text {Central }}=397, n_{\text {Eastern }}=511$ (7 households from Kampala not included in analysis). The thickness of bars represents the amount of households within the class

\subsection{Discussion}

We structure the discussion around our research questions and hypotheses on how food availability differed across Uganda, how activities contributing to food availability and cropping patterns differed with food availability and how our findings could guide intervention strategies of policy and development actors.

\subsubsection{What proportion of Ugandan households is food deficient and how does food availability differ across the country?}

Overall 23\% of the households across Uganda were food deficient. Similarly, the national poverty rate was observed to be around 24\% in 2010 (Daniels and Minot 2015) and the FAO Hunger map identified $24.8 \%$ of the total population to be unable to meet their minimum dietary 
energy requirements over one year in the period from 2010 to 2012 (FAO 2016a). Because our food availability indicator did not consider non-food expenses, our figures may underestimate the country's food insecurity status.

In the Northern region more households are food deficient. Household food availability varied greatly across Uganda with generally smaller food availability in the north, which corresponds to less optimal agroecological conditions (e.g. rainfall quantity and distribution) and poorer market access due to weaker road infrastructure and absence of large urban markets. The low food availability in the north matched with a smaller mean cash value of production and a smaller mean daily income.

Agroecological conditions are known to affect food security (Hyman et al. 2005). For example, in Malawi Fisher and Lewin (2013) observed that relatively high annual rainfall corresponds to a greater likelihood of households being food secure. Rural households in the Northeast experience low annual rainfall and a prolonged dry season (UBOS 2013), which can affect agricultural production and subsequently household food availability. However, while parts in the Southwest receive similar amounts of annual rainfall as in the Northeast, food availability in the Southwest was generally greater, indicating that regional differences in food security are subject to multiple factors that go beyond rainfall distribution.

Differences in infrastructure and market access may be one reason for the regional differences in food availability. Frelat et al. (2016) observed a positive relation between market access and food availability. The long-lasting conflicts in northern Uganda prior to 2009/2010 (Tusiime et al. 2013) caused insecurity and destroyed infrastructure, including food production and distribution systems in the north (FANTA-2 2010; Martiniello 2013). In addition, most larger urban centres in Uganda with a high demand for food are located in the Central and Western regions. Mean values of farm production resources (farm size and tropical livestock units) could not explain the lesser food availability in the Northern region compared to the other regions.

\section{Households in the Eastern region were more food deficient than in central and western}

Uganda. Regional mean household food availability was less in the east than in the Central and Western regions, although aggregations at district level showed a more diverse picture. Also regional mean gross daily income and mean cash value of production were lower in the Eastern region. Similar to the north, farming systems in the east (except for the Mount Elgon region) are more based on annual crops and less on major cash crops such as coffee. 


\subsubsection{How do contributing activities differ with food availability and across Uganda?}

The activities contributing to food availability varied strongly between households and regions and with household food availability. Consumption of crops produced on-farm was the major contributor to food availability across all households, matching observations by Frelat et al. (2016). However, while consumption of crops produced on-farm was particularly important for households with low food availability, off-farm income and market-oriented on-farm activities increased in their importance with greater household food availability, thereby partly supporting Hypothesis II. The changes in the activities along a food availability gradient suggest that rural households follow different livelihood strategies, related to their food availability. Three major strategies for food availability are discussed: Food self-sufficiency (1), cash crop production (2), and off-farm income generation (3).

Food self-sufficiency as a strategy for rural households. Although consumption of crops produced on-farm was generally important for food availability, the majority of the households were not food self-sufficient. Instead, the sale of food crops played an important role also for the food deficient households. Two factors may be at play: First, many households choose to diversify their livelihoods towards income-generating activities before they are food selfsufficient (Frelat et al. 2016; Ritzema et al. 2017). Second, particularly the food deficient households are often unable to achieve food self-sufficiency, because they need to sell some of their food crop harvest to pay for non-food expenses (Leonardo et al. 2015). In the Northern region, food self-sufficiency was less than in the other regions both overall and per class. Food self-sufficiency was thus not a strategy towards food security for households in the north despite poor market access and infrastructure. This is perhaps partly due to low productivity resulting from the low and variable rainfall. Harris and Orr (2014) identified three potential pathways out of poverty: Extensification by increasing land area, diversification and commercialisation of crop production, and diversification of income. The smaller proportion of food self-sufficient households on relatively large farms in the north suggests that extensification seemed not to be a strategy towards food security and poverty reduction in that area. Instead, households focus on income-generating activities, particularly off-farm income.

Cash crops as a strategy for rural households. Crop commercialisation can lift households out of poverty (Harris and Orr 2014) and has positive effects on food security (Kristjanson et al. 2010). In addition, cash crops have beneficial effects on the overall farm, as they generate money for households to reinvest in their food crops. This reinvestment can increase the productivity of the food crops and thereby benefit household food security (Govereh and Jayne 2003). Indeed, the contribution of cash crops (e.g. coffee) increased from deficient to food surplus households. Yet, the contribution strongly depended on the region. At district and livelihood zone levels, the median cash crop contribution was zero for most of the north and 
the northeast of Uganda and between zero and 10\% in most districts in the west. These patterns match the differences in infrastructure across Uganda and highlight that market access is paramount for venturing into cash crops.

Off-farm income as a strategy for rural households. Overall, the contribution of off-farm income to food availability increased with the household food availability status. This observation contrasts with other studies that identified off-farm income to be particularly important for the poorest (e.g. Jayne et al. 2014). However, Haggblade et al. (2010) observed that poorer households have no access to high quality sources of off-farm income. Instead, they remain in low-pay market segments (e.g. unskilled casual labour) with few opportunities to step out of poverty. For these poorer households, off-farm income is rather a means of survival. Yet, off-farm income activities can serve as an important safety net for food insecure or poor households during periods of stress. For example, during drought years off-farm income activities stabilise household income (Haggblade et al. 2010). The north of Uganda is particularly vulnerable to droughts and weather-related impacts because of its unimodal rainfall and variability of rainfall (UBOS 2013). Indeed, at all spatial aggregation levels, off-farm income contribution was largest in these low-potential agricultural areas in the north. This is in line with Matsumoto et al. (2006) who observe that the likelihood of households participating in off-farm activities is greater in low-potential areas.

\subsubsection{How do cropping patterns differ with food availability and across Uganda?}

The contribution of major crops (banana, maize, cassava and sorghum) to the crop part of food availability varied along a food availability gradient and across regions. While the contribution of sorghum and maize as major staple crops decreased from deficient to food surplus households, the contribution of banana increased, thereby only partly supporting Hypothesis III that staple crops are more important for food insecure households. Banana was a predominant crop in western and central Uganda with increasing importance from deficient to food surplus households, while cropping systems in northern and eastern Uganda had greater crop diversity. Such regional diversity patterns are expected to reflect the crop diversity at farm level. What remains hypothetical is to what extent such differences in crop diversity on the farm level result in differences in household dietary diversity (e.g. Carletto et al. 2015; Dillon et al. 2015). In fact, the Western region of Uganda has poor nutritional diversity (FANTA-2 2010; UBOS 2013), which matches our observations of low crop diversity in western Uganda.

East African highland banana is an important food and cash crop. East African highland banana is one of the most important food crops in Uganda (Komarek and Ahmadi-Esfahani 2011) and contributes considerably to household food availability. At national level, the 
contribution of highland banana was largest for food surplus households. Banana is both an important food crop and cash crop in Uganda, particularly in western Uganda (Komarek and Ahmadi-Esfahani 2011; Jassogne et al. 2013a). The larger banana contribution for food surplus households can be explained in two ways. On the one hand, most food surplus households are located in western and central Uganda, two regions that are important for banana production as a cash crop. However, this coincidence results in a large banana contribution to the crop part of food availability for the overall dataset, but does not reflect causal relations between banana contribution and food availability. On the other hand, the larger banana contribution to the food availability of food surplus households may also be related to the properties of banana as a perennial crop. Perennial crops show potential benefits for food security over annual crops (e.g. maize, sorghum). These benefits include reduced expenditures on seeds, fertilizers and other inputs, reduced labour for planting and weeding (thereby saving labour to invest in off-farm activities), and extended growing seasons that enable farmers to harvest over longer periods of time (Batello et al. 2013). The second reason can also explain the greater food self-sufficiency in western and central as compared with northern and eastern Uganda. Finally, as one of the most important staple crops in central and western Uganda, demand for highland banana is high in the urban areas generating an attractive market.

Crop contributions to FA were quantified assuming that all harvest that was not reported as sold, was consumed. In reality, farmers use part of the harvest as seed for the following season and part is lost during handling or storage. Because of this simplification, the FA approach quantifies the potential FA rather than the actual FA. Differences in on-farm post-harvest losses (PHL) between crops could affect the contribution of crops to household FA. For example, while maize grains can be easily stored, harvested banana must be sold and consumed soon after harvest. This difference in storage characteristics of crops can result in differences in onfarm PHL between crops.

At the national level in Uganda PHL for banana are larger than for maize (approximately 12\% for banana as compared to $6 \%$ for maize), while on-farm PHL are similar (less than $3 \%$ for banana as compared to about 4\% for maize) (Kikulwe 2017; Kaminski and Christiaensen 2014). On-farm, banana is harvested for each meal thereby reducing food wastage (Kikulwe 2017). By contrast, crops like maize are stored for longer, increasing the risk of damage (Affognon et al. 2015). Estimating the effect of PHL on FA remains challenging, because data are scanty (Affognon et al. 2015), and PHL vary depending on crops, post-harvest management and location (Affognon et al. 2015; Kaminski and Christiaensen 2014). Yet, the figures mentioned above suggest that differences in on-farm PHL between major crops are small. 


\subsubsection{Targeting interventions: Intensifying food production, increasing market access or generating off-farm income sources - What makes households food secure?}

Our results show that agricultural interventions alone will not achieve household food security in Uganda's north, where $\mathrm{m}$ arket access is poor and agroecological conditions are unfavourable. Instead, holistic livelihood interventions are needed that promote opportunities for off-farm income generation, such as improved access to education and urban employment (Haggblade et al. 2010). Yet, interventions must also support agriculture (particularly through food markets and security of land tenure). Given that northern Uganda is still recovering after a period of insecurity this may explain the smaller role of agricultural activities for household food availability as compared with the other regions (FANTA-2 2010).

Cash crops were important for food availability while the contribution of food crops remained limited. Improving access to (cash crop) markets and to urban centres will probably contribute more to improving household food security than focusing solely on closing the yield gap of food crops. This observation is confirmed by the small proportion of food self-sufficient households and the fact that sale of food crops, particularly short-cycle crops such as maize, was not related to increasing food availability. Barrett (2008) observed that smallholder participation in food crop markets only benefits the households with sufficient available assets (land, livestock, capital and technology similar to the sustainable livelihood framework capital assets). The poor households, in contrast, do not manage to produce marketable surpluses from which to derive income that could be used to borrow or buy assets and thus to step out of poverty (Barrett 2008). Also the often low prices for food crops (Harris and Orr 2014) and large investment barriers for closing the yield gap (e.g. Tittonell and Giller 2013) may be reasons why commercialisation of most food crops was not observed as a key strategy for food availability in our data. For that reason, current programmes that focus on the promotion of maize for poverty reduction (e.g. the USAID Feed the Future programme in Uganda) need to be evaluated on their success in increasing household food security.

East African highland banana is an exception to our observations on the role of food crops for household food availability in western and central Uganda, as banana is an important cash crop but also important in supporting household food security. Potential interventions include breaking down the barriers for access to cash crop markets along with facilitating the uptake of yield-improving technologies and establishing access to productive assets (Barrett 2008). However, simply establishing cash crop markets is not enough to improve household food security. While the cultivation of cash crops increases the frequency and amount of household income, they also increase the dependency on local markets and on highly unstable food prices (Anderman et al. 2014). Therefore, for a positive effect of cash crop cultivation on food 
security, interventions (e.g. cross-border trade, grain storage, no export bans in drought period) also need to promote access and price stability of food crop markets (Anderman et al. 2014).

\subsubsection{Zooming in and zooming out - Contributions of the FA framework}

District aggregation is strictly administrative and can be questionable when contrasting livelihood systems are found within districts. Averaging indicators across these systems introduces bias. Therefore, FEWS NET developed livelihood zones to represent core livelihood activities (Boudreau 1998). For some areas in Uganda these livelihood zones are defined at a coarser level than the districts, for others in finer detail. Our approach, based on individual household data, showed that aggregation to livelihood zones did not capture small-scale variation within zones, suggesting bias also at livelihood zone level. This said, aggregation at both district and livelihood zone levels must be interpreted with caution. For any policy decision, further zooming in using representative datasets is needed.

A major contribution of our FA approach is the use of household-data to provide quantitative information on livelihood strategies in relation to food availability. The approach enables us to describe countrywide patterns while preserving the original household level variability, thus capturing a large diversity of household strategies at the smallest scale. In this way it is a useful addition to frameworks on vulnerability and risk assessments (such as the sustainable livelihood framework linking assets, vulnerability, livelihood strategies and outcomes). The FA approach can further be used to validate aggregation zones, for example by comparing livelihood zone descriptions on major crops with the household information from the FA approach (Browne and Glaeser 2010). Such a comparison on crop level among the livelihood zone descriptions and our LSMS household information revealed that in some zones where cassava was described as an im portant crop, it contributed little to households' food availability (e.g. in the northwest and in central and southern parts of Uganda). In contrast, in livelihood zones where banana was not described as an important crop, the household data revealed that banana was important for household food availability (in central and southern areas) (Browne and Glaeser 2010).

\subsection{Conclusions}

Uganda's rural households follow diverse livelihood strategies, which differ across the regions and with their degree of food availability. Households with greater food availability tend to diversify their on-farm and off-farm activities, thus spreading the risk. Those households with surplus food availability have more income from on-farm and off-farm activities as compared to households with insufficient food availability. In areas with good market access and 
infrastructure, cash crops can be an important strategy contributing to household food availability, while in areas with poor infrastructure and less favourable agroecological conditions, off-farm income, probably of low quality, plays a more important role. Most staple crops are more important for the households with insufficient food availability, while East African highland banana was identified to be one of the key crops for income generation in western and central Uganda and most important for households with surplus food availability.

The diversity of livelihood strategies must be considered when targeting interventions. Holistic livelihood interventions, including access to off-farm activities, are needed to improve household food availability in Uganda's north. Instead of focusing on food self-sufficiency, households with low food availability already diversify towards income-generating activities. Interventions need to facilitate these diversification strategies by improving access to food and cash crop markets and to off-farm activities. Current programmes often focus on promoting maize as a cash crop for food security, but our results show that maize is important for households with insufficient food availability, but not as a cash crop for the households with a food surplus. In contrast, we show East African highland banana to be both an important food and cash crop. However, this crop has so far received scant attention in investment programmes.

Our analytical framework provides a basis to account for diverse household strategies in decision-making on interventions. The food availability analysis quantifies where and which activities are important for which group of farmers and can help to identify suitable interventions for rural households. We identify differences in livelihood strategies across a food availability gradient and across the country. Both dimensions are necessary for targeting interventions.

\section{Acknowledgements}

This work was financed by the CGIAR Research Program on Climate Change, Agriculture and Food Security, with additional support from the CGIAR Research Program on Humid Tropics and Wageningen University and Research. We thank two anonymous referees for their critical and constructive criticism. 


\section{Supplementary materials of Chapter 2}

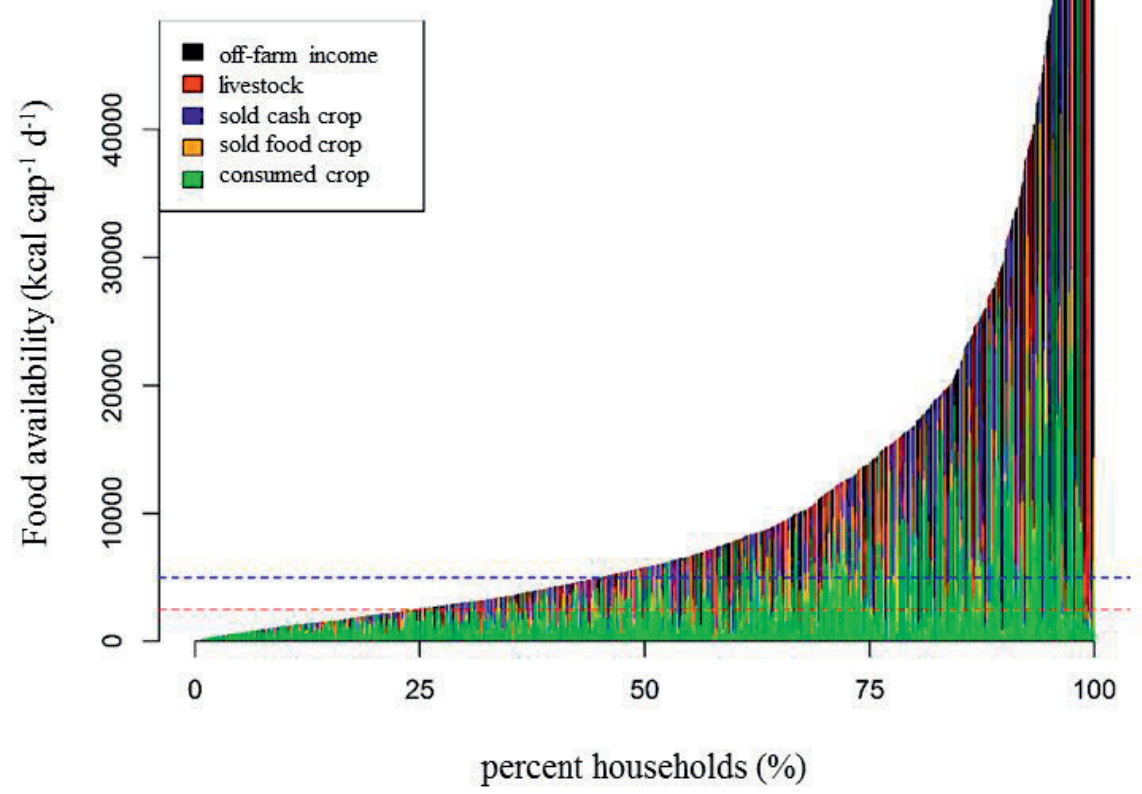

Fig S2.1 Household food availability for 1,927 households across Uganda. Households are ordered by increasing food availability along the $\mathrm{x}$-axis where each bar represents one household. The red dashed line represents a food availability value of $2,500 \mathrm{kcal} \mathrm{cap}^{-1} \mathrm{day}^{-1}$, the daily energy need of a male adult (Holden et al. 2001) and the blue dashed line represents 5,000 kcal cap ${ }^{-1}$ day $^{-1}$, the lower boundary of 'food surplus households'. This figure, in contrast to Fig 2.2a, does not include a moving average 


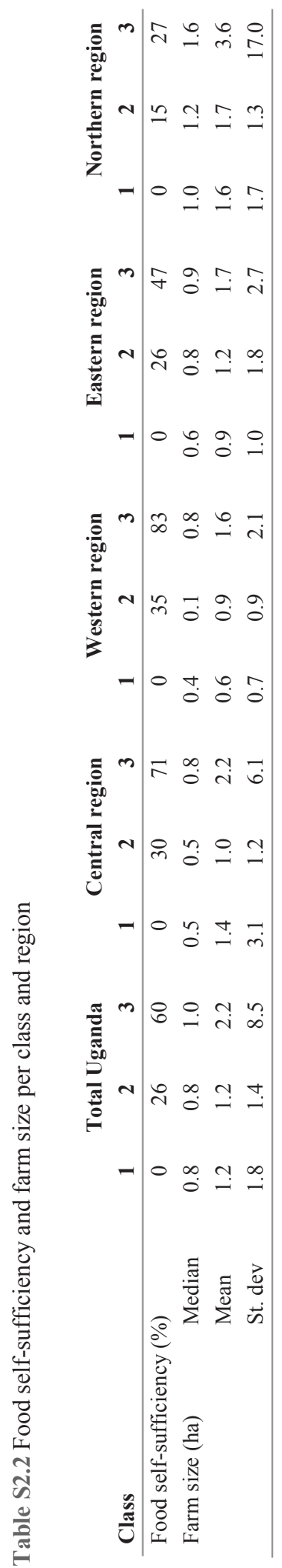




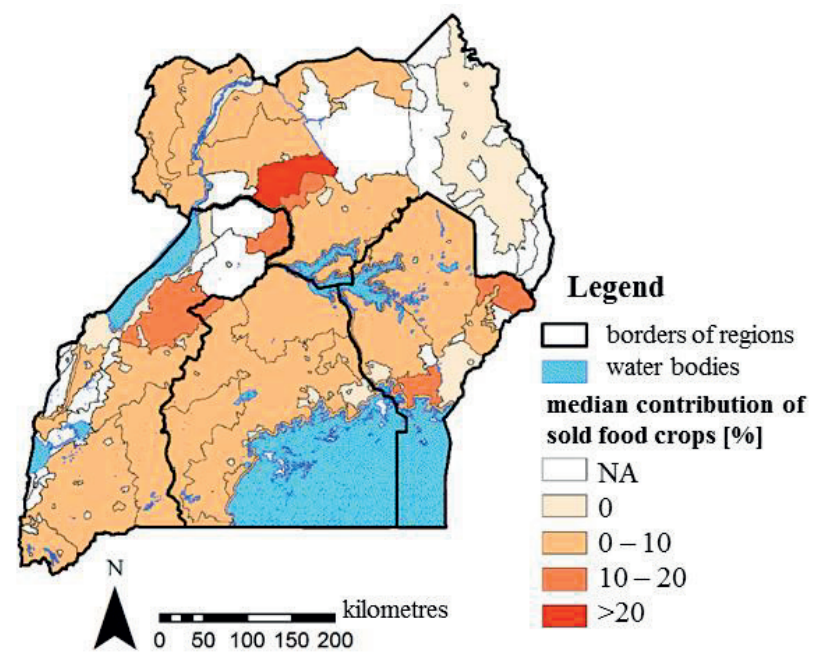

Fig S2.3 Median contribution of sold food crops to household food availability per livelihood zone. All zones with at least eight households taken into account. The maps reveal patterns, while individual livelihood zone values must be interpreted with care as LSMS data is not representative at livelihood zone level and their location (in latitude/longitude) was randomly off-set adding uncertainty to the exact location. Sources: Thompson (2016), clipped from WRI (2009), FEWS NET (2013)

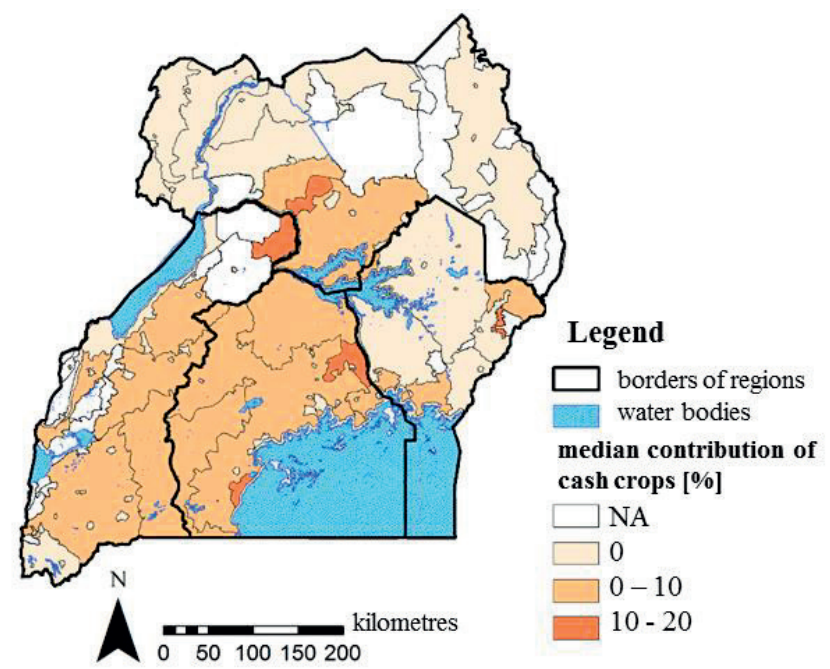

Fig S2.4 Median contribution of cash crops to household food availability per livelihood zone. All zones with at least eight households taken into account. The maps reveal patterns, while individual livelihood zone values must be interpreted with care as LSMS data is not representative at livelihood zone level and their location (in latitude/longitude) was randomly off-set adding uncertainty to the exact location. Sources: Thompson (2016), clipped from WRI (2009), FEWS NET (2013) 


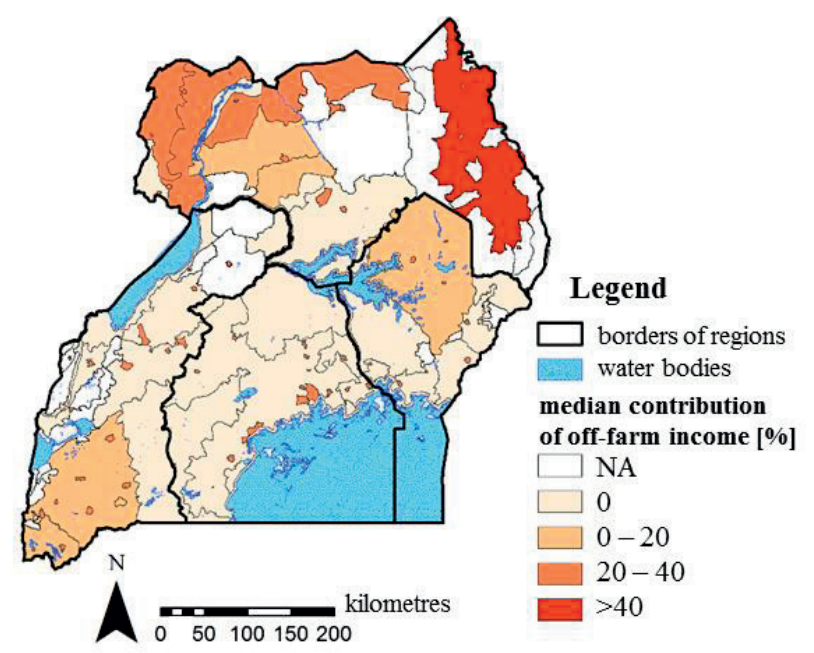

Fig S2.5 Median contribution of off-farm income to household food availability per livelihood zone. All zones with at least eight households taken into account. The maps reveal patterns, while individual livelihood zone values must be interpreted with care as LSMS data is not representative at livelihood zone level and their location (in latitude/longitude) was randomly off-set adding uncertainty to the exact location. Sources: Thompson (2016), clipped from WRI (2009), FEWS NET (2013)

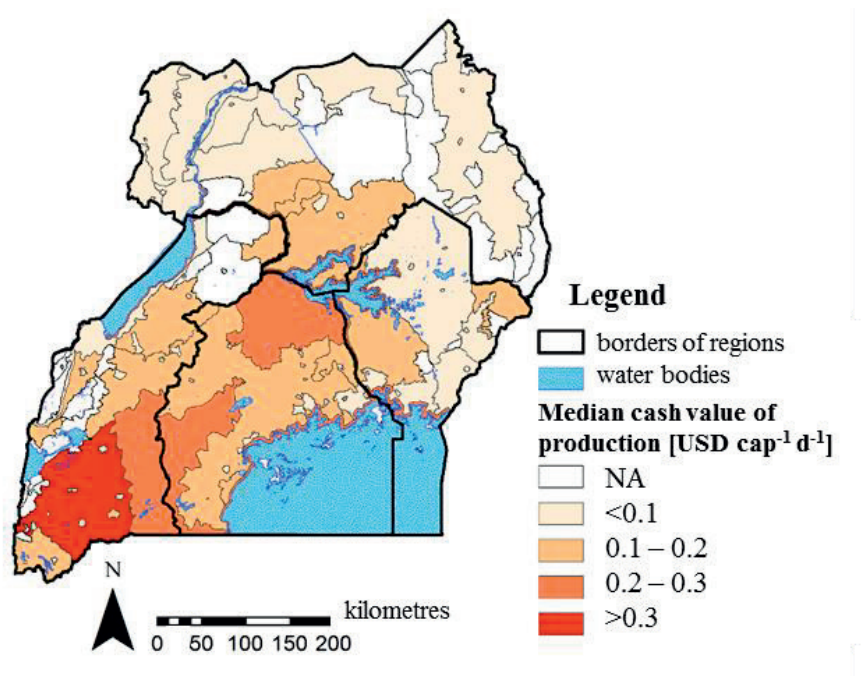

Fig S2.6 Median cash value of production (USD cap $^{-1}$ year $^{-1}$ ) per livelihood zone. All zones with at least eight households taken into account. The maps reveal patterns, while individual livelihood zone values must be interpreted with care as LSMS data is not representative at livelihood zone level and their location (in latitude/longitude) was randomly off-set adding uncertainty to the exact location. Sources: Thompson (2016), clipped from WRI (2009), FEWS NET (2013) 


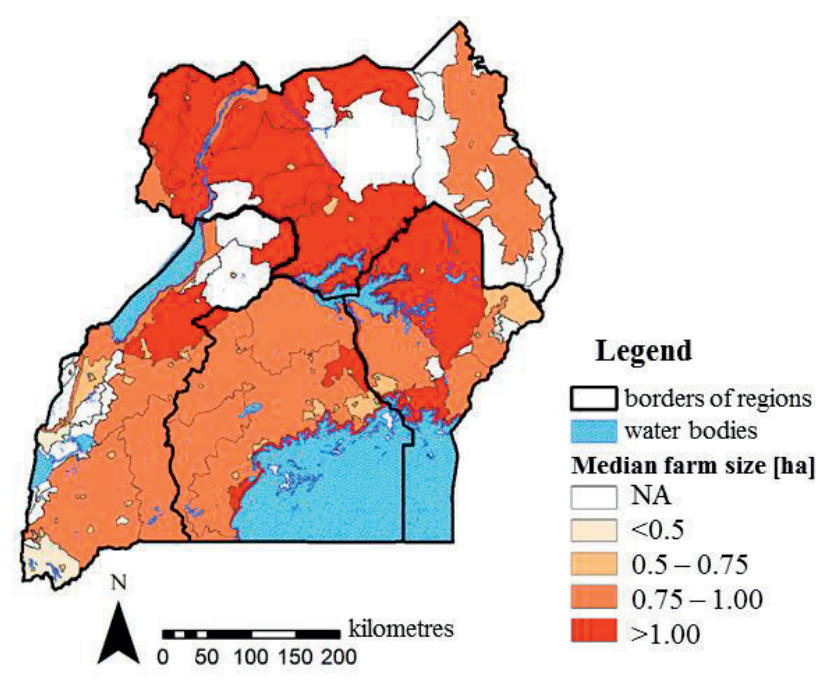

Fig S2.7 Median farm size (ha) of the households per livelihood zone. All zones with at least eight households taken into account. The maps reveal patterns, while individual livelihood zone values must be interpreted with care as LSMS data is not representative at livelihood zone level and their location (in latitude/longitude) was randomly off-set adding uncertainty to the exact location. Sources: Thompson (2016), clipped from WRI (2009), FEWS NET (2013) 



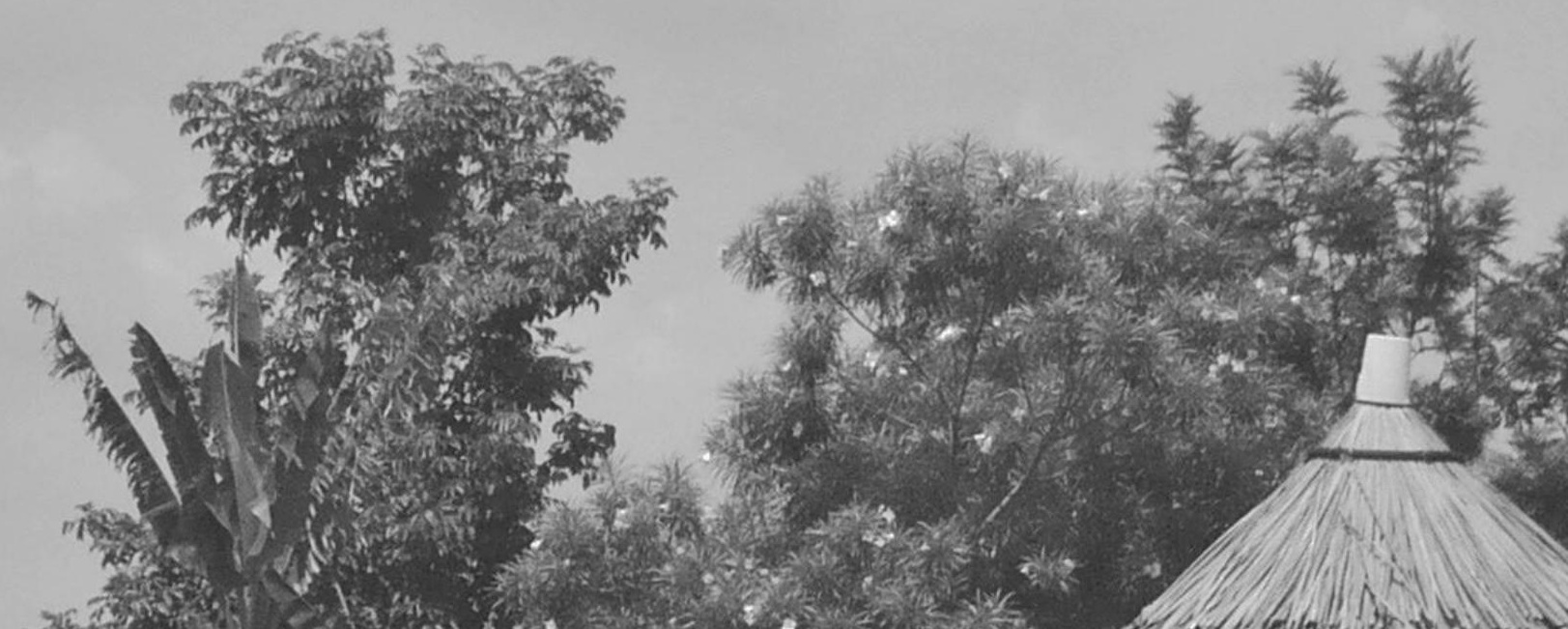

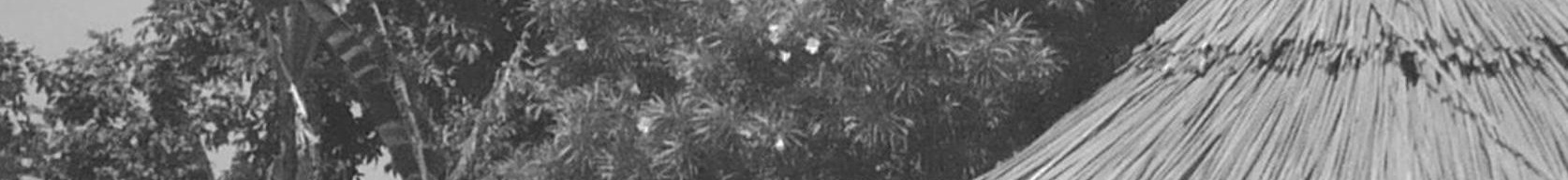
(3) $(1+2)$ (2. 2. $+2 x^{2}+2 \pi$ 4. 2. ate $x=2 x$ 1) 


\section{Chapter 3}

\section{Using household survey data to identify large-scale food security patterns across Uganda}

This chapter is based on the publication:

Wichern, J., van Heerwaarden, J., de Bruin, S., Descheemaeker, K., van Asten, P. J. A., Giller, K. E., van Wijk, M. T. (2018). Using household survey data to identify largescale food security patterns across Uganda. PLoS ONE 13(12). 


\begin{abstract}
To target food security interventions for smallholder households, decision makers need largescale information, such as maps on poverty, food security and key livelihood activities. Such information is often based on expert knowledge or aggregated data, despite the fact that food security and poverty are driven largely by processes at the household level. At present, it is unclear if and how household level information can contribute to the spatial prediction of such welfare indicators or to what extent local variability is ignored by current mapping efforts. A combination of geo-referenced household level information with spatially continuous information is an underused approach to quantify local and large-scale variation, while it can provide a direct estimate of the variability of welfare indicators at the most relevant scale. We applied a stepwise regression kriging procedure to translate point information to spatiallyexplicit patterns and create country-wide predictions with associated uncertainty estimates for indicators on food availability and related livelihood activities using household survey data from Uganda. With few exceptions, predictions of the indicators were weak, highlighting the difficulty in capturing variability at larger scale. Household explanatory variables identified little additional variation compared to environmental explanatory variables alone. Spatial predictability was strongest for indicators whose distribution was determined by environmental gradients. In contrast, indicators of crops that were more ubiquitously present across agroecological zones showed large local variation, which often overruled large-scale patterns.
\end{abstract}

Our procedure adds to existing approaches that often only show large-scale patterns by revealing that local variation in welfare is large. Interventions that aim to target the poor must recognise that diversity in livelihood activities for income generation within any given area often overrides the variability of livelihood activities between distant regions in the country.

Keywords: smallholder farm, household level, regression kriging, food security map, farming Systems, East Africa 


\subsection{Introduction}

Smallholder farming is the basis of living for many of the most vulnerable on earth (Samberg et al. 2016) and one of the most common forms of agriculture worldwide (FAO 2014). For the majority of the rural households in sub-Saharan Africa, agriculture contributes a substantial part of their livelihood. There is a strong link of smallholder farming with poverty, malnutrition and hunger of the rural population (UNCTAD 2015), so that targeting interventions on smallholder farming is important for achieving Sustainable Development Goal 2 (Zero Hunger) of the United Nations. Decision makers need large-scale quantitative information, such as displayed in maps, for targeting interventions, assessing vulnerability of rural households to poverty and food insecurity, and for planning emergency relief.

Maps on poverty and food security are often derived from aggregated information or based on expert knowledge. Until recently, expert-based aggregation masks (Grillo and Holt 2009) were typically used. Recent more advanced approaches using machine learning to predict the distribution of poverty from satellite imagery (Jean et al. 2016) have relied on aggregated household data. While often justified, the aggregation of household data potentially hides relevant information and variability at the household level. After all, poverty and food security tend to be locally driven processes with large variation at small scale, for example between nearby households (Ritzema et al. 2017).

An alternative approach would be to model variability at the household level directly, using household survey data in combination with spatially-explicit environmental and socioeconomic data, and to produce maps that allow identifying spatial patterns at this scale. This would provide a direct estimate of the variability and predictability of welfare indicators at the most relevant scale and would allow evaluation of the importance of explanatory variables at the household level. Such a combination of geo-referenced household level information with spatially continuous information (Robinson et al. 2007; Nelson et al. 2012) is an underused approach to quantify local and large-scale variation and improve targeting of interventions.

In our study we developed and tested a stepwise procedure to translate point information to spatially-explicit patterns and create country-wide spatial predictions of welfare indicators using household survey information. We thereby addressed the following questions:

1. Can spatial variability in welfare at the household level be reliably modelled using spatially-explicit environmental and socio-economic data in combination with household survey data?

2. Do household resource variables offer additional explanatory power compared to environmental and socio-economic variables alone? 
3. Is there remaining spatial information in unexplained variability that can be exploited for generating spatial predictions?

Welfare and particularly food security was represented using the household food availability framework (Frelat et al. 2016), which enables to identify the importance of different livelihood activities and agricultural products to a household's potential food availability (as approximation to food security). By differentiating rural households in terms of their livelihood activities and resources contributing to household welfare, the approach generates important insights for effective policy making and provides relevant information for vulnerability and risk assessments (Samberg et al. 2016).

Household level data were acquired from the Living Standard Measurement Study - Integrated Survey on Agriculture (LSMS-ISA) of the World Bank, which provides country-wide household survey data in several countries in sub-Saharan Africa containing information on household welfare and smallholder production (Kilic et al. 2015). We used the LSMS-ISA data from Uganda (UBOS 2011) as an exam ple because of the country's large variability in agre ecosystems and related livelihoods. A majority of households in Uganda lives in rural areas and is involved in agriculture production on small farms (FAO 2016b). Farming systems in Uganda are diverse, ranging from coffee-banana systems in the humid tropical climate of the south-east to agro-pastoral systems in the semi-arid north. Most farming systems combine crop and livestock activities. Livestock and particularly cattle is dom inant in Uganda's 'cattle corridor', an area of pastoral rangelands stretching from the Southwest to the Northeast (Sempiira et al. 2017; Government of Uganda 2004). Temperature in Uganda mostly depends on elevation and show little annual variation with maxima between 25 to $30^{\circ} \mathrm{C}$. Annual rainfall varies from $<750$ $\mathrm{mm}$ in the northeast to $>1,750 \mathrm{~mm}$ at higher elevations and near Lake Victoria. Rainfall distribution is bim odal in Uganda's south, but gradually changes to unimodal as we move northeast where the dry season becomes more prolonged (Mwebaze 1999). The majority of Ugandans live in the western, central and eastern parts of the country which also have the densest road networks and major towns (WorldPop 2015; Nelson 2008). While the poverty rate of Uganda has declined in the recent past, it is unclear if this benefited all segments of the population (UBOS 2010a; Daniels and Minot 2015). While the poverty rate of Uganda has declined in the recent past, it is unclear in how far the benefits have been equally distributed (UBOS 2010; Daniels and Minot 2015). The GINI coefficient (an indicator of inequality) of Uganda increased from 41 in 2012 to 42.8 in 2016 and is similar to neighbouring countries (e.g. 40.8, 37.8 and 45.1 for Kenya, Tanzania and Rwanda, respectively) (The World Bank 2018). This indicates that local variability in poverty and food security is similar in Uganda as other countries in East Africa. 


\subsection{Material and methods}

Protocol on: dx.doi.org/10.17504/protocols.io.vb6e2re

We identified a set of household level indicators to determine food availability (as approximation for food security) and related livelihood activities. We used a regression kriging approach with a set of spatially continuous environmental and socio-economic explanatory variables and household resource explanatory variables (herd size, total cultivated land area, household size) to identify large-scale and local variation.

\subsubsection{Data and data preparation}

\subsubsection{Data}

We used cross-sectional household survey data for Uganda from the World Bank Living Standard Measurement Study - Integrated Surveys on Agriculture (LSMS-ISA) (Kilic et al. 2015; UBOS 2011). In total 2,671 geo-referenced households were sampled across Uganda over a 12-month period from 2010 to 2011. The LSMS-ISA has been designed to be nationally representative on rural/ urban and regional levels. Households were sampled per enumeration area, based on a random selection of enumeration areas per region (Kampala, Central, Eastern, Northern and Western) (The World Bank 2012). We used survey data on household characteristics, farm size, crop and livestock production and off-farm income for the household food availability analysis and on herd size, total cultivated land area and household size as household resource explanatory variables for the regression analysis (see below). The three household resource explanatory variables were chosen because they reflect productive resources, which link to the food availability analysis looking at household productivity. We present results from the dataset from the year 2010-11. Other years (LSMS 2011-12) were used to check for consistency of patterns, which revealed that patterns remained similar across years for most variables (for details see Supplementary materials Figs S3.1-3.3). We were interested in the agricultural households and excluded households without land holdings as well as households without any livelihood activities (i.e. no agricultural production and no off-farm income; final sample: 1,927 households, Fig 3.1). For the spatial analysis we collected environmental and socio-econom ic explanatory variables (henceforth: 'environmental explanatory variables') that were available as raster layers, including elevation (Jarvis et al. 2008), temperature and rainfall (Hijmans et al. 2005), length of growing period (HarvestChoice 2015), soil conditions (Hengl et al. 2017), population density (WorldPop 2015) and market access (Nelson 2008) (Table 3.1). 


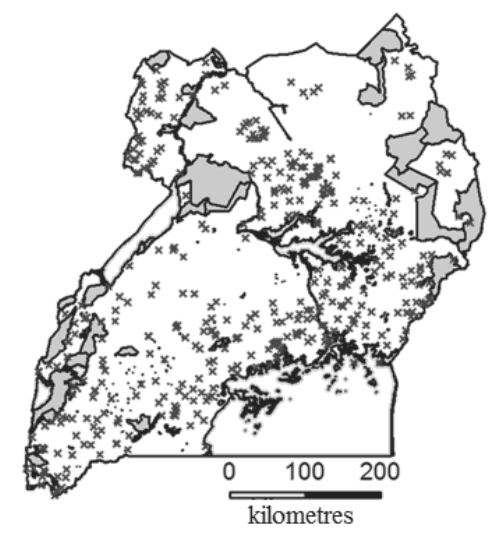

Fig 3.1 Locations of the households included in analysis $(n=1,927)$. Each $x$ represents one household. Grey areas are protected areas (e.g. nature reserves)

Table 3.1 Characteristics of the environmental explanatory variables used in the regression analysis

\begin{tabular}{|c|c|c|c|}
\hline Code & Spatially continuous environmental variable & $\begin{array}{l}\text { Original } \\
\text { resolution }\end{array}$ & Source \\
\hline DEM & elevation (m.a.s.l.) & $3 \operatorname{arcs}$ & Jarvis et al. (2008) \\
\hline TEMP & $\begin{array}{l}\text { Average annual mean temperature in period } 1950-2000 \\
\left({ }^{\circ} \mathrm{C}\right)\end{array}$ & $30 \operatorname{arcs}$ & Hijmans et al. (2005) \\
\hline TEMP_R & $\begin{array}{l}\text { Average annual temperature range in period } 1950-2000 \\
\text { (max temperature of warmest month minus min } \\
\text { temperature of coldest month, }{ }^{\circ} \mathrm{C} \text { ) }\end{array}$ & $30 \operatorname{arcs}$ & Hijmans et al. (2005) \\
\hline RAIN & Average annual rainfall in period $1950-2000\left(\mathrm{~mm} \mathrm{year}^{-1}\right)$ & $30 \operatorname{arcs}$ & Hijmans et al. (2005) \\
\hline RAIN_V & $\begin{array}{l}\text { Average annual rainfall variation (coefficient of variation } \\
\text { calculated on monthly rainfall) }\end{array}$ & $30 \operatorname{arcs}$ & Hijmans et al. (2005) \\
\hline LGP & $\begin{array}{l}\text { average length of growing period in period } 1965-1995 \\
\text { (days year-1) }\end{array}$ & 5 arc min & HarvestChoice (2015) \\
\hline $\mathrm{BD}$ & $\begin{array}{l}\text { bulk density for three soil layers: } 0-5 \mathrm{~cm}, 5-15 \mathrm{~cm}, 15-30 \\
\mathrm{~cm} \text { soil depth }\left(\mathrm{Mg} \mathrm{m}^{-3}\right)\end{array}$ & $250 \mathrm{~m}$ & Hengl et al. (2017) \\
\hline SOC & $\begin{array}{l}\text { soil organic carbon content for three soil layers: } 0-5 \mathrm{~cm}, 5- \\
15 \mathrm{~cm}, 15-30 \mathrm{~cm} \text { soil depth }\left(\mathrm{kg} \mathrm{C} \mathrm{Mg}^{-1}\right)\end{array}$ & $250 \mathrm{~m}$ & Hengl et al. (2017) \\
\hline SCARB & $\begin{array}{l}\text { soil carbon stock, calculated from soil data, mean across } \\
\text { three layers }\left(\mathrm{kg} \mathrm{C} \mathrm{Mg}^{-1}\right)\end{array}$ & - & - \\
\hline POP & human population density (number $\mathrm{km}^{-2}$ ) & $\sim 100 \mathrm{~m}$ & WorldPop (2015) \\
\hline TRAV & $\begin{array}{l}\text { market access in travel time to nearest town of }+50,000 \\
\text { inhabitants based on road network from } 2000 \text { (minutes) }\end{array}$ & $30 \operatorname{arcs}$ & Nelson (2008) \\
\hline
\end{tabular}

\subsubsection{Data preparation and calculation of food availability indicator}

The household locations were randomly displaced by the publishing authority with an offset $\leq 10$ kilometres and several households were clustered resulting in multiple households 
relocated to the same location (UBOS 2011). For the kriging unique locations are required. We therefore randomly offset the household locations using a random distance of $\leq 50$ meters and a random direction. We sampled the values of the raster layers of the environmental explanatory variables at these new household points. To minimise the unknown errors in the sampled environmental explanatory variables introduced from offsetting the household locations, we resampled all raster layers to a resolution of 5 arc minutes, which approximates a grid cell size of $10 \times 10 \mathrm{~km}$ near the equator. Given the small spatial offset compared with the country-wide scale of analysis, we consider the remaining uncertainty to be negligible. Raster layers and household points were geo-referenced to WGS84 coordinates.

We calculated soil carbon stock SCARB $\left(\mathrm{kg} \mathrm{C} \mathrm{Mg}^{-1}\right)$ from the soil organic matter content SOC $\left(\mathrm{kg} \mathrm{C} \mathrm{Mg}^{-1}\right)$ and the bulk density $B D\left(\mathrm{Mg} \mathrm{m}^{-3}\right)$ for three soil layers of increasing thickness $\Delta z$ (m, $0-0.05 \mathrm{~m}, 0.05-0.15 \mathrm{~m}, 0.15-0.3 \mathrm{~m})$ :

$$
S C A R B=B D \times \Delta z \times S O C \times 10^{4}
$$

We calculated the mean carbon stock value across the three layers for each grid cell.

To approximate food security we chose the food availability framework by (Frelat et al. 2016) because it enables to identify the importance of different livelihood activities, crops and livestock types for a household's welfare (in term s of food availability). Although the food availability indicator (FA) does not consider all dimensions of food security (FAO 2009), it closely correlates with well-established indicators such as the Household Dietary Diversity Index (HDDS) and the Household Food Insecurity Access Scale (HFIAS) (Hammond et al. 2016). For each household we calculated the FA estimating the potential amount of daily food energy that is available to a male adult equivalent household member $\left(\mathrm{kcal} \mathrm{cap}^{-1} \mathrm{day}^{-1}\right)$ :

$$
F A=\frac{\left(E_{\text {consumed }}+E_{\text {income }}\right)}{365 \times n_{\text {hh-mae }}}
$$

Where $E_{\text {consumed }}$ is the annual direct consumption of potential food energy from on-farm products $\left(\mathrm{kcal}^{\mathrm{year}}{ }^{-1}\right), E_{\text {income }}$ is the annual indirect consumption of potential food energy from on- and off-farm income ( $\mathrm{kcal}^{\mathrm{year}}{ }^{-1}$ ), and $n_{\text {hh-mae }}$ is the household size in male adult equivalents. $E_{\text {consumed }}$ was derived from information on produced amounts of crops and livestock products and the respective kilo-caloric energy values of the crops and livestock products. These were obtained from the standard product list of the US Department of Agriculture (source: ndb.nal.usda.gov/ndb/search/list, accessed 02/07/16) and from the FAO (source: http://www.fao.org/docrep/x5557e/x5557e00.htm\#Contents, accessed 02/07/16). Consumption was then quantified from the difference between produced and sold quantities of 
the respective product. Total household income was calculated from reported quantities of crop and livestock product sales and from off-farm income. Assuming that all this income could have been used to purchase the staple food (maize) we translated the monetary value to kilocalories equivalent $\left(E_{\text {income }}\right)$. Household size was standardised to male adult equivalents $\left(n_{h h-}\right.$ mae) using sex and age dependent daily energy requirements relative to that of an adult male (2,500 kcal cap ${ }^{-1}$ day $^{-1}$, Holden et al. 2001).

Livelihood activities were derived from the different food energy sources contributing to FA and were expressed as relative contribution to FA (values between 0 and 1, Tables 3.2 and Supplementary materials Table S3.4). We distinguished between livelihood activities on-farm (crop contribution to FA, livestock contribution to FA) and off-farm (off-farm income contribution to FA). We subdivided the on-farm livelihood activities into key crops (highland banana, sorghum, maize, cassava, beans, and coffee) and livestock types (cattle and poultry) that contributed to the crop and the livestock part of the FA, respectively. Details on the methodology are provided in (Wichern et al. 2017). The data analysis was performed in $\mathrm{R}$ (version 3.2.3, R Development Core Team 2008).

\subsubsection{General approach}

Our procedure aims at generating a spatial prediction of food availability indicators using household and environmental data, taking full account of variability at the household level. It combines a predictive model of household level variation for an indicator of interest with a spatial model of unexplained variation. Although machine learning algorithms have been used successfully for building predictive models of poverty indicators, we opted for a regression approach to allow for formal tests of model improvement when using different types of explanatory variables. By comparing predictive models using both environmental and household resource explanatory variables to models only using environmental explanatory variables we established to what extent model fit from environmental data was sufficient to perform prediction on a spatial grid. Modelling of the unexplained variation (i.e. the model residuals) was done by a classic spatial kriging approach (see below). Finally spatial predictions based on explained and unexplained variation were combined into a single map. A detailed description of the procedure (Fig 3.2) is provided in the following sections. An example of the procedure for highland banana contribution is illustrated in Fig 3.3 (Results). 


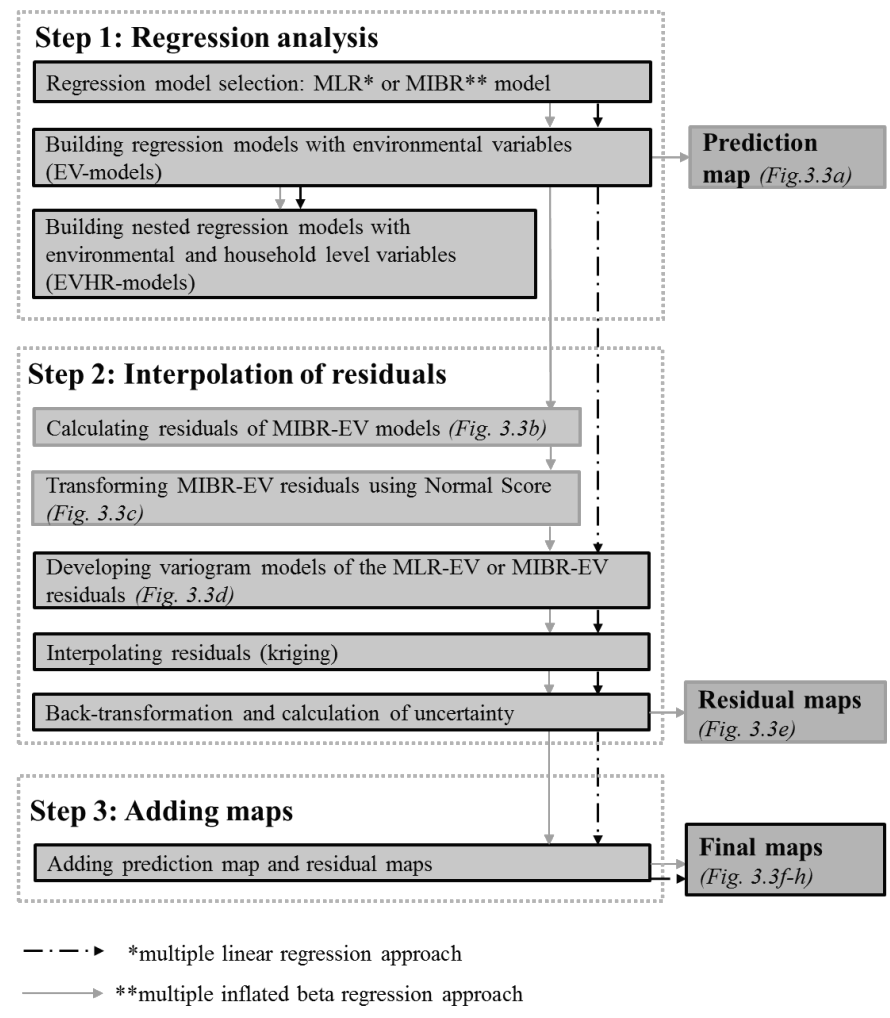

Fig 3.2 The stepwise procedure. See text for further explanation

\subsubsection{Step 1: Regression analysis}

\subsubsection{Regression model selection}

The indicators FA and the contributions of crops, livestock and livelihood activities to FA were the response variables in the regression models and the environmental variables were the explanatory variables (Table 3.2). If the indicator was transformable so that regression residuals were approximately normally distributed, a multiple linear regression (MLR) model was used. This was possible for FA after log-transformation. The contributing livelihood activities, variables representing proportions containing a large number of zeros and ones, were not transformable to a (near-)normal distribution and required an alternative regression model.

For this purpose we used a multiple zero-and-one inflated beta regression (MIBR) model that can handle distributions where the observation, $y$, is a proportion including many zeros and ones (Ferrari and Cribari-Neto 2004; Ospina and Ferrari 2010). The MIBR model uses a mixed 
continuous-discrete distribution that defines both the probabilities $\mathrm{P}_{0}(y=0), \mathrm{P}_{1}(y=1)$ and 1$\mathrm{P}_{0}-\mathrm{P}_{1}(0<y<1)$ and the probability distribution of the values of $\mathrm{y}$ between 0 and 1 , which is given by a beta distribution with shape parameters $\alpha$ and $\beta$. This complete probability distribution of $y$ is defined by four parameters, $\mu, \sigma, v$ and $\tau$, where $\mu, \sigma$ define the shape of the beta distribution as $\alpha=\mu\left(1-\sigma^{2}\right) / \sigma^{2}, \beta=(1-\mu)\left(1-\sigma^{2}\right) / \sigma^{2}$ while $v$ and $\tau$ describe the probabilities $\mathrm{P}_{0}=v /(1+v+\tau)$ and $\mathrm{P}_{1}=\tau /(1+v+\tau)$. The expectation of $y$ under this distribution is given by $\mathrm{E}(y)=(\tau+\mu) /(1+v+\tau)$ (Ospina and Ferrari 2012). For variables with no or few (i.e. $\leq 3$ ) observations of $y=1$, we considered the sample too small for making reasonable predictions of $y=1$. Therefore, we used a multiple zero-inflated beta regression model (MIBR-0), leaving out the distribution parameter $\tau$. This was the case for the contributing livelihood activities 'coffee' and 'livestock'.

MLR $m$ odels were estim ated using the ordinary least squared m ethod and the R package 'stats'. The MLR model fit was evaluated based on R-Squared $\left(R^{2}\right)$. MIBR were fitted by maximumlikelihood m ethods using the R package 'gam lss' (Stasinopoulos and Rigby 2007). Details are in (Rigby and Stasinopoulos 2010). The MIBR model fit was evaluated by the squared correlation of fitted and observed $y$ (henceforth 'pseudo $\mathrm{R}^{2}$ ').

Table 3.2 Food availability indicators as response variables and environmental and household resource explanatory variables of the analyses

\begin{tabular}{|c|c|c|}
\hline Response variables (food availability indicators) & $\begin{array}{l}\text { Spatially continuous } \\
\text { environmental } \\
\text { explanatory variables }\end{array}$ & $\begin{array}{l}\text { Household resource } \\
\text { explanatory variables }\end{array}$ \\
\hline Household food availability (FA) & Elevation & \multirow{2}{*}{ Total cultivated land area } \\
\hline Variables contributing to FA (livelihood activities): & Mean annual temperature & \\
\hline Crop contribution & Annual temperature range & \multirow[t]{10}{*}{ Herd size } \\
\hline Livestock contribution & Annual rainfall & \\
\hline off-farm income contribution & Annual rainfall variation & \\
\hline Variables contributing to the crop part of $F A$ : & Length of growing period & \\
\hline banana contribution & Soil carbon stock & \\
\hline sorghum contribution & Human population density & \\
\hline maize contribution & Market access & \\
\hline cassava contribution & & \\
\hline beans contribution & & \\
\hline coffee contribution & & \\
\hline Variables contributing to the livestock part of $F A$ : & & \\
\hline ibution & & \\
\hline poultry contribution & & \\
\hline
\end{tabular}




\subsubsection{Building regression models with environmental explanatory variables (EV-models)}

For each indicator, the environmental explanatory variables that were used to build the regression models were selected in two steps: First, we built simple MLR or MIBR models for each environmental explanatory variable and selected those variables that gave a significant slope in the simple models at $p<0.1$ for further analysis. Second, we analysed the significant environmental explanatory variables on collinearity using the variance inflation factor (VIF) approach (R package 'usdm ') and included all envionmental explanatory variables with VIF $<10$ in the multiple regression analysis (Dormann et al. 2013).

The MLR model was fit using the step-function with forward direction. The MIBR model was fit using the stepGAICAll.A function (R package 'gam lss'), which uses a forward selection and backward elimination approach for each model parameter and selects the best final model based on the akaike information criterion (AIC). To reduce the chance for model overfitting, we simplified the selected best MIBR model (full model) by removing the last coefficient of any of the m odel param eters $(\mu, \sigma, v$ and $\tau$ ) if that one had a significance of $p<0.1$. We rejected the simplified model if the difference between the AIC of the full model and the AIC of the simplified model $>10$ (Burnham and Anderson 2002). The regression models were used to generate prediction maps for each indicator for the entire country. For the MIBR models we

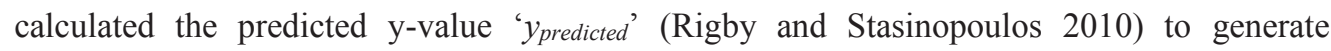
prediction maps.

\subsubsection{Building nested regression models with environmental and household resource explanatory variables (EVHR-models)}

To identify how much of the variation was explained by the environmental explanatory variables in comparison with the household level variables, we built nested regression models for each indicator: We used the regression model with environmental explanatory variables (EV-model, see Step 2) and added household resource variables (EVHR-model). The household resource variables had first been tested on collinearity using the VIF approach and no collinearity was observed.

\subsubsection{Step 2: Spatial interpolation of regression residuals}

The regression models did not capture all the spatial structure in the data. To account for remaining spatial structure, we interpolated the residuals of the MLR and MIBR models. 


\subsubsection{Calculation and transformation of MIBR residuals}

While the residuals of the MLR model could be directly derived from the MLR model results, the MIBR residuals were calculated at the household locations:

$$
\text { Residuals }_{M I B R, i}=y_{\text {observed }, i}-y_{\text {predicted }, i}
$$

Where $y_{\text {observed }}$ is the value of the indicator $y$ observed for household $i$ and $y_{\text {predicted }}$ is the value of the indicator $y$ predicted from the MIBR model at the location of household $i$. To account for the spatial interpolation requirement of normally distributed residuals, the MIBR regression residuals were transformed using a quantile-based normal score transformation for 100 intervals (Deutsch and Journel 1998). With this approach the tails of the distribution $(<0.5 \%$ and $>99.5 \%)$ were truncated. This trade-off was acceptable, since we were interested in the larger patterns rather than in predictions for particular regions.

\subsubsection{Variogram models of the MLR and MIBR residuals}

To identify spatial autocorrelation in the residuals, we fitted variogram models using the method of moments with weights based on the number of point pairs over the squared distance. We selected the best variogram models based on the weighted sum of squared errors and verified the variogram models by cross-validation (krige.cv-function of the $\mathrm{R}$ package 'gstat'). Variogram models are described by three main characteristics, the nugget, the sill and the range. The nugget is the value at which the variogram (almost) crosses the y-axis and indicates the level of local variation at distances smaller than the sampling interval. The sill is the y-value at which the curve of the variogram model flattens out indicating the level of spatial autocorrelation. The range indicates the distance at which the curve of the variogram model flattens out and thus the distance of spatial autocorrelation (https://gisgeography.com/semivariogram-nugget-range-sill/, accessed 16/07/18). We calculated the nugget-sill ratio to identify how much of the variation in the residuals was explained by spatial autocorrelation in relation to local variation.

\subsubsection{Interpolation of the MLR and MIBR residuals}

For the MLR model, we used the residual variogram model in combination with regression kriging (R package 'gstat') to com pute a final $\mathrm{m}$ ap of the logtransformed FA. This approach takes into account spatial correlations of the regression residuals in the regression model fit. For the MIBR models we used the variogram models of the normal score transformed residuals to interpolate the transformed residuals by kriging and produce residual maps. We used the 
MIBR model as a deterministic surface, which was a model choice implying that all uncertainty was attributed to lack of fit of the MIBR models in the further steps of the procedure.

Subsequently, all uncertainty was captured in the prediction intervals of the interpolated MIBR residuals (see below).

\subsubsection{Backtransformation and calculation of uncertainty}

For the MLR model, the kriging results of the log-transformed FA were back-transformed to obtain the expected median $E(Y)$ of FA (Johnson et al. 1994):

$$
E(Y)=e^{\mu}
$$

Where $\mu$ is the mean of the log-transformed FA. The uncertainty of the expected mean of FA was identified calculating the back-transformed upper and lower $95 \%$ bounds of the prediction interval $(P I 95, u, M L R ; P I 95, l, M L R)$ :

$$
P I_{95, u / l, M L R}=e^{(\mu \pm 1.96 \times \sigma)}
$$

Where $\sigma$ is the standard deviation of the log-transformed FA. For the MIBR model, the upper and lower $95 \%$ bounds (PI95, u, MIBR; PI95, l, MIBR) of the interpolated transformed prediction intervals were calculated as follows:

$$
P I_{95, u / l, M I B R}=\mu \pm 1.96 \times \sigma
$$

Where $\mu$ is the m ean and $\sigma$ the standard deviation of the interpolated transform ed residuals. The interpolated means and upper and lower 95\% bounds of the prediction interval of the transformed MIBR residuals were back-transformed using the inverse of the normal score transformation. In this way, the mean of the transformed residuals represents the median of the back-transformed residuals.

\subsubsection{Step 3: Adding the prediction and residual maps}

For the MLR models Steps 2 and 3 were performed in one step using regression kriging ( $\mathrm{R}$ package 'gstat'). For the MIBR m odels the prediction $\mathrm{m}$ ap and the backtransformed median residual map were added to generate a final map of the variable. Uncertainty in the interpolated MIBR residuals was mapped by adding the MIBR prediction map and the back-transformed MIBR residual maps of the upper and lower bounds of the prediction interval, respectively. 
Where $y>1$ or $y<0$ as a result of the addition, values were corrected to remain within the bounds of proportional data $(0,1)$.

\subsection{Results}

\subsubsection{The stepwise procedure}

The stepwise procedure is illustrated with the example of highland banana contribution to the crop part of FA (Fig 3.3). Highland banana contribution was first predicted based on the MIBR model (Step 1, Fig 3.3a). The regression residuals (Fig 3.3b) were transformed to a normal distribution using normal score (Fig 3.3c) and spatial autocorrelation of the transformed residuals was quantified in the variogram model (Step 2, Fig 3.3d). The transformed residuals were interpolated using the variogram model and simple kriging and were then backtransformed to generate a map of the median residuals (Fig 3.3e). The prediction map was added to the back-transformed median of the interpolated residuals, lower $95 \%$ bound of the prediction interval (PI) and upper 95\% PI of the interpolated residuals (Step 3, Fig 3.3f-h). Results of the single steps for all indicators are discussed below.

\subsubsection{Regression models using environmental explanatory variables}

Spatial variation in FA was explained by the length of growing period, soil carbon stock, annual rainfall variation, population density and travel time to the market, but explanatory power was low $\left(\mathrm{R}^{2}=0.10\right.$, Table 3.3). Among the MIBR-EV models, the models predicting highland banana and sorghum contributions revealed the largest explanatory power $\left(\mathrm{R}^{2}=0.35\right.$ and 0.53 , respectively), while for all other indicators the model performance was poor $\left(\mathrm{R}^{2} \leq 0.12\right.$, Table 3.4, details Supplementary materials Tables S3.5-S3.7). Variation in highland banana contribution was explained by annual mean temperature, annual temperature range, annual rainfall, soil carbon stock and travel time to the market. Variation in sorghum contribution was explained by annual temperature range, annual rainfall variation, length of growing period and soil carbon stock. The results indicate that the available environmental explanatory variables explained little of the variation for most of the indicators (except for highland banana and sorghum). 
a)

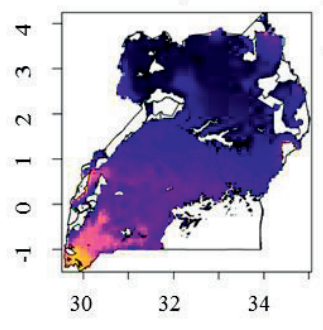

d)

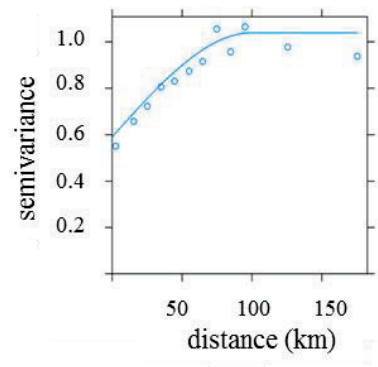

f)

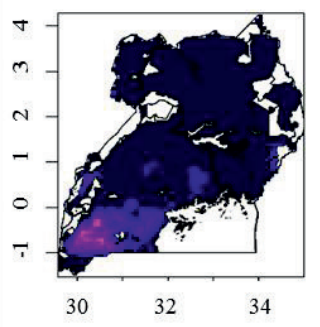

b) relative contribution
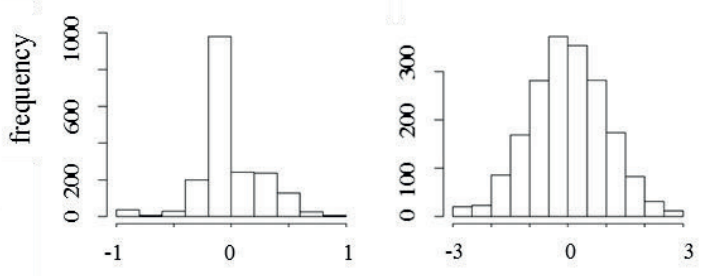

e)

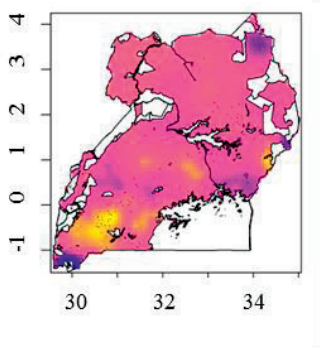

g)

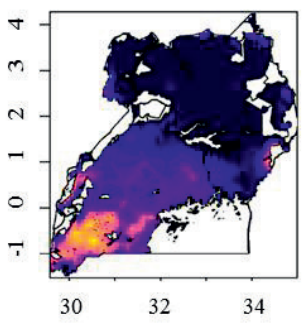

relative contribution

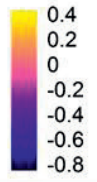

Fig 3.3 Mapping livelihood activities contributing to food availability (FA) following the procedure of Fig 3.2 on the example of highland banana contribution to the crop part of FA. a) Highland banana contribution predicted by a multiple inflated beta regression (MIBR) model. b) Histogram of the regression residuals from the MIBR model. c) Histogram of the regression residuals after Normal Score Transformation. d) Variogram model of the transformed regression residuals. e) Unexplained structure in the regression residuals interpolated by kriging, after back-transformation. f) Prediction map (a) added to the lower $95 \%$ bound of the prediction interval (PI) of the interpolated residuals. For $y<0$, values are set to 0 . g) Prediction map (a) added to the interpolated residuals (e). For $y>1$, values are set to 1 ; for $y$ $<0$, values are set to 0 . h) Prediction map (a) added to the upper 95\% PI of the interpolated residuals. For $y>1$, values are set to 1 . White areas are protected areas (e.g. national parks) and water bodies 
Table 3.3 Multiple linear regression (MLR) model of food availability (FA) with environmental explanatory variables (MLR-EV) and with environmental and household resource explanatory variables (MLR-EVHR) as explanatory variables

\begin{tabular}{|c|c|c|c|c|c|}
\hline Explanatory variable & Coefficient & Beta $^{a}$ & Std. Error & t-Statistic & Sign. (p-value) \\
\hline $\begin{array}{l}\text { MLR-EV model } \\
\text { (intercept) }\end{array}$ & 7.34 & - & $5.99 \times 10^{-1}$ & 12.25 & $* * *$ \\
\hline LGP & $6.75 \times 10^{-3}$ & 0.12 & $1.57 \times 10^{-3}$ & 4.29 & $* * *$ \\
\hline SCARB & $1.94 \times 10^{-5}$ & 0.16 & $3.49 \times 10^{-6}$ & 5.55 & $* * *$ \\
\hline RAIN_V & $-2.13 \times 10^{-2}$ & -0.11 & $5.37 \times 10^{-3}$ & -3.96 & $* * *$ \\
\hline POP & $-2.23 \times 10^{-2}$ & -0.10 & $5.35 \times 10^{-3}$ & -4.16 & $* * *$ \\
\hline TRAV & $-1.13 \times 10^{-3}$ & -0.08 & $3.60 \times 10^{-4}$ & -3.15 & $* *$ \\
\hline R-squared & 0.10 & & & & \\
\hline Adjusted R-squared & 0.10 & & & & \\
\hline F-statistic & 42.27 & & & & \\
\hline MLR-EVHR model & & & & & \\
\hline (intercept) & 7.62 & - & $5.93 \times 10^{-1}$ & 12.84 & $* * *$ \\
\hline LGP & $6.20 \times 10^{-3}$ & 0.11 & $1.55 \times 10^{-3}$ & 3.99 & $* * *$ \\
\hline TLU & $4.31 \times 10^{-2}$ & 0.16 & $5.94 \times 10^{-3}$ & 7.24 & $* * *$ \\
\hline SCARB & $2.03 \times 10^{-5}$ & 0.16 & $3.45 \times 10^{-6}$ & 5.90 & $* * *$ \\
\hline RAIN_V & $-2.21 \times 10^{-2}$ & -0.11 & $5.29 \times 10^{-3}$ & -4.18 & $* * *$ \\
\hline POP & $-2.00 \times 10^{-2}$ & -0.09 & $5.28 \times 10^{-3}$ & -3.78 & $* * *$ \\
\hline TRAV & $-1.32 \times 10^{-3}$ & -0.10 & $3.56 \times 10^{-4}$ & 3.72 & $* * *$ \\
\hline HH_SIZE & $-2.28 \times 10^{-2}$ & -0.06 & $8.25 \times 10^{-3}$ & -2.76 & $* *$ \\
\hline LANDD & $8.78 \times 10^{-3}$ & 0.04 & $4.44 \times 10^{-3}$ & 1.98 & $*$ \\
\hline R-squared & 0.13 & & & & \\
\hline Adjusted R-squared & 0.13 & & & & \\
\hline F-statistic & 35.31 & & & & \\
\hline
\end{tabular}

Explanatory variables: LGP $=$ average length of growing period, RAIN_V $=$ average annual rainfall variation, RAIN $=$ average annual rainfall, $\mathrm{SCARB}=$ mean soil carbon stock, TRAV $=$ market access in travel time to nearest town of $+50,000$ inhabitants, LAND $=$ total cultivated land area, TLU $=$ herd size, HH_SIZE $=$ number of household members. Significance: $* * *<0.001, * *<0.01, *<0.05, .<0.1$. ${ }^{\mathrm{a} B e t a}=$ coefficient $\mathrm{X}$ standard deviation of variable $\mathrm{x} /$ standard deviation of FA 


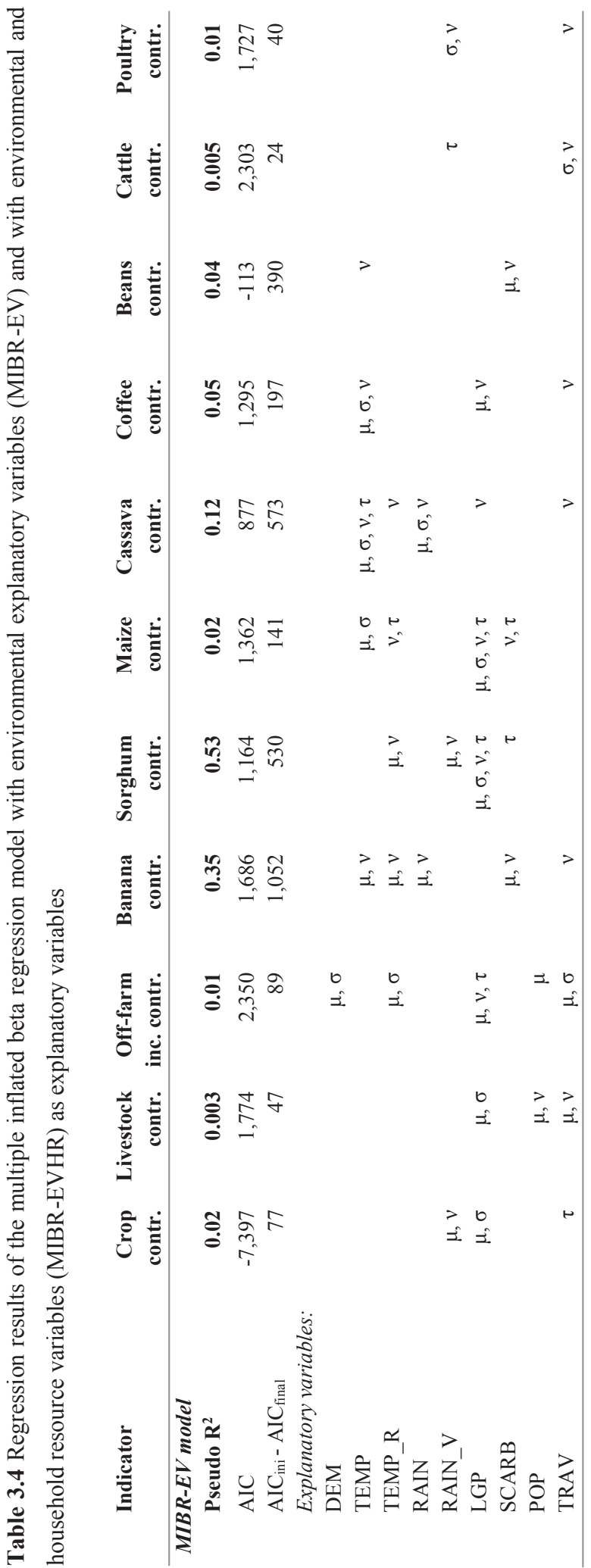




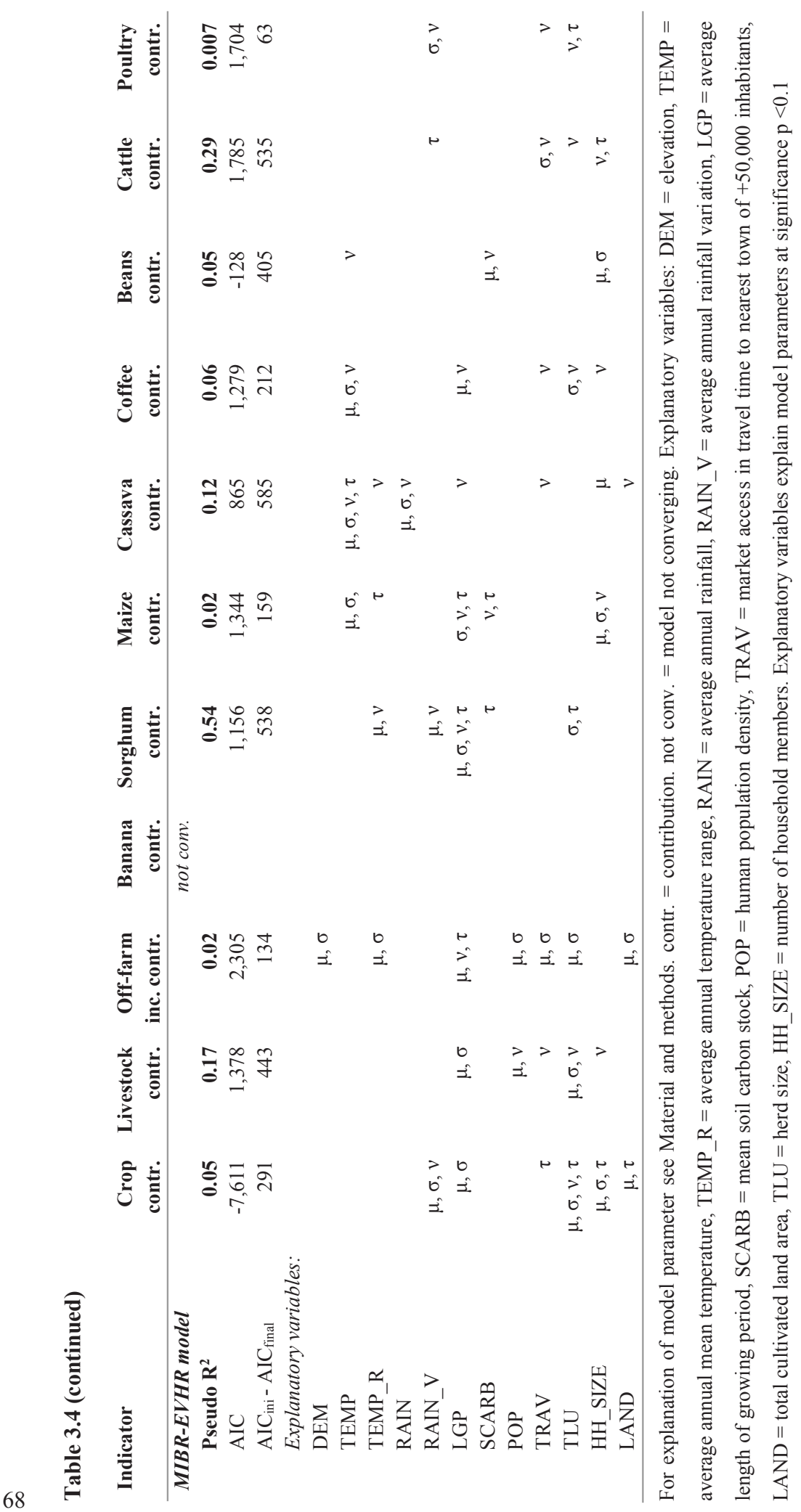




\subsubsection{Nested regression models}

Adding the household resource explanatory variables herd size, total cultivated land area and household size to the MLR-EV model (MLR-EVHR) increased the explanatory power for FA somewhat $\left(\mathrm{R}^{2}=0.13\right.$, against 0.1 for the MLR-EV model, Table 3.3), but most of the variation remained unexplained. Our results differed from findings of Frelat et al (2016), who explained a larger part of FA with herd size, total cultivated land area and household size $\left(\mathrm{R}^{2}=0.33\right.$ using artificial neural networks). Adding household resource explanatory variables to the MIBR-EV models (MIBR-EVHR) raised explanatory power only for the livestock and cattle contribution models due to the strong link between livestock and cattle contribution and herd size (pseudo $\mathrm{R}^{2}=0.17$ and 0.29 , against 0.003 and 0.005 for the MLR-EV model; Table 3.4, details Supplementary materials Tables S3.8-S3.10). Explanatory power did not increase for the models of crop contribution.

\subsubsection{Spatial structure in the regression residuals}

We chose a nugget-sill ratio $\leq 0.7$ to indicate spatial autocorrelation. Seven indicators (highland banana, sorghum, maize, cassava and coffee contributions to the crop part of FA, and cattle and poultry contributions to the livestock part of FA) revealed spatial autocorrelation in the regression residuals with varying strength. While spatial autocorrelation accounted for $52 \%$ of the variance in the regression residuals of coffee contribution, this was only $30 \%$ for cassava (nugget-sill ratios 0.48 and 0.7 , respectively). The other variables (FA, livestock and off-farm income contributions to FA and beans contribution to the crop part of FA) had little or no spatial autocorrelation in their regression residuals. For crop contribution to FA the variogram model did not converge, but the observed (experimental) variogram indicates little spatial autocorrelation (Table 3.5, Supplementary materials Fig S3.11). Particularly for FA and offfarm income contribution the curves of the variogram models were flat (small sill) and nuggets were large. The range of spatial autocorrelation of the regression residuals of the seven indicators with nugget-sill ratio $\leq 0.7$ varied from $40 \mathrm{~km}$ for the residuals of coffee contribution to $175 \mathrm{~km}$ for the residuals of sorghum contribution. 


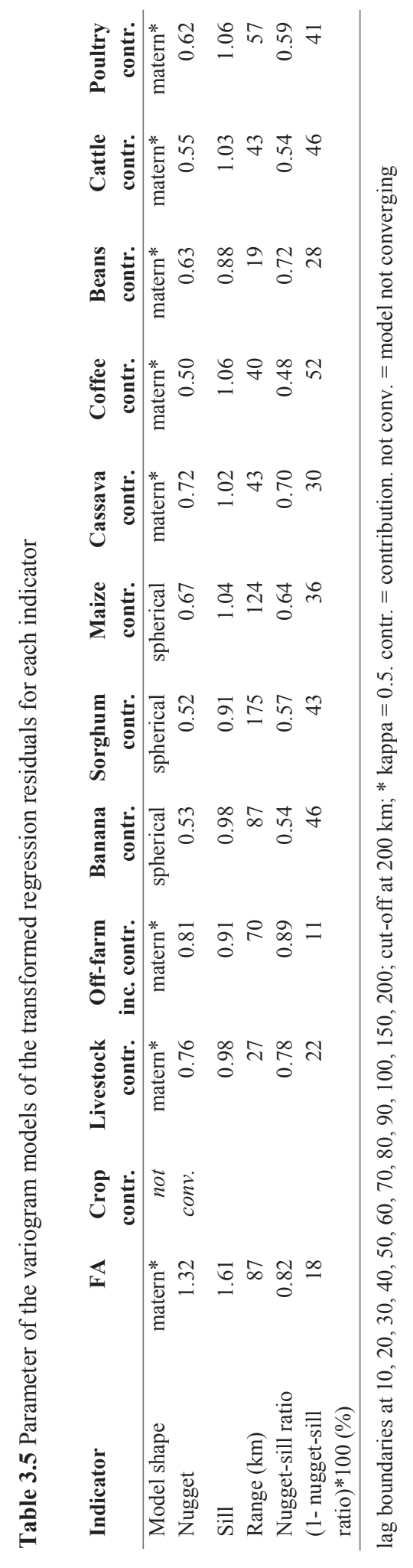




\subsubsection{Mapping FA and contributing livelihood activities}

Application of the stepwise procedure to FA identified a larger FA in the southwest of Uganda (median values $\geq 15,000 \mathrm{kcal} \mathrm{cap}^{-1} \mathrm{day}^{-1}$ ) and the smallest FA in the north and northeast (median values $<5,000 \mathrm{kcal} \mathrm{cap}^{-1} \mathrm{day}^{-1}$ ) (Fig 3.4a middle). However, the large local variation of the regression residuals indicated much spatial uncertainty about FA (Fig 3.4a left and right). The maps of the contributions of livestock, off-farm income and beans indicated uniform patterns across the country with few hotspots for livestock and off-farm income contribution (Fig 3.4b, c, Fig 3.5a middle). Also here the uncertainty in the patterns was large (Fig 3.4b, c, Fig 3.5a left and right) due to an enormous local variation in the regression residuals (nugget-sill ratios $\geq 0.72$ ) and poor explanatory power of the MIBR-EV models (pseudo $\mathrm{R}^{2} \leq 0.04$ ). These results indicate that spatial variation was huge at a range shorter than supported by the resolution of the environmental explanatory variables $(<10 \mathrm{~km})$.

In contrast, the highland banana and sorghum contributions revealed distinct large-scale spatial patterns. Highland banana contribution was largest in Uganda's Southwest, around Lake Victoria, in the highland regions and in central Uganda (Fig 3.3g). Uncertainty in these patterns was large in the central areas and in the mountain ranges (Fig 3.3f, h) as a result of large local variation in the residuals (Fig 3.3d, e) and potentially also due to low observation density at some locations. Sorghum contribution was largest in the Northeast of Uganda (Fig 3.5b). While uncertainty in the residuals of sorghum contribution was low for most of the country, the upper $95 \%$ bound of the prediction interval of the residuals indicated that sorghum contribution might be under-predicted in the Northeast, parts of the central area and of the west and southwest of the country. The MIBR-EV models of highland banana and sorghum contributions were the only models that had a pseudo $\mathrm{R}^{2}>0.3$, resulting in smaller residuals than for the other variables. Cassava, maize and coffee contributions indicated weak large-scale patterns (Fig 3.5c-e), and uncertainty in these patterns was huge, attributed to the large local variation of regression residuals indicated in the variogram models (nugget-sill ratios $\geq 0.64$, exception coffee: 0.48 ) and occasionally low observation density. Similarly, poultry and cattle contributions indicated weak spatial patterns (very localised for cattle; relatively uniform for poultry; Fig 3.4d-e) with large uncertainties despite smaller nugget-sill ratios. 
a) Food availability (FA)
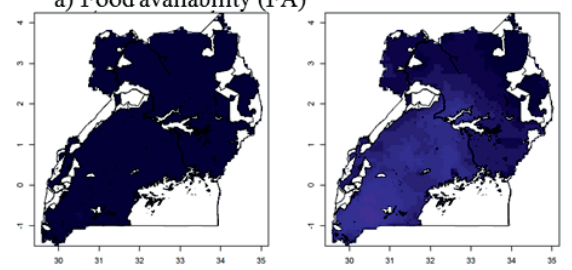

b) Livestock contribution
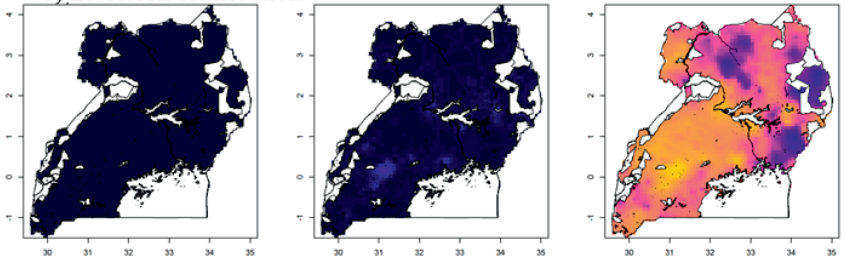

c) Off-farm income contribution
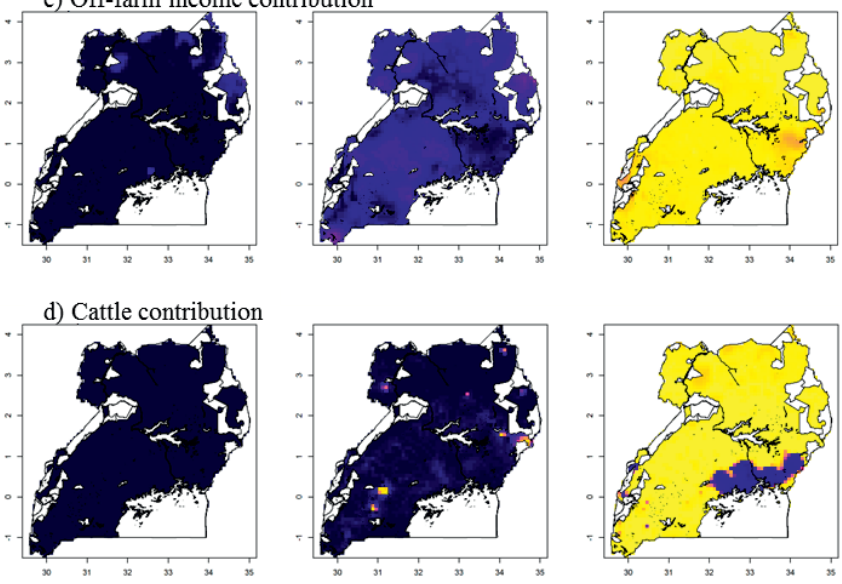

e) Poultry contribution
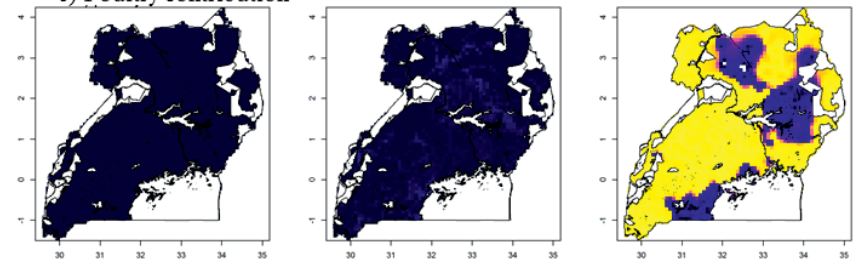

kcal cap ${ }^{-1} \mathrm{~d}^{-1}$

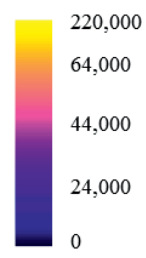

relative contribution

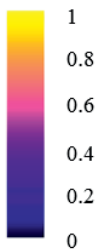

relative contribution

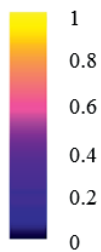

relative contribution

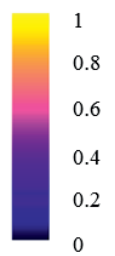

relative contribution

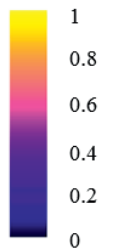

Fig 3.4 Predictions and uncertainty maps of the food availability indicators FA, off-farm income, livestock, cattle and poultry contributions. a) Predicted food availability (FA, in kcal cap ${ }^{-1}$ day $^{-1}$ ) across Uganda. Left: Lower 95\% bound of prediction interval (PI); Middle: median FA; Right: upper 95\% PI. b-e) Livelihood activities contributing to FA across Uganda. Left: Lower 95\% PI (MIBR prediction map + lower 95\% PI of residuals; for $y<0$, values are set to 0); Middle: MIBR prediction map + median residuals; for $\mathrm{y}>1$, values are set to 1 ; for $\mathrm{y}<0$, values are set to 0 ); Right: Upper $95 \%$ PI (MIBR prediction map + upper 95\% PI of residuals; for $y>1$, values are set to 1 ). White areas are protected areas (e.g. national parks) and water bodies 
a) Beans contribution
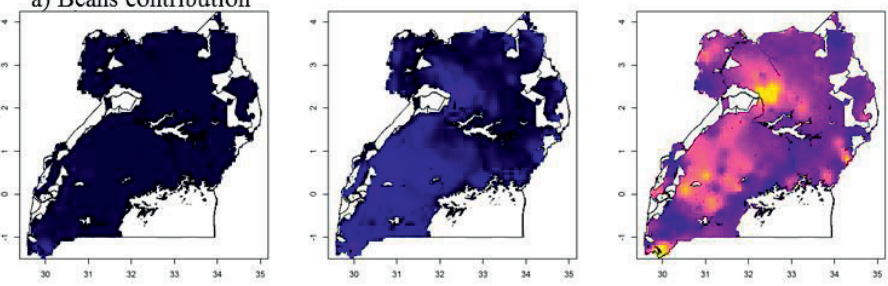

b) Sorghum contribution

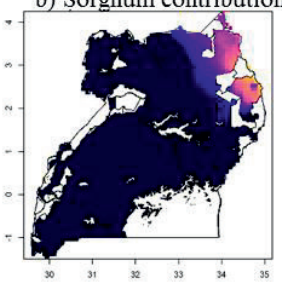

c) Cassava contribution

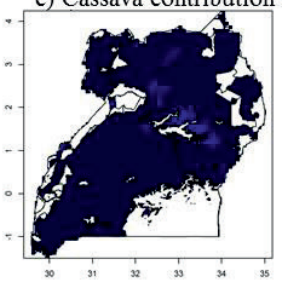

d) Maize contribution

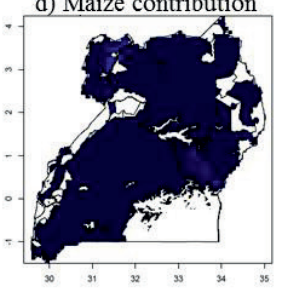

e) Coffee contribution

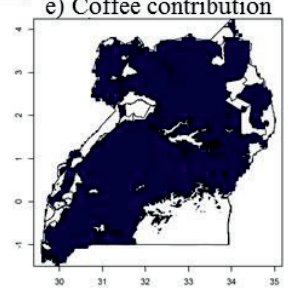

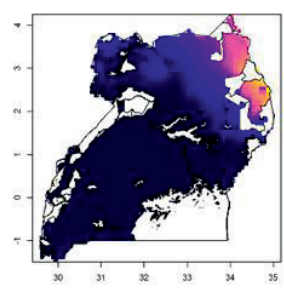
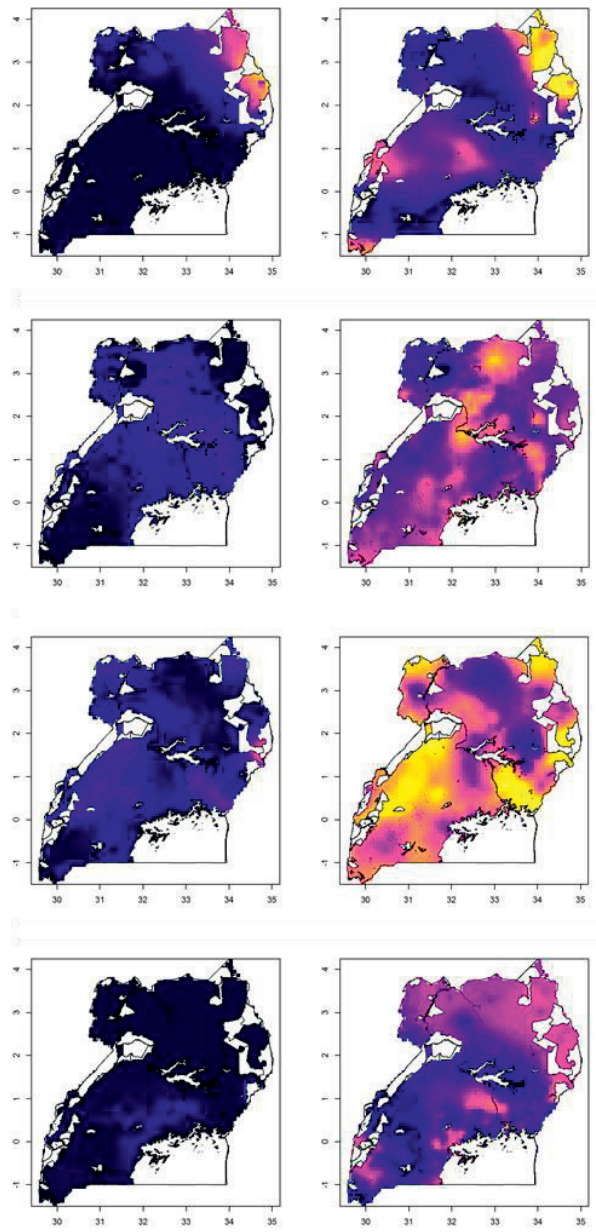

relative contribution

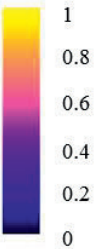

relative contribution

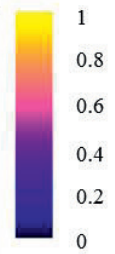

relative contribution

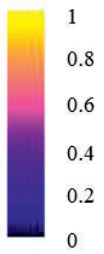

relative contribution

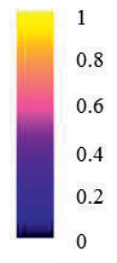

relative contribution

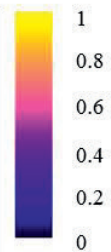

Fig 3.5 Predictions and uncertainty maps of the food availability indicators a) Beans, b) Sorghum, c) Cassava, d) Maize and e) Coffee contributions. Left: Lower 95\% PI (MIBR prediction map + lower 95\% PI of residuals; for $y<0$, values are set to 0 ); Middle: MIBR prediction map + median residuals; for $\mathrm{y}>1$, values are set to 1 ; for $\mathrm{y}<0$, values are set to 0 ); Right: Upper 95\% PI (MIBR prediction map + upper $95 \%$ PI of residuals; for $y>1$, values are set to 1). White areas are protected areas (e.g. national parks) and water bodies 


\subsection{Discussion}

\subsubsection{Local variation of household welfare indicators masked large-scale patterns}

Differences between households at short distance were huge across Uganda. This was indicated by the overall low explanatory power of the regression models using environmental explanatory variables (Tables 3.3, 3.4) and the large nuggets in the variogram models of the regression residuals (Table 3.5). Spatial predictability using environmental explanatory variables was strongest for highland banana and sorghum contributions, while for most indicators the large local variation masked large-scale patterns, which was apparent both in the regression models and in the residuals (questions 1 and 3). Household resource variables only added explanatory power for the indicators of livestock and cattle contributions (question 2).

The spatial patterns of FA matched observations from other studies that identified patterns of food security and poverty across Uganda (Wichern et al. 2017; UBOS 2013; Robinson et al. 2007; Nelson et al. 2012). However, our results revealed that local variation in FA is much larger than the variability across agroecologies. In a study across East and West Africa, (Ritzema et al. 2017) similarly found large local differences in FA within locations in contrast to more gradual differences among locations. Their analysis revealed that household resource characteristics such as farm size overrule agroecological characteristics in determining FA. Although land size was not the most important household variable in our analysis, household resource characteristics (particularly herd size and household size) explained part of the variation in FA. The remaining unexplained (most likely local) variation in the household data could be related to other household characteristics affecting food security, for example education level and age of the household head, social capital (e.g. being part of knowledge networks) or access to market information (Fisher and Lewin 2013; Mango et al. 2014; Saint Ville et al. 2016), which we did not consider in the analysis.

Key crops for which temperature and rainfall ranges seem to predominantly determine their distribution (highland banana, sorghum) could be linked to FA patterns, while other crops (maize, cassava, beans) were more ubiquitously present across diverse agroecological zones. Sorghum was predominant in the farming systems of the northeast of Uganda, while highland banana was important in the central, west and southwest of the country and largely absent in the north, resembling patterns observed in the past (McMaster 1962). Our observations match findings by (Wichern et al. 2017) on regional differences of major crops contributing to FA, while our results also show that for all crops the local variation was large. 
Similar conclusions can be drawn for livestock, cattle and poultry contributions. Despite the existence of the 'cattle corridor' in Uganda (Governm ent of Uganda 2004; Sempiira et al. 2017) and the known association of livestock keeping (particularly poultry production) to urban centres (Amadou et al. 2012), such patterns were not or poorly observed in the livestock, cattle and poultry contributions. The overruling local variation in livestock contribution may have several reasons. One could be that the indicator does not capture all the different contributions of livestock to a Ugandan rural household. In mixed crop-livestock systems in sub-Saharan Africa livestock serves as draught power, provides manure to the crops, is a regular source of food and income to the households and functions as insurance in times of shocks (Herrero et al. 2010). Income from services such as draught power and manure was not captured in the livestock contribution to FA. Another reason could be that livestock data collection using surveys in sub-Saharan Africa is complicated and data are often unreliable given that these surveys are based on long recall periods, while the farmers usually lack records and are reluctant to share information on wealth indicators like livestock (Fraval et al. 2018b). Lastly, although the number of cattle may be higher in the cattle corridor in Uganda, these consist mainly of large herds that have numerous cattle but few owners. As such, the region may have many cattle, but the majority of its households may not be strongly engaged in cattle keeping themselves or depend on it for their food security.

Similarly, local differences in off-farm income contribution to FA were stronger than largescale patterns and this may be explained by the diverse ways in which they take shape. Offfarm income sources can be of diverse types. Salary-based off-farm income may be more important in peri-urban areas or in areas with more economic activities (Reardon et al. 2006) and for people of higher education. By contrast, informal off-farm income and remittances may be spread diffusely across the country resulting in weak spatial patterns. For example, migration of household members for off-farm jobs is important for the income (as remittances) of Ugandan households (Matsumoto et al. 2006).

\subsubsection{Five reasons explain large local variation of regression residuals}

Besides above-mentioned non-spatial variation (I) at the household level (for example due to education, age or access to information), four additional reasons can explain the large local variation (nugget) that was identified in the regression residuals of the indicators: II) Missing explanatory variables: We used a limited set of environmental explanatory variables, while there may be more spatial characteristics that explain variation in FA and the contributing livelihood activities, for example market dynamics or regional governmental programmes promoting agricultural commodities. Additional environmental explanatory variables could contribute to improving the regression model performance and hence reducing the nugget and 
sill of the regression residual variogram. III) Spatial mismatch: The exact locations of the household data were unknown and the environmental explanatory variables that were sampled per household were based on randomly off-set, clustered household locations, which grouped several households on short distances that in reality might live kilometres apart. The clustering of households and the sampling of environmental explanatory variables at the offset locations introduced noise, which affected both the performance of the regression models using environmental explanatory variables and the nugget of the variogram models. Performing the analyses on the real locations of the households (and their fields) is expected to reduce the level of local variation and improve information on large-scale patterns in response to environmental explanatory variables. $I V)$ Measurement errors: Information on FA and livelihood activities was obtained from survey data, known to be subject to constraints and erroneous information (Fraval et al. 2018b; Desiere and Jolliffe 2018; Carletto et al. 2017). V) Model structural error: The model used functions to approximate trends, while these may not reflect real structures. For example, using linear models on non-linear effects might have introduced structural error. Sophisticated predictive techniques such as machine learning (Jean et al. 2016) are compatible with our procedure and could improve the regression predictions.

\subsubsection{Interventions must recognise the diversity in livelihood activities within areas}

Our procedure enables to systematically evaluate spatial patterns and the quality of maps of farming systems and household welfare and adds to existing approaches in which local variation often remains hidden (Robinson et al. 2007). The latter can be misleading if only larger patterns are shown without indicating how much of the total variation is explained by these patterns. Our results reveal that local differences in welfare and welfare-related activities can be large, which has implications for the planning of interventions. For example, our findings on the large local variation in livestock contribution to FA indicate that in Uganda's cattle corridor as well as in other regions there is a large local diversity in livestock ownership, which needs to be considered in targeting livestock interventions. Our cattle map shows that dependency of the households on cattle for income and food security in the cattle corridor is not substantially different to other areas in Uganda. Earlier work has shown that small livestock was more important in contributing to food availability for the poorer households, whereas cattle was important for the wealthier households (Frelat et al. 2016). When targeting the poor, interventions focusing on small livestock therefore remain relevant, also within cattle areas. Similarly, despite revealing distribution patterns that resemble those of other existing maps, the contributions of major crops contain large local variation. For exam ple, within Uganda's banana-coffee system areas, smallholders exist that have little or no banana or coffee in their system. Interventions that aim to target the poor must thus recognise that diversity in livelihood 
activities for income generation within any given area often overrides the variability of livelihood activities between distant regions in the country.

\subsection{Conclusions}

We applied a stepwise procedure to 1,927 farm households across Uganda to identify countrywide patterns of indicators on FA and contributing livelihood activities using spatially-explicit environmental and socio-economic data and household resource characteristics as explanatory variables. With few exceptions, predictions of the indicators were weak, highlighting the difficulty in capturing variability at larger scale. Also household explanatory variables identified little additional variation compared to environmental explanatory variables alone. Spatial predictability was strongest for indicators for which environmental gradients determined their distribution, such as highland banana contribution to the crop part of FA. In contrast, indicators of crops that were more ubiquitously present across agroecological zones showed large local variation, which often overruled large-scale patterns (e.g. cassava and maize contributions to the crop part of FA, and livestock and off-farm income contributions to FA).

Our procedure enables to systematically evaluate spatial patterns of farming systems and household welfare (e.g. food security) and to quantify local and large-scale variation. Thereby, it adds to existing approaches, which often only address large-scale patterns and, given the substantial local variation observed, may hide relevant heterogeneity. This has implications for planning of interventions. Decision makers targeting interventions in an area such as the Ugandan cattle corridor need to take into account that the importance of cattle for the livelihoods of the households in these areas varies enormously. While the cattle corridor may harbour many cattle, these belong to few herd owners. Instead, for targeting the poor, interventions on small livestock may be more relevant. Similarly, the importance of crops such as banana or coffee for household welfare in areas where banana-coffee systems are predominant varies largely. Interventions that aim to target the poor must thus recognise the large diversity in livelihood activities within any given area, which often overrides the variability between regions. Our approach generates spatially continuous and quantitative information on livelihood activities for food availability, including a quantification of uncertainty in these patterns, and provides a basis for further analyses to identify vulnerability of different regions and households to future changes by linking this approach to scenarios on climate change and price variability. 


\section{Acknowledgements}

This work was implemented as part of the CGIAR Research Program on Climate Change, Agriculture and Food Security (CCAFS), which is carried out with support from CGIAR Fund Donors and through bilateral funding agreements. For details please visit https://ccafs.cgiar.org/donors. The views expressed in this document cannot be taken to reflect the official opinions of these organisations. Additional support was received from the Plant Production Systems Group of Wageningen University and Research. We thank the anonymous referees for their critical and constructive criticism. 


\section{Supplementary materials of Chapter 3}

LSMS 2010-11

LSMS 2011-12

Food availability $\left(\mathrm{kcal} \mathrm{cap}^{-1} \mathrm{~d}^{-1}\right)$
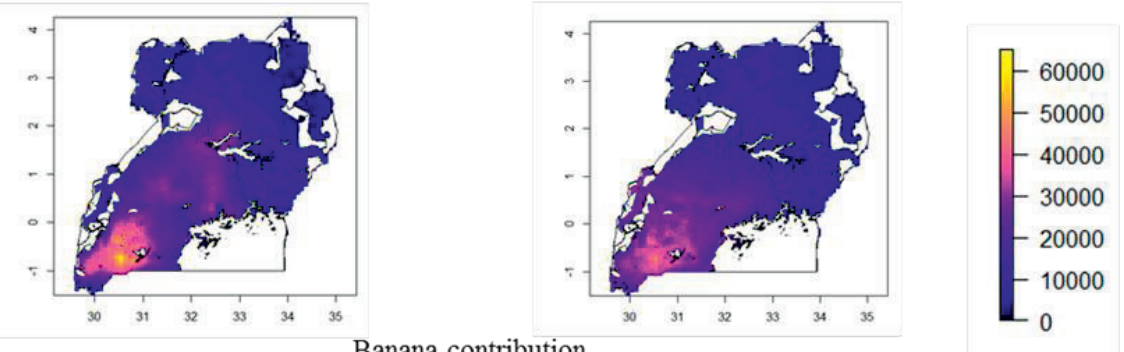

Banana contribution

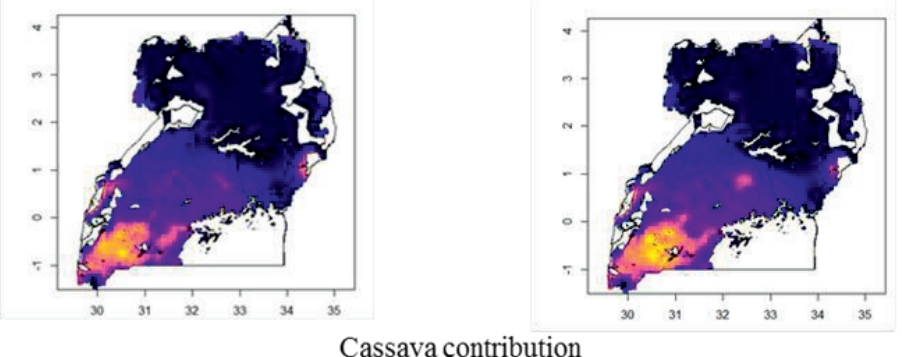

$$
\left[\begin{array}{l}
1.0 \\
-0.8 \\
-0.6 \\
-0.4 \\
-0.2 \\
0.0
\end{array}\right.
$$

Cassava contribution
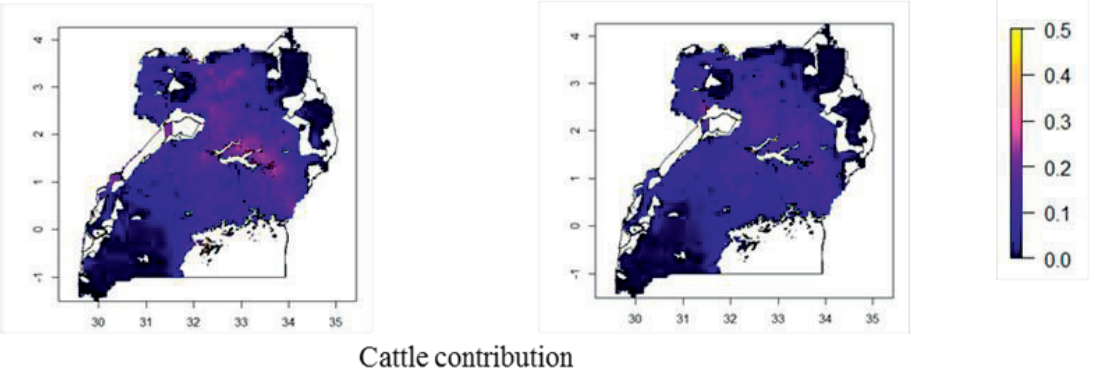

Cattle contribution
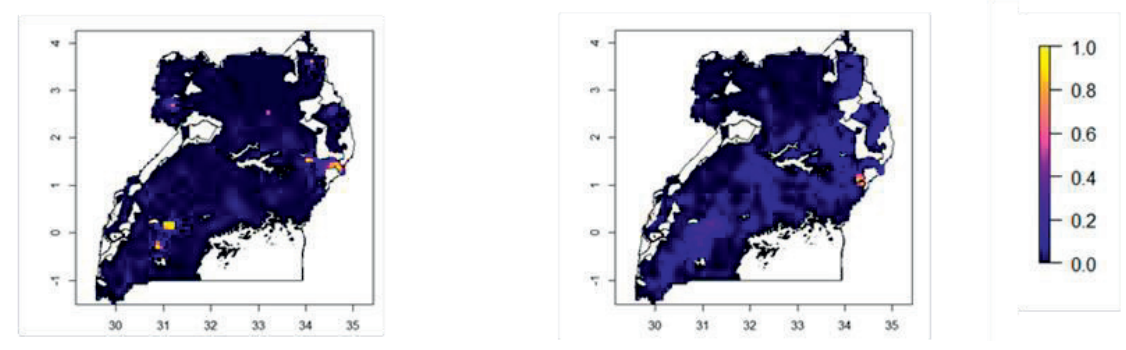

Fig S3.1 Maps of key indicators using LSMS data from 2010/11 and 2011/12. Overall patterns of the maps of key indicators for the LSMS data from 2010/11 and 2011/12 were similar with largest differences for food availability (FA) and the cattle contribution 
Banana difference (2010/11 - 2011/12)

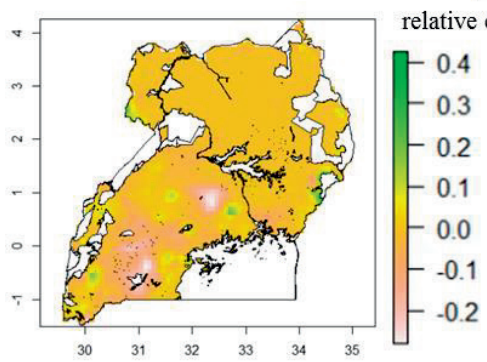

Cattle difference $(2010 / 11-2011 / 12)$

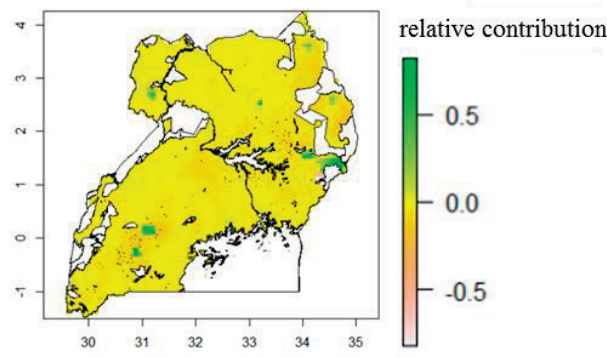

Cassava difference (2010/11 - 2011/12)

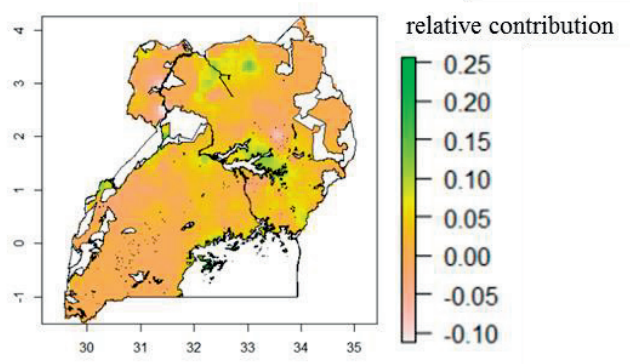

Food availability difference $(2010 / 11-2011 / 12)$

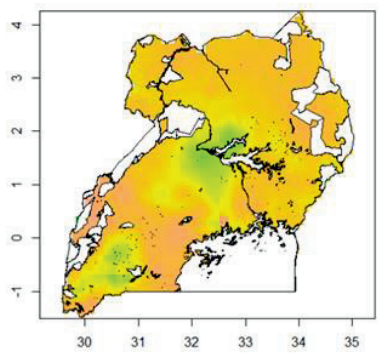

kcal cap ${ }^{-1} \mathrm{~d}^{-1}$

$-30000$

$-20000$

$-10000$

$-0$

$-10000$

$-20000$

Fig S3.2 Difference maps. Maps from 2011/12 are subtracted from maps from 2010/11. Positive results (green, yellow) indicate that FA or the contribution of the variable in 2010/11 was larger than in 2011/12. Negative results (white) indicate that FA or the contribution of the variable in 2010/11 was smaller than in 2011/12. FA, cassava contribution (some regions) and cattle contribution tended to be larger in 2010/11 than in 2011/12 
Banana RMSE (2010/11 - 2011/12)

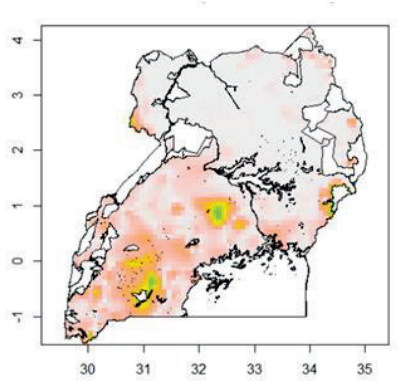

relative contribution

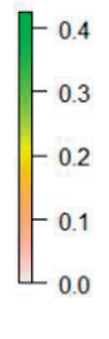

Cattle RMSE (2010/11 - 2011/12)

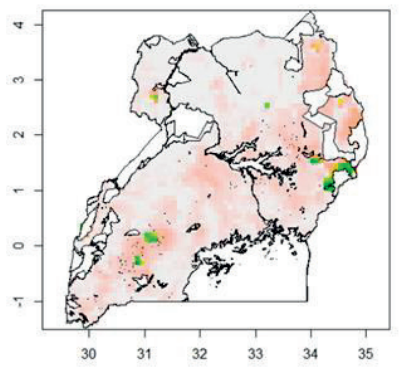

relative contribution

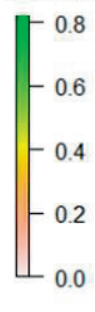

Cassava RMSE (2010/11 - 2011/12)

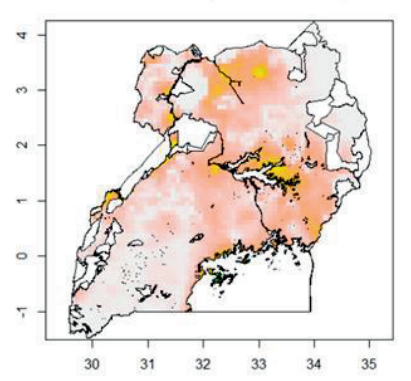

relative contribution

Food availability RMSE (2010/11 - 2011/12)

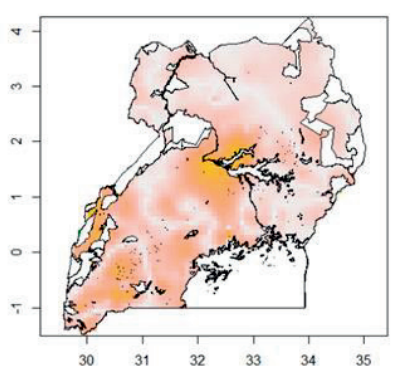

kcal cap ${ }^{-1} \mathrm{~d}^{-1}$
$-0.25$

$-0.20$

0.15

$-0.10$

$-0.05$

0.00

- 35000

- 30000

25000

- 20000

$-15000$

$-10000$

$-5000$

Fig S3.3 Root mean squared error (RMSE) maps comparing LSMS data from 2010/11 and 2011/12. Root $m$ ean squared error was calculated as: $\sqrt{ }\left((\text { LSMS201011-LSMS20112 })^{\wedge} 2\right)$. It gives an indication about the spread between the two years. Maps indicate that differences between the two years were locally large (green) for banana and cattle contributions and less for cassava contribution and FA 
Table S3.4 Food availability and livelihood activities as dependent variables for the regression analyses

\begin{tabular}{|c|c|c|c|c|c|c|c|}
\hline Dependent variable & $\min$ & $\mathbf{1}^{\text {st }} \mathbf{q u}$. & median & mean & $3^{\text {rd }} q u$. & $\max$ & $\begin{array}{r}\text { Regression } \\
\text { model* }\end{array}$ \\
\hline Food Availability (FA) & 5 & $3 \times 10^{3}$ & $6 \times 10^{3}$ & $20 \times 10^{3}$ & $14 \times 10^{3}$ & $93 \times 10^{5}$ & MLR \\
\hline \multicolumn{8}{|c|}{ Livelihood activities contributing to FA } \\
\hline Crops & 0 & 0.31 & 0.78 & 0.65 & 1.0 & 1.0 & MIBR \\
\hline Livestock & 0 & 0 & 0 & 0.09 & 0.08 & 1.0 & MIBR-0 \\
\hline Off-farm income & 0 & 0 & 0 & 0.26 & 0.51 & 1.0 & MIBR \\
\hline \multicolumn{8}{|c|}{ Crops contributing to the livelihood activity 'crops' } \\
\hline Banana & 0 & 0 & 0.03 & 0.26 & 0.54 & 1.0 & MIBR \\
\hline Sorghum & 0 & 0 & 0 & 0.05 & 0 & 1.0 & MIBR \\
\hline Cassava & 0 & 0 & 0.01 & 0.11 & 0.13 & 1.0 & MIBR \\
\hline Maize & 0 & 0 & 0.06 & 0.16 & 0.24 & 1.0 & MIBR \\
\hline Coffee & 0 & 0 & 0 & 0.05 & 0 & 1.0 & MIBR-0 \\
\hline Beans & 0 & 0 & 0.04 & 0.10 & 0.14 & 1.0 & MIBR \\
\hline \multicolumn{8}{|c|}{ Livestock types contributing to the livelihood activity 'livestock' } \\
\hline Cattle & 0 & 0 & 0 & 0.16 & 0 & 1.0 & MIBR \\
\hline Poultry & 0 & 0 & 0 & 0.09 & 0 & 1.0 & MIBR \\
\hline
\end{tabular}

*MLR: Multiple linear regression model; MIBR: Multiple zero-and-one inflated beta regression model; MIBR-0:

Multiple zero inflated beta regression model 
Table S3.5 Regression coefficients and significance of environmental explanatory variables in multiple inflated beta regression model (MIBR-EV) for the dependent variables 'crops contr.', 'livestock contr.' and 'off-farm income contr.' as livelihood activities contributing to food availability

\begin{tabular}{|c|c|c|c|c|}
\hline \multicolumn{2}{|c|}{ Parameter } & \multirow{2}{*}{ Crop contr. } & \multirow{2}{*}{$\begin{array}{r}\text { Livestock contr. } \\
-\end{array}$} & \multirow{2}{*}{$\begin{array}{r}\text { Off-farm income contr. } \\
-6.2 \times 10^{-4 * * * *}\end{array}$} \\
\hline$\mu_{1}$ & DEM & & & \\
\hline$\mu_{2}$ & TEMP & - & - & - \\
\hline$\mu_{3}$ & TEMP_R & - & - & $-7.7 \times 10^{-3 *}$ \\
\hline$\mu_{4}$ & PREC & - & - & - \\
\hline$\mu_{5}$ & PREC_S & $-1.9 \times 10^{-2 * *}$ & - & - \\
\hline$\mu_{6}$ & LGP & $6.6 \times 10^{-3 * * *}$ & $-5.6 \times 10^{-3 * *}$ & $-4.5 \times 10^{-3 *}$ \\
\hline$\mu_{7}$ & SCARB & - & - & - \\
\hline$\mu_{8}$ & POP & - & $2.6 \times 10^{-2 * *}$ & $4.3 \times 10^{-2 * *}$ \\
\hline$\mu_{9}$ & TRAV & - & $8.2 \times 10^{-4}$ & $1.2 \times 10^{-3 *}$ \\
\hline$\sigma_{1}$ & DEM & - & - & $-4.4 \times 10^{-4 * * * *}$ \\
\hline$\sigma_{2}$ & TEMP & - & - & - \\
\hline$\sigma_{3}$ & TEMP_R & - & - & $6.5 \times 10^{-3 * *}$ \\
\hline$\sigma_{4}$ & PREC & - & - & - \\
\hline$\sigma_{5}$ & PREC_S & & - & - \\
\hline$\sigma_{6}$ & LGP & $3.8 \times 10^{-3 * * *}$ & $4.5 \times 10^{-3 *}$ & - \\
\hline$\sigma_{7}$ & SCARB & - & - & - \\
\hline$\sigma_{8}$ & POP & - & - & - \\
\hline$\sigma_{9}$ & TRAV & - & - & $1.2 \times 10^{-3 * * *}$ \\
\hline$v_{1}$ & DEM & - & - & - \\
\hline$v_{2}$ & TEMP & - & - & - \\
\hline$v_{3}$ & TEMP_R & - & - & - \\
\hline$v_{4}$ & PREC & - & - & - \\
\hline$v_{5}$ & PREC_S & $1.1 \times 10^{-1 * * *}$ & - & - \\
\hline$v_{6}$ & LGP & - & - & $5.7 \times 10^{-3 * *}$ \\
\hline$v_{7}$ & SCARB & - & - & - \\
\hline$v_{8}$ & POP & - & $3.9 \times 10^{-2 * *}$ & - \\
\hline$v_{9}$ & TRAV & - & $3.1 \times 10^{-3 * * *}$ & - \\
\hline$\tau_{1}$ & DEM & - & n.a. & - \\
\hline$\tau_{2}$ & TEMP & - & n.a. & - \\
\hline$\tau_{3}$ & TEMP_R & - & n.a. & - \\
\hline$\tau_{4}$ & PREC & - & n.a. & - \\
\hline$\tau_{5}$ & PREC_S & - & n.a. & - \\
\hline$\tau_{6}$ & LGP & - & n.a. & $-3.3 \times 10^{-2 * *}$ \\
\hline$\tau_{7}$ & SCARB & - & n.a. & - \\
\hline$\tau_{8}$ & POP & - & n.a. & - \\
\hline$\tau_{9}$ & TRAV & $1.4 \times 10^{-3 *}$ & n.a. & - \\
\hline Pse & Ido $\mathrm{R}^{2}$ & 0.02 & 0.003 & 0.01 \\
\hline $\mathrm{AIC}$ & ini $-\mathrm{AIC}_{\text {final }}$ & 77 & 47 & 91 \\
\hline
\end{tabular}

Significance: $* * *<0.001, * *<0.01, *<0.05, .<0.1$. For explanation of model parameter see Material and methods. contr. $=$ contribution. n.a. $=$ not applicable. Environmental explanatory variables: DEM $=$ elevation, TEMP $=$ average annual mean temperature, TEMP_R $=$ average annual temperature range, PREC $=$ average annual precipitation, PREC_S $=$ average annual precipitation variation, $L G P=$ average length of growing period, SCARB $=$ soil carbon stock, $\mathrm{POP}=$ human population density, TRAV $=$ market access in travel time to nearest town of $+50,000$ inhabitants 
Table S3.6 Regression coefficients and significance of environmental explanatory variables multiple inflated beta regression model (MIBR-EV) for major crops contributing to the livelihood activity 'crop contribution'

\begin{tabular}{|c|c|c|c|c|c|c|c|}
\hline \multicolumn{2}{|c|}{ Parameter } & \multirow{2}{*}{$\begin{array}{r}\text { Banana } \\
\text { contr. } \\
-\end{array}$} & \multirow{2}{*}{$\begin{array}{r}\begin{array}{r}\text { Sorghum } \\
\text { contr. }\end{array} \\
-\end{array}$} & \multirow{2}{*}{$\begin{array}{r}\text { Maize contr. } \\
-\end{array}$} & \multirow{2}{*}{$\begin{array}{r}\text { Cassava } \\
\text { contr. } \\
-\end{array}$} & \multirow{2}{*}{$\begin{array}{r}\text { Coffee contr. } \\
-\end{array}$} & \multirow{2}{*}{$\begin{array}{r}\text { Beans contr. } \\
-\end{array}$} \\
\hline$\mu_{1}$ & DEM & & & & & & \\
\hline$\mu_{2}$ & TEMP & $-3.3 \times 10^{-2 * * *}$ & - & $1.0 \times 10^{-2 * * *}$ & $4.6 \times 10^{-2 * * *}$ & $2.0 \times 10^{-2 * * *}$ & - \\
\hline$\mu_{3}$ & TEMP_R & $-7.8 \times 10^{-3}$ & $-1.9 \times 10^{-2 * * *}$ & - & - & - & - \\
\hline$\mu_{4}$ & PREC & $-1.1 \times 10^{-3 * * *}$ & - & - & $2.0 \times 10^{-3 * * *}$ & - & - \\
\hline$\mu_{5}$ & PREC_S & - & $5.3 \times 10^{-2 * * *}$ & - & - & - & - \\
\hline$\mu_{6}$ & LGP & - & $-2.0 \times 10^{-2 * * *}$ & $-2.6 \times 10^{-3}$. & - & $9.9 \times 10^{-3 * *}$ & - \\
\hline$\mu_{7}$ & SCARB & $1.1 \times 10^{-3}$ & - & - & - & - & $8.8 \times 10^{-6 * * *}$ \\
\hline$\mu_{8}$ & POP & - & - & - & - & - & - \\
\hline$\mu 9$ & TRAV & - & - & - & - & - & - \\
\hline$\sigma_{1}$ & DEM & - & - & - & - & - & - \\
\hline$\sigma_{2}$ & TEMP & - & - & $-3.5 \times 10^{-3 *}$ & $2.6 \times 10^{-2 * * *}$ & $-1.4 \times 10^{-2 * *}$ & - \\
\hline$\sigma_{3}$ & TEMP_R & - & - & - & - & - & - \\
\hline$\sigma_{4}$ & PREC & - & - & - & $1.1 \times 10^{-3 * * *}$ & - & - \\
\hline$\sigma_{5}$ & PREC_S & - & - & - & - & - & - \\
\hline$\sigma_{6}$ & LGP & - & $-5.7 \times 10^{-3 * *}$ & $-4.6 \times 10^{-3 * * *}$ & - & - & - \\
\hline$\sigma_{7}$ & SCARB & - & - & - & - & - & - \\
\hline$\sigma_{8}$ & POP & - & - & - & - & - & - \\
\hline$\sigma_{9}$ & TRAV & - & - & - & - & - & - \\
\hline$v_{1}$ & DEM & - & - & - & - & - & - \\
\hline$v_{2}$ & TEMP & $2.5 \times 10^{-2 * * * *}$ & - & - & $-3.6 \times 10^{-2 * * *}$ & $2.4 \times 10^{-2 * * * *}$ & $5.0 \times 10^{-2 * * * *}$ \\
\hline$v_{3}$ & TEMP_R & $8.9 \times 10^{-2 * * *}$ & $2.5 \times 10^{-2 * * *}$ & $9.0 \times 10^{-3}$. & $1.8 \times 10^{-2 * *}$ & - & - \\
\hline$v_{4}$ & PREC & $-7.7 \times 10^{-4 *}$ & - & - & $-1.5 \times 10^{-3 * * *}$ & - & - \\
\hline$v_{5}$ & PREC_S & - & $-1.0 \times 10^{-3 * * *}$ & - & - & - & - \\
\hline$v_{6}$ & LGP & - & $3.0 \times 10^{-2 * * *}$ & $-1.5 \times 10^{-2 * * *}$ & $-1.2 \times 10^{-2 * * *}$ & $-1.8 \times 10^{-2 * * *}$ & - \\
\hline$v_{7}$ & SCARB & $-4.8 \times 10^{-5 * * *}$ & - & $3.7 \times 10^{-5 * * *}$ & - & - & $-4.4 \times 10^{-5 * * *}$ \\
\hline$v_{8}$ & POP & - & - & - & - & - & - \\
\hline$v_{9}$ & TRAV & $3.3 \times 10^{-3 * * *}$ & - & - & $3.5 \times 10^{-3 * * *}$ & $3.2 \times 10^{-3 * * *}$ & - \\
\hline$\tau_{1}$ & DEM & - & - & - & - & n.a. & - \\
\hline$\tau_{2}$ & TEMP & - & - & - & $5.1 \times 10^{-2 *}$ & n.a. & - \\
\hline$\tau_{3}$ & TEMP_R & - & - & $8.7 \times 10^{-2 * * *}$ & - & n.a. & - \\
\hline$\tau_{4}$ & PREC & - & - & - & - & n.a. & - \\
\hline$\tau_{5}$ & PREC_S & - & - & - & - & n.a. & - \\
\hline$\tau_{6}$ & LGP & - & $-5.1 \times 10^{-2 * * *}$ & $-3.5 \times 10^{-2 * *}$ & - & n.a. & - \\
\hline$\tau_{7}$ & SCARB & - & $-1.0 \times 10^{-4 *}$ & $7.5 \times 10^{-5 *}$ & - & n.a. & - \\
\hline$\tau_{8}$ & POP & - & - & - & - & n.a. & - \\
\hline$\tau_{9}$ & TRAV & - & - & - & - & n.a. & - \\
\hline & ddo $R^{2}$ & 0.35 & 0.53 & 0.02 & 0.12 & 0.05 & 0.04 \\
\hline & ini $-\mathrm{AIC}_{\text {final }}$ & 1052 & 530 & 141 & 573 & 197 & 390 \\
\hline
\end{tabular}

Significance: $* * *<0.001, * *<0.01, *<0.05, .<0.1$. For explanation of model parameter see Material and methods. contr. $=$ contribution. n.a. $=$ not applicable. Environmental explanatory variables: DEM $=$ elevation, TEMP $=$ average annual mean temperature, TEMP_R = average annual temperature range, PREC = average annual precipitation, PREC_S = average annual precipitation variation, LGP = average length of growing period, SCARB $=$ soil carbon stock, $\mathrm{POP}=$ human population density, TRAV $=$ market access in travel time to nearest town of $+50,000$ inhabitants. 
Table S3.7 Regression coefficients and significance of environmental explanatory variables multiple inflated beta regression model (MIBR-EV) for m ajor livestock groups 'cattlecontr.' and 'poultry contr.' contributing to the livelihood activity 'livestock contribution'

\begin{tabular}{|c|c|c|c|}
\hline \multicolumn{2}{|c|}{ Parameter } & \multirow{2}{*}{$\begin{array}{r}\text { Cattle contr. } \\
-\end{array}$} & \multirow{2}{*}{ Poultry contr. } \\
\hline$\mu_{1}$ & DEM & & \\
\hline$\mu_{2}$ & TEMP & - & - \\
\hline$\mu_{3}$ & TEMP_R & - & - \\
\hline$\mu_{4}$ & PREC & - & - \\
\hline$\mu_{5}$ & PREC_S & - & - \\
\hline$\mu_{6}$ & LGP & - & - \\
\hline$\mu_{7}$ & SCARB & - & - \\
\hline$\mu_{8}$ & POP & - & - \\
\hline$\mu_{9}$ & TRAV & - & - \\
\hline$\sigma_{1}$ & DEM & - & - \\
\hline$\sigma_{2}$ & TEMP & - & - \\
\hline$\sigma_{3}$ & TEMP_R & - & - \\
\hline$\sigma_{4}$ & PREC & - & - \\
\hline$\sigma_{5}$ & PREC_S & - & $2.2 \times 10^{-2}$. \\
\hline$\sigma_{6}$ & LGP & - & - \\
\hline$\sigma_{7}$ & SCARB & - & - \\
\hline$\sigma_{8}$ & POP & - & - \\
\hline$\sigma_{9}$ & TRAV & $-2.3 \times 10^{-3 * *}$ & - \\
\hline$v_{1}$ & DEM & - & - \\
\hline$v_{2}$ & TEMP & - & - \\
\hline$v_{3}$ & TEMP_R & - & - \\
\hline$v_{4}$ & PREC & - & - \\
\hline$v_{5}$ & PREC_S & - & $-4.2 \times 10^{-2 * * * *}$ \\
\hline$v_{6}$ & LGP & - & - \\
\hline$v_{7}$ & SCARB & - & - \\
\hline$v_{8}$ & POP & - & - \\
\hline$v_{9}$ & TRAV & $1.7 \times 10^{-3 * *}$ & $5.3 \times 10^{-3 * * *}$ \\
\hline$\tau_{1}$ & DEM & - & - \\
\hline$\tau_{2}$ & TEMP & - & - \\
\hline$\tau_{3}$ & TEMP_R & - & - \\
\hline$\tau_{4}$ & PREC & - & - \\
\hline$\tau_{5}$ & PREC_S & $-3.1 \times 10^{-2 * *}$ & - \\
\hline$\tau_{6}$ & LGP & - & - \\
\hline$\tau_{7}$ & SCARB & - & - \\
\hline$\tau_{8}$ & POP & - & - \\
\hline$\tau_{9}$ & TRAV & - & - \\
\hline Pse & Ido $R^{2}$ & 0.005 & 0.01 \\
\hline $\mathrm{AIC}$ & ini $-\mathrm{AIC}_{\text {final }}$ & 24 & 40 \\
\hline
\end{tabular}

Significance: $* * *<0.001, * *<0.01, *<0.05, .<0.1$. For explanation of model parameter see Material and methods. contr. $=$ contribution. Environmental explanatory variables: DEM = elevation, TEMP $=$ average annual mean temperature, TEMP_R $=$ average annual temperature range, PREC $=$ average annual precipitation, PREC_S $=$ average annual precipitation variation, $\mathrm{LGP}=$ average length of growing period, $\mathrm{SCARB}=$ soil carbon stock, POP $=$ human population density, TRAV $=$ market access in travel time to nearest town of $+50,000$ inhabitants. 
Table S3.8 Regression coefficients and significance of environmental and household level explanatory variables in multiple inflated beta regression model (MIBR-EVHR) for the dependent variables 'crop contr.', 'livestock contr.' and 'off-farm income contr.' as livelihood activities contributing to food availability

\begin{tabular}{|c|c|c|c|c|}
\hline \multicolumn{2}{|c|}{ Parameter } & \multirow{2}{*}{$\begin{array}{r}\text { Crop contr. } \\
-\end{array}$} & \multirow{2}{*}{$\begin{array}{r}\text { Livestock contr. } \\
-\end{array}$} & \multirow{2}{*}{$\begin{array}{r}\text { Off-farm income contr. } \\
-\mathrm{x} 10^{-4 * * *}\end{array}$} \\
\hline$\mu_{1}$ & DEM & & & \\
\hline$\mu_{2}$ & TEMP & - & - & - \\
\hline$\mu_{3}$ & TEMP_R & - & - & - \\
\hline$\mu_{4}$ & PREC & - & - & - \\
\hline$\mu_{5}$ & PREC_S & $-2.3 \times 10^{-2 * * *}$ & - & - \\
\hline$\mu_{6}$ & LGP & $5.7 \times 10^{-3 * *}$ & $-7.2 \times 10^{-3 * * *}$ & $-2.7 \times 10^{-3}$ \\
\hline$\mu_{7}$ & SCARB & - & - & - \\
\hline$\mu_{8}$ & РOP & - & $2.8 \times 10^{-2} * *$ & $4.4 \times 10^{-2 * * * *}$ \\
\hline$\mu_{9}$ & TRAV & - & - & $1.2 \times 10^{-3 *}$ \\
\hline$\mu_{10}$ & TLU & $-4.3 \times 10^{-2 * * * *}$ & 3.6x $10^{-2 * * *}$ & $-4.4 \times 10^{-2 * * *}$ \\
\hline$\mu_{11}$ & HH_SIZE & $-4.2 \times 10^{-2 * * * *}$ & - & $3.4 \times 10^{-2 * *}$ \\
\hline$\mu_{12}$ & LANDD & $7.8 \times 10^{-3 *}$ & - & $-8.4 \times 10^{-3 * * *}$ \\
\hline$\sigma_{1}$ & DEM & - & - & $-4.6 \times 10^{-4 * * * *}$ \\
\hline$\sigma_{2}$ & TEMP & - & - & - \\
\hline$\sigma_{3}$ & TEMP_R & - & - & $6.7 \times 10^{-3 * *}$ \\
\hline$\sigma_{4}$ & PREC & - & - & - \\
\hline$\sigma_{5}$ & PREC_S & - & - & - \\
\hline$\sigma_{6}$ & LGP & $3.7 \times 10^{-3 * * *}$ & $7.4 \times 10^{-3 * * * *}$ & - \\
\hline$\sigma_{7}$ & SCARB & - & - & - \\
\hline$\sigma_{8}$ & POP & - & - & - \\
\hline$\sigma_{9}$ & TRAV & - & - & $1.2 \times 10^{-3 * * * *}$ \\
\hline$\sigma_{10}$ & TLU & $-3.9 \times 10^{-2 * * *}$ & $-1.6 \times 10^{-2 *}$ & \\
\hline$\sigma_{11}$ & HH_SIZE & $-1.7 \times 10^{-2 *}$ & - & \\
\hline$\sigma_{12}$ & LANDD & - & - & $-3.1 \times 10^{-2 * * * *}$ \\
\hline$v_{1}$ & DEM & - & - & - \\
\hline$v_{2}$ & TEMP & - & - & - \\
\hline$v_{3}$ & TEMP_R & - & - & - \\
\hline$v_{4}$ & PREC $^{-}$ & - & - & - \\
\hline$v_{5}$ & PREC S & $1.2 \times 10^{-1 * * *}$ & - & - \\
\hline$v_{6}$ & LGP & - & - & $6.1 \times 10^{-3 * *}$ \\
\hline$v_{7}$ & SCARB & - & - & - \\
\hline$v_{8}$ & POP & - & $1.9 \times 10^{-2}$ & - \\
\hline$v_{9}$ & TRAV & - & $3.5 \times 10^{-3 * * * *}$ & - \\
\hline$v_{10}$ & TLU & $4.0 \times 10^{-2}$ & $-4.4 \times 10^{-1} * * *$ & - \\
\hline$v_{11}$ & HH SIZE & - & $-4.6 \times 10^{-2 * *}$ & $-5.4 \times 10^{-2 * * *}$ \\
\hline$v_{12}$ & LANDD & - & - & - \\
\hline
\end{tabular}




\section{Table S3.8 (continued)}

\section{Parameter}

$\tau_{1} \quad \mathrm{DEM}$

$\tau_{2} \quad$ TEMP

$\tau_{3}$ TEMP R

$\tau_{4} \quad \mathrm{PREC}$

$\tau_{5} \quad$ PREC S

$\tau_{6} \quad$ LGP

$\tau_{7} \quad \mathrm{SCARB}$

$\tau_{8} \quad$ POP

$\tau_{9}$ TRAV

$\tau_{10} \quad$ TLU

$\tau_{11}$ HH SIZE

$\tau_{12} \quad$ LAND

Pseudo $\mathrm{R}^{2}$

$\mathrm{AIC}_{\text {ini }}-\mathrm{AIC}_{\text {final }}$
Crop contr.

Livestock contr.

Off-farm income contr.

Significance: $* * *<0.001, * *<0.01, *<0.05, .<0.1$. For explanation of model parameter see Material and methods. contr. = contribution. n.a. = not applicable. Environmental explanatory variables: DEM = elevation, TEMP = average annual mean temperature, $\mathrm{TEMP}_{-} \mathrm{R}=$ average annual temperature range, $\mathrm{PREC}=$ average annual precipitation, PREC_S = average annual precipitation variation, LGP = average length of growing period, SCARB $=$ soil carbon stock, $\mathrm{POP}=$ human population density, TRAV $=$ market access in travel time to nearest town of $+50,000$ inhabitants, TLU $=$ herd size, HH_SIZE $=$ number of household members, LAND $=$ total cultivated land area. 
Table S3.9 Regression coefficients and significance of environmental and household level explanatory variables multiple inflated beta regression model (MIBR-EVHR) for major crops contributing to the livelihood activity 'crop contribution'

\begin{tabular}{|c|c|c|c|c|c|c|c|}
\hline \multicolumn{2}{|c|}{ Parameter } & \multirow{2}{*}{$\begin{array}{r}\text { Banana } \\
\text { contr. } \\
-\end{array}$} & \multirow{2}{*}{$\begin{array}{r}\text { Sorghum } \\
\text { contr. }\end{array}$} & \multirow{2}{*}{$\begin{array}{r}\text { Maize contr. } \\
-\end{array}$} & \multirow{2}{*}{$\begin{array}{r}\text { Cassava } \\
\text { contr. }\end{array}$} & \multirow{2}{*}{$\begin{array}{r}\text { Coffee contr. } \\
-\end{array}$} & \multirow{2}{*}{$\begin{array}{r}\text { Beans contr. } \\
-\end{array}$} \\
\hline$\mu_{1}$ & DEM & & & & & & \\
\hline$\mu_{2}$ & TEMP & - & - & $1.1 \times 10^{-2 * * *}$ & $4.6 \times 10^{-2 * * *}$ & $1.9 \times 10^{-2 * * *}$ & - \\
\hline$\mu_{3}$ & TEMP_R & - & $-1.9 \times 10^{-2 * * *}$ & - & - & - & - \\
\hline$\mu_{4}$ & PREC & - & - & - & $2.0 \times 10^{-3 * * *}$ & - & - \\
\hline$\mu_{5}$ & PREC_S & - & $5.1 \times 10^{-2 * * *}$ & - & - & - & - \\
\hline$\mu_{6}$ & LGP & - & $-2.0 \times 10^{-2 * * * *}$ & - & - & $9.5 \times 10^{-3 * *}$ & - \\
\hline$\mu_{7}$ & SCARB & - & - & - & - & - & $7.8 \times 10^{-6 * *}$ \\
\hline$\mu_{8}$ & POP & - & - & - & - & - & - \\
\hline$\mu_{9}$ & TRAV & - & - & - & - & - & - \\
\hline$\mu_{10}$ & TLU & - & - & - & - & - & - \\
\hline$\mu_{11}$ & HH_SIZE & - & - & $-3.2 \times 10^{-2 * * *}$ & $-2.6 \times 10^{-2 * *}$ & - & $-4.0 \times 10^{-2 * * * *}$ \\
\hline$\mu_{12}$ & LAND & - & - & - & - & - & - \\
\hline$\sigma_{1}$ & DEM & - & - & - & - & - & - \\
\hline$\sigma_{2}$ & TEMP & - & - & $-3.9 \times 10^{-3 *}$ & $2.6 \times 10^{-2 * * *}$ & $-1.5 \times 10^{-2 * *}$ & - \\
\hline$\sigma_{3}$ & TEMP_R & - & - & - & - & - & - \\
\hline$\sigma_{4}$ & PREC & - & - & - & $1.2 \times 10^{-3 * * *}$ & - & - \\
\hline$\sigma_{5}$ & PREC_S & - & - & - & - & - & - \\
\hline$\sigma_{6}$ & LGP & - & $-5.9 \times 10^{-3 * *}$ & $-4.5 \times 10^{-3 * * * *}$ & - & - & - \\
\hline$\sigma_{7}$ & SCARB & - & - & - & - & - & - \\
\hline$\sigma_{8}$ & POP & - & - & - & - & - & - \\
\hline$\sigma_{9}$ & TRAV & - & - & - & - & - & - \\
\hline$\sigma_{10}$ & TLU & - & $-2.9 \times 10^{-2}$ & - & - & $-5.0 \times 10^{-2 *}$ & - \\
\hline$\sigma_{11}$ & HH_SIZE & - & - & $-1.9 \times 10^{-2} *$ & - & - & $-2.2 \times 10^{-2 * *}$ \\
\hline$\sigma_{12}$ & LAND & - & - & - & - & - & - \\
\hline$v_{1}$ & DEM & - & - & - & - & - & - \\
\hline$v_{2}$ & TEMP & - & - & - & $-3.6 \times 10^{-2 * * *}$ & - & $5.0 \times 10^{-2 * * * *}$ \\
\hline$v_{3}$ & TEMP_R & - & $2.5 \times 10^{-2 * * * *}$ & - & $1.8 \times 10^{-2 * *}$ & $2.4 \times 10^{-2 * * * *}$ & - \\
\hline$v_{4}$ & PREC & - & - & - & $-1.5 \times 10^{-3 * * *}$ & - & - \\
\hline$v_{5}$ & PREC_S & - & $-9.9 \times 10^{-2 * * *}$ & - & - & - & - \\
\hline$v_{6}$ & LGP & - & $3.0 \times 10^{-2 * * * *}$ & $-1.6 \times 10^{-2 * * *}$ & $-1.2 \times 10^{-2 * * *}$ & $-1.8 \times 10^{-2 * * * *}$ & - \\
\hline$v_{7}$ & SCARB & - & - & $3.1 \times 10^{-5 * * *}$ & - & - & $-4.4 \times 10^{-5 * * *}$ \\
\hline$v_{8}$ & POP & - & - & - & - & - & - \\
\hline$v_{9}$ & TRAV & - & - & - & $3.5 \times 10^{-3 * * *}$ & $3.0 \times 10^{-3 * * *}$ & - \\
\hline$v_{10}$ & TLU & - & - & - & - & $6.3 \times 10^{-2 * *}$ & - \\
\hline$v_{11}$ & HH_SIZE & - & - & $-5.4 \times 10^{-2 * * * *}$ & - & $-4.2 \times 10^{-2 *}$ & - \\
\hline$v_{12}$ & LAND & - & - & - & - & - & - \\
\hline
\end{tabular}


Table S3.9 (continued)

\begin{tabular}{|c|c|c|c|c|c|c|c|}
\hline \multicolumn{2}{|c|}{ Parameter } & \multirow{2}{*}{$\begin{array}{r}\text { Banana } \\
\text { contr. } \\
-\end{array}$} & \multirow{2}{*}{$\begin{array}{r}\begin{array}{r}\text { Sorghum } \\
\text { contr. }\end{array} \\
-\end{array}$} & \multirow{2}{*}{$\begin{array}{r}\text { Maize contr. } \\
-\end{array}$} & \multirow{2}{*}{$\begin{array}{r}\text { Cassava } \\
\text { contr. }\end{array}$} & \multirow{2}{*}{$\begin{array}{r}\text { Coffee contr. } \\
\text { n.a. }\end{array}$} & \multirow{2}{*}{$\begin{array}{r}\text { Beans contr. } \\
-\end{array}$} \\
\hline$\tau_{1}$ & DEM & & & & & & \\
\hline$\tau_{2}$ & TEMP & - & - & - & $5.9 \times 10^{-2 * *}$ & n.a. & - \\
\hline$\tau_{3}$ & TEMP_R & - & - & $8.3 \times 10^{-2 * * *}$ & - & n.a. & - \\
\hline$\tau_{4}$ & PREC & - & - & - & - & n.a. & - \\
\hline$\tau_{5}$ & PREC_S & - & - & - & - & n.a. & - \\
\hline$\tau_{6}$ & LGP & - & $-5.1 \times 10^{-2 * * *}$ & $-3.6 \times 10^{-2 * *}$ & - & n.a. & - \\
\hline$\tau_{7}$ & SCARB & - & $-1.1 \times 10^{-4 *}$ & $7.2 \times 10^{-5 *}$ & - & n.a. & - \\
\hline$\tau_{8}$ & POP & - & - & - & - & n.a. & - \\
\hline$\tau_{9}$ & TRAV & - & - & - & - & n.a. & - \\
\hline$\tau_{10}$ & TLU & - & $-5.7 \times 10^{-1}$. & - & - & - & - \\
\hline$\tau_{11}$ & HH_SIZE & - & - & - & - & - & - \\
\hline$\tau_{12}$ & LAN̄D & - & - & - & $-7.3 \times 10^{-1}$. & - & - \\
\hline \multicolumn{2}{|c|}{ Pseudo $\mathrm{R}^{2}$} & Model not & 0.54 & 0.02 & 0.12 & 0.06 & 0.05 \\
\hline \multicolumn{2}{|c|}{$\mathrm{AIC}_{\text {ini }}-\mathrm{AIC}_{\text {final }}$} & converging & 538 & 159 & 585 & 212 & 405 \\
\hline
\end{tabular}

Significance: $* * *<0.001, * *<0.01, *<0.05, .<0.1$. For explanation of model parameter see Material and methods. contr. $=$ contribution. n.a. $=$ not applicable. Environmental explanatory variables: DEM $=$ elevation, TEMP $=$ average annual mean temperature, TEMP_R = average annual temperature range, PREC = average annual precipitation, PREC_S = average annual precipitation variation, LGP = average length of growing period, SCARB $=$ soil carbon stock, $\mathrm{POP}=$ human population density, TRAV $=$ market access in travel time to nearest town of $+50,000$ inhabitants, TLU $=$ herd size, HH_SIZE $=$ number of household members, LAND $=$ total cultivated land area. 
Table S3.10 Regression coefficients and significance of environmental and household level explanatory variables multiple inflated beta regression model (MIBR-EVHR) for major livestock groups contributing to the livelihood activity 'livestock contribution'

\begin{tabular}{|c|c|c|c|}
\hline \multicolumn{2}{|c|}{ Parameter } & \multirow{2}{*}{ Cattle contr. } & \multirow{2}{*}{ Poultry contr. } \\
\hline$\mu_{1}$ & DEM & & \\
\hline$\mu_{2}$ & TEMP & - & - \\
\hline$\mu_{3}$ & TEMP_R & - & - \\
\hline$\mu_{4}$ & PREC & - & - \\
\hline$\mu_{5}$ & PREC_S & - & - \\
\hline$\mu_{6}$ & LGP & - & - \\
\hline$\mu_{7}$ & SCARB & - & - \\
\hline$\mu_{8}$ & POP & - & - \\
\hline$\mu_{9}$ & TRAV & - & - \\
\hline$\mu_{10}$ & TLU & - & - \\
\hline$\mu_{11}$ & HH_SIZE & - & - \\
\hline$\mu_{12}$ & LAND & - & - \\
\hline$\sigma_{1}$ & DEM & - & - \\
\hline$\sigma_{2}$ & TEMP & - & - \\
\hline$\sigma_{3}$ & TEMP_R & - & - \\
\hline$\sigma_{4}$ & PREC & - & - \\
\hline$\sigma_{5}$ & PREC_S & - & $2.2 \times 10^{-2}$. \\
\hline$\sigma_{6}$ & LGP & - & - \\
\hline$\sigma_{7}$ & SCARB & - & - \\
\hline$\sigma_{8}$ & POP & - & - \\
\hline$\sigma_{9}$ & TRAV & $-2.3 \times 10^{-3 * *}$ & - \\
\hline$\sigma_{10}$ & TLU & - & - \\
\hline$\sigma_{11}$ & HH_SIZE & - & - \\
\hline$\sigma_{12}$ & LAND & - & - \\
\hline$v_{1}$ & DEM & - & - \\
\hline$v_{2}$ & TEMP & - & - \\
\hline$v_{3}$ & TEMP_R & - & - \\
\hline$v_{4}$ & PREC & - & - \\
\hline$v_{5}$ & PREC_S & - & $-4.4 \times 10^{-2 * * *}$ \\
\hline$v_{6}$ & LGP & - & - \\
\hline$v_{7}$ & SCARB & - & - \\
\hline$v_{8}$ & POP & - & - \\
\hline$v_{9}$ & TRAV & $3.1 \times 10^{-3 * * *}$ & $5.5 \times 10^{-3 * * *}$ \\
\hline$v_{10}$ & TLU & $-5.4 \times 10^{-1 * * *}$ & $-5.0 \times 10^{-2 * * *}$ \\
\hline$v_{11}$ & HH_SIZE & $-9.5 \times 10^{-2 * * *}$ & - \\
\hline$v_{12}$ & LAN̄D & - & - \\
\hline
\end{tabular}


Table S3.10 (continued)

\begin{tabular}{llrr}
\multicolumn{2}{l}{ Parameter } & Cattle contr. & Poultry contr. \\
\hline$\tau_{1}$ & DEM & - & - \\
$\tau_{2}$ & TEMP & - & - \\
$\tau_{3}$ & TEMP_R & - & - \\
$\tau_{4}$ & PREC & - & - \\
$\tau_{5}$ & PREC_S & $-5.6 \times 10^{-2 * * *}$ & - \\
$\tau_{6}$ & LGP & - & - \\
$\tau_{7}$ & SCARB & - & - \\
$\tau_{8}$ & POP & - & - \\
$\tau_{9}$ & TRAV & - & - \\
$\tau_{10}$ & TLU & - & $-1.8 \times 10^{-1 * * *}$ \\
$\tau_{11}$ & HH_SIZE & $-5.4 \times 10^{-2 *}$ & - \\
$\tau_{12}$ & LAND & - & - \\
\hline Pseudo R & 0.29 & 0.007 \\
AIC & ini - AIC final & 535 & 63 \\
\hline
\end{tabular}

Significance: $* * *<0.001, * *<0.01, *<0.05, .<0.1$. For explanation of model parameter see Material and methods. contr. $=$ contribution. Environmental explanatory variables: DEM = elevation, TEMP = average annual mean temperature, TEMP_R $=$ average annual temperature range, $\mathrm{PREC}=$ average annual precipitation, $\mathrm{PREC} \_\mathrm{S}=$ average annual precipitation variation, $\mathrm{LGP}=$ average length of growing period, SCARB = soil carbon stock, POP $=$ human population density, TRAV $=$ market access in travel time to nearest town of $+50,000$ inhabitants, TLU $=$ herd size, HH_SIZE = number of household members, LAND = total cultivated land area. 


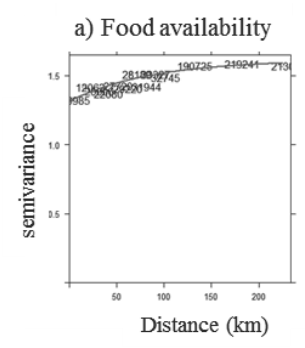

e) Sorghum contribution

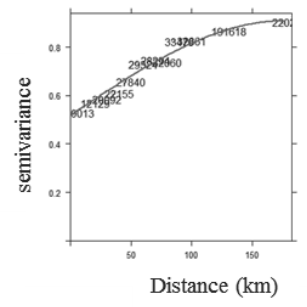

i) Beans contribution

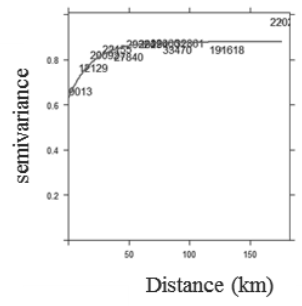

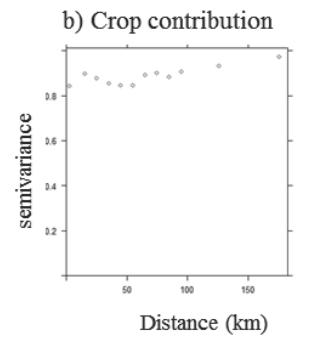

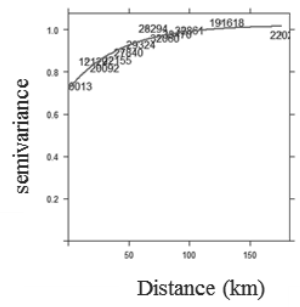

j) Cattle contribution

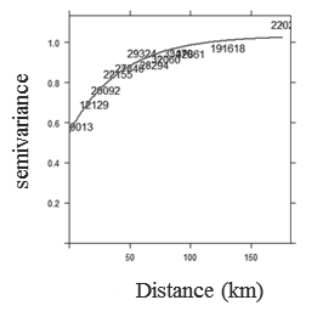

k) Poultry contribution

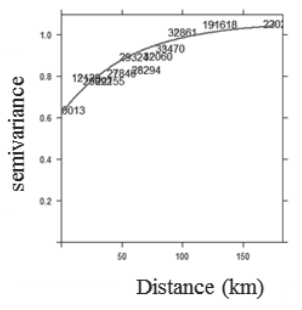

c) Livestock contribution

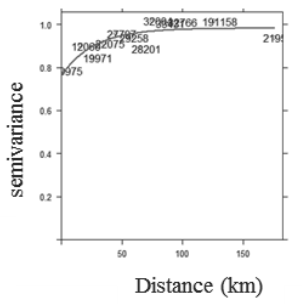

g) Maize contribution

d) off-farm income contribution

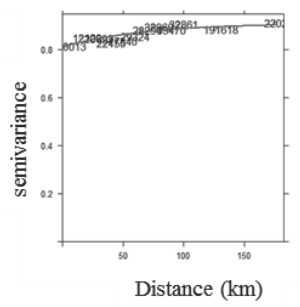

h) Coffee contribution
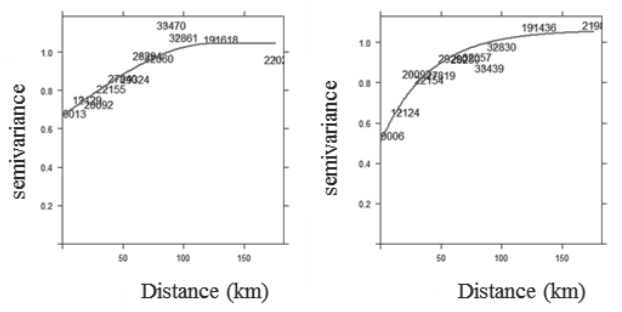

Fig S3.11 Variogram models of the indicators 



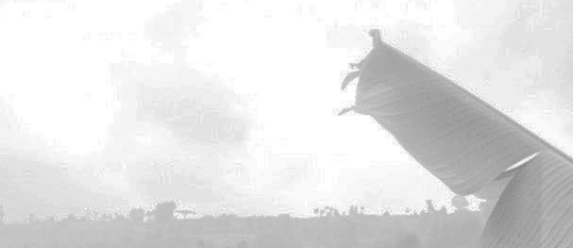

$\frac{3 x}{45}$

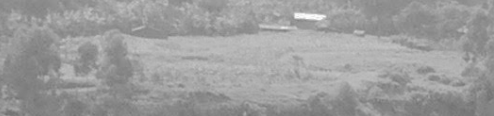

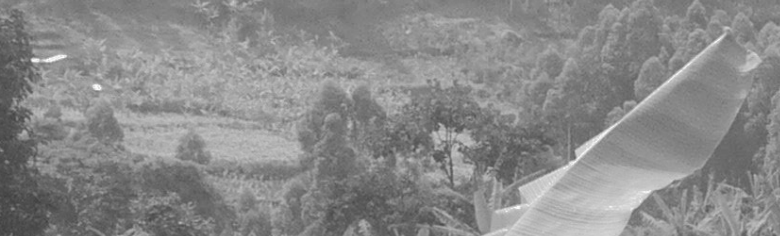

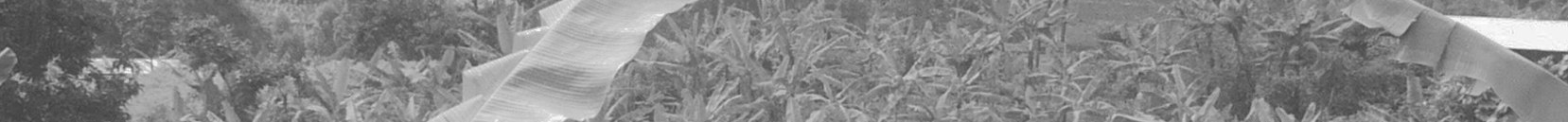

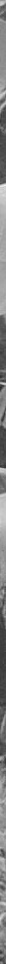

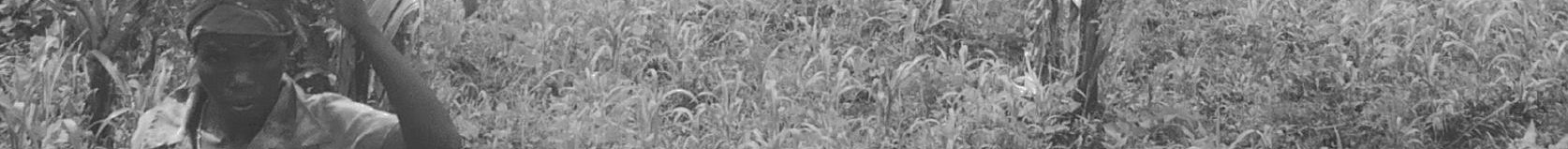

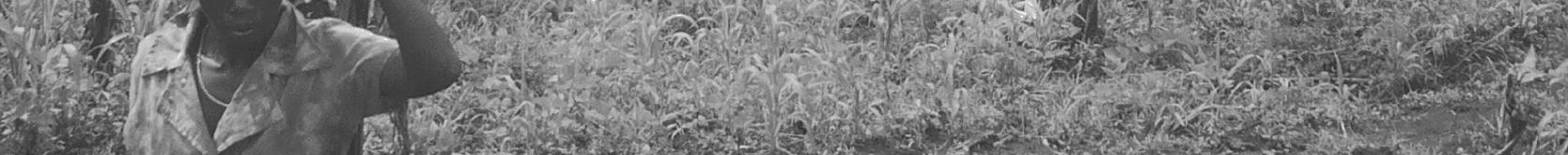

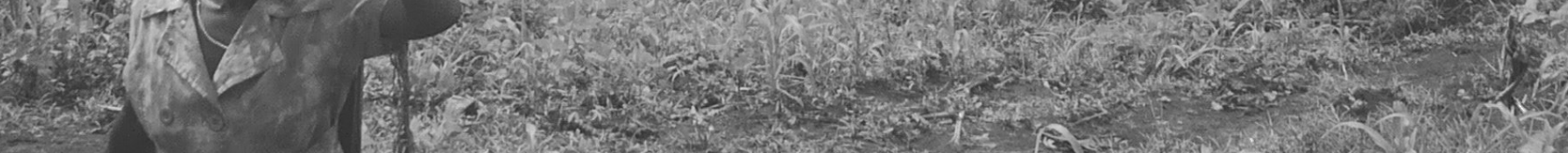
(1)

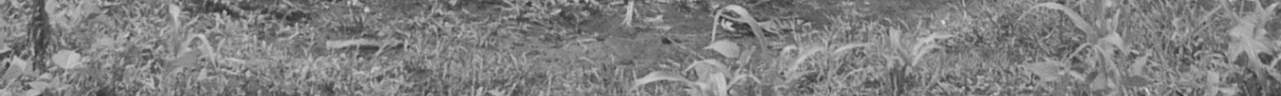
Q5.

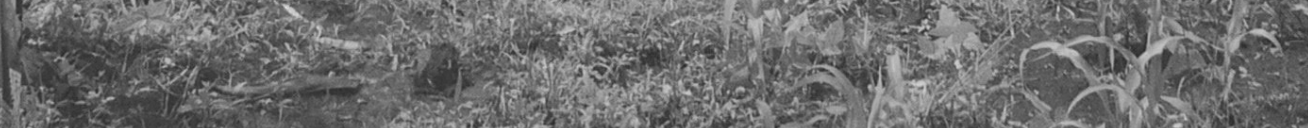




\section{Chapter 4}

\section{Vulnerability and adaptation options to climate change for rural livelihoods - a country-wide analysis for Uganda}

This chapter is based on a submission for publication as:

Wichern, J., Descheemaeker, D., Giller, K. E., Ebanyat, P., Taulya, G., van Wijk, M. T.: Vulnerability and adaptation options to climate change for rural livelihoods - a country-wide analysis for Uganda. Agricultural Systems 


\begin{abstract}
Rural households in sub-Saharan Africa earn a substantial part of their living from rain-fed smallholder agriculture, which is highly sensitive to climate change. There is a growing number of multi-level assessments on impacts and adaptation options for African smallholder systems under climate change, yet they often fail to connect information at the household level with the larger sub-national and national levels. Further, few studies translate impacts at the individual crop level to vulnerability at the household level, at which other livelihood activities need to be considered. We developed a framework that combines crop suitability maps with a household food availability analysis to quantify household vulnerability to climate-related impacts on crop production and effects of adaptation options from household to sub-national and national levels. The framework was tested for Uganda identifying four hotspot areas of household vulnerability. About $30 \%$ of the households in the hotspot areas in (central) southwest were vulnerable to a combination of $3^{\circ} \mathrm{C}$ temperature increase and $10 \%$ rainfall decline through declining suitability for several key crops (including highland banana, cassava, maize and sorghum). In contrast only $10 \%$ of the households in West Nile and central northern Uganda were negatively affected and this was mainly related to declining suitability of common beans. Households that depended on common beans and lived at lower elevations in West Nile and central north were vulnerable to a 2 to $3^{\circ} \mathrm{C}$ temperature increase, while households located at higher elevations (above 1,1002,000 m.a.s.l. depending on the crop) benefitted. Options for adaptation to increasing temperatures were most suitable in northern Uganda, while drought-related adaptation options were more suitable in the southwest. Being spatially-explicit in nature and taking the variability at the household level to broader scales, the framework enables to identify where households are vulnerable, to determine why households are vulnerable and to test which adaptation options could work in which regions.
\end{abstract}

Keywords: Crop suitability, household food security, adaptation, vulnerability, impact assessment 


\subsection{Introduction}

Rain-fed smallholder agriculture is an essential source of livelihood for most of the rural households in sub-Saharan Africa (The World Bank 2009). Although in many countries these households produce the $m$ ajority of the country's food (Herrero et al. 2017), they are often the most food insecure (von Grember et al. 2018). Food insecurity will be exacerbated in the future due to population growth, but one of the other most pressing challenges for achieving food security is climate change (Godfray et al. 2010). Those rural households that are already susceptible to food insecurity will probably also be the most vulnerable to climate change (Müller et al. 2011).

Crop production is an important livelihood activity for the food insecure households in subSaharan Africa (Frelat et al. 2016) and is also sensitive to climate change. When assessing climate change impacts and potential adaptation options for crop production, many studies have focused on individual crops (e.g. Thornton et al. 2009a; Traore et al. 2015; Rowhani et al. 2011). Yet, a household's vulnerability depends on the contribution of different crops to the household's food security and incom e. Therefore, assessm ents are needed that identify im pacts and adaptation options at the farm and household level while also taking into account non-crop sources of food and income such as livestock and off-farm income (Descheemaeker et al. 2016a).

There is an increasing body of literature assessing climate change impacts on and adaptation options for smallholder systems in sub-Saharan Africa. These studies identify how climate change will affect regions, communities, households and livelihoods and which adaptation options are most suitable in which context (Traore et al. 2017; Henderson et al. 2018; Williams et al. 2018). Multi-level assessments combine the local (household) level with higher levels such as the community (e.g. Asare-Kyei et al. 2017), the district (Oluoko-Odingo 2011) or the regional level (Herrero et al. 2014). Although such assessments have the potential to take local information to higher levels, this is hardly done. Yet, recent work has shown that variability between nearby households can be enormous and needs to be considered for targeting interventions for the most vulnerable at national and sub-national levels (Wichern et al. 2018). A tool that uses household level information for assessments at higher levels would enable to identify hotspots of vulnerable households and to identify adaptation options suitable for different hotspots and households.

In our study we aim at approaching these existing gaps by combining analyses of climate change impacts on multiple key crops with the household livelihood context (i.e. the contribution of affected crops to a household's incom e, food security and vulnerability). The 
approach uses a country-wide household survey dataset to scale up information on climate change impacts and adaptation options from the crop level to the household, sub-national and national levels. We determine household vulnerability to climate-related impacts on key crops and identify hotspots for which we assess important livelihood activities and possible adaptation options. In this explorative study we do not consider climate impacts on non-crop livelihood activities, such as livestock production and off-farm income generation, but our framework has the potential to do so in the future. We address the following research questions: Where are the climate change hotspot areas in Uganda? Which households are vulnerable to climate change? How can household vulnerability to climate change in the hotspot areas be reduced?

\subsection{Material and methods}

\subsubsection{Uganda as an ideal case study}

We used Uganda as a case study country because of its diversity in agro-ecology ranging from perennial banana-coffee systems in the humid highlands to dryland pastoral savannah systems in the northeast (Pender et al. 2004; Wortmann and Eledu 1999). In Uganda crop production is an important livelihood activity of rural households for achieving food and income security. Especially the poorer and food insecure households tend to be most dependent on (rain-fed) crop production (Wichern et al. 2017), making them vulnerable to climate shocks and climate change.

Minimum and maximum temperatures have been rising in Uganda during the past decades (Kikoyo and Nobert 2016; Mubiru et al. 2012; Nsubuga et al. 2014) and trends are expected to continue in the near future. A study by the Government of Uganda projects seasonal temperatures to increase by $>3{ }^{\circ} \mathrm{C}$ under the Representative Concentration Pathway (RCP) 8.5 scenario. Under RCP4.5 scenario temperature is projected to increase by $2{ }^{\circ} \mathrm{C}$ across Uganda for mid-century and by up to $2.5^{\circ} \mathrm{C}$ for end-century (Nsubuga and Rautenbach 2018; Government of Uganda 2015). Studies on rainfall patterns of the recent past identified both declining and increasing trends for Uganda. This depends on the location and time of the year with a drying trend particularly observed from March to May affecting the first cropping season (Lyon and DeWitt 2012; Maidment et al. 2015; Funk et al. 2008; Muthoni et al. 2018). Rainfall projections for East Africa are more uncertain than temperature projections. While global circulation models tend to predict a wetter climate in East Africa towards end-century, regional models suggest that parts of the region (here East Africa) become drier (Shongwe et al. 2011; Patricola and Cook 2011; Niang et al. 2014). For Uganda, under the RCP8.5 and RCP4.5 
scenarios changes in annual rainfall of $< \pm 10 \%$ were projected for mid-century with the west and northwest of Uganda becoming slightly wetter, while particularly the southern and central parts becoming drier. A projected increase in rainfall from December to February indicated an extended second cropping season (Nsubuga and Rautenbach 2018; Government of Uganda 2015). Trends in heavy rainfall events and droughts in the past decade indicate an increasing frequency of extreme events (Lyon and DeWitt 2012; Funk et al. 2008), which is likely to continue in the future.

Climate change will affect crop production in Uganda. Maize production is expected to be more negatively affected than sorghum or millet with considerable yield reductions of up to $45 \%$ (Adhikari et al. 2015; Thornton et al. 2010; Thornton et al. 2011). Also common beans are expected to experience large yield losses (Thornton et al. 2011), while cassava production may be less or even positively affected in the region (Lobell et al. 2008; Jarvis et al. 2012; Rosenthal and Ort 2012). Coffee, an important cash and export crop, is expected to experience major losses in yield and coffee bean quality due to temperature increases reducing the extent of suitable areas and increasing the risk for pests and diseases (Adhikari et al. 2015; Jaramillo et al. 2011). Highland banana already experiences water-constrained conditions and yields may be negatively affected in the future if water stress continues or gets worse in combination with higher temperatures (van Asten et al. 2011; Adhikari et al. 2015).

\subsubsection{Conceptualising vulnerability and introducing the approach}

Schneider et al. (2007) described vulnerability as a degree to which a system is susceptible to an adverse impact and unable to cope with it. Vulnerability can be captured by identifying exposure, sensitivity and adaptive capacity of a system. Exposure to climate change does not only incorporate the hazard itself, but relates to the presence of people or assets that could be adversely affected (Oppenheimer et al. 2014). Sensitivity relates to the susceptibility of a system to adverse changes and adaptive capacity to the ability of a system to cope with or adapt to adverse changes. In our framework we determined the vulnerability $(V)$ of households based on exposure $(E)$ and sensitivity $(S): V=f(E, S)$. Exposure was simulated with climate scenarios in which monthly temperature and rainfall values were changing. These climate scenarios affected the suitability of different crops. The degree of sensitivity of households to these climate scenarios was determined by the importance of the different crops for household food security and income. Vulnerability of households was then based on combining crop suitability with the im portance of the crops for a household's livelihood under current and future clim ate. We did not include adaptive capacity in the assessment of vulnerability, but estimated it by testing the effects of different adaptation options in various regions. 
Our approach consists of four main steps: In Step 1, we calculated and mapped current crop and household level suitability. Suitability maps were generated for eight key crops of Uganda based on spatially-explicit temperature and rainfall data under current climate using the Ecocrop model approach (Ramirez-Villegas et al. 2013). Household food availability and the contribution of the eight key crops to household food availability was calculated using a crosscountry household survey dataset (Wichern et al. 2017). Household level suitability was determined from the suitability maps of the key crops and their contributions to household food availability. In Step 2, we used six climate scenarios capturing changes in temperature and rainfall to calculate how crop and household level suitability would change under climate change. From the resulting map on household level suitability change of the most pessimistic climate scenario, we identified four hotspot areas (henceforth 'hotspots') with negative household level suitability change for further in-depth analysis. In Step 3, we classified the households within the four hotspots according to their household level suitability change to estimate vulnerability and identified major differences in livelihood activities between the more and the less vulnerable households. In Step 4, based on the outcomes from Steps 1 to 3, we determined potential adaptation options per hotspot and used different adaptation scenarios to identify which of these options were most suitable for which region.

\subsubsection{Data}

For the crop suitability analysis we obtained crop specific parameters on temperature and rainfall requirem ents and on the length of the crop cycle from the R package 'dism o' (Hijm ans et al. 2017) and updated them with information from the FAO database Ecocrop (http://ecocrop.fao.org/ecocrop/srv/en/home). We used crop area maps from You et al. (2017) to distinguish between the presence of Arabica or Robusta coffee in a farming system. Climate data were retrieved from WorldClim, which contains average monthly climate data for minimum, mean and maximum temperature and for rainfall for the period 1970 to 2000 (version 2.0, resolution 5 arcmin, Fick and Hijmans 2017).

We obtained household level food security and agricultural production characteristics from a cross-country household survey dataset for Uganda from the World Bank Living Standard Measurement Study - Integrated Surveys on Agriculture (LSMS-ISA) (Kilic et al. 2015; UBOS 2011). In total 2,671 geo-referenced households across Uganda were sampled over a 12-month period in 2010/2011. The LSMS-ISA is nationally representative on rural/ urban and regional levels. The households were sampled per enumeration area, which were randomly sampled per region (Kampala, Central, Eastern, Northern and Western) (The World Bank 2012). Our analysis included data on household location, household characteristics, agricultural production and off-farm income. We were interested in the agricultural households and therefore excluded 
those households without any land holdings. Another twelve households had no latitude or longitude information and could not be included in the analysis. The resulting final sample comprised 1,927 households. All analyses and mapping were performed in R.

\subsubsection{Step 1: Crop and household level suitability analyses}

\subsubsection{Ecocrop model}

Crop suitability was calculated for eight crops that are of major importance in Uganda: Highland banana (Musa acuminata Colla, henceforth 'banana'), com $\mathrm{m}$ on beans Phaseolus vulgaris L., henceforth 'beans'), cassava (Manihot esculenta Crantz), Arabica coffee (Coffea arabica L.), Robusta coffee (Coffea canephora L.), maize (Zea mays L.), sorghum (Sorghum bicolor (L.) Moench) and groundnut (Arachus hypogaea L.). To calculate crop suitability we used the Ecocrop model, which is a basic mechanistic model that integrates expert knowledge on environmental ranges (from the FAO Ecocrop database, http:/ecocrop.fao.org/ecocrop/srv/en/home, accessed 26/11/18) in order to identify the niche of a crop and to produce a crop suitability index as output (values from 0 to 1 with $0=$ unsuitable and 1 = highly suitable) (Ramirez-Villegas et al. 2013). The model uses monthly temperature and seasonal rainfall thresholds to identify two ecological ranges for a specific crop (Fig 4.1). The absolute range (grey) is derived from the minimum and maximum absolute temperatures and rainfall amounts at which the crop can grow and beyond which the suitability is zero. The optimum range is derived from the optimum minimum and maximum temperatures and rainfall amounts (black). An additional temperature parameter identifies a monthly minimum temperature below which the crop dies $\left(\mathrm{T}_{\text {kill }}\right)$, defining the location as unsuitable for the crop. If mean temperature or rainfall conditions are between the absolute and optimum thresholds, suitability ranges between 0 and 1 based on a linear function of temperature/ rainfall between the thresholds. If conditions are within the optimum range, suitability equals 1 . Overall crop suitability is calculated in four steps: First, temperature suitability is calculated per month within a season and the minimum monthly temperature suitability determines the seasonal temperature suitability. Second, rainfall suitability is calculated per season. Third, seasonal crop suitability is determined using the minimum value of the seasonal temperature and rainfall suitability indices. Fourth, if the location has two cropping seasons in a year, overall crop suitability is determined by the mean of the two seasonal crop suitability values. The model is described in detail in Supplementary materials S4.1. Crop suitability was calculated for each grid cell. 


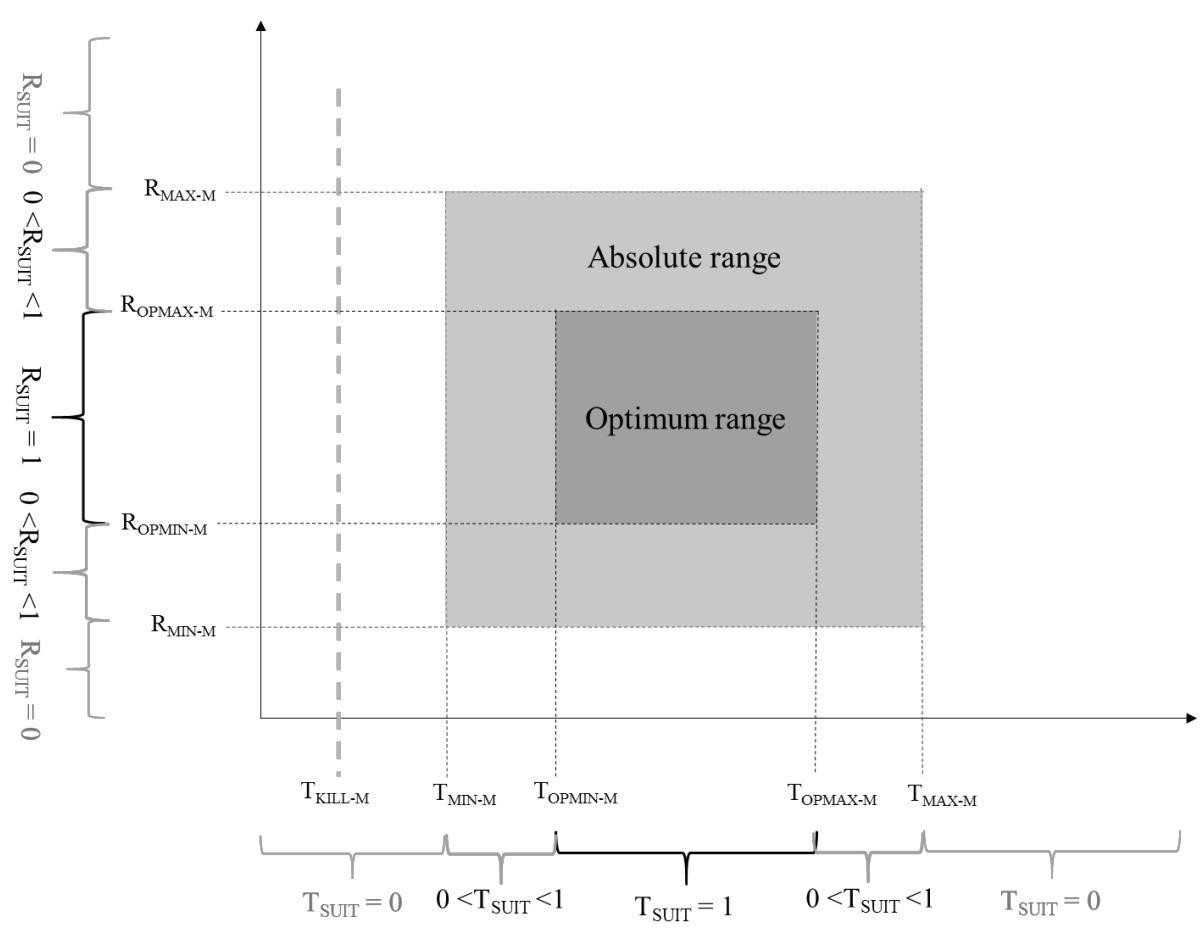

Fig 4.1 Ecocrop model, adapted from Ramirez-Villegas et al. (2013). $\mathrm{T}_{\mathrm{SUIT}}=$ temperature suitability. $\mathrm{R}_{\text {SUIT }}=$ rainfall suitability. $\mathrm{T}_{\text {KILL-Mi }}=$ minimum temperature parameter below which crop dies. $\mathrm{T}_{\mathrm{MIN}-\mathrm{M}}=$ minimum absolute temperature, $\mathrm{T}_{\mathrm{OPMIN}-\mathrm{M}}=$ minimum optimum temperature, $\mathrm{T}_{\mathrm{OPMAX}-\mathrm{M}}=$ maximum optimum temperature, $\mathrm{T}_{\text {MAX-M }}=$ maximum temperature. $\mathrm{R}_{\text {MIN-M }}=$ minimum absolute rainfall, $\mathrm{R}_{\mathrm{OPMIN}-\mathrm{M}}$ $=$ minimum optimum rainfall, $\mathrm{R}_{\mathrm{OPMAX}-\mathrm{M}}=$ maximum optimum rainfall, $\mathrm{R}_{\mathrm{MAX}-\mathrm{M}}=$ maximum absolute rainfall

Most of Uganda has two cropping seasons per year, but some parts of the northeast have just one cropping season. To distinguish between the regions with one and with two seasons, we used the livelihood zone descriptions of FEWS NET (2010). These descriptions were also used to select optional starting dates of the seasons (between February and April for cropping season 1 and between July and September for cropping season 2). We calculated seasonal temperature and rainfall suitabilities for each optional starting month for the length of each of the individual crop cycles and determined the optimal starting month per season and grid cell by selecting the maximum suitability, for example for season 1 :

Suit $_{S 1}=\max \left(\right.$ Suit $_{S 1, \text { starting month } 1}$, Suit $\left._{S 1, \text { starting month } 2}, \ldots\right)$

This way the optimal window for crop cultivation was selected by the model rather than choosing a fixed month. We considered static lengths of crop cycles for both seasons under the 
current and future climate. In reality, crop cycle lengths are expected to change with global warming due to accelerating effects of increased temperature on the phenological development of the crop (Schlenker and Lobell 2010; Traore et al. 2017), which can negatively affect crop suitability. By contrast, drought (in combination with potassium deficiency) delays bunch development in banana (Taulya 2013; Taulya et al. 2014). Crop suitability was calculated for current climate and for the different climate and adaptation scenarios (below).

\subsubsection{Adjustment of Ecocrop model parameters}

The parameters determining the optimum and absolute temperature and rainfall ranges of the crops were initially retrieved from the R package 'dism o' and updated with inform ation from the FAO Ecocrop database (this was only valid for T KILL-M for banana). These initial parameters were then adjusted based on input from local experts on the suitability of the different crops in Uganda under current climate and based on information from literature. The length of the crop cycle was derived using the geometric mean of the maximum and minimum crop cycle length reported in the Ecocrop database (Manners and van Etten 2018) and translated from days to months (rounding to nearest integer). For banana and Arabica and Robusta coffee, suitability was calculated for the entire year. Supplementary materials Table S4.2 shows the adjusted parameters and the literature used for the crop suitability calculations.

\subsubsection{Household food availability analysis}

Household food security was estimated using household food availability. The food availability indicator (FA), calculated following Frelat et al. (2016) and Wichern et al. (2017), estimates the potential food energy available to a male adult equivalent (MAE) household member per day ( $\mathrm{kcal} \mathrm{MAE}^{-1} \mathrm{day}^{-1}$ ) based on the annual reported agricultural production activities and offfarm income. The indicator uses survey data on directly consumed annual agricultural products (in food energy, kcal year-1) and on indirectly consumed annual food energy potentially obtained from using all the household income to purchase staple food (maize) (in food energy of the staple food, kcal year ${ }^{-1}$ ). Food energy values of the crop and livestock products (kcal) were obtained from the standard product list of the US Department of Agriculture (source: https://ndb.nal.usda.gov/ndb/search/list, accessed 02/07/16) and from the FAO (source: http://www.fao.org/docrep/x5557e/x5557e00.htm\#Contents, accessed 02/07/16). By using the medians of reported prices for crops and livestock products we reduced potential effects of erroneous prices in the reported data. We identified the on- and off-farm livelihood activities that contributed to the food availability and expressed them as relative contribution to FA (values from 0 to 1 ): Crop contribution to FA, livestock contribution to FA and off-farm income contribution to FA. The crop contribution to FA was further subdivided into contributions of 
banana, beans, cassava, coffee, maize, sorghum, groundnut and other crops to the crop production of FA.

\subsubsection{Indicators of household level suitability}

To estimate household vulnerability with our conceptual model $V=f(E, S)$, we linked the effects from the exposure $E$ (crop suitabilities dependent on the climate scenarios) to household sensitivity $S$ (crop contributions to households food availability). The food availability analysis was the basis for calculating two indicators of household level suitability: the first indicator, household level crop suitability, quantified the weighted effect of the suitabilities of the single key crops on the crop production part of household food availability, while in the second indicator, household level suitability, also the other activities considered in the food availability analysis (i.e. livestock production and off-farm income generation) were taken into account. Household vulnerability $V$ was then estimated by quantifying the change in household level suitability from current to future climate. We determined household level suitability change for different climate scenarios.

Household level crop suitability (HHCropSuit) is the weighted sum of suitabilities of the single key crops. The weightings depend on the crop contributions to the crop part of household food availability (eq. 4.2). As such, HHCropSuit ranges between 0 and 1 with $1=$ highly suitable and $0=$ not suitable. The contribution of 'other crops' was m ultiplied by a suitability of 1 , because we had no information on the suitability of these other crops.

HHCropSuit $_{j}=\sum_{i}\left(\right.$ CropSuit $_{k c i, j} \times$ CropContr $\left._{k c i, j}\right)+1 \times$ CropContr $_{o c, j}$

Where: CropContrkci,j: contribution of key crop $i$ to the crop production of FA of household $j$, CropContr $_{o c, j}$ : contribution of other crops to the crop production of FA of household $j$, HHCropSuit $t_{j}$ : household level crop suitability of household $j$, and CropSuit kc $i, j_{j}$ : crop suitability of crop $i$ of household $j$. The LSMS household survey data did not distinguish between Arabica and Robusta coffee. Therefore, we used a crop distribution map of Arabica coffee to estimate which coffee plant was likely to be cultivated (You et al. 2017).

Household level suitability (HHSuit) is the weighted sum of suitabilities of household livelihood activities (crop production, livestock production and off-farm income generation). Crop production suitability is estimated by HHCropSuit. Livestock production suitability and off-farm income generation suitability are set to 1 ('highly suitable') as we had no inform ation on the suitabilities of these activities. The suitabilities are weighted by the contributions of the livelihood activities to household food availability resulting in HHsuit $\leq 1$ (eq. 4.3). 
HHSuit $_{j}=$ HHCropSuit $_{j} \times$ Contr $_{\text {crops }, j}+1 \times$ Contr $_{\text {other }}$ activities,$j$

Where: HHSuit $t_{j}$ : household level suitability of household $j$. Contr $_{\text {crops }, j}$ : Contribution of all crops to FA of household $j$. Controther activities, $j$ : Contribution of other activities (livestock production and off-farm income generation) to FA of household $j$.

HHCropSuit and HHSuit were calculated both for current clim ate conditions ('cu-cl') and for future clim ate scenarios ('fucl'), thereby diagnosing deterioration or improvement of the suitability scores (eq. 4.4 and 4.5 ):

HHCropSuitChange $_{j}=$ HHCropSuit $_{f u-c l, j}-$ HHCropSuit $_{c u-c l, j}$

HHSuitChange $_{j}=$ HHSuit $_{f u-c l, j}-$ HHSuit $_{c u-c l, j}$

Where: HHCropSuitChange $e_{j}$ : Change of household level crop suitability of household $j$. HHSuitChange $_{j}$ : Change of household level suitability of household $j$.

By including the contributions of other crops, livestock and off-farm income as householdspecific constants in our household level suitability calculations, we were able to reflect the sensitivity of households to climate-related crop suitability changes given the other livelihood activities. Off-farm income generation and livestock production are important livelihood activities for African rural households to be food secure and to buffer risks from climate shocks (Wichern et al. 2017; Wichern et al. submitted). These activities need to be included to be able to compare households with different compositions of livelihood activities in terms of their sensitivity to crop suitability change. Furthermore, this way our framework provides a basis to include climate impacts on more crops and non-crop livelihood activities in the future.

\subsubsection{Step 2: Climate scenarios}

A baseline climate scenario contained spatially-explicit current climate data from WorldClim. The baseline was modified for a set of climate scenarios with an increase of monthly mean and minimum temperatures by 2 and $3^{\circ} \mathrm{C}$, a $10 \%$ rainfall increase, a $10 \%$ rainfall decrease, and a combination of $3{ }^{\circ} \mathrm{C}$ temperature increase and $10 \%$ rainfall change, uniform for the entire country and across all the months of the year (Table 4.1). Temperature scenarios were chosen based on reported projections of temperature increases around 2 to $3^{\circ} \mathrm{C}$ for mid-century under RCP4.5 and RCP8.5, respectively (Nsubuga and Rautenbach 2018; Government of Uganda 2015). As rainfall projections are more uncertain, we included both scenarios with rainfall increase and scenarios with rainfall decline. 
Table 4.1 Climate scenarios. $\mathrm{BL}=$ baseline (current climate), $+\mathrm{T} 2 /+\mathrm{T} 3=$ Temperature increase by $2{ }^{\circ} \mathrm{C} /$ $3^{\circ} \mathrm{C}$. $-\mathrm{R} 10=10 \%$ rainfall decline, $+\mathrm{R} 10=10 \%$ rainfall increase

\begin{tabular}{lll} 
& Scenario name & Characteristic of scenario \\
\hline 1 & BL (Baseline) & Current climate $($ WorldClim) \\
2 & $+\mathrm{T} 2$ & Current climate $+2^{\circ} \mathrm{C}$ in monthly minimum and mean temperatures \\
3 & $+\mathrm{T} 3$ & Current climate $+3^{\circ} \mathrm{C}$ in monthly minimum and mean temperatures \\
4 & $+\mathrm{R} 10$ & Current climate $+10 \%$ rainfall \\
5 & $-\mathrm{R} 10$ & Current climate $-10 \%$ rainfall \\
6 & $+\mathrm{T} 3-\mathrm{R} 10$ & Current climate $+3^{\circ} \mathrm{C}-10 \%$ rainfall \\
7 & $+\mathrm{T} 3+\mathrm{R} 10$ & Current climate $+3^{\circ} \mathrm{C}+10 \%$ rainfall \\
\hline
\end{tabular}

\subsubsection{Step 3: Assessing household vulnerability in the hotspots}

We identified four regions in Uganda where HHCropSuit and HHSuit were negatively affected under the clim ate scenarios (see Results section). For these four 'hotspots' we perform ed household level analyses to determine how livelihood activities were related to changes in HHCropSuit and HHSuit. First, we classified the households according to (1) their FA (Class 1: food deficient households with $<2,500 \mathrm{kcal} \mathrm{cap}^{-1} \mathrm{day}^{-1}$; Class 2: food adequate households with 2,500-5,000 kcal cap ${ }^{-1}$ day $^{-1}$; Class 3: food surplus households with $>5,000 \mathrm{kcal} \mathrm{cap}^{-1}$ day $^{-}$ ${ }^{1}$ ) and (2) their HHSuitChange in +T3-R10 compared to the baseline (Class 1: 'negative change', if HHSuitChange $<-0.05$; Class 2: 'no change', if $-0.05<H H S u i t C h a n g e<0.05$; Class 3: 'positive change', if HHSuitChange $>0.05$ ). If households experienced negative change, we called them more vulnerable households, if they experienced no or positive change, we called them less vulnerable households. Second, we explored differences in livelihood activities for a) all households in a hotspot, b) households with $<40 \%$ off-farm income, and c) households with $<40 \%$ off-farm incom e and $>65 \%$ contribution of key crops to the household's crop production of FA. This was done to interpret correctly the potential bias caused by the household-specific constants on contributions of other crops, livestock and off-farm income included in the framework. Within the four hotspots environmental conditions and farming systems varied, influencing the vulnerability of households to the climate scenarios. Third, to disentangle these effects we identified patterns of HHSuitChange for the different livelihood zones (FEWS NET 2010) and along an elevation gradient within each hotspot.

\subsubsection{Step 4: Adaptation scenarios in the hotspots}

Adaptation scenarios were applied to the climate scenario +T3-R10 to assess their effects on household vulnerability in the four hotspots. These adaptation scenarios included a) alternative crop varieties, b) regulation of temperature or water availability in the cropping system and c) 
substitution of key crops. Adaptation scenarios were identified based on information on crops most affected to climate change, which was extracted in the household level analysis in Step 3. Adaptation options were mimicked by changing crop parameters in the Ecocrop model (a), climate data in the climate scenarios (b), or crop contributions in the food availability calculations (c). We identified which adaptation options were most suitable per hotspot by determining the percentage of households that experienced negative $(\leq-0.05)$ and positive $(\geq 0.05)$ HHSuitChange under the climate scenario $+\mathrm{T} 3-\mathrm{R} 10$ in comparison to current climate if they used no adaptation or one of the adaptation options.

\subsection{Results}

\subsubsection{Step 1: Suitability on crop and household level under current climate}

The suitability under current climate was smallest in the northeast and southwest for all key crops except for sorghum (Fig 4.2). Rainfall was the main factor that limited suitability of banana, beans, maize, groundnut, coffee (both Arabica and Robusta) and to some extent of cassava in the central southwest and the northeast of Uganda. Temperature was limiting for banana, beans, cassava, groundnut, Robusta coffee and sorghum in the high elevations, and for Arabica coffee in the northwest of the country.

a) Banana

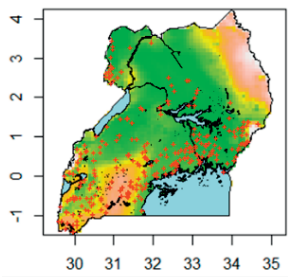

e) Arabica coffee

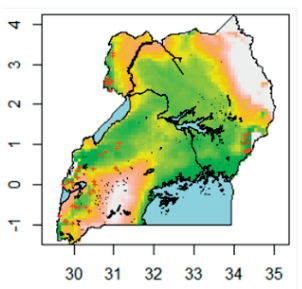

b) Beans

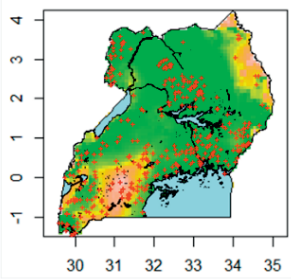

f) Robusta coffee

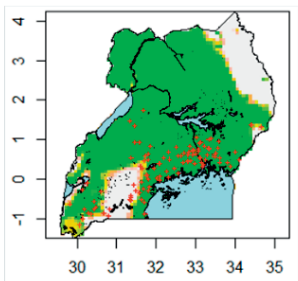

c) Cassava

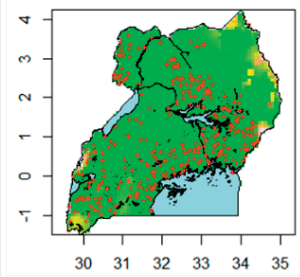

g) Maize

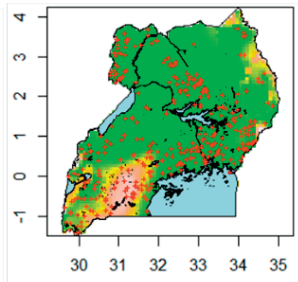

d) Groundnut

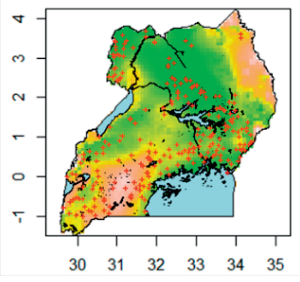

h) Sorghum

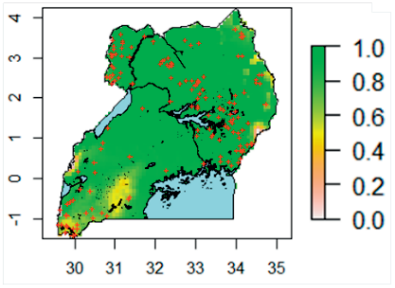

Fig 4.2 Crop suitability under current climate for eight key crops based on thresholds of monthly temperature and seasonal rainfall using the Ecocrop model. A suitability score $=1$ means highly suitable, a suitability score $=0$ means not suitable. The red + represent the households with the particular crop present in their system 
HHCropSuit under current climate was $>0.7$ for the majority of the households, only in the central southwest and for a few isolated cases in West Nile and in the east it was $<0.7$ (and partly <0.3). Similarly, HHSuit, taking into account other livelihood activities besides crop production (i.e. off-farm income and livestock contributions to FA), was $>0.7$ for most households across Uganda and only smaller in the central southwest and for some isolated cases in the east (Supplementary materials Fig S4.3).

\subsubsection{Step 2: Changes in crop and household level suitability under climate scenarios}

Effects of temperature increase depended on the particular crop but generally resulted in positive crop level suitability changes in the higher elevations and negative crop level suitability changes for some crops in the north and east. Rainfall changes mainly affected regions in Uganda's south. Crop level suitability changes are exemplified for scenario +T3-R10 (Fig 4.3) and showed both positive and negative trends depending on the location and crop. Among all crops most positive changes were observed for Arabica coffee in elevations approximately $>2,000$ m.a.s.1., while most negative changes occurred for Robusta coffee in the southwest of Uganda. For Arabica and Robusta coffee, beans, cassava and maize, the crop suitability was improved under $+\mathrm{T} 3-\mathrm{R} 10$ when grown at higher elevations ranging from approximately $>1,100$ m.a.s.l. for cassava to approximately $>2,000$ m.a.s.l. for beans and Arabica coffee. In the southwest, banana, cassava, maize and sorghum experienced negative suitability change. In the north, particularly beans, cassava (West Nile) and Arabica coffee were negatively affected. Also in parts in the east, Arabica coffee experienced negative changes.

a) Banana

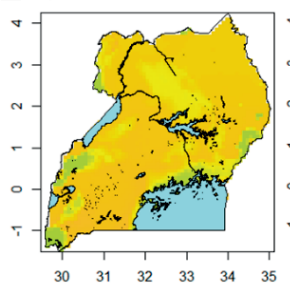

e) Arabica coffee

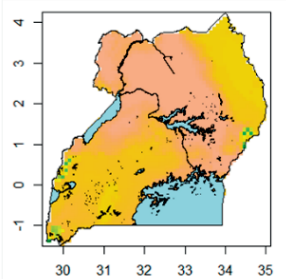

b) Beans

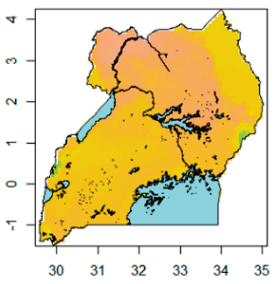

f) Robusta coffee

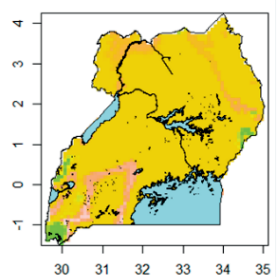

c) Cassava

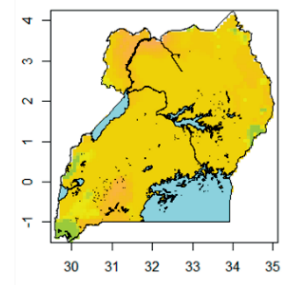

g) Maize

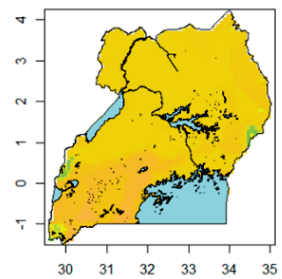

d) Groundnut

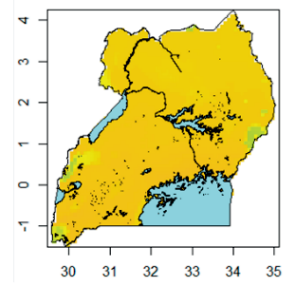

h) Sorghum

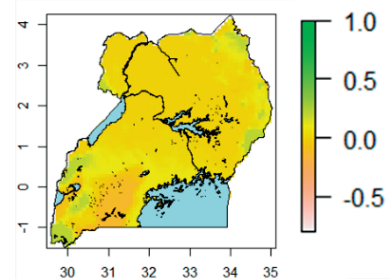

Fig 4.3 Change in crop level suitability of eight key crops under climate scenario +T3-R10 compared to current climate $\left(\right.$ maps show difference $=$ crop level suitability+T3-R10 - crop level suitability currentclimate $_{\text {(ita }}$ 
When aggregating the individual crop effects to overall crop production (HHCropSuit) and subsequently to household level (HHSuit), regions with positive and negative predicted change were visible (Fig 4.4). Under a temperature increase by 2 or $3^{\circ} \mathrm{C} \mathrm{HHCropSuit}$ and HHsuit declined in the northern parts of West Nile and in the central north, while they increased at the higher elevations of West Nile, southwestern, and eastern Uganda and along Lake Victoria (Fig 4.4a-b, g-h). Uganda's south benefited under a uniform 10\% increase of $\mathrm{m}$ onthly rainfall (Fig $4.4 \mathrm{c}, \mathrm{i})$, while particularly the central southwest and the southwest were negatively affected when monthly rainfall declined by $10 \%$ (Fig 4.4d, j). Similar patterns were observed for the scenarios combining temperature increase and rainfall change (Fig 4.4e-f, k-1). For our further analyses we focused on the HHSuitChange under the combined temperature increase and rainfall decline scenario $+\mathrm{T} 3-\mathrm{R} 10\left(3^{\circ} \mathrm{C}\right.$ temperature increase, $10 \%$ rainfall decrease $)$ because it included pessimistic projections of both temperature and rainfall trends for Uganda (e.g. Government of Uganda 2015; Funk et al. 2008; Lyon and DeWitt 2012; Shongwe et al. 2011). 


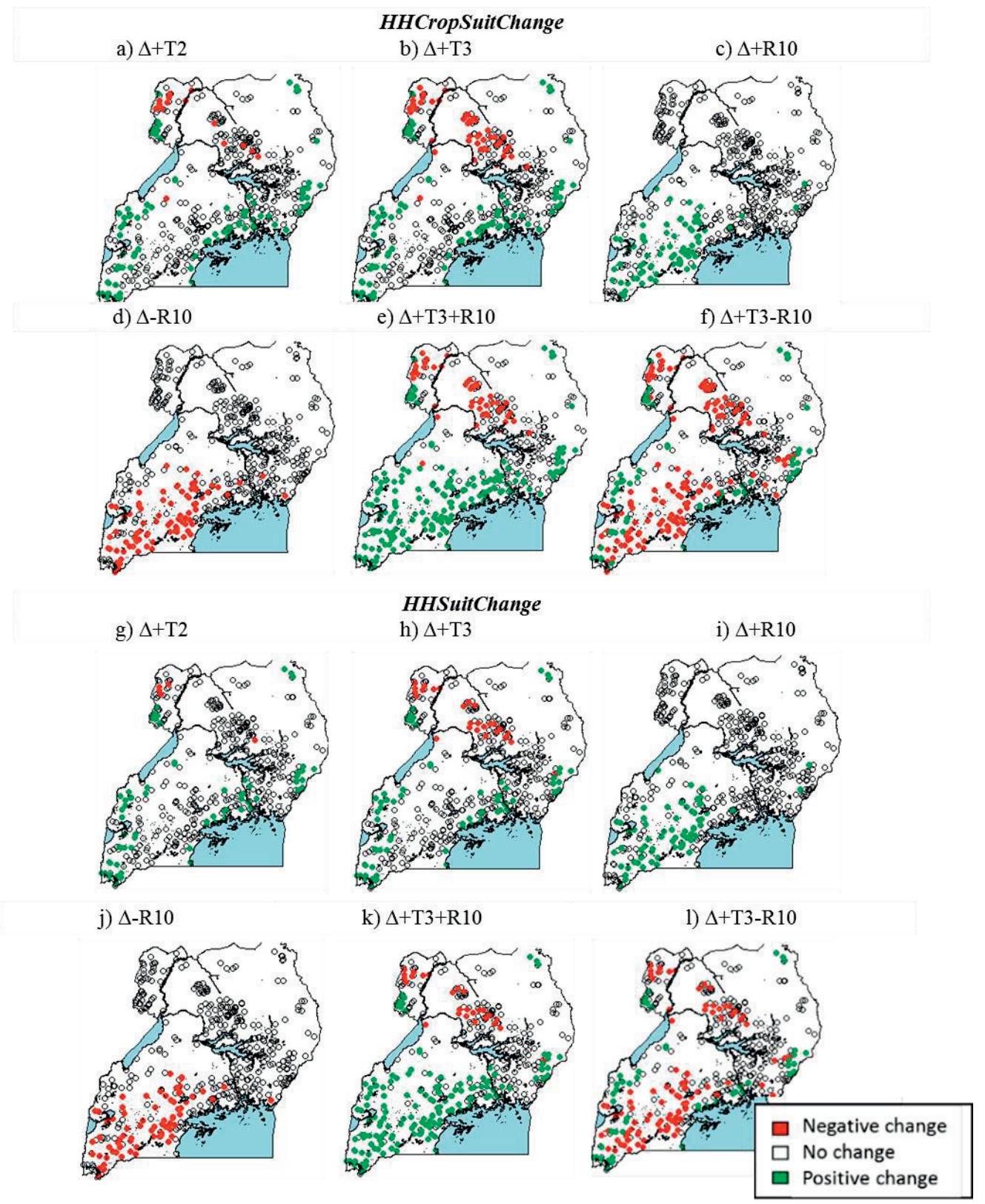

Fig 4.4 Change in household level crop suitability (HHCropSuitChange, a-f) and in household level suitability (HHSuitChange, g-1) under six climate scenarios: Difference between scenario $+\mathrm{T} 2$ and BL $(\mathrm{a}, \mathrm{g}) ;+\mathrm{T} 3$ and BL (b, h); +R10 and BL (c, i); -R10 and BL (d, j), +T3+R10 and BL (e, k); +T3-R10 and $\mathrm{BL}(\mathrm{f}, 1) . \mathrm{BL}=$ current climate, $+\mathrm{T} 3=3^{\circ} \mathrm{C}$ monthly minimum and mean temperature increase, $+\mathrm{R} 10$ $=10 \%$ monthly rainfall increase, $-10 \%=10 \%$ monthly rainfall decline 


\subsubsection{Step 3: Differences between households across four hotspots}

\subsubsection{Household food availability and crop characteristics}

We identified four hotspots where a large number of households was negatively affected under the climate scenario +T3-R10: West Nile, central north, southwest and central southwest (Fig 4.5). In all four hotspots, the food surplus households $\left(>5,000 \mathrm{kcal} \mathrm{cap}^{-1} \mathrm{day}^{-1}\right)$ tended to depend more on off-farm income and less on crop production as compared to the food deficient households $\left(<2,500 \mathrm{kcal} \mathrm{cap}^{-1} \mathrm{day}^{-1}\right)$ and crops contributing to the crop production of FA differed between hotspots and FA classes (Fig 4.6). In West Nile and central north food deficient households tended to be slightly more vulnerable (i.e. HHSuitChange was more negative) under scenario +T3-R10, but generally average changes were small. However, there were substantial changes in suitability for individual households, i.e. the small average change hides a large variation in possible changes. In southwest and central southwest Uganda the relation between food availability and HHSuitChange was not that strong, while overall HHSuitChange was larger than in West Nile and central north.

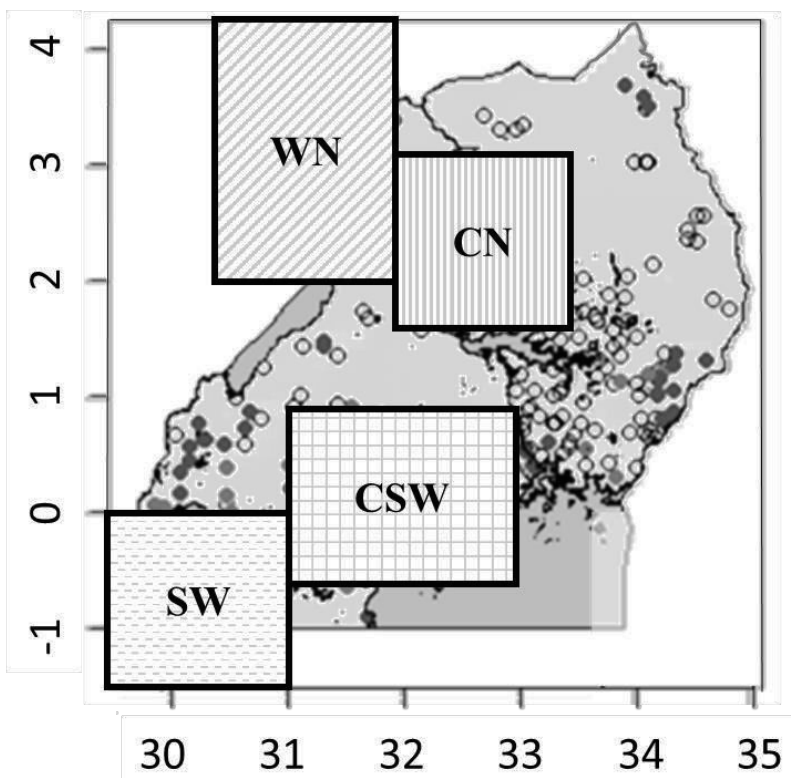

Fig 4.5 Hotspots for zoomed-in household level analysis. WN = West Nile (206 households), $\mathrm{CN}=$ central north (251 households), SW = southwest (289 households), SWC = central southwest (362 households) 


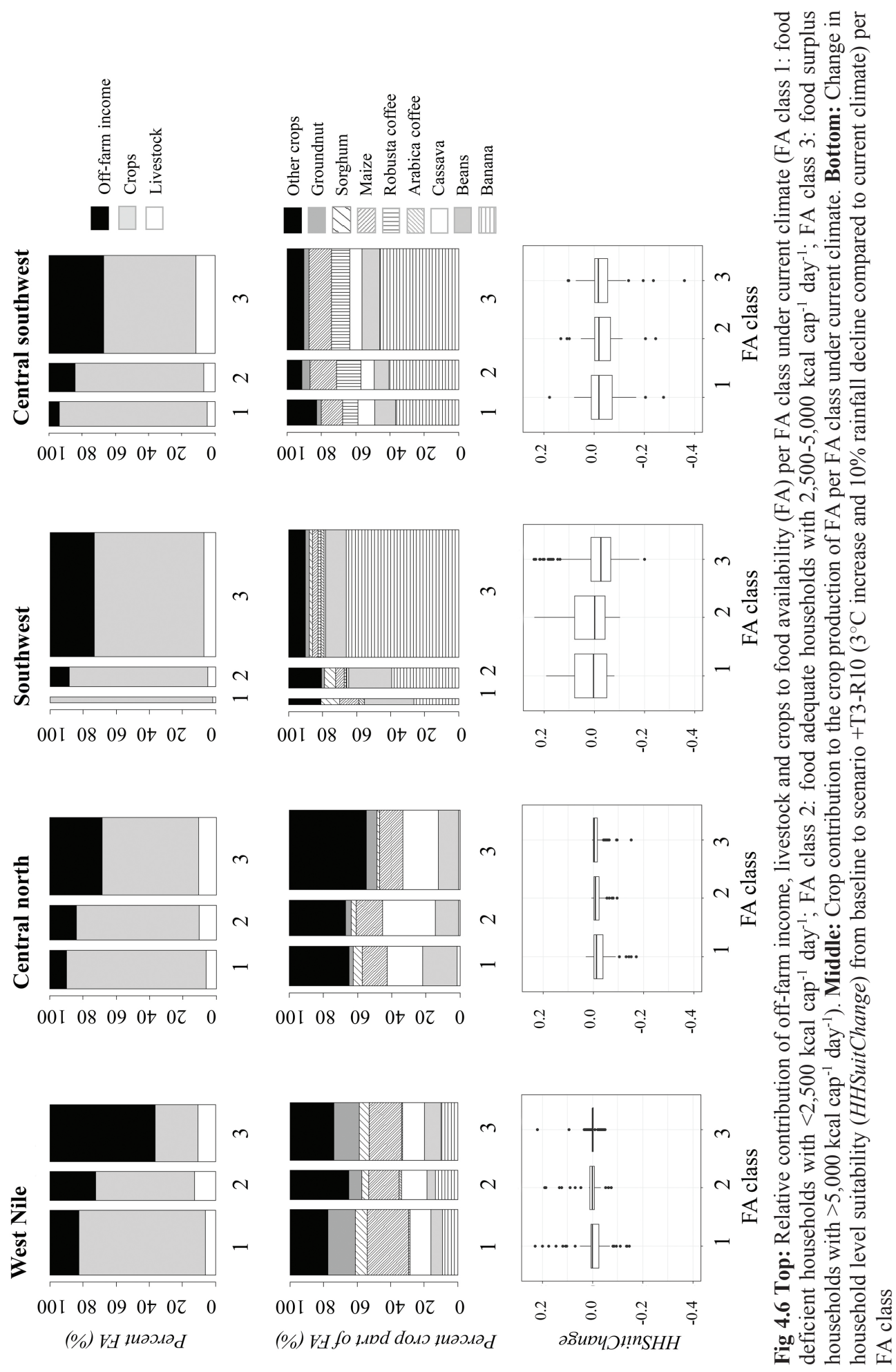




\subsubsection{Identifying underlying patterns of household level crop suitability change}

Strong relations existed between the contribution of key crops to FA and HHCropSuitChange for West Nile and central north where temperature increase determined crop suitability. In West Nile the larger contribution of banana correlated with a positive HHCropSuitChange under the scenario +T3-R10, while larger contributions of beans or Arabica coffee were related to a negative HHCropSuitChange (Fig 4.7). In central north a tight correlation existed with the contribution of beans: The larger the contribution of beans the more negatively affected the households. The correlation between crop contributions and HHCropSuitChange was less strong in the southwest and central southwest regions. Here rainfall change largely determined crop suitability of several crops, which all influenced HHCropSuitChange under +T3-R10 scenario.

\subsubsection{Determining livelihood activities of less and more vulnerable households}

Households were classified according to HHSuitChange (negative change, no change, positive change) under scenario +T3-R10 compared to the baseline. While in the southwest and central southwest hotspots about $30 \%$ of households were affected by negative HHSuitChange, only about $10 \%$ were affected in West Nile and central north (see Table 4.3). The class with no change was characterised by large contributions of off-farm income and livestock to FA (Fig 4.8a) and of other crops to the crop production of FA (Fig 4.8b top). This was a result of the analysis framework in which off-farm income, livestock and other (less important) crops were considered not affected by the climate scenarios. Therefore, we looked at a subset of households in which the eight key crops played a major role to separate relevant livelihood activities from the effects of the framework (Fig 4.8b bottom). For these households (West Nile: 84 households representing $42 \%$ of the sample population, central north: 91 households representing 36\%, southwest: 177 households representing 65\%, and Central southwest: 236 households representing $65 \%$ of the sample population) the contribution of key crops differed per hotspot and HHSuitChange class: In West Nile, households with positive HHSuitChange under climate scenario +T3-R10 were particularly the ones where banana was more important. These households were located in the southern part of West Nile. Here temperatures were lower (due to higher elevations) and farming systems focused more on coffee and banana systems compared to the northern part of West Nile, where households depended on annual crops and HHSuitChange was negative. In the central north beans were less important and maize and cassava more important for the households with no change in HHSuit compared to the households with negative HHSuitChange. In the southwest, differences in crop contributions were minor between households with positive compared to those with negative HHSuitChange, while those with no change had slightly less banana. In central southwest households with 
positive change depended more on cassava and less on maize and households with no change had more Robusta coffee and less banana.

\subsubsection{Zooming in further: Differences between livelihood zones}

A strong elevation gradient was associated with HHSuitChange for West Nile and the southwest (Fig 4.9). Households in the livelihood zones in the higher elevations were positively affected under the climate scenario +T3-R10, while households in the livelihood zones in the lower elevations were negatively affected. These patterns were weaker in central north and central southwest where the elevation gradient was smaller. HHSuitChange was heterogeneous with both positive and negative changes within the livelihood zones 'UG15, West Nile Tobacco Cassava Sorghum Zone' (West Nile), 'UG19, Mid North Sim sim Maize Cassava Zone' (central north), 'UG39, Southwest Midland Banana Robusta Coffee Cattle Zone' (southwest) and 'UG26, Midwest Central and Lake Victoria Crescent Robusta Coffee Banana Maize and Cattle Zone' (central southwest). Within these livelihood zones, the contribution of beans to the crop production of FA explained some of the variability in HHSuitChange in the north of Uganda (Supplementary materials Fig S4.5). Signals were weaker in the southwest and central southwest with coffee and banana contribution explaining a small part of the variability. 

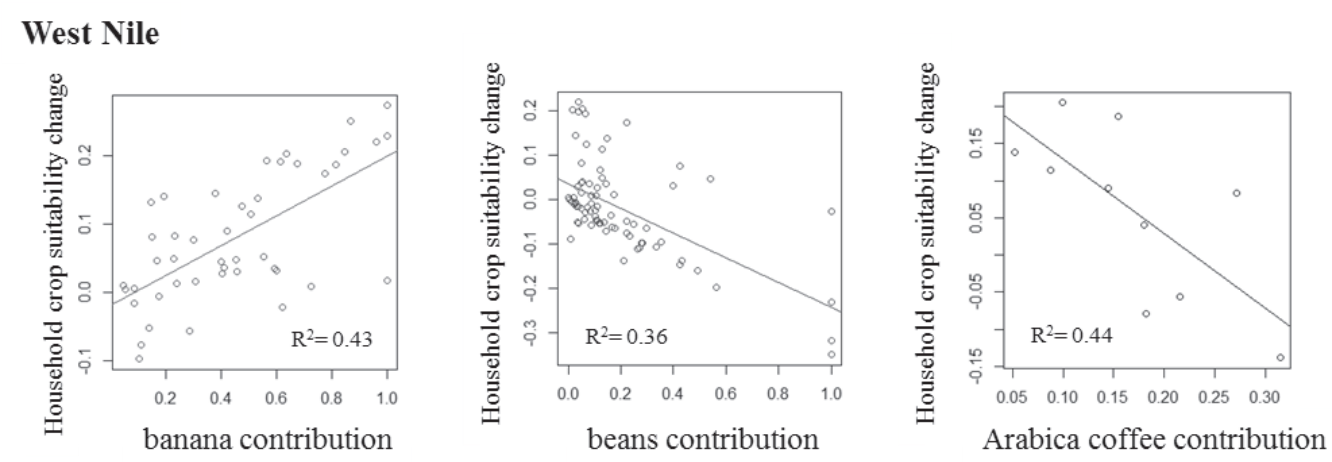

\section{Central north}
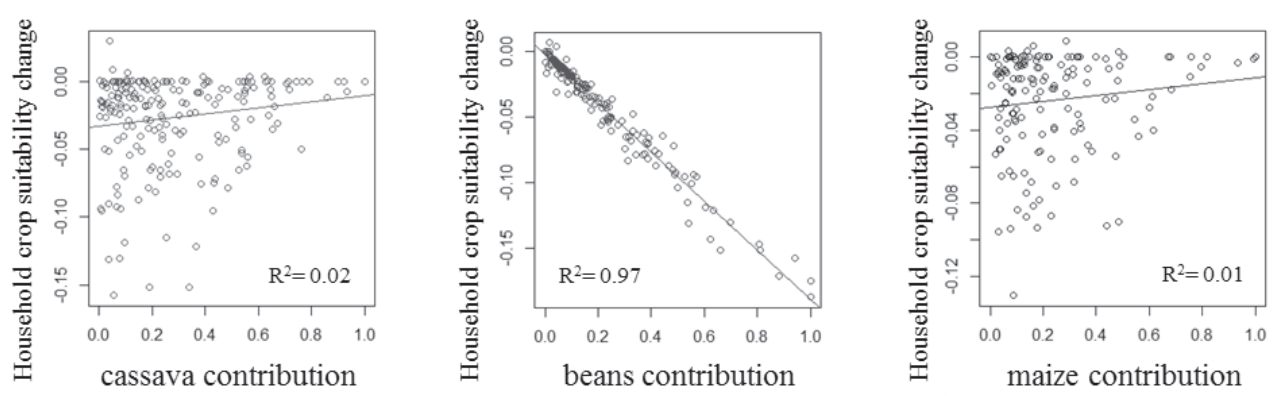

\section{Southwest}

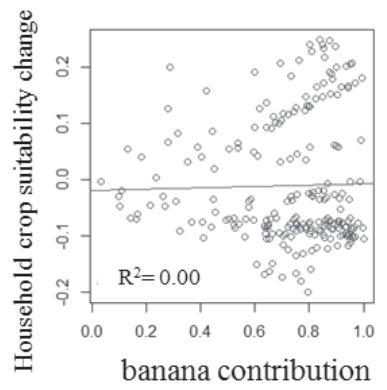

\section{Central southwest}
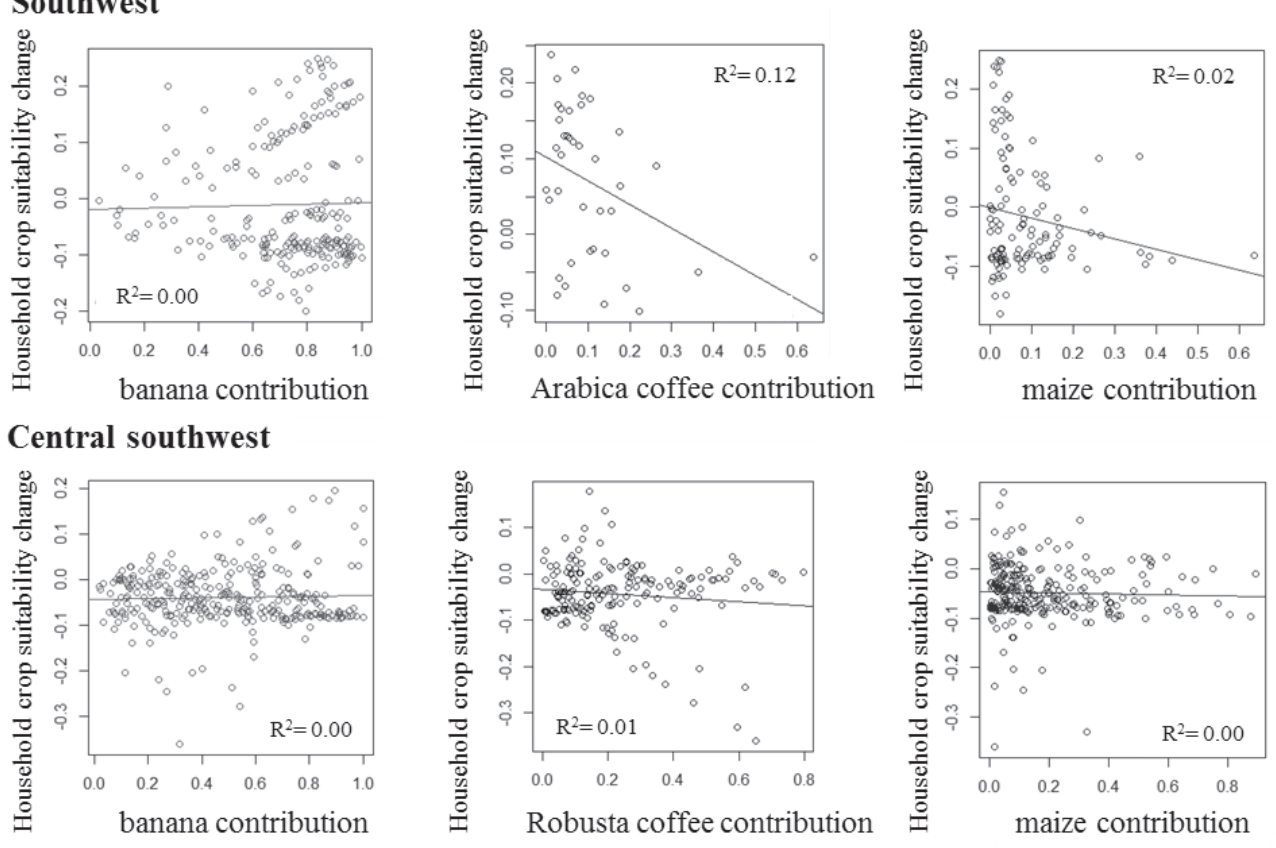

Fig 4.7 Relative contribution of key crops per hotspot to food availability in relation to change in household level crop suitability (HHCropSuitChange) under climate scenario $+\mathrm{T} 3-\mathrm{R} 10\left(3^{\circ} \mathrm{C}\right.$ increase and $10 \%$ rainfall decrease compared to current climate) 

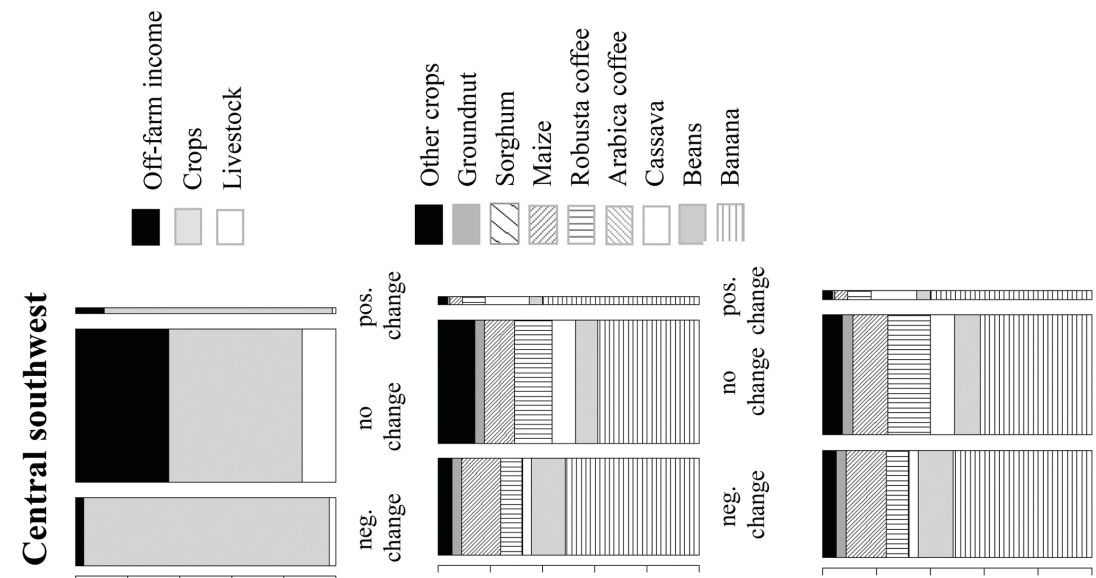

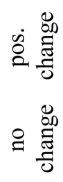

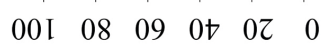

$\begin{array}{llllll}00 \mathrm{I} & 08 & 09 & 0 t & 0 Z & 0\end{array}$
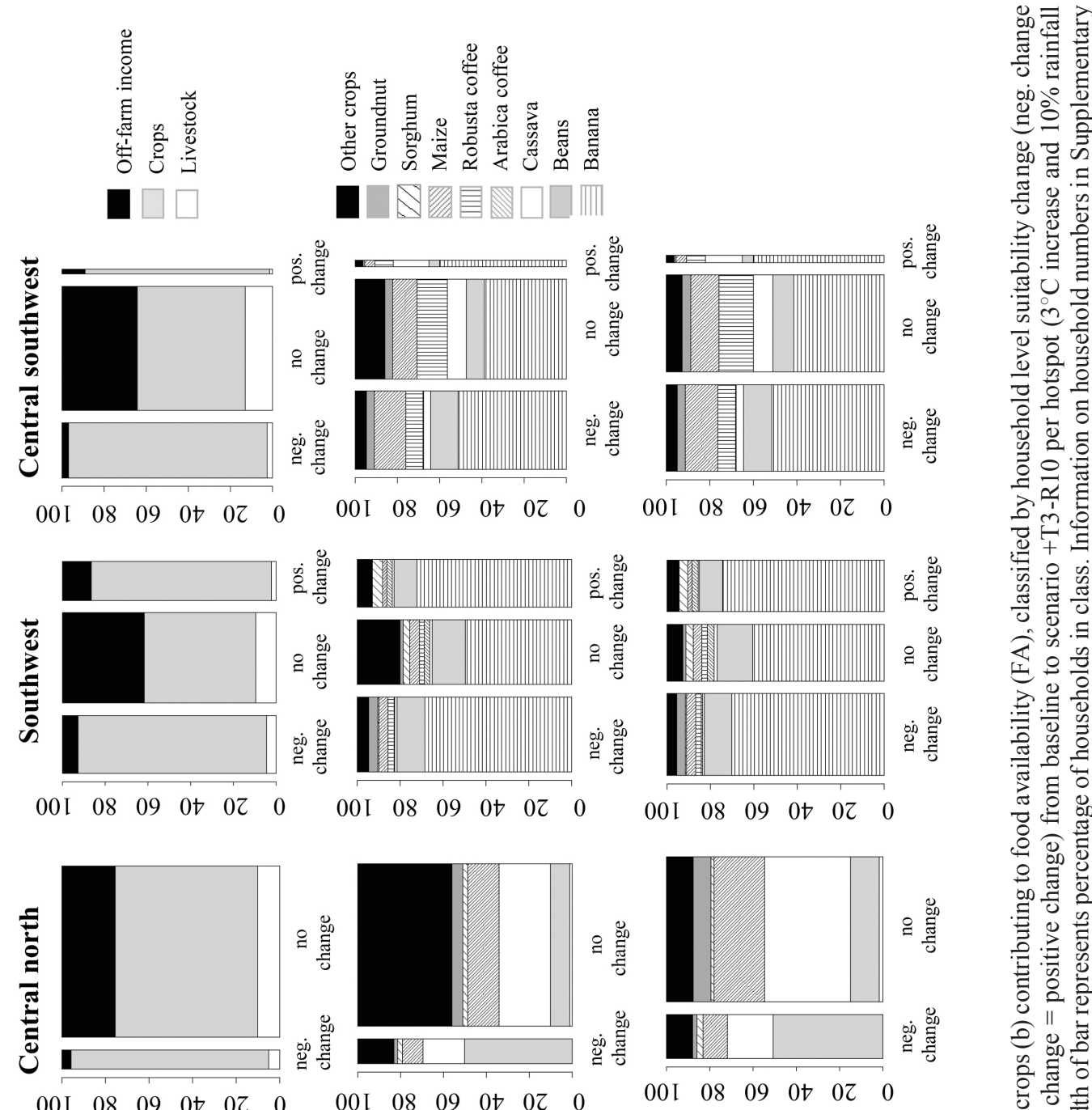

\section{咹}

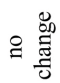

要

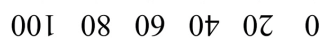

00I $\begin{array}{lllll}08 & 09 & 0 t & 0 Z & 0\end{array}$

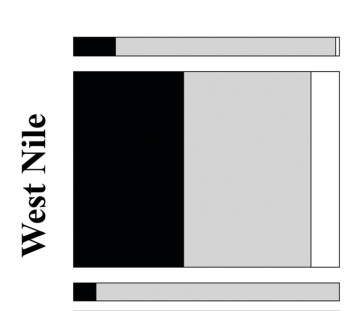

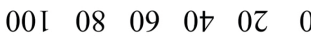

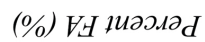

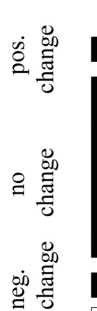

00I 08 O9 09 0t 02

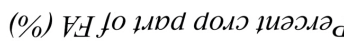

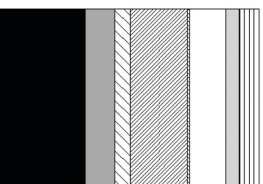

施警

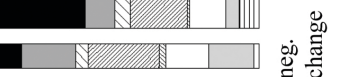

욜

i⿱

00I 08 09 0t $02 \quad 0$

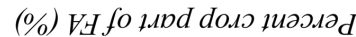

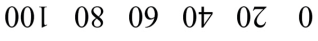

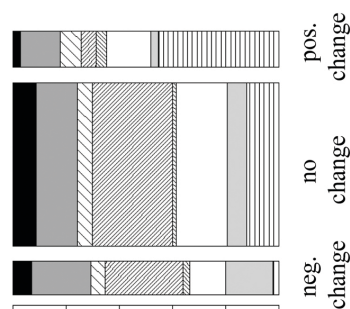

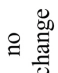

竞

$\frac{8}{\frac{.0}{0}}$

용

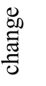

蜜

.

.

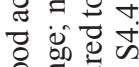

完 苛啇

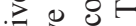

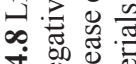

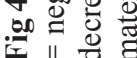




\section{West Nile}
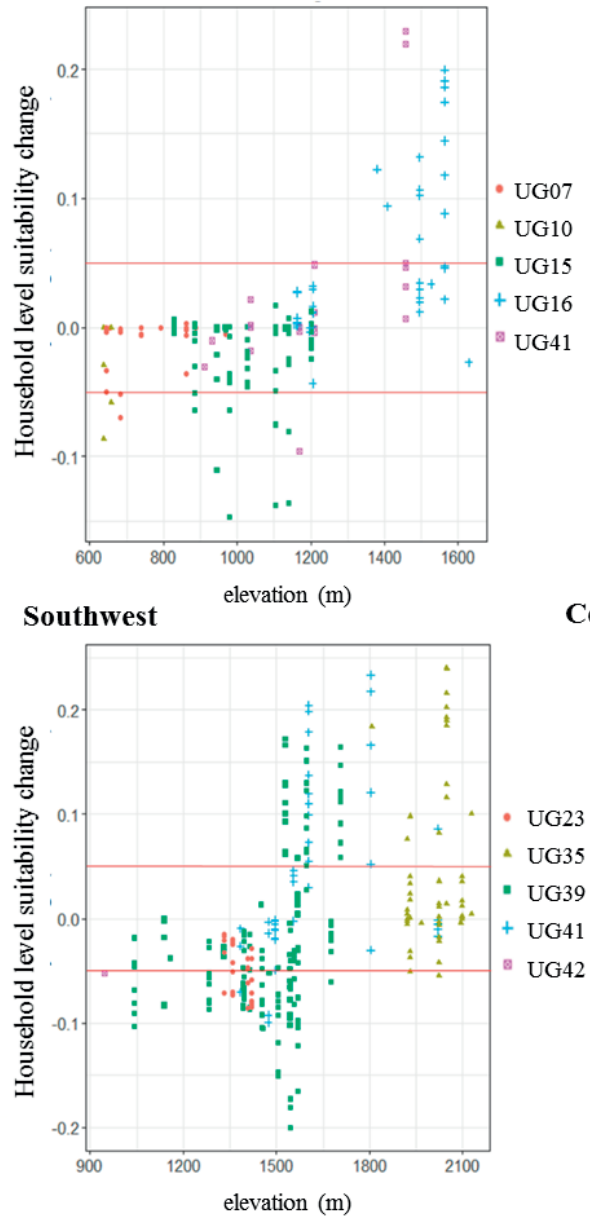

Central north

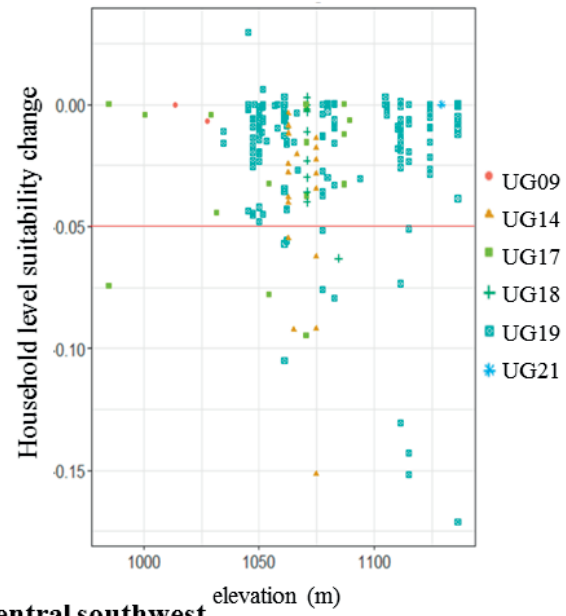

Central southwest

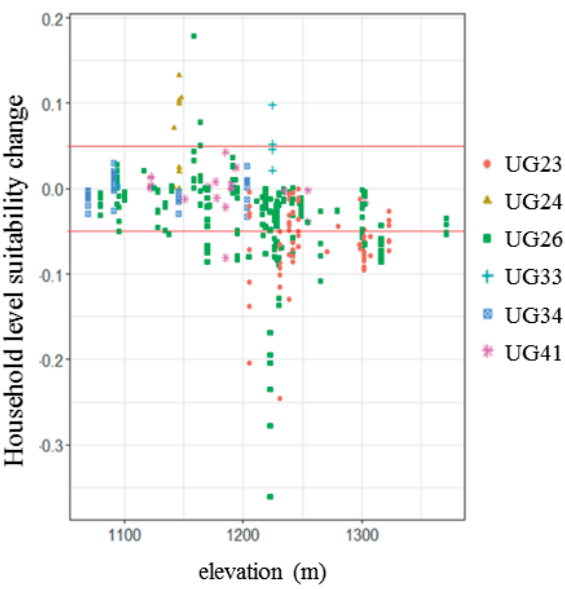

Fig 4.9 Household level suitability change (HHSuitChange) in relation to elevation, indicated per FEWSNET livelihood zone. Red lines represent thresholds of change at 0.05 and -0.05 . UG07: West Nile Simsim Sorghum Livestock Zone. UG09: South Kitgum Pader Abim Simsim Groundnuts Sorghum Cattle Zone. UG10: West Nile Lowland Cattle Zone. UG14: Karuma Masindi Oyam Tobacco Maize Cassava Zone. UG15: West Nile Tobacco Cassava Sorghum Zone. UG16: West Nile Arabica Coffee Banana Zone. UG17: Amuru Gulu Rice Groundnut Sorghum Livestock Zone. UG18: Eastern Central Lowland Cassava Sorghum and Groundnut Zone. UG19: Mid North Simsim Maize Cassava Zone. UG23: Central and Southern Cattle Cassava Maize Zone. UG24: Lakeshore and Riverbank Fishing Zone. UG26: Midwest Central and Lake Victoria Crescent Robusta Coffee Banana Maize and Cattle Zone. UG33: East Central Plantation Outgrower Zone. UG34: Kayunga Masaka Pineapple Banana Robusta Coffee and Cassava Zone. UG35: SW Highland Irish Potato Sorghum Vegetable Zone. UG39: Southwestern Midland Banana Robusta Coffee Cattle Zone. UG41: Urban. UG42: National Park (Source: FEWS NET 2010) 


\subsubsection{Step 4: Identifying suitable adaptation options per hotspot}

Several adaptation options were explored per hotspot based on the results from the previous steps. These adaptation options included the use of different crop varieties (A1-A3), the regulation of temperature or water in the cropping system (A4-A5) and the substitution of key crops (A6-A9, Table 4.2). Adaptation scenarios A6 and A8 particularly targeted the southwest and central southwest, while A7 and A9 aimed at targeting the two hotspots in the north. Heattolerant bean or maize varieties were tested because of their importance in the farming system in the two hotspots in the north, an area sensitive to temperature increase. Drought-tolerant maize varieties and irrigation of banana plantations were tested because of the impact of declining rainfall on households in the southwestern hotspots. Similarly, substitution of maize/ beans by cassava/ groundnut was chosen as an adaptation option because of the larger ranges in minimum and maximum rainfall/ temperature of cassava/ groundnut compared to maize/ beans, respectively. Sensitivity of coffee to climate change was addressed by testing the use of shade trees to regulate temperature.

A clear differentiation in the effectiveness of different adaptation options by hotspot was visible when testing these options (Table 4.3). In West Nile the most effective adaptation was to introduce heat-tolerant bean varieties reducing the number of negatively affected households by six percent points from 8 to $2 \%$. This was particularly relevant for the livelihood zones 'UG10' and 'UG15' (Supplementary materials Table S4.6). Substituting beans by groundnut showed a smaller effect of four percent points reduction in the number of negatively affected households. In central north introducing a heat-tolerant bean variety and replacing beans by groundnut were the most relevant adaptation options reducing the number of negatively affected households by up to ten percent points to $0-2 \%$ across all major livelihood zones. In southwest and central southwest improving the water availability for banana through irrigation had the most positive effect on HHSuitChange reducing the number of negatively affected households by 29 and 27 percent points, respectively. In central southwest introducing a drought-tolerant maize variety or reducing maize production and substituting it by cassava improved the percentage of negatively affected households from 30 to $23-11 \%$, but effects differed per livelihood zone. Not all households in a hotspot benefitted from the adaptation options in the same way. While at hotspot level, some adaptation options led to improvement, at the household level diverse effects were noted. For example, the reduction of beans and simultaneous increase of groundnut (A7) in central north reduced the number of households negatively affected under scenario $+\mathrm{T} 3-\mathrm{R} 10$ from 25 to five households. However, of these 25 households three households still had a HHsuitChange <-0.05, while the other 22 households were no longer negatively affected. Although these three households improved through the adaptation measure, the improvement was not sufficient to compensate for the negative effects 
caused by temperature increase and rainfall decline. In addition, two new households became negatively affected under the adaptation scenario A7, that were not negatively affected under scenario $+\mathrm{T} 3-\mathrm{R} 10$ and this was because groundnut had a lower suitability score than beans at those two locations.

Table 4.2 Adaptation scenarios used under climate scenario $+\mathrm{T} 3-\mathrm{R} 10\left(3^{\circ} \mathrm{C}\right.$ increase, $10 \%$ rainfall decrease) to evaluate adaptation options for the four hotspots

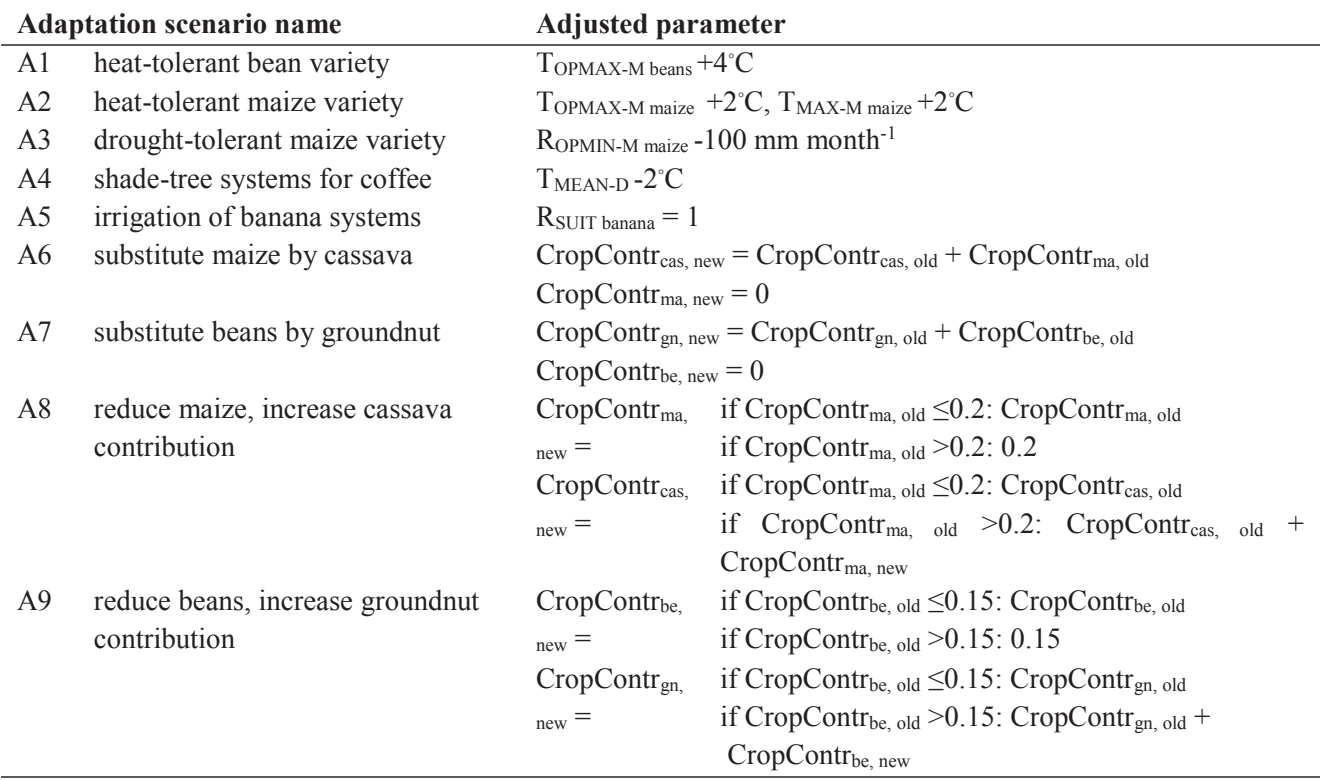

TOPMAX-M i : model parameter for maximum optimum temperature of crop $i$; TMAX-M $\mathrm{i}:$ model parameter for maximum temperature of crop $i$; ROPMIN-M $\mathrm{i}$ : model parameter for minimum optimum rainfall of crop $i$; TMEAN-D i : monthly mean temperature of crop $i$ (in data); $\mathrm{R}_{\text {SulT } \mathrm{i}}$ : rainfall suitability for crop $i$; CropContr cas $_{\text {c }}$ contribution of cassava to the crop production of FA, CropContr ${ }_{\mathrm{ma}}$ : contribution of maize to the crop production of FA, CropContr $_{\text {be }}$ : contribution of beans to the crop production of FA, CropContrgn : contribution of groundnut to the crop production of FA 


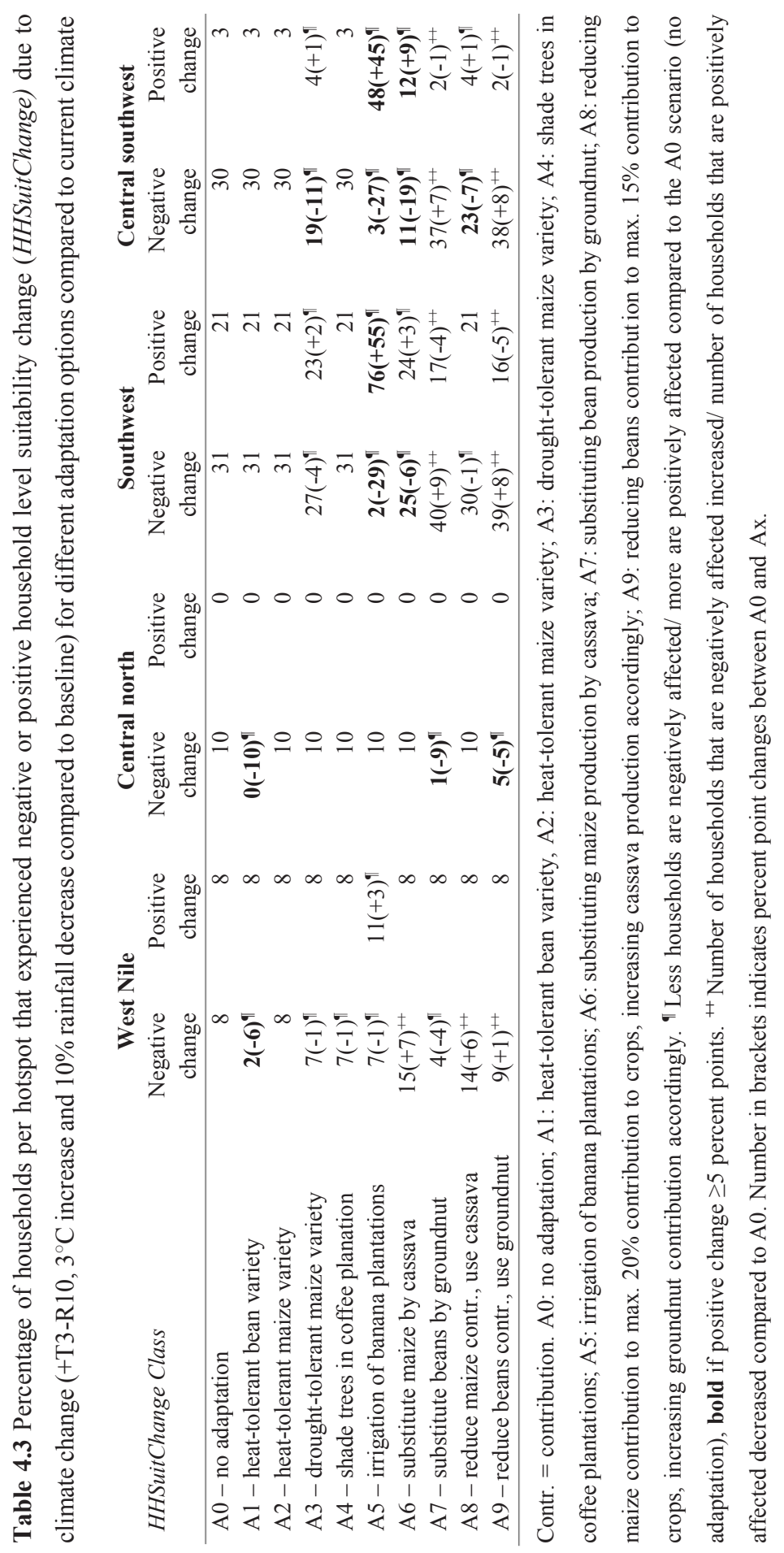




\subsection{Discussion}

\subsubsection{Crop suitability and climate change hotspots in Uganda}

We identified four hotspots of household vulnerability in Uganda (West Nile, central north, southwest and central southwest) driven by the change in suitability of different crops and their importance in the farm livelihood. The results show how agro-ecological conditions and farm livelihood strategies combine to create a mosaic of possible climate change effects. Promising adaptation options in this assessment framework match this mosaic, thereby creating a nuanced overview of what farmers can do in which regions to adapt to climate change. Different adaptation options play out differently in different locations for different farmers. As such this framework is a first step towards quantifying the potential benefits of adaptation options in limiting negative effects of climate change. The framework also indicates that under some agroecological conditions (e.g. at higher elevations) climate change may improve crop productivity.

Rainfall more than temperature constrained suitability of the eight key crops (banana, beans, cassava, coffee Arabica, coffee Robusta, groundnut, maize and sorghum) under current climate conditions and particularly in southwestern Uganda. These results match with observations that banana production, which is an im portant crop in Uganda'ssouthwest, is currently constrained by water availability (van Asten et al. 2011). Suitability of sorghum looked similar to existing maps (Ramirez-Villegas et al. 2013). Compared with earlier research (Jassogne et al. 2013b), our Arabica coffee suitability map had better suitability across the country and was determined by rainfall rather than temperature. Jassogne et al. (2013b) used a different approach, in which the crop parameters of the suitability model were trained based on present occurrence locations of coffee (Bunn 2015). By contrast, we used universally applicable crop suitability thresholds that were adjusted based on expert knowledge. This approach also explains why some of the crops were present in areas where suitability was small (e.g. Robusta coffee, beans or groundnut). In future climate scenarios, temperature increase particularly affected household vulnerability in northern Uganda, while rainfall changes affected household vulnerability in southwestern Uganda. The households in the southwestern and central southwestern hotspots would be hit hardest if future climate becomes drier since they already live under drought-prone conditions (Rojas et al. 2011; Mulinde et al. 2016).

\subsubsection{Characteristics of households vulnerable to climate change}

We diagnosed a differentiation in household vulnerability to climate change at different levels. First, proportionally more households were negatively affected under +T3-R10 in the southwestern and central southwestern hotspots than in West Nile and the central north 
indicating that the two southwestern hotspots were more vulnerable. Second, the magnitude of household level suitability change was larger for households in southwest and central southwest than in the two northern hotspots suggesting that also at the household level vulnerability was larger in the southwestern hotspots. The differences in vulnerability between the southwestern and the northern hotspots were probably because many crops in the southwestern hotspots were already limited by rainfall conditions under current climate. By contrast, in the northern hotspots, basically only beans were negatively affected if temperature increased, limiting both the magnitude of effect and the proportion of households affected in a hotspot. In addition, smaller magnitude of household level suitability change in the northern hotspots could be explained by the larger contributions of off-farm income and of other crops serving as a buffer in our framework (36 to $42 \%$ of households in West Nile and central north largely depended on key crops and off-farm income as compared to $65 \%$ in southwest and central southwest). Although our approach does not allow conclusions to be drawn on the role of off-farm income under global change, off-farm income is an important buffer when dealing with climate shocks (Wichern et al. submitted). For the further development of our framework, inclusion of future socio-economic scenarios on off-farm income sources and opportunities would therefore be useful to identify in which regions off-farm income works as a buffer.

Within the four hotspots, especially the food insecure households (Class 1) depended on crop production for their living (see also Wichern et al. 2017) making them more sensitive to climaterelated impacts on their overall crop production compared to the more food secure households (Classes 2 and 3). In West Nile and central north the food insecure households were also the ones more vulnerable to household level suitability change as compared to the more food secure households. These patterns were weaker for households in the southwest and central southwest. These results indicate that vulnerability to climate-related impacts on crop production is related to but not exclusive for the poorest in a community.

The crop compositions of the less vulnerable households (i.e. those that had non-negative household level suitability change under the climate scenarios) differed to those of the more vulnerable households (i.e. with negative household level suitability change): The less vulnerable depended less on beans (in central north and West Nile), more on banana (in West Nile) and less on Arabica coffee (in West Nile and southwest). In West Nile and southwest these trends were closely related to elevation and livelihood systems with some livelihood systems being more affected by temperature or rainfall change than others. In central north, where beans were strongly affected by temperature increase and were particularly important for the food insecure, these households may be extra vulnerable to climate impacts because they usually have few means to buffer from shocks (Wichern et al. submitted). 
By focusing the zoomed-in vulnerability analysis on the T3-R10 scenario we looked at the most pessimistic scenario among the ones tested, which also resulted in a pessimistic vulnerability assessment. However, results give a good indication on why and how different households would be affected by temperature increase and/ or rainfall decline, which is becoming a reality for many households in Uganda (Nsubuga et al. 2014; Lyon and DeWitt 2012; Muthoni et al. 2018).

\subsubsection{Adaptation options to reduce vulnerability to climate change in the hotspots}

We identified and tested hotspot-specific adaptation options for vulnerable households. In West Nile and central north temperature-related adaptation options showed positive effects on household level suitability, while in the southwest and central southwest drought-related adaptation options were most effective. Measures to deal with drought such as securing water resources and cultivating drought-tolerant crops are already adopted by farmers in southwestern Uganda (Cooper and Wheeler 2017) and the potential positive effects of cultivating heattolerant bean varieties under future climate change have been demonstrated for Uganda as well (CIAT 2009). However, the feasibility of these adaptation options will have to be evaluated carefully within the local context. For example, implementing irrigation systems requires sufficient water to be available for agricultural use. This can be a challenge in times of extended droughts but also when competition for water rises due to population growth. Eventually, adaptation options $\mathrm{m}$ ust fit the household's socioecological context in order to be suitable for a household (Descheemaeker et al. 2016b) and a supportive institutional setting is needed that allows adaptation options to be effective and efficient (Agrawal and Perrin 2008; Unks et al. 2019; Clay and King 2019). These issues indicate that multi-level (country-wide) assessments need to be linked to contextualised in-depth research within identified hotspots to assess who can benefit from these suitable adaptation options.

Adaptation options that go beyond the crop level were not explored with this framework, yet they have the potential to decrease household vulnerability to climate change by reducing the household's dependency on crop production. Such household level adaptation options can, for example, include generation of off-farm income, strengthening of the livestock asset base, or diversification of income sources. Since both off-farm income sources and livestock can also be sensitive to climate shocks (Descheemaeker et al. 2016a; Gbegbelegbe et al. 2018), non-crop adaptation options need to be assessed with a holistic vulnerability assessment framework taking into account climate effects on non-crop livelihood activities. 


\subsubsection{The power and the limitations of the framework}

The framework does not take account of interacting effects of rainfall and temperature, seasonal differences within a year (e.g. if the first season is drier and the second season wetter) and changes in the length of the cropping cycles under climate change. Crop parameters on temperature and rainfall determine the crop suitability, while in reality crop suitability is also influenced by other parameters such as soil conditions. We used average monthly rainfall and temperature changes, while increasing night temperature, heat waves, dry spells, floods and other extreme events also have an influence on crop production. We used average lengths of cropping cycles, although the length differs between varieties. Finally, a 'whole-household' perspective that takes into account the effects of climate change on other livelihood activities such as livestock production and off-farm income generation was beyond the scope of this study.

Despite these limitations the framework identifies hotspots of vulnerable households across Uganda, determines which crops drive household vulnerability and assesses which adaptation options can work where. The framework provides a basis for further analyses, for example by including climate change effects on other crops, livestock and off-farm income or by assessing the effects of different adaptation options on household income and food security. Suitable adaptation options were identified based on positive effects in household level suitability change. However, households will only adopt options if these benefit the households' goals, for example to achieve food and/or income security. Even if future yields of crops such as maize may be lower than today, households might still cultivate them if maize provides sufficient income. Crop prices are sensitive to climate impacts (Wossen et al. 2018). Thus even if a switch from maize to cassava or to other crops seems logical from a crop suitability perspective, price dynam ics of these crops m ay influence a farm er's decision on which crops to cultivate. Within this framework we can adjust price and production values for specific crops to (re)calculate income and food availability to get an idea what the effect of different adaptation options would be on household food security or income. Finally, when using other coherent large datasets of farm household characterisation data (e.g. the RHoMIS effort, Hammond et al. 2016), this framework can perform more detailed analyses per hotspot and better quantify effects beyond the simple food availability indicator (e.g. on nutrition (Fraval et al. submitted a), poverty, and other food security indicators (Fraval et al. submitted b)). 


\subsection{Conclusions}

We present a framework that can be used to link from crop to household and sub-national levels and show that this is needed to understand the relative importance of adaptation strategies in different regions. Being spatially-explicit in nature and taking the variability at the household level to broader scales, this multi-level framework enables to identify hotspots of vulnerable households (where they are), determine the crops per hotspot that drive household vulnerability (why households are vulnerable), and test relevant adaptation options (what could work where).

\section{Acknowledgements}

We thank the Plant Production Systems Group of Wageningen University and Research for funding this research. 


\section{Supplementary materials of Chapter 4}

S4.1 Crop suitability analysis

Crop suitability is calculated in several steps.

1) Temperature suitability

Temperature suitability $\left(T_{S U I T}\right)$ is calculated per month $k$ for location $j$ and crop $i$ :

$$
T_{\text {SUIT } i j k}=\left\{\begin{array}{cc}
0, & T_{M I N-D j k}<T_{K I L L-M i} \\
0, & T_{M E A N-D j k}<T_{M I N-M i} \\
\frac{T_{M E A N-D j k}-T_{M I N-M i}}{T_{O P M I N-M i}-T_{M I N-M i},} & T_{M I N-M i} \leq T_{M E A N-D j k}<T_{O P M I N-M i} \\
1, & T_{O P M I N-M i} \leq T_{M E A N-D j k}<T_{O P M A X-M i} \\
\frac{T_{M A X-M i-T_{M E A N-D j k}},}{T_{M A X-M i-T_{O P M A X-M i}}} & T_{O P M A X-M i} \leq T_{M E A N-D j k}<T_{M A X-M i} \\
0, & T_{M E A N-D j k}>T_{M A X-M i}
\end{array}\right.
$$

\section{Where:}

$\mathrm{T}_{\text {MIN-Djk }}$ : monthly minimum temperature at location $j$ for month $k$

$\mathrm{T}_{\text {MEAN-Djk }}$ : monthly mean temperature at location $j$ for month $k$

$\mathrm{T}_{\text {KILL-Mi }}$ : killing temperature for crop $i$

$\mathrm{T}_{\mathrm{MIN}-\mathrm{Mi}}:$ minimum temperature for crop $i$

TOPMIN-Mi : minimum optimum temperature for crop $i$

TOPMAX-Mi: maximum optimum temperature for crop $i$

$\mathrm{T}_{\text {MAX-Mi }}$ : maximum temperature for crop $i$

Temperature suitability per cropping season is determined by selecting the minimum monthly temperature suitability within the cropping season. The length of the cropping season for each crop is determined from the geometric mean of the maximum and minimum length of the cropping cycle provided in the FAO Ecocrop database.

Seasonal temperature suitabilities were calculated for three different starting months per season (season 1: February, March, April; season 2: July, August, September). Final seasonal temperature suitability was then calculated taking the maximum suitability value for these three seasonal temperature suitabilities. 
2) Rainfall suitability

Rainfall suitability $\left(R_{S U I T}\right)$ is calculated per cropping season $x$ for location $j$ and crop $i$ :

$$
\begin{aligned}
& R_{\text {SUIT } i j x}= \\
& \left\{\begin{array}{cc}
0, & R_{\text {total-Djx }}<R_{M I N-M i} \\
\frac{R_{\text {total }-D j x}-R_{M I N-M i}}{R_{O P M I N-M i}-R_{M I N-M i}}, & R_{M I N-M i} \leq R_{\text {total }-D j x}<R_{\text {OPMIN-Mi }} \\
1, & R_{\text {OPMIN-Mi }} \leq R_{\text {total-Djx }}<R_{\text {OPMAX-Mi }} \\
\frac{R_{M A X-M i}-R_{\text {total-Djx }}}{R_{M A X-M i}-R_{O P M A X-M i}}, & R_{\text {OPMAX-Mi }} \leq R_{\text {total-Djx }}<R_{M A X-M i} \\
0, & R_{\text {total-Djx }}>R_{M A X-M i}
\end{array}\right.
\end{aligned}
$$

\section{Where:}

$\mathrm{R}_{\text {total-Djx }}$ : total rainfall at location $j$ for season $x$

$\mathrm{R}_{\mathrm{MIN}-\mathrm{Mi}}$ : minimum seasonal rainfall for crop $i$

$\mathrm{R}_{\mathrm{OPMIN}-\mathrm{Mi}}$ : minimum optimum seasonal rainfall for crop $i$

ROPMAX-Mi : maximum optimum seasonal rainfall for crop $i$

$\mathrm{R}_{\mathrm{MAX}-\mathrm{Mi}}$ : maximum seasonal rainfall for crop $i$

Seasonal rainfall suitabilities were calculated for three different starting months per season (season 1: February, March, April; season 2: July, August, September). Final seasonal rainfall suitability was then calculated taking the maximum suitability value for these three seasonal rainfall suitabilities.

3) Seasonal temperature and rainfall suitability

Crop suitability was calculated per cropping season $x$ for location $j$ and crop $i$ :

$$
\text { Suit }_{i j x}=\min \left(T_{\text {SUIT } i j x}, R_{\text {SUIT } i j x}\right)
$$

4) Overall crop suitability

Overall crop suitability is calculated by taking the average of the two seasons:

$$
\text { Suit }_{i j}=\frac{\text { Suit }_{i j 1}+\text { Suit }_{i j 2}}{2}
$$




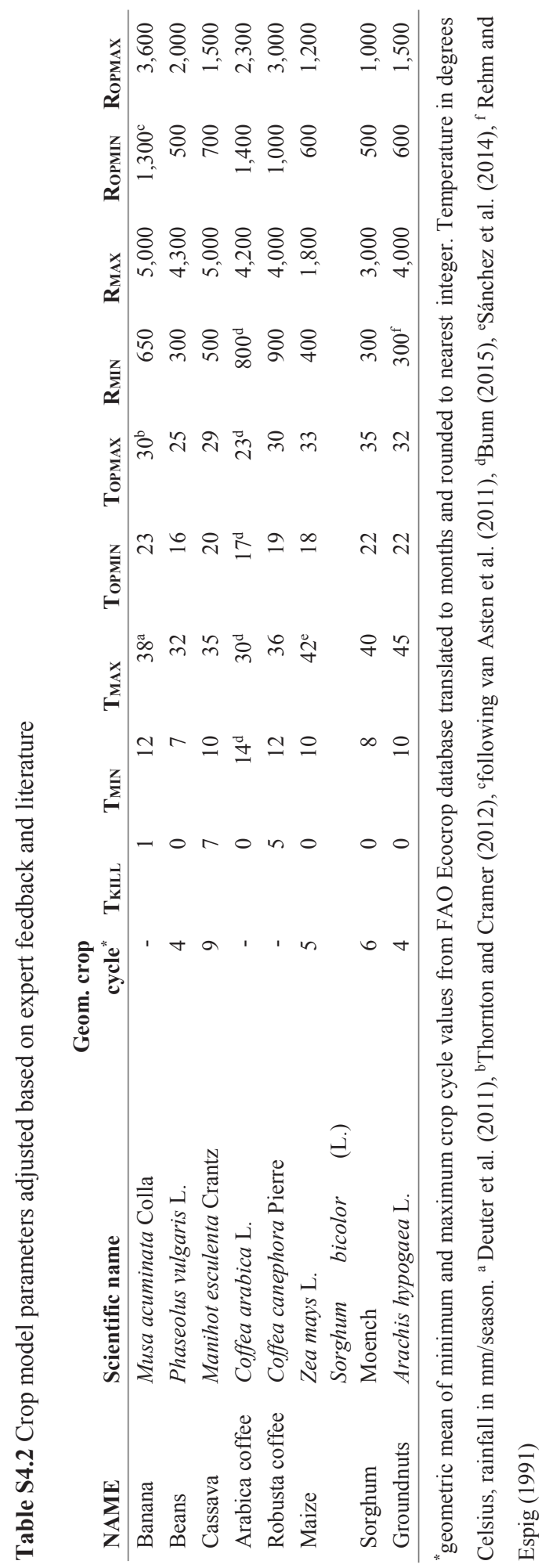



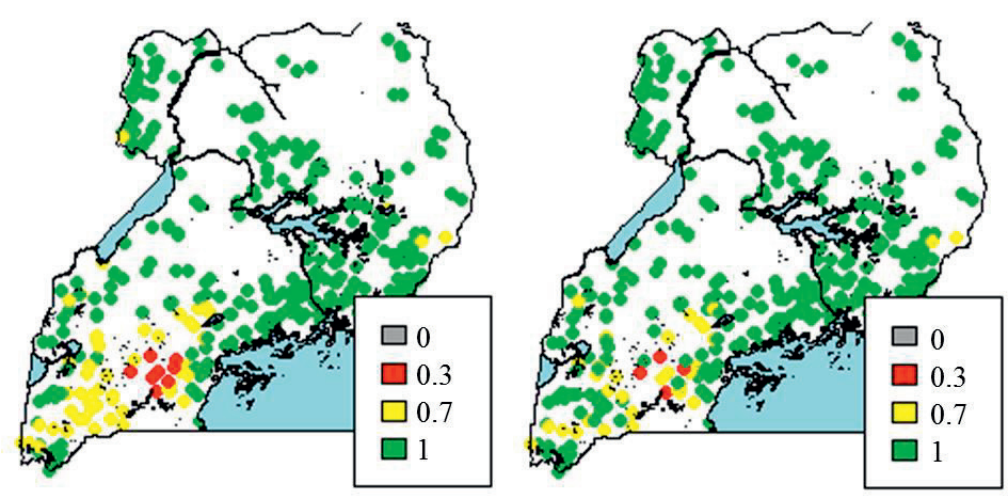

Fig S4.3 Household level crop suitability (left) and household level suitability (right) under current climate. 1 = highly suitable, $0=$ unsuitable

Table S4.4 Number of households per hotspot and class of household level suitability change

\begin{tabular}{|c|c|c|c|c|}
\hline $\begin{array}{l}\text { Household } \\
\text { suitability change }\end{array}$ & West Nile & Central north & Southwest & Central southwest \\
\hline \multicolumn{5}{|c|}{ All households in the region } \\
\hline Negative change & 15 & 25 & 84 & 108 \\
\hline No change & 167 & 226 & 132 & 244 \\
\hline Positive change & 16 & 0 & 57 & 10 \\
\hline \multicolumn{5}{|c|}{ Households $<40 \%$ off-farm income contribution to food availability } \\
\hline Negative change & 13 & 25 & 78 & 108 \\
\hline No change & 96 & 166 & 67 & 138 \\
\hline Positive change & 13 & 0 & 50 & 9 \\
\hline \multicolumn{5}{|c|}{$\begin{array}{l}\text { Households }<40 \% \text { off-farm income contribution to food availability and }>65 \% \text { key crops contribution to the } \\
\text { crop production of food availability }\end{array}$} \\
\hline Negative change & 12 & 21 & 76 & 107 \\
\hline No change & 59 & 70 & 53 & 120 \\
\hline Positive change & 13 & 0 & 48 & 9 \\
\hline
\end{tabular}


West Nile, livelihood zone UG15: West Nile Tobacco Cassava Sorghum Zone $(\mathrm{n}=80)$
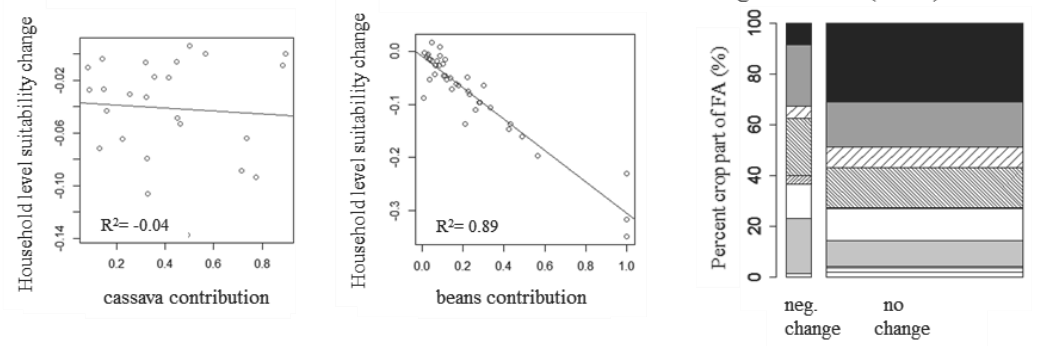

Central north, livelihood zone UG19: Mid North Simsim Maize Cassava Zone ( $\mathrm{n}=162)$
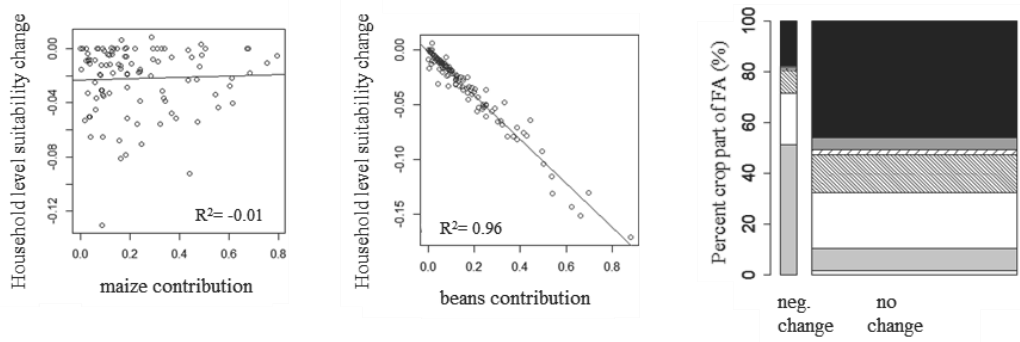

Southwest, livelihood zone UG39: Southwest Midland Banana Robusta Coffee Cattle Zone ( $\mathrm{n}=156)$
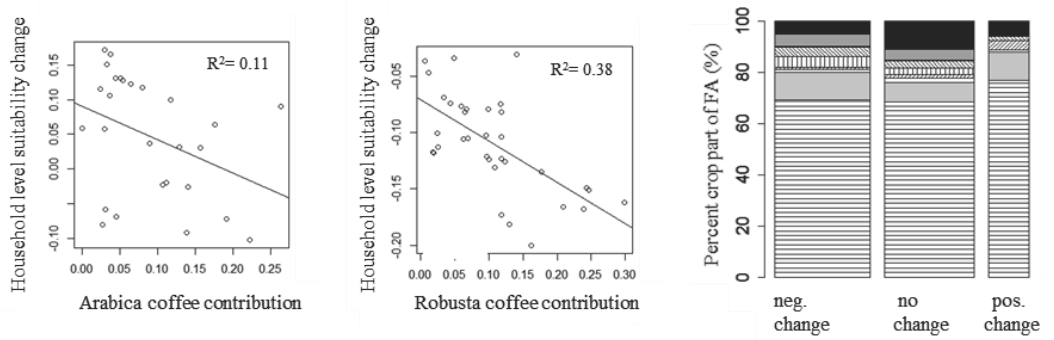

Central southwest, livelihood zone UG26: Midwest Central and Lake Victoria Crescent Robusta Coffee Banana Maize and Cattle Zone $(n=207)$
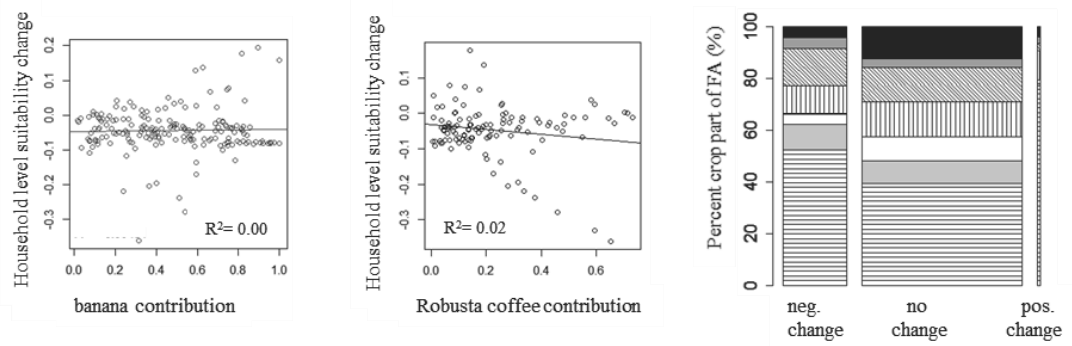

Other crops Groundnut

7 sorghum

NM Maize

|III Robusta coffee

24 Arabica coffee

Cassava

Beans

Banana

Fig S4.5 Crop contribution in relation to household crop level suitability change per hotspot. Neg. change $=$ negative change; pos . change $=$ positive change 


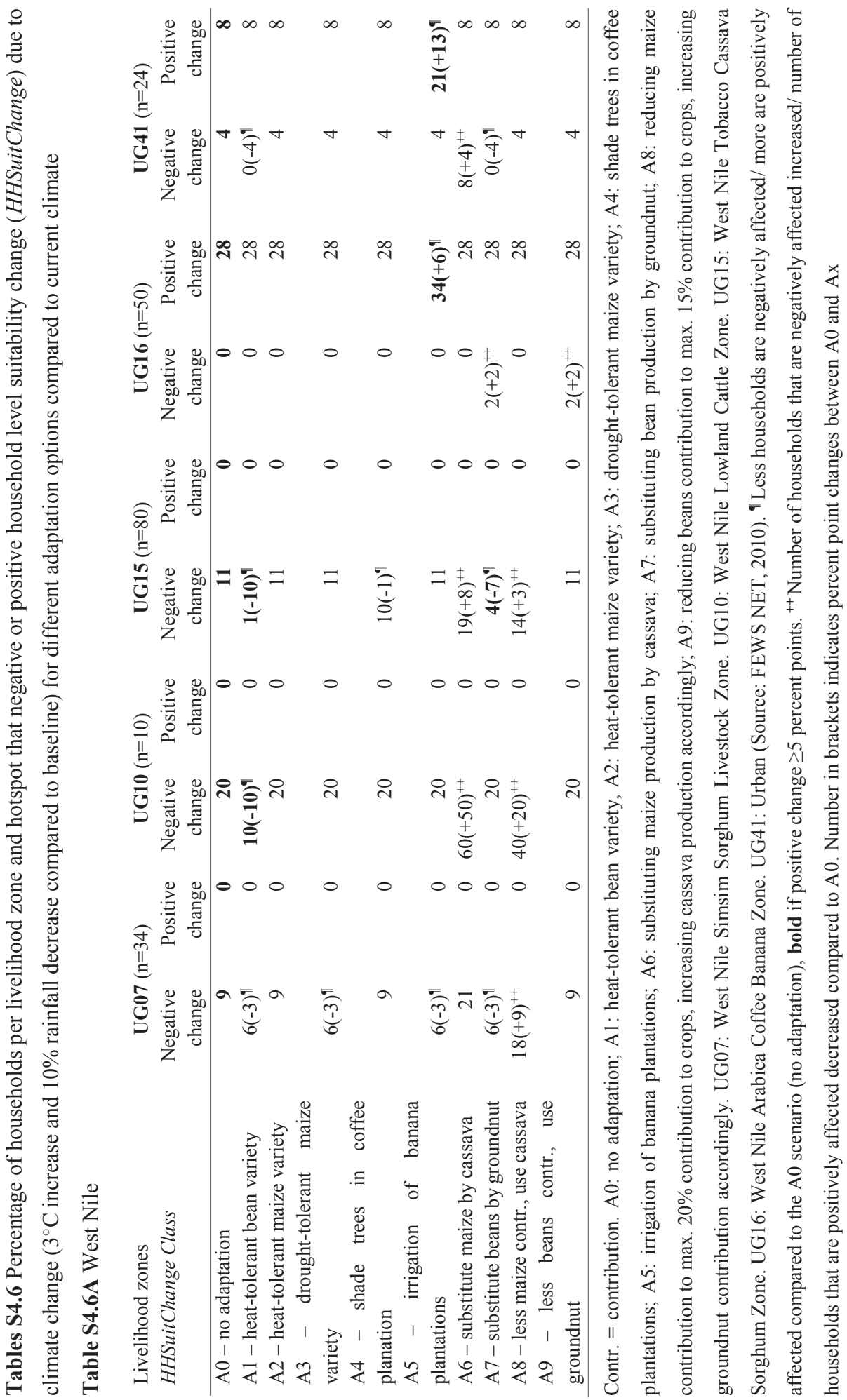




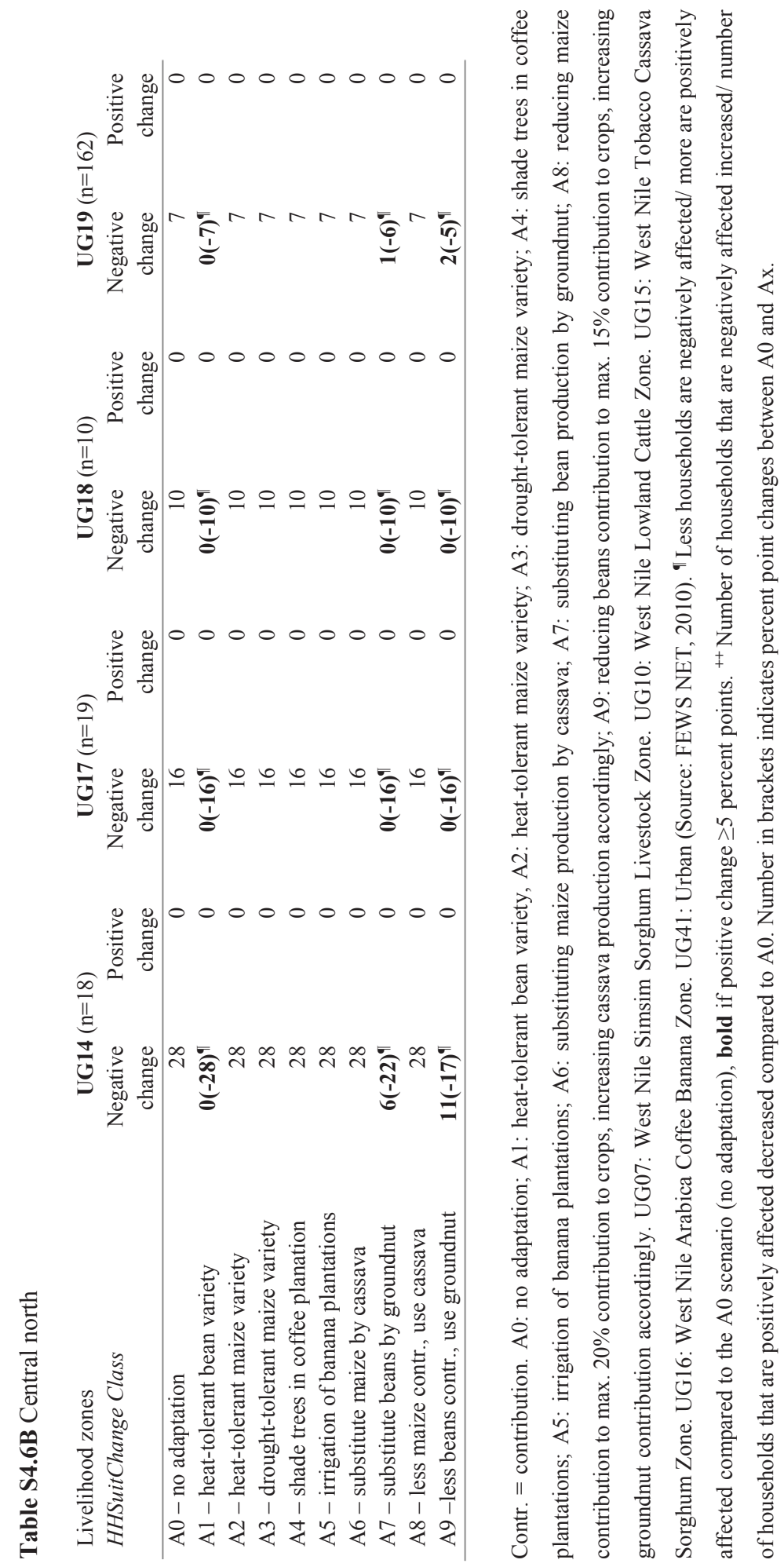




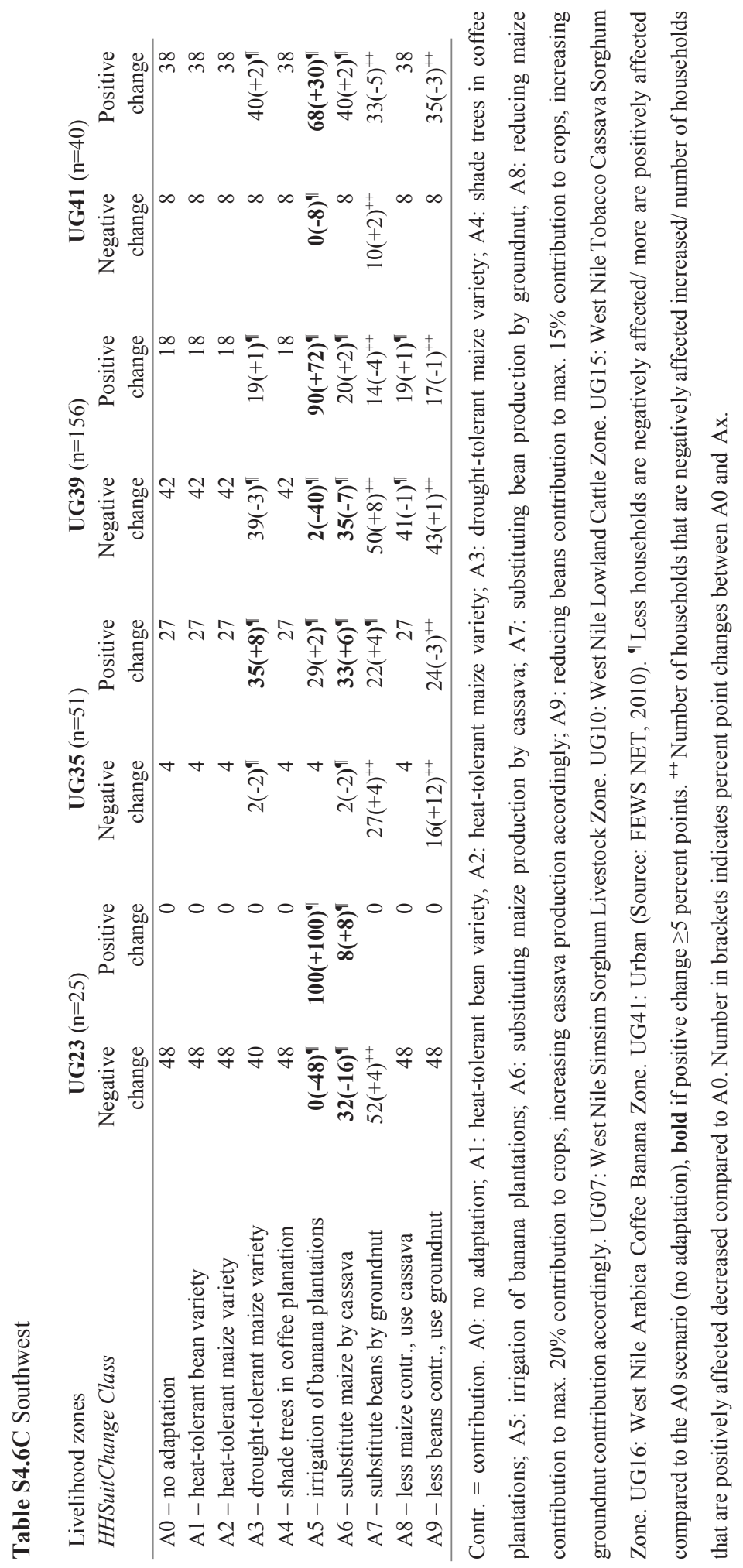




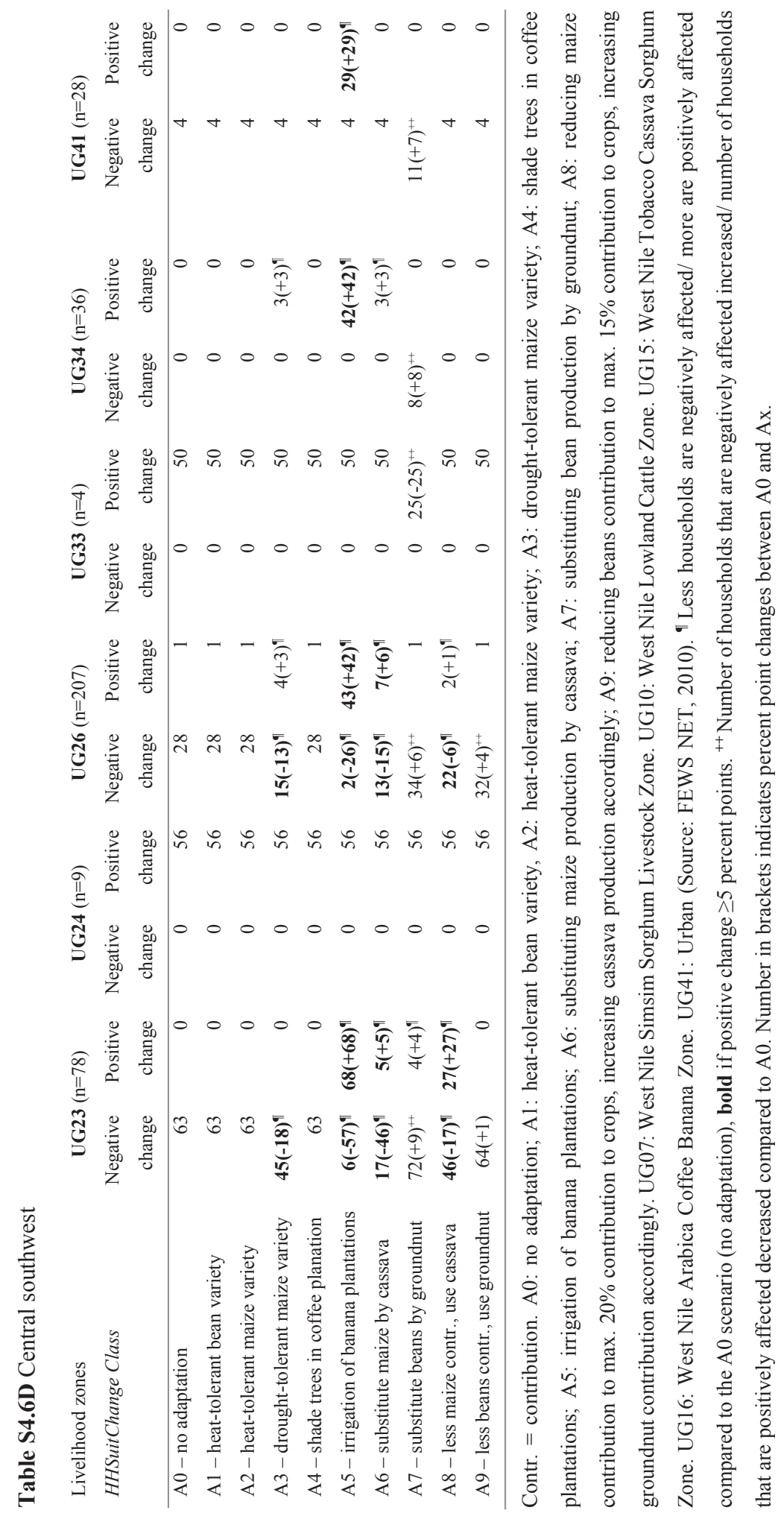





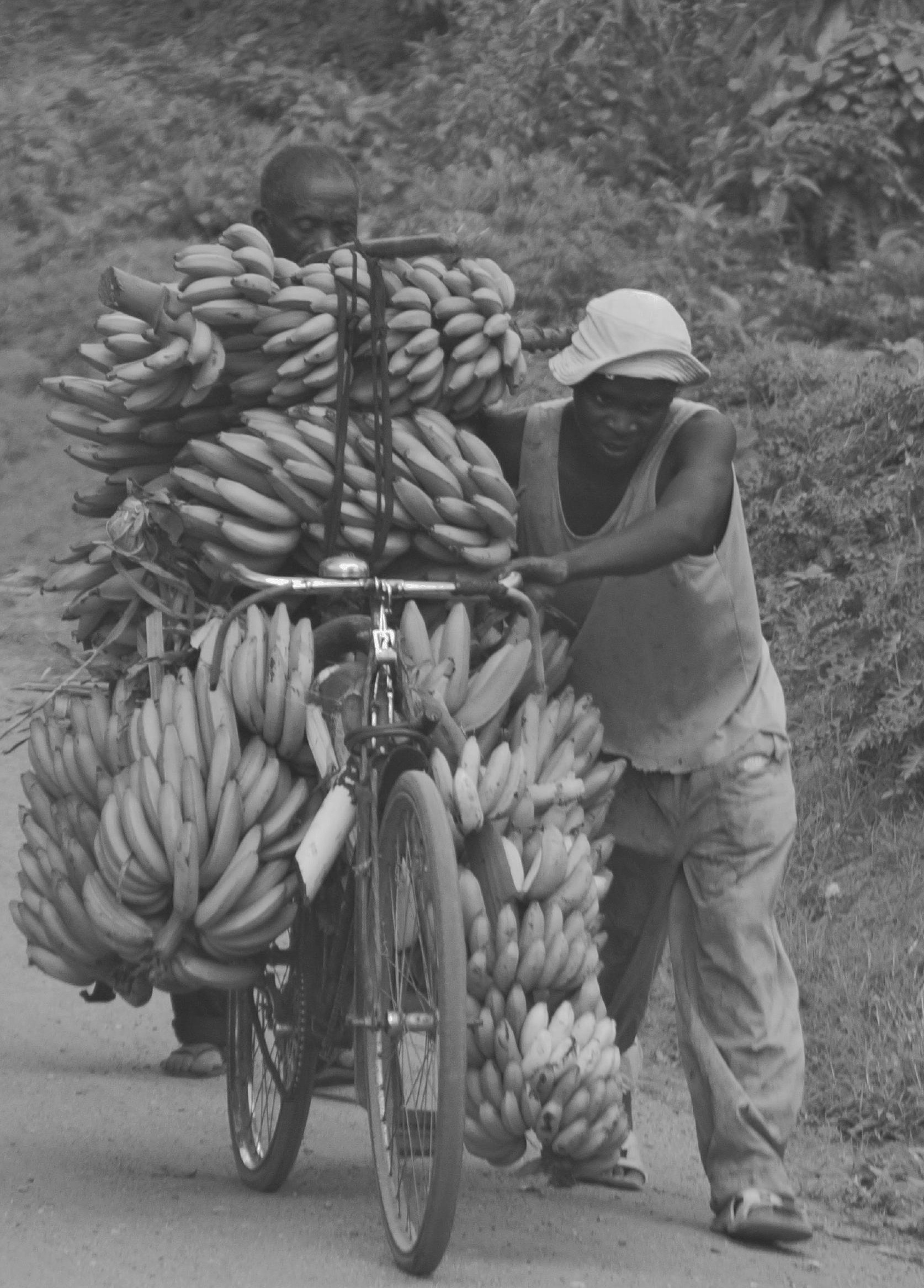




\section{Chapter 5}

\section{Production variability and coping strategies of Ugandan smallholders in the face of climate variability and market shocks}

This chapter is based on a submission for publication as:

Wichern, J., Descheemaeker, K., Hammond, J., Giller, K. E., van Wijk, M. T. (under review). Production variability and coping strategies of Ugandan smallholders in the face of climate variability and market shocks. Climate and Development. 


\begin{abstract}
Climate-related variability in crop production and market price variability affect food and income security of Uganda's rural households. We used household surveys from two contrasting sites in Uganda to quantify the relationships between crop production variability, coping strategies and household wealth. Variability of production was large for all crops with almost doubling of yields under good conditions and halving of yields in bad years. The most frequent coping strategies, for households with the resources to do so, were relying on off-farm income and sales of livestock, followed by eating less, which was common among the poorer households. However, using off-farm income or selling livestock to compensate for crop damage were unfeasible for $25-50 \%$ of the population. Few households applied ex-ante coping strategies, mostly requiring little investment such as switching crops, which was common for households with more land available. These results are alarming in the face of expected increases in clim ate variability. Interventions m ust aim at reducing households' sensitivity to variability in crop production and prices by increased preparedness to shocks, strengthening the asset base, and diversifying the livelihood portfolio. Social protection programmes are important for the poor that have no means to cushion effects from climate or price variability.
\end{abstract}

Keywords: sub-Saharan Africa, food prices, vulnerability, sensitivity, adaptive capacity, climate variability, climate change, price variability 


\subsection{Introduction}

Rain-fed agricultural production remains a key source of livelihood for the majority of households in Uganda (Berman et al. 2015), making them vulnerable to climate change and food price variability. The climate is changing with mean annual temperature increasing by $1.3^{\circ}$ Celsius since 1960 and decreasing annual and summer rainfall across Uganda (McSweeney et al. 2010; Williams et al., 2012). Expected further increases in temperature and in the frequency of extreme rainfall events will affect crop production and increase the risk of food insecurity and poverty (McSweeney et al., 2010; Ongoma et al. 2018). Climate variability and climate change influence food price dynamics (Wossen et al. 2018) bearing additional risks for these households to make a living from their agricultural production. Against this background, decision makers need to target interventions that cushion impacts on the households that are most vulnerable to climate and market shocks.

Already now households are exposed to an uncertain environment with variable weather conditions and markets with highly volatile prices for agricultural commodities (Burke et al. 2017; Thomas et al. 2007). Food production and income generation are sensitive to these variable conditions, while households respond to these risks by applying coping strategies (Below et al. 2010; P. Cooper et al., 2008; Helgeson et al. 2013). Coping strategies can be applied ex-ante (i.e. before the season begins, e.g. the choice of crops, area planted), withinseason (e.g. adjustment in pest management) or ex-post (i.e. after a shock occurred, e.g. selling livestock to compensate for a crop loss) (Cooper et al., 2008). Ex-ante strategies are applied to cope with variability in production and prices, although they depend on the farm ers' perception of weather or price variability, which can be inconsistent and lead to poor adaptation (Gbegbelegbe et al., 2018). Farmers anticipate whether a season may be good or bad for their major crops based on seasonal weather forecasts and local environmental indicators such as the onset of rain or spiritual indicators. Similarly, farmers try to anticipate price developments, for example using prices from previous seasons. Based on their experience, farmers adjust their crop management to minimise risks of production and financial losses (Thomas et al., 2007; Waha et al., 2013), depending on the type of risk faced and the household's abilities.

Vulnerability is a function of exposure, sensitivity and adaptive capacity (Schneider et al., 2007). While exposure to variability or a shock is similar for households in a particular region, a household's sensitivity (e.g. variation in crop production or incom e) and adaptive capacity (capacity to respond to the exposure by applying coping strategies) depends on the farm structure and function. The ability to respond is related to the household wealth characteristics and the socio-economic and environmental setting (Berman et al., 2015; Cooper and Wheeler, 2017). Cooper et al. (2008) highlighted that households with a strong, resilient and varied 
capital base have a strong adaptive capacity. However, many studies in the past have mainly focused on the types of strategies in general, rather than taking the diversity of households into account explicitly (e.g. Alemayehu and Bewket, 2017; Below et al., 2010; Gbegbelegbe et al., 2018). Furthermore, studies that have linked coping strategies to household wealth characteristics usually did not investigate the relation with the households' sensitivity to crop production variability (Antwi-Agyei et al. 2014; Below et al., 2010; Berman et al., 2015).

In climate change adaptation studies, variability in crop production may be estimated using crop models (e.g. Thornton et al. 2009), national statistics (e.g. Alemayehu and Bewket, 2016; Rowhani et al. 2011) or long-term trials (Traore et al., 2015). These studies are unable to disaggregate data to the household level and thus cannot use production variability to indicate sensitivity of different households and are often restricted to a limited number of major crops. Household level data enables to investigate possible links between crop production variability and reported coping strategies, and to identify both sensitivity and adaptive capacity of households depending on their wealth characteristics. Such household level analyses can inform decision makers and enable them to identify target populations for different interventions aim ing at reducing a household's vulnerability towards price and clim ate variability.

In this study we use household survey data to analyse the sensitivity and adaptive capacity of households of different resource endowment in relation to expected (ex-ante) and experienced (ex-post) variability in crop production and market prices. We used a structured questionnaire to survey 106 households in two sites in Uganda with contrasting agroecological conditions to address the following questions:

1. How does the production of major food and cash crops vary between good and bad harvests for households of different resource endowment (sensitivity)?

2. How do households cope with variability in crop production and crop prices and how does that differ between households of different resource endowment (adaptive capacity)?

3. To what extent can the coping strategies buffer the effects of crop and income losses of the households?

\subsection{Methods}

\subsubsection{Study sites}

The two sites in Uganda (Fig 5.1) were chosen because of their contrasting agroecological settings and farming systems while being representative for many mixed crop-livestock systems in East Africa. The site in Nwoya district (northern Uganda) receives 1,500 mm annual rainfall 
with an annual mean temperature of $23^{\circ}$ Celsius. The site in Rakai district (southcentral Uganda) receives $1,200 \mathrm{~mm}$ annual rainfall with an annual mean temperature of $20^{\circ}$ Celsius. Both regions experience bimodal rainfall patterns with a longer dry season in Nwoya. Average rainfall seasonality (coefficient of variation of annual rainfall) is $48 \%$ in Nwoya and $54 \%$ in Rakai (WorldClim version 1.4, Hijmans et al., 2005). Population density is about 37 people $\mathrm{km}^{-}$ 2 in Nwoya and 198 people $\mathrm{km}^{-2}$ in Rakai (source: https://www.citypopulation.de/php/ugandaadmin.php, accessed 19/06/18). Mixed crop-livestock systems are common with groundnut, beans and rice being major crops in Nwoya and the perennials banana and coffee and the annuals maize, beans and potatoes being important crops in Rakai. Smallholders in Nwoya tend to be labour-constrained, while smallholders in Rakai generally lack land. Inter-seasonal dry spells, droughts and uncertainty about the onset of rain are major challenges in both sites (Kyazze and Kristjanson, 2011; Mwongera et al., 2014; Wortmann and Eledu, 1999).

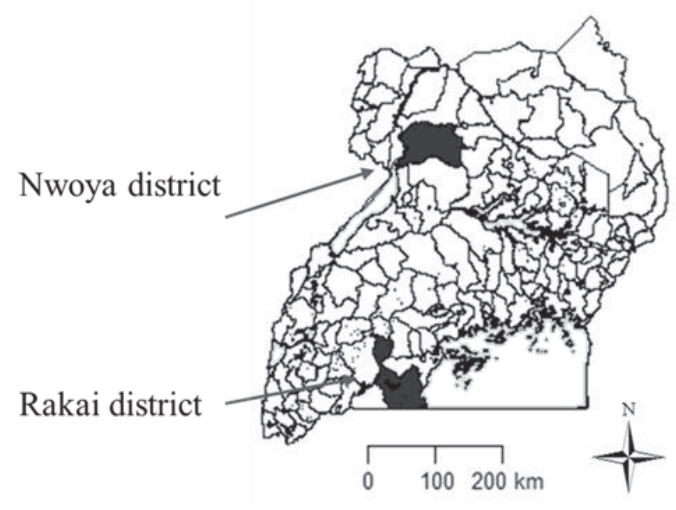

Fig 5.1 Location of the two districts where the study sites are located, Nwoya and Rakai district (Sources: UBOS 2012; WRI 2009; Thompson 2016)

\subsubsection{Household surveys}

The household survey was conducted in spring 2016 and 2017 interviewing 51 households in Rakai and 55 households in Nwoya. The survey collected information on:

- household characteristics and on- and off-farm livelihood activities,

- 'good', 'bad' and 'norm al' production of m ajor food and cash crops,

- ex-ante and within-season coping strategies that households apply to their major food and cash crops when they a) expect a good/ bad season, b) expect a high/ low price,

- ex-post coping strategies that households apply a) to get food or income after their major crops were damaged or destroyed, b) after the price of their major cash crop declined at the end of the season. 
A good/ bad season was related to expected weather patterns, for example a bad season was described by farmers as a season when rains started late or a dry spell occurred early in the season. Ex-ante and within-season coping strategies (henceforth 'ex-ante coping strategies') were defined as strategies dealing with expected production outcomes or prices and aimed at improving the harvest by crop-level interventions before or during a season. We use the term coping strategy for responses to both a good and a bad season (and to a high/ low price) and questions were asked for specific crops. Ex-post coping strategies were defined as strategies applied after the harvest was poor or the price of a major crop dropped and refers to alternative interventions, which were crop-specific or at farm level. Ex-post coping strategies related to poor harvests were associated with climate shocks such as within-season droughts that farmers recalled from the past few years. The survey round in 2017 collected information on agricultural production and wealth indicators using the Rural Household Multi-Indicator Survey (RHoMIS) tool (Hammond et al., 2016). The households were sampled from previously conducted surveys with 200 households in Rakai (Rufino et al., 2013a) and 400 households in Nwoya (Mwungu et al., 2017). A stratified random sampling design was used based on an á priori calculated food availability indicator (Frelat et al., 2016; Wichern et al., 2017) to ensure equal distribution of households of different wealth status across the sample.

\subsubsection{Indicator calculation}

We calculated six household level wealth indicators related to a household's agricultural resource base (herd size, cultivated land), food security using food availability (FA) as a proxy, poverty (gross income, total value of activities) and labour availability (household size). Rural households use livestock as a financial resource to cope with shocks such as crop failure but also for traction to substitute labour, while the size of cultivated land estim ates a households' capacity for agricultural production. Gross income is the total annual household income generated from sold farm products and off-farm activities. Because gross income underestimates the benefits that households receive from consumption of own agricultural production, we also calculated the 'total value of activities', which identifies the potential total annual income of a household if all on-farm products were sold. Both, gross income and total value of activities are standardised per household member and day and corrected by purchasing power parity $\left(\$ \mathrm{cap}^{-1} \mathrm{day}^{-1}\right)$. Household size was standardised to male adult equivalents (MAE) based on sex and age dependent food energy requirements (Holden, Shiferaw, and Pender, 2001). The food availability indicator was calculated following Frelat et al. (2016) and Wichern et al. (2017) to estimate the potential daily amount of food energy available to a MAE household member (kcal MAE ${ }^{-1}$ day $^{-1}$ ). Food availability was calculated from reported data on annual direct consumption of agricultural products (in food energy, kcal year ${ }^{-1}$ ) and from annual 
indirect consumption of potential food energy a household could obtain if it used all its income to purchase staple food (maize) (in food energy of the staple food, kcal year ${ }^{-1}$ ). Kilo-caloric energy values of the crops and livestock products were obtained from the standard product list of the US Department of Agriculture (source: ndb.nal.usda.gov/ndb/search/list, accessed 02/07/16) and from the FAO (source: http://www.fao.org/docrep/x5557e/x5557e00.htm\#Contents, accessed 02/07/16). Potential effects of erroneous prices reported for crops and livestock products were reduced using medians of reported prices. Where prices were unknown or unrealistically large, we used regional price information from Infotrade Uganda (www.infotradeuganda.com). To compare variation in good, bad and normal production between households, reported good and bad production was translated to percentage deviation from a normal production.

\subsubsection{Statistical analysis and calculations of feasible coping strategies}

Households were classified according to their wealth indicators (Table 5.1) and differences between each two classes were tested for significance using Mann-Whitney-Wilcoxon tests, Kruskal-Wallis tests and Generalized Linear Models (GLM) using binomial family. Thresholds were used to distinguish households with less than sufficient food available $\left(<5,000 \mathrm{kcal} \mathrm{MAE}^{-}\right.$ ${ }^{1}$ day $\left.^{-1}\right)$, small area of cultivated land $(<1.5 \mathrm{ha})$, herd size of less than one cow equivalent $(<0.7$ TLU) or gross income or total value of activities below a poverty threshold of $1.25 \$ \mathrm{cap}^{-1}$ day $^{-}$ 1. Households were classified for each indicator separately. Analyses were performed per region. Good production values $>400 \%$ above normal production was removed from the analyses.

Table 5.1 Wealth indicators and thresholds for household classification. Households were classified for each indicator separately

\begin{tabular}{|c|c|c|}
\hline Wealth indicator & Class 1 & Class 2 \\
\hline Food availability (kcal MAE ${ }^{-1}$ day $\left.^{-1}\right)$ & $\leq 5,000$ & $>5,000$ \\
\hline Cultivated land (ha household ${ }^{-1}$ ) & $\leq 1.5$ & $>1.5$ \\
\hline Herd size (TLU household $\left.{ }^{-1}\right)$ & $\leq 0.7$ & $>0.7$ \\
\hline Gross income $\left(\$\right.$ cap $^{-1}$ day $\left.^{-1}\right)$ & $\leq 1.25$ & $>1.25$ \\
\hline Cash value $\left(\$\right.$ cap $^{-1}$ day $\left.^{-1}\right)$ & $\leq 1.25$ & $>1.25$ \\
\hline Household size (MAE household ${ }^{-1}$ ) & $\leq 4.5$ & $>4.5$ \\
\hline
\end{tabular}

We calculated the proportion of households in Rakai and Nwoya for whom the two major expost coping strategies 'use off-farm incom e/ rem ittances' and 'sell livestock' were feasible. This was assessed from financial production losses for the regions' $\mathrm{m}$ ajor cash crops groundnut (Nwoya) and coffee (Rakai), based on regional medians of reported annual production, yield declines in a bad season and crop prices. We calculated regional quantiles for off-farm income 
and herd size to identify the share of the sample population for which the particular coping strategy was theoretically feasible. These simple calculations ignore price dynamics across seasons and effects of climate variability on production and prices of other crops, livestock and off-farm income, but provide an idea on the feasibility of major ex-post coping strategies.

\subsection{Results}

\subsubsection{Household wealth characteristics}

Overall, the medians of food availability, cultivated land area, herd size, gross income and cash value were similar for Rakai and Nwoya (Fig 5.2). However, the boxplots of these five wealth indicators were taller for Rakai than for Nwoya with larger upper quantiles. This indicates that the wealth status of the sample population in Rakai was more diverse and generally more people were better off in Rakai than in Nwoya. In Rakai, perennial and annual crops were important with banana and maize as the major food crops and coffee as the major cash crop. In Nwoya, annual crops like beans and cassava (food crops) and groundnut, rice and sesame (cash crops) were most important.
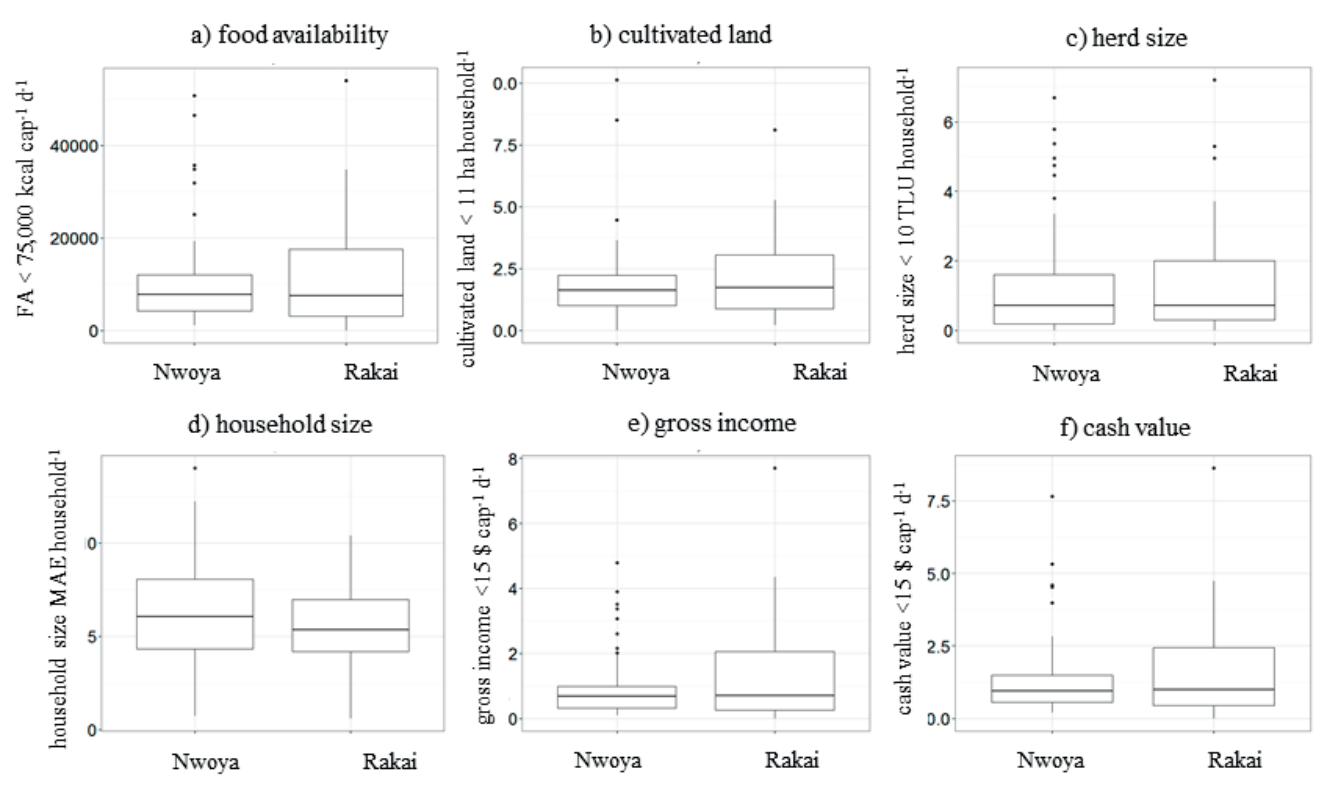

Fig 5.2 Distributions of household wealth characteristics for Nwoya and Rakai. Households with FA $>75,000 \mathrm{kcal} \mathrm{MAE}^{-1} \mathrm{day}^{-1}$, cultivated land $>11$ ha, herd size $>10$ TLU or gross income/ cash value $>15 \$$ cap $^{-1}$ day $^{-1}$ were excluded (1-2 households) 


\subsubsection{Production variability}

Reported good and bad production of major crops were strongly different from normal production for all major crops in both sites and there was a large variability in the deviation between households (Fig 5.3). Median production of all major crops was $>75 \%$ and $>50 \%$ higher for good production compared to a normal production in Nwoya and Rakai, respectively (with the exception of beans in Rakai). However, the variability in deviation from the normal between households was particularly large for groundnut and cassava in Nwoya and for banana, coffee and $\mathrm{m}$ aize in Rakai. Sim ilarly, $\mathrm{m}$ edian production of all $\mathrm{m}$ ajor crops was $\leq 50 \%$ for a bad production compared to a normal production both in Nwoya and Rakai (with the exception of cassava in Nwoya). Also here, the variability in deviation from the normal between households was large for cassava, groundnut and beans in Nwoya and for banana, coffee and maize in Rakai. The largest variability in deviation from the normal between households was observed for cassava, which was most likely related to the difficulty of farmers to quantify cassava production as a food crop that is usually harvested on demand. Few significant differences were observed in production variability between wealthier and poorer households (Supplementary materials Table S5.1) suggesting that all households were sensitive to production variability.

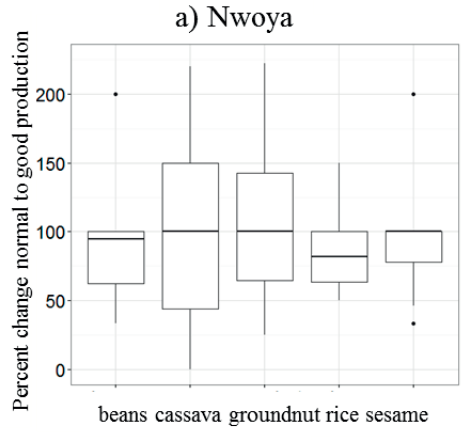

c) Nwoya

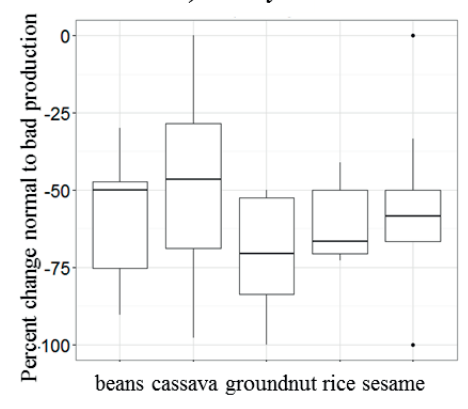

b) Rakai

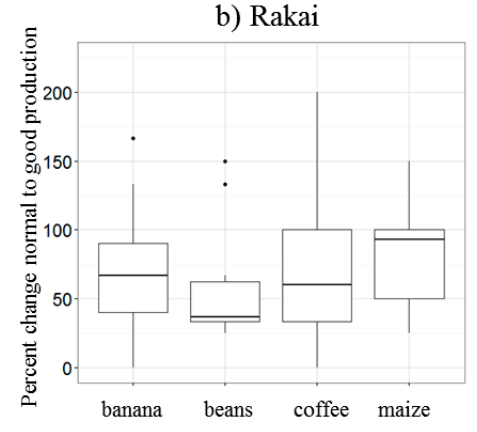

d) Rakai

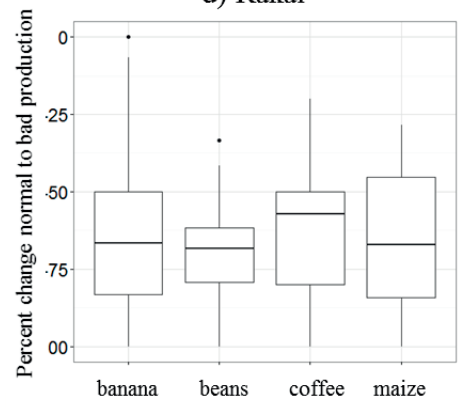

Fig 5.3 Boxplots of production change of the most common crops for Nwoya and Rakai. a) and b) normal to good production, c) and d) normal to bad production (Nwoya: $\mathrm{n}=80 ; \mathrm{n}_{\text {beans }}=24, \mathrm{n}_{\text {cassava }}=16$, $\mathrm{n}_{\text {groundnut }}=20, \mathrm{n}_{\text {rice }}=11, \mathrm{n}_{\text {sesame }}=9 ;$ Rakai: $\mathrm{n}=97 ; \mathrm{n}_{\text {banana }}=30, \mathrm{n}_{\text {beans }}=10, \mathrm{n}_{\text {coffee }}=33, \mathrm{n}_{\text {maize }}=24$ ) 


\subsubsection{Coping strategies for production or price variability}

\subsubsection{Ex-ante coping strategies}

In Rakai, 53\% of the households applied coping strategies when expecting a good season and only $28 \%$ when expecting a bad season. In Nwoya, both when expecting a good and a bad season $62 \%$ of the households ${ }^{3}$ applied coping strategies. In Rakai, households with gross income or total value of activities $>1.25 \$ \mathrm{cap}^{-1} \mathrm{day}^{-1}$ were more likely to apply strategies in a good season (Table 5.2). The most important strategy in a good season was to increase the area under the main food or cash crop, followed by increasing weeding intensity or frequency (Nwoya). Input-related strategies (e.g. increased use of pesticides, fertilizer or manure) were less common and more likely to be applied by households with herd size $>0.7$ TLU or gross income $>1.25 \$$ cap $^{-1}$ day $^{-1}$ (Nwoya) (Table 5.2, Supplementary materials Fig S5.2a).

For a bad season the main coping strategy was to decrease the area under the main food or cash crop and to use it for other crops (Supplementary materials Fig S5.2b). In Nwoya, households reduced rice, groundnut and beans to plant for example soybean, cassava or millet (Supplementary materials Table S5.3). In Rakai, households reduced maize to plant beans or beans to plant cassava. In Nwoya, households with household size $\leq 4.5$ MAE were m ore likely to apply management strategies (such as intercropping or weeding) when expecting a bad season, while households with cultivation land $>1.5$ ha reduce the area under cultivation and substitute it by another crop.

Only few households applied ex-ante coping strategies related to expected price increases or decreases (12 and 4\% respectively in Rakai, and 38 and 16\% in Nwoya). Farmers were either unable to predict prices or to act on price variability. Among households applying coping strategies if a price increase was expected, cultivating more area or increasing weeding frequency or intensity were most common (Supplementary materials Fig S5.2c). If a price decrease was expected cultivating less area and substituting the crop were mentioned (Supplementary materials Fig S5.2d).

\footnotetext{
${ }^{3}$ Eighty-five percent of these households are the same for a good and a bad season 


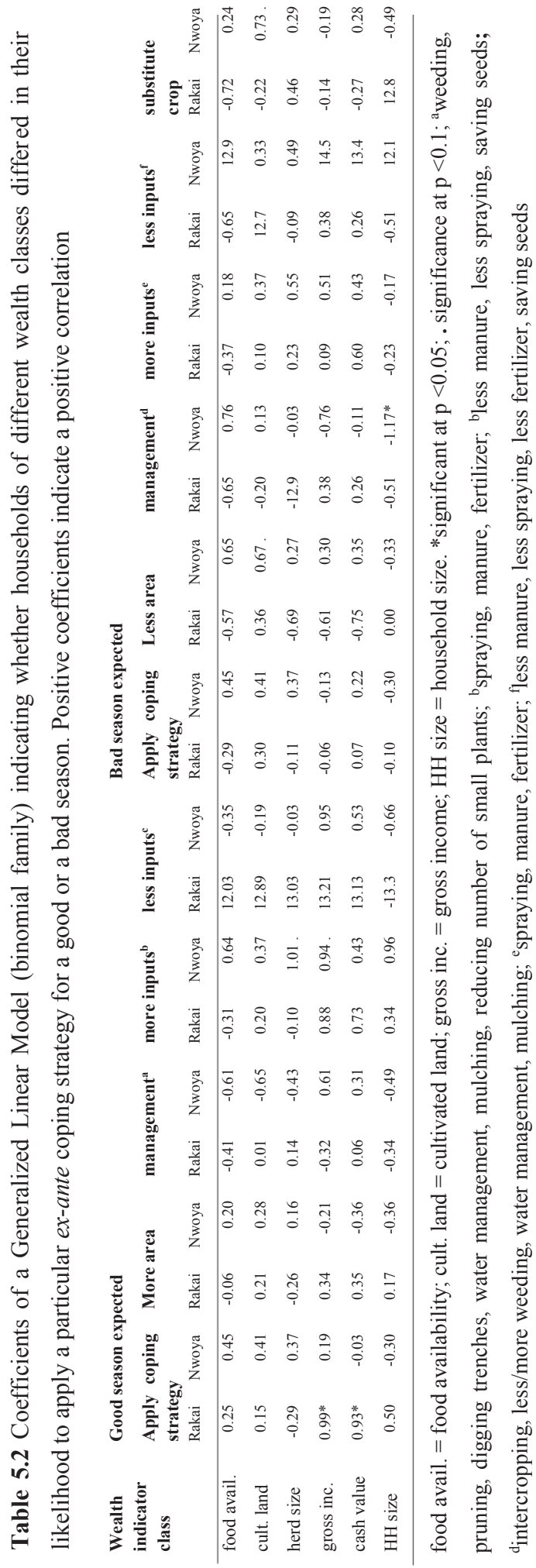




\subsubsection{Ex-post coping strategies}

When households experienced failure of their major crop(s), they most commonly relied on offfarm income and remittances (Fig 5.4). Other common coping strategies included selling livestock (such as goats, cattle, chicken, pigs, sheep), reducing food consumption, living from other crops (such as cassava, vegetables, sorghum and sweet potatoes) or livestock products, cultivating wetlands in the dry season (Nwoya) and borrowing money (Rakai). More households in Nwoya applied these three coping strategies than in Rakai with 50\% of households reducing food consumption and selling livestock and $>70 \%$ using off-farm income.

In Nwoya, reducing food consumption was a common strategy of households with cultivated land $\leq 1.5$ ha, food availability $\leq 5,000 \mathrm{kcal} \mathrm{MAE}^{-1} \mathrm{day}^{-1}$, or household size $\leq 4.5 \mathrm{MAE}$ and in Rakai by households with food availability $\leq 5,000 \mathrm{kcal} \mathrm{MAE}^{-1}$ day $^{-1}$, herd size $\leq 0.7 \mathrm{TLU}$ or gross incom e or total value of activities $\leq 1.25 \$$ cap $^{-1}$ day $^{-1}$ (Table 5.3). In both sites, households with herd sizes $>0.7$ TLU were more likely to sell livestock. In Rakai, off-farm income was more often used by households with food availability $\leq 5,000 \mathrm{kcal} \mathrm{MAE}^{-1} \mathrm{day}^{-1}$, while households with herd size $\leq 0.7$ TLU tended to more often live from other crops. In Nwoya, using off-farm income and living from other crops seemed to be strategies universally applied across households of different wealth characteristics.

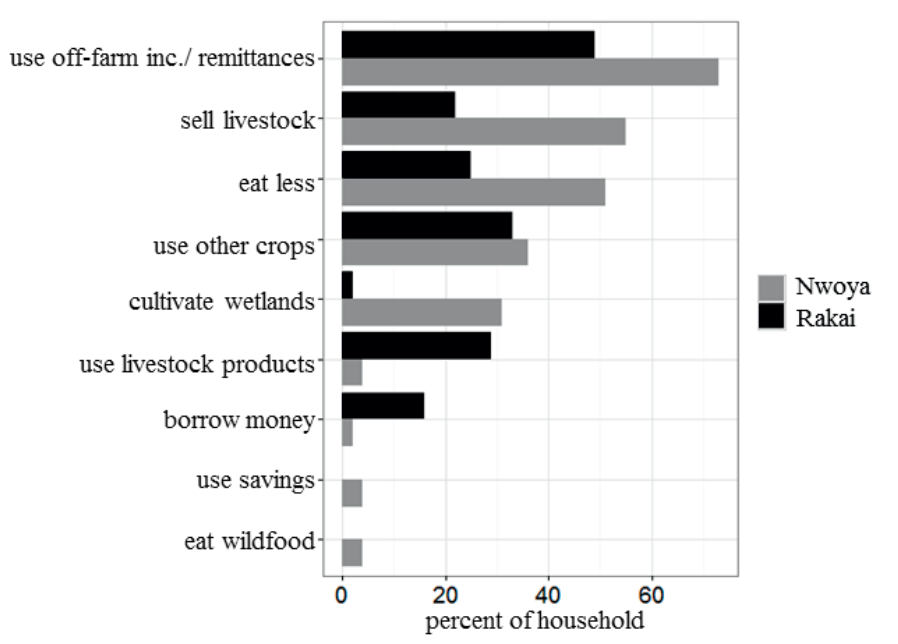

Fig 5.4 Percentage of households that applied ex-post coping strategies after damage or failure of their major crop(s) per site 
Table 5.3 Coefficients of a Generalized Linear Model (binominal family) indicating whether households of different wealth classes differed in their likelihood to apply a particular ex-post coping strategy. Positive coefficients indicate positive correlations

\begin{tabular}{lllllllll} 
Wealth indicator & \multicolumn{2}{c}{ consume less } & \multicolumn{2}{c}{ off-farm income } & \multicolumn{2}{c}{ sell livestock } & \multicolumn{2}{c}{ use other crops } \\
& Rakai & Nwoya & Rakai & Nwoya & Rakai & Nwoya & Rakai & Nwoya \\
\hline Food availability & $-1.01^{*}$ & -0.74 & -0.81 & 0.61 & 0.55 & 0.55 & 0.09 & 0.15 \\
Cultivated land & -0.48 & $-0.82^{*}$ & -0.15 & 0.12 & 0.62 & -0.41 & -0.24 & 0.40 \\
Herd size & -0.95 & -0.05 & -0.38 & -0.63 & $1.84^{*}$ & $0.79^{*}$ & -0.85. & -0.26 \\
Gross income & $-1.17^{*}$ & -0.03 & 0.49 & -0.26 & -0.41 & -0.17 & -0.20 & -0.12 \\
Cash value & -0.89 & -0.04 & 0.49 & 0.28 & -0.18 & 0.04 & -0.11 & -0.14 \\
Household size & 0.11 & -0.74 & 0.25 & -0.46 & 0.26 & 0.18 & -0.66 & -0.05 \\
\hline
\end{tabular}

*significant at $\mathrm{p}<0.05 ;$. significance at $\mathrm{p}<0.1$

At the time of harvest, when prices typically drop, $62 \%$ of the households ${ }^{4}$ in Nwoya stored their crops to wait for better prices whereas in Rakai $74 \%$ of the households sold all or part of their crops immediately. The regional differences in coping strategy were related to the differences in the crops grown. Banana, the major food crop in Rakai, cannot be stored and also coffee, the major cash crop in Rakai, was sold immediately by $>50 \%$ of the households, often fresh and to coffee traders. In contrast, most common crops in Nwoya (beans, cassava, groundnuts, rice and sesame) can more easily be stored. The differences in storage characteristics among crops largely overruled differences between wealth classes (Supplementary materials Table S5.4).

\subsubsection{Feasibility of common ex-post coping strategies}

We calculated the feasibility for households to apply the most common ex-post coping strategies 'off-farm incom e/ rem ittances' or 'selling livestock' when they experienced a bad crop harvest of their major cash crop (groundnut in Nwoya; coffee in Rakai). Using regional median values for crop production, yield decline and household income, bad production of groundnut resulted in a financial loss of $285 \$$ per household in Nwoya ( $16 \%$ of median total household income), and bad production of coffee in a $244 \$$ loss per household in Rakai (15\% of median total household income, Table 5.4). More than $50 \%$ of the households in Nwoya and more than $25 \%$ of the households in Rakai did not have enough off-farm income to compensate for this financial loss. Similarly, about three goats (equals a herd size of $0.3 \mathrm{TLU}$ ) would have to be sold to compensate for the financial loss (using a median price of $96 \$$ per goat). In Nwoya $>25 \%$ and in Rakai slightly less than $25 \%$ of the households had herd sizes $<0.3$ TLU and thus had no capacity to cope with the shock by selling their livestock.

\footnotetext{
${ }^{4}$ Sixty-five percent of these households are also among the ones applying an ex-ante coping strategy when expecting a good or bad season
} 
Table 5.4 Median production, yield decline and prices for major cash crops per site to calculate production losses. Off-farm income and livestock holding distributions per site. All values are per year

\begin{tabular}{|c|c|c|}
\hline & Nwoya & Rakai \\
\hline Major cash crop & Groundnut & Coffee \\
\hline Median annual cash crop production $(\mathrm{kg})$ & 400 & 500 \\
\hline Median yield decline in bad season compared to normal season (\%) & 68 & 56 \\
\hline Median crop price $\left(\$ \mathrm{~kg}^{-1}\right)$ & 1.05 & 0.87 \\
\hline Annual production loss $(\mathrm{kg})^{\mathrm{a}}$ & 272 & 280 \\
\hline Costs annual production loss $(\$)^{b}\left(\right.$ financial loss $\left.{ }^{\mathrm{c}}\right)$ & 286 & 244 \\
\hline \multicolumn{3}{|l|}{ Annual off-farm income distribution (quartiles, \$) } \\
\hline $25 \%$ & 87 & 42 \\
\hline $50 \%$ & 192 & 334 \\
\hline $75 \%$ & 432 & 1105 \\
\hline \multicolumn{3}{|l|}{ Livestock holding distribution (quartiles, TLU) } \\
\hline $25 \%$ & 0.19 & 0.32 \\
\hline $50 \%$ & 0.72 & 0.87 \\
\hline $75 \%$ & 1.60 & 2.17 \\
\hline
\end{tabular}

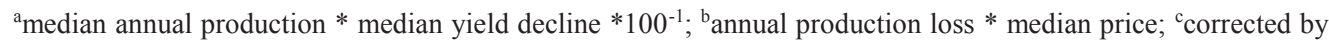
purchasing power parity

\subsection{Discussion}

Variability of crop production was large across all crops with almost doubling of yields in years of good production and halving of yields in years of bad production (Fig 5.3). This was similar in Rakai and Nwoya, despite the contrasting agroecological conditions. The most frequent coping strategies, for the households with the resources to do so, were increasing reliance on off-farm income or sales of livestock. The next most common coping strategy was simply to eat less - which was common among the poorer households (Table 5.3). More households in Nwoya applied these coping strategies than in Rakai with half of the households reducing food consumption and selling livestock and $>70 \%$ using off-farm income (Fig 5.4). This shows that households in Nwoya applied several ex-post coping strategies at the same time to cope with a climate shock. This is supported by the calculations showing that using off-farm income or selling livestock alone to compensate for crop damage were not feasible for $25-50 \%$ of the population due to having too little off-farm income or too few livestock (in both sites). Few households applied ex-ante coping strategies, and those applied required little investment such as changing cultivated area, switching crops and adjusting weeding intensity/ frequency. Households in Nwoya more often applied ex-ante and within-season coping strategies than in Rakai. 


\subsubsection{Sensitivity to production variability}

The large variability in crop production indicates that households are highly sensitive to variable environmental conditions such as weather, pests and diseases, which are likely to worsen under more extreme conditions in the future (Niang et al., 2014). However, while sensitivity to crop production was similar for different households under different agroecological conditions and farming systems, at farm level more resource endowed households might be better able to absorb the impacts of a climate shock through ex-post coping strategies.

The large difference between normal and bad production matches the small proportion of households applying ex-ante coping strategies. If more households applied ex-ante coping strategies, less households might experience a large drop in production. Therefore, enhancing the households' capacity to apply ex-ante coping strategies could reduce household sensitivity to production variability.

\subsubsection{Adaptive capacity to apply coping strategies}

Particularly the poorer households are restricted in their choice of coping strategies. Their offfarm income and livestock reserves are too small to compensate for a major (cash) crop damage. This exacerbates inequalities between wealthier and poorer households (Wossen et al., 2018). Although ex-post coping strategies can be effective to deal with shocks, they increase the vulnerability of the households by eroding their financial and physical capital base risking to drive them into long-term asset poverty traps (Wossen et al. 2018).

The large percentages of households in Nwoya using major ex-post coping strategies (using offfarm income; selling livestock; reducing food consumption) indicating that households use several coping strategies simultaneously let assume that households in Nwoya either experienced worse climate shocks or were more vulnerable to climate shocks than the households in Rakai. Latter assumption is supported by the overall smaller resource base (particularly smaller gross income and cash value) in Nwoya compared to Rakai providing smaller buffer to cope with shocks for many households. However, for drawing thorough conclusions on whether Nwoya's households are at risk of long-term asset poverty traps we need research that looks at the changes of household assets over time and in relation to specific climate shocks.

While our households relied to a large extent on ex-post coping strategies, their capacity to implement ex-ante coping strategies was limited. Pauline et al. (2016) similarly observed that 
most coping strategies used during a food shortage are short-term and reactive, directly addressing the current food crisis, rather than aiming at longer term benefits. The low application rate of ex-ante coping strategies is likely to be related to a lack of capacity of the households for two main reasons:

Households lack resources. The ex-ante coping strategies that were applied tended to require low financial investment, while costly strategies such as (increased) input use were less common. Also other studies found that while low-cost options such as changing planting decisions were implemented, large investments (e.g. agroforestry or irrigation) could only be made by few farmers (Alemayehu and Bewket, 2017; Bryan et al., 2013). Applying costly strategies can be too risky for households and, although resulting in higher yields, may not result in more profit (Traore et al., 2015).

Households lack access. Many households lack access to reliable information on seasonal weather forecasts and price developments, as well as seeds, inputs, credits, and external support, which limits their options and increases their risk to apply ex-ante coping strategies (Pauline et al., 2016). This was also observed by Bryan et al. (2013) who identified that larger adjustments such as changing crop varieties was problematic due to poor access to reliable improved seeds.

Additionally, the context determines the options for ex-ante coping strategies (Berman et al., 2015) as the comparison between Rakai and Nwoya has shown. Households in Nwoya were better able to apply ex-ante coping strategies to prepare for climate or price variability than households in Rakai, which was probably related to the different farming system characteristics. In Rakai, perennials like banana and coffee were important crops but provided limited options to apply low-cost coping strategies such as adjusting cultivation area during bad or good seasons. In Nwoya, crop systems consisted of annuals, which can more easily be substituted by other crops when expecting a good or bad season. Crops like banana and coffee can also not (easily) be stored limiting options to respond to price variability. In fact, farmers in Rakai reported that the climate was too humid for drying and storing coffee on-farm. In contrast the longer dry period in Nwoya and the characteristics of their annual crops more easily allowed households to store their crops over a longer period before selling them on the market. Despite these advantages of annuals over perennials for ex-ante coping strategies, perennial crops like banana also have advantages in farm management as they require lower expenditures (for seeds and other inputs), less labour input and have extended harvest periods offering food and income security of households throughout most of the year (Batello et al., 2013). 


\subsubsection{Vulnerability and intervention options}

Cooper et al. (2008) suggested that the ability of farmers in sub-Saharan Africa to cope with future climate change depends on an improved capacity to cope with current climate variability. Now, ten years later, our results indicate that little has changed. Households are still vulnerable to crop and price fluctuations and enhancing coping strategies for current variabilities is still urgently needed. Particularly those households with small land size, little off-farm income, small herd size and low crop diversity are likely to be the most vulnerable with limited options to cope and large fluctuations in crop production and prices.

Our results show that household characteristics and types of (ex-post) coping strategies are closely related with the wealthier households having more options to cope while the poorer are left with the option to eat less. These results open up opportunities for targeting interventions and emergency relief. Decision makers need to target interventions that i) reduce the sensitivity to fluctuations by better preparing households for expected shocks (ex-ante coping strategies), and ii) increase the household's capacity to deal with shocks without long-term degradation of the asset base (ex-post coping strategies).

To reduce the sensitivity of crop production to climate shocks, crop level management practices such as water harvesting and the use of drought-tolerant varieties are important (Cooper and Wheeler, 2017). Farmers can be cushioned against the effects of price fluctuations through promoting farmer cooperatives, improving (community-level) storage facilities or providing post-harvest loans (Beekman and Meijerink, 2010; Burke et al., 2017). Households need better access to information on weather forecasts and how to use them, on better management practices and on market price developments, to input and output markets, and to (micro)credit systems (Below et al. 2012; Cooper and Wheeler 2017; Gbegbelegbe et al. 2018; Wossen et al. 2018). Weather forecasts can be used by households to better plan farm operations and could reduce wrong perceptions on climate change (Gbegbelegbe et al. 2018). However, the case of Rakai shows also that the type of the cropping system can restrict the ability of households to respond to seasonal forecasts, especially if households are resource-limited. Communication of weather forecasts for regions like Rakai is therefore particularly important at regional policy levels to prepare food support earlier in times of shocks.

Long-term alternatives of income should be promoted to reduce the sensitivity of households to shocks by enabling them to invest in ex-ante coping strategies, and for times of shocks to avoid that households use coping strategies that erode their assets (Wossen et al. 2018). Alternative sources of income should address diversification options at the farm household level as well as alternatives for those that want to leave farming. Diversification of activities is 
important for households to cope with variability, but households need adequate access to resources such as land, inputs and markets to be able to diversify (Antwi-Agyei et al., 2014; Waha et al., 2018). Alternative income options outside farming require improved access to offfarm activities, particularly for the poorer households, and alternatives that do not depend on natural or agricultural resources to reduce vulnerability to climate shocks. Im proving a region's access to larger urban centres is important for that because it reduces the dependence on local off-farm activities that can be affected by such (local) climatic shocks (Gbegbelegbe et al. 2018). Finally, social protection programmes are important to protect the poorest from climate and price shocks as they have shown to increase food security as well as productive asset holdings and can have multiplier effects with agricultural interventions (Hidrobo et al. 2018; Tirivayi et al. 2016).

\subsection{Conclusions}

We analysed the sensitivity (variability of crop production) and adaptive capacity (capacity to respond to the exposure by applying coping strategies) of households of different wealth characteristics in relation to variability in crop production and market prices. We focused on two sites in Uganda that are contrasting in their agroecological settings and farming systems and are representative for many mixed crop-livestock systems in East Africa. The variability of crop production was large for all major cash and food crops with almost doubling of yields under good production and halving of yields under bad production indicating large sensitivity of all households. Although most common ex-post coping strategies were to use off-farm income or selling livestock, these strategies were not feasible for $25-50 \%$ of the sample population. Few households applied ex-ante coping strategies and these mainly required low investment. Household characteristics and types of (ex-post) coping strategies were closely related: Wealthier households had more options to cope while poorer households tended to be left with the only option to eat less. The low application of ex-ante coping strategies and the fact that major ex-post coping strategies were limited for large parts of the population is alarming considering that climate change studies show that weather variability and extreme weather events are expected to worsen and to jeopardise crop production. Interventions are needed that aim at reducing the sensitivity to production and price variability by better preparing households for expected shocks through improved access to information, inputs and credit. Interventions need to strengthen the household asset base to increase the household capacity to deal with shocks and variability. Social protection programmes such as safety nets or social assistance programmes are important to protect the poorest and must be synergised with the agricultural interventions. Executing this type of analysis on larger scale can provide key information for governmental institutions on which interventions are needed where and for 
whom. Further research should focus on understanding which households are more successful with their coping strategies on the long-term, how shocks affect their resource base and how fast they are able to recover from the shock.

\section{Acknowledgements}

The baseline data were provided by the International Livestock Research Institute (ILRI) for the project site in Rakai and by the International Institute for Tropical Agriculture (IITA) in Kampala, Uganda for the project site in Nwoya. Thank you to all who contributed to this research, particularly the farmers who took time out of their busy lives and to the field team, in particular Sylivia Kyomugisha, Peninnah Atwijukire, Lydia Katushabe, Lawrence Kirangwa, Sunday Amale, Walther Opio and Kamran Taherkhani who supported data collection, farmer mobilisation and translation work. Financial support was received from the Plant Production Systems research group of Wageningen University and Research and from the Climate Change, Agriculture and Food Security Program of the CGIAR (CCAFS). 


\section{Supplementary materials of Chapter 5}

Table S5.1 p-values of Mann-Whitney-Wilcoxon test to identify differences of production variability of food and cash crops between wealth classes; values $>400 \%$ (good production) removed

Good production

Bad production

\begin{tabular}{lrrrrrrrr}
\hline \multirow{2}{*}{$\begin{array}{l}\text { Wealth indicator } \\
\text { classes }\end{array}$} & \multicolumn{2}{c}{ Food crops } & \multicolumn{2}{c}{ Cash crops } & \multicolumn{2}{c}{ Food crops } & \multicolumn{2}{c}{ Cash crops } \\
& Rakai & Nwoya & Rakai & Nwoya & Rakai & Nwoya & Rakai & Nwoya \\
\hline Food availability & 0.71 & 0.34 & 0.15 & 0.97 & 0.24 & 0.73 & 0.33 & 0.20 \\
Cultivated land & 0.51 & 0.08. & 0.43 & 0.41 & 0.24 & 0.80 & 0.22 & 0.18 \\
Herd size & 0.35 & 0.36 & 0.77 & 0.90 & 0.75 & 0.67 & 0.56 & 0.79 \\
Gross income & 0.70 & 0.17 & 0.75 & 0.70 & 0.42 & 0.46 & 0.61 & 0.19 \\
Cash value & 0.88 & $0.049^{*}$ & 0.37 & 0.89 & 0.15 & 0.55 & 0.87 & 0.67 \\
Household size & 0.81 & 0.34 & 0.33 & 0.88 & 0.80 & 0.72 & 0.54 & 0.58 \\
\hline
\end{tabular}

* significant at $\mathrm{p}<0.05 ;$. significance at $\mathrm{p}<0.1$

a)

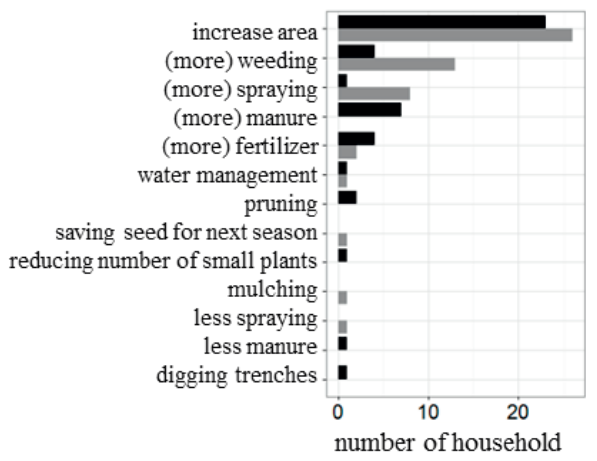

c)

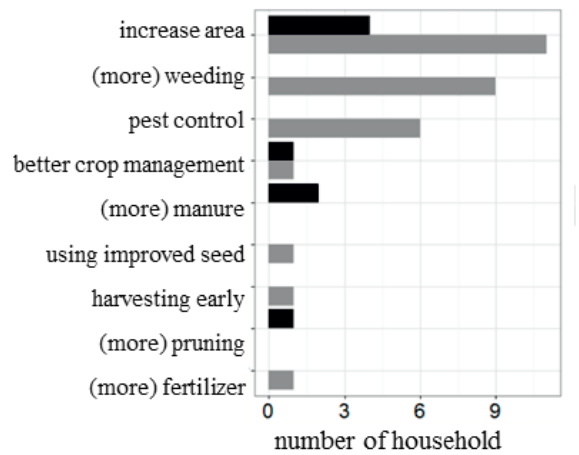

b)

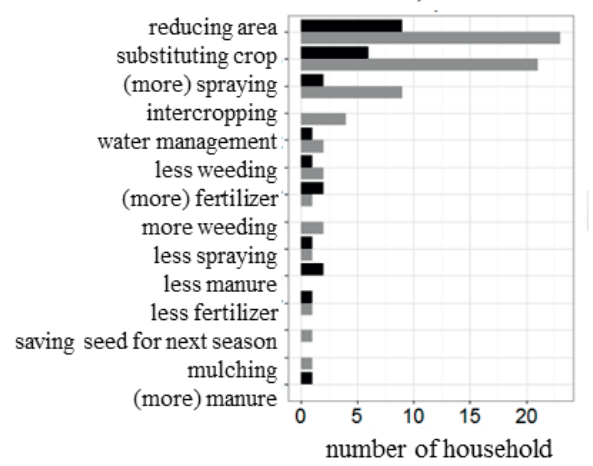

d)

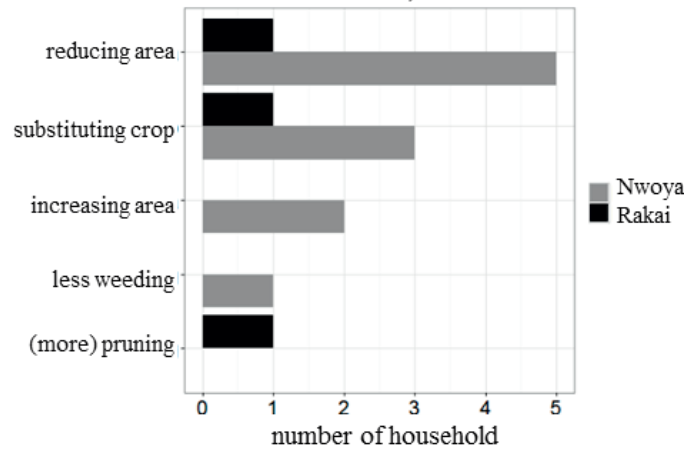

Fig S5.2 Number of household applying different ex-ante coping strategies when they expect a a) good season, b) bad season, c) price increase, d) price decrease for one of their major crops. Water management refers to for example water conservation measures 
Table S5.3 Types of crops and their substitute if bad season expected

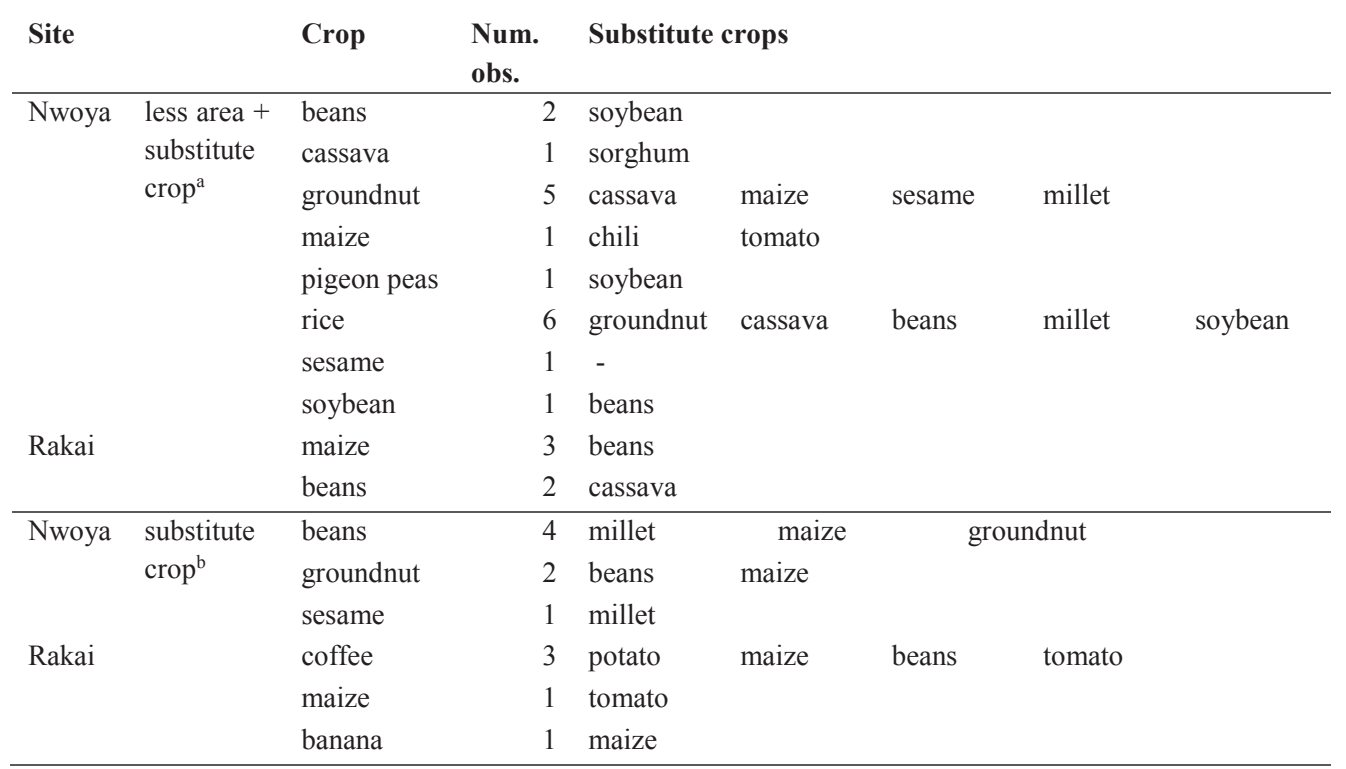

Num. obs. $=$ number of observations. ${ }^{a}$ use the area to plant another crop; ${ }^{b}$ change focus for income/ food on the substitute crop

Table S5.4 Coefficients of a Generalized Linear Model (binominal family) indicating whether households of different wealth classes differed in their likelihood to store or sell their crop immediately after harvest

\begin{tabular}{lrrrrrr} 
Wealth & \multicolumn{2}{l}{ stock harvest } & \multicolumn{2}{c}{ sell immediately } & \multicolumn{2}{c}{ stock and sell } \\
indicator class & Rakai & Nwoya & Rakai & Nwoya & Rakai & Nwoya \\
\hline Food availability & -0.29 & 0.23 & 0.21 & -0.88 & 0.13 & 0.13 \\
Cultivated land & 0.25 & 0.41 & 0.44 & -13.17 & -0.69 & -0.14 \\
Herd size & 0.40 & 0.15 & -0.04 & 0.49 & -0.25 & -0.40 \\
Gross income & 0.31 & -0.44 & -0.14 & -12.00 & -0.17 & 0.76 \\
Cash value & 0.16 & -0.28 & 0.12 & -12.12 & -0.33 & 0.64 \\
Household size & 0.70 & -0.59 & -0.08 & 12.08 & -0.29 & 0.29 \\
\hline
\end{tabular}

*significant at $\mathrm{p}<0.05$; . significance at $\mathrm{p}<0.1$ 


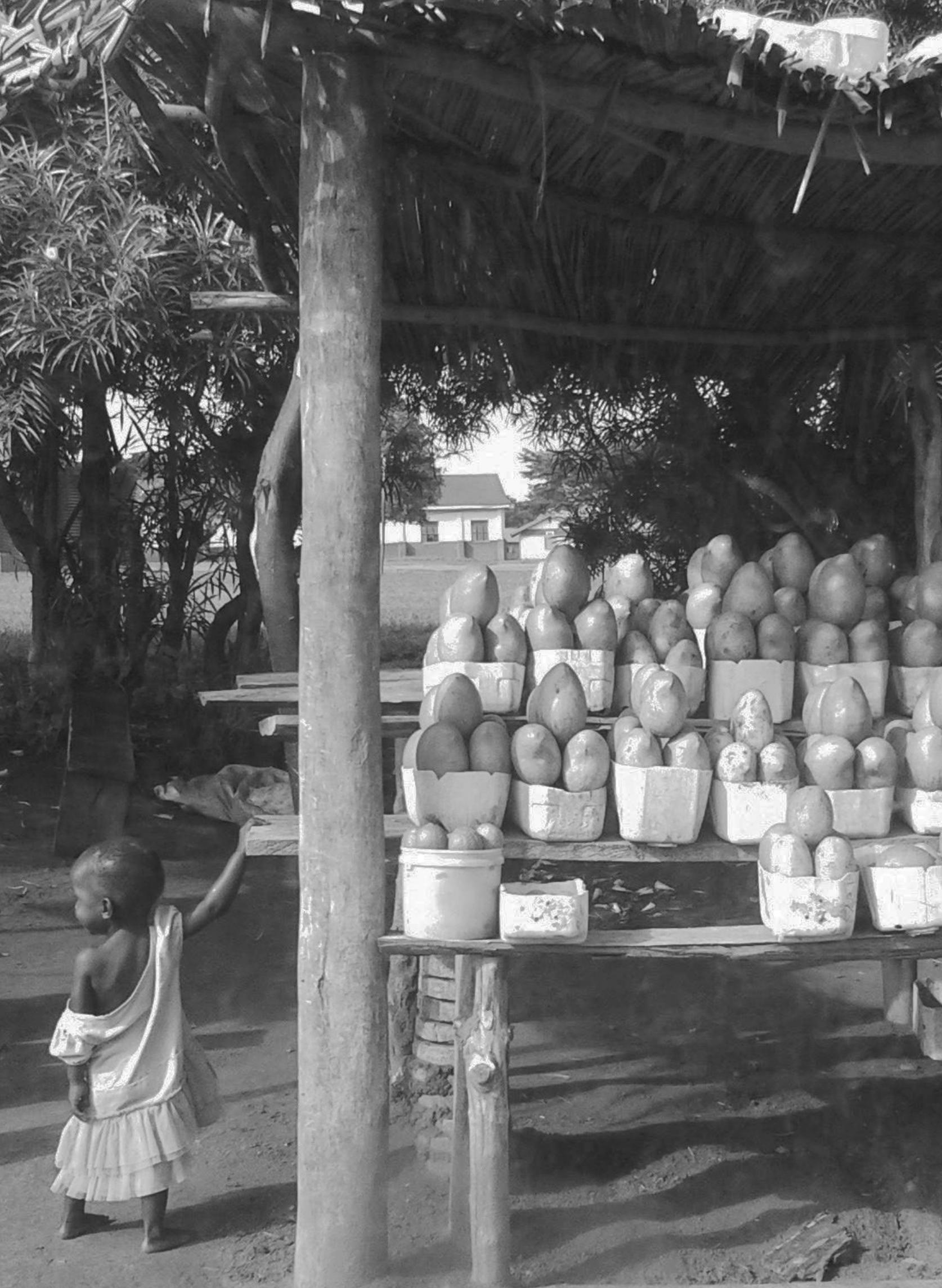


Chapter 6

General discussion 


\subsection{Introduction}

To achieve Sustainable Development Goal 2: Zero Hunger where climate change is an increasing challenge for smallholder farming, interventions are needed that target the rural households that are most at risk of being food insecure and vulnerable. A key challenge is to identify what kinds of interventions work in which regions and for which households. Blanket recommendations are often ineffective and poorly adopted (Ojiem et a. 2006; Wairegi and van Asten 2010; Descheemaeker et al. 2016b). Instead, the large diversity of households within and across regions requires interventions that are tailored to the local context. Guidance is needed on how the large diversity of households can be considered in interventions planning at higher levels (Franke et al. 2014; Descheemaeker et al. 2016b).

Many models targeting agricultural development for food security are top-down approaches ${ }^{5}$ (e.g. macro-economic models or large-scale land use models) that risk to insufficiently account for the local diversity of households. Bottom-up approaches ${ }^{6}$ (e.g. using household level information) often only go up to the community or landscape level (van Wijk 2014). Since food security and vulnerability tend to be locally driven with large variation at small scale, approaches are needed that can analyse country-wide patterns while preserving information on the local variability. In this thesis I assessed how micro-level information ${ }^{7}$ from household survey data collected across the country could be used to improve planning of interventions. The corresponding research aim was to understand within-country patterns of livelihood strategies in relation to food security and vulnerability to climate change of rural households in sub-Saharan Africa (with Uganda as an example), using micro-level information from household survey data.

In this chapter I address the research aim with the following two questions and corresponding hypotheses:

1) How can micro-level information be used for planning interventions for food security and reducing vulnerability of rural households at national and sub-national level?

(I) By preserving information on the local heterogeneity of households at broader scales, micro-level information can enhance the identification of interventions at national and sub-national levels.

2) How do livelihood activities for food security and vulnerability to climate change differ across a country and what are the implications for interventions planning?

\footnotetext{
${ }^{5}$ Approaches that use large-scale information breaking them down into smaller units to understand system processes at smaller scales.

${ }^{6}$ Approaches that use detailed information on small scale (here the household level) to understand system processes at broader scales.

${ }^{7}$ In this thesis micro-level information refers to household level information
} 
(II) Livelihood activities for food security differ across a country related to agroecological conditions allowing us to identify target areas for groups of interventions and assess for which households what kinds of interventions are suitable in these target areas.

This discussion is split into two main parts: Part 1 (section 6.2) addresses Hypothesis I, focusing at the usability of micro-level information for interventions planning and thereby at the methodological component of this thesis. I first summarise the approaches and lessons learnt from Chapters 2 to 5 (6.2.1), discuss important methodological assumptions and limitations for my approaches and suggestions for improvement (6.2.2), evaluate existing major initiatives for food security interventions planning at national to sub-national level in the context of my learning lessons (6.2.3), and finally present a stepwise approach for using micro-level information in multi-level interventions planning (6.2.4). Part 2 (section 6.3) addresses Hypothesis II, focusing at the understanding of livelihood activities in the Ugandan context and how that influences interventions planning. First, I elaborate how the work of Chapter 2 to 5 increased our understanding on the livelihood systems in Uganda (6.3.1), explain why targeting of interventions in the Ugandan context needs to account more for the local diversity than for regional characteristics (6.3.2) and demonstrate why cross-country vulnerability and adaptation assessments should be combined with contextualised research for specific areas (6.3.3). I end this chapter with concluding remarks and implications for future research (section 6.4).

\subsection{On the use of cross-country micro-level information for interventions planning}

\subsubsection{An exploration using LSMS-ISA data in Uganda}

Cross-country micro-level information can be used in different ways to inform decision making at higher levels by 1) aggregating household level information to higher (administrative) levels (Chapter 2), 2) spatially interpolating household point information (Chapter 3) or 3) identifying hotspot areas (henceforth hotspots) of household vulnerability before aggregation (Chapter 4). We used the Living Standard Measurement Study - Integrated Surveys on Agriculture (LSMSISA) of the World Bank to explore these approaches. Methods and corresponding lessons learnt per chapter are summarised in Fig 6.1 demonstrating how the learning lessons influenced the development of the subsequent chapter. It was an exercise of continuous testing and adjusting methods to use micro-level information contributing to increasingly understand the livelihood systems (the latter is elaborated on in section 6.3). In this way the thesis delivers a unique contribution to the research world where methods are often predefined and static, whereas here we adjusted our approaches based on the lessons learnt from the previous chapter(s). 


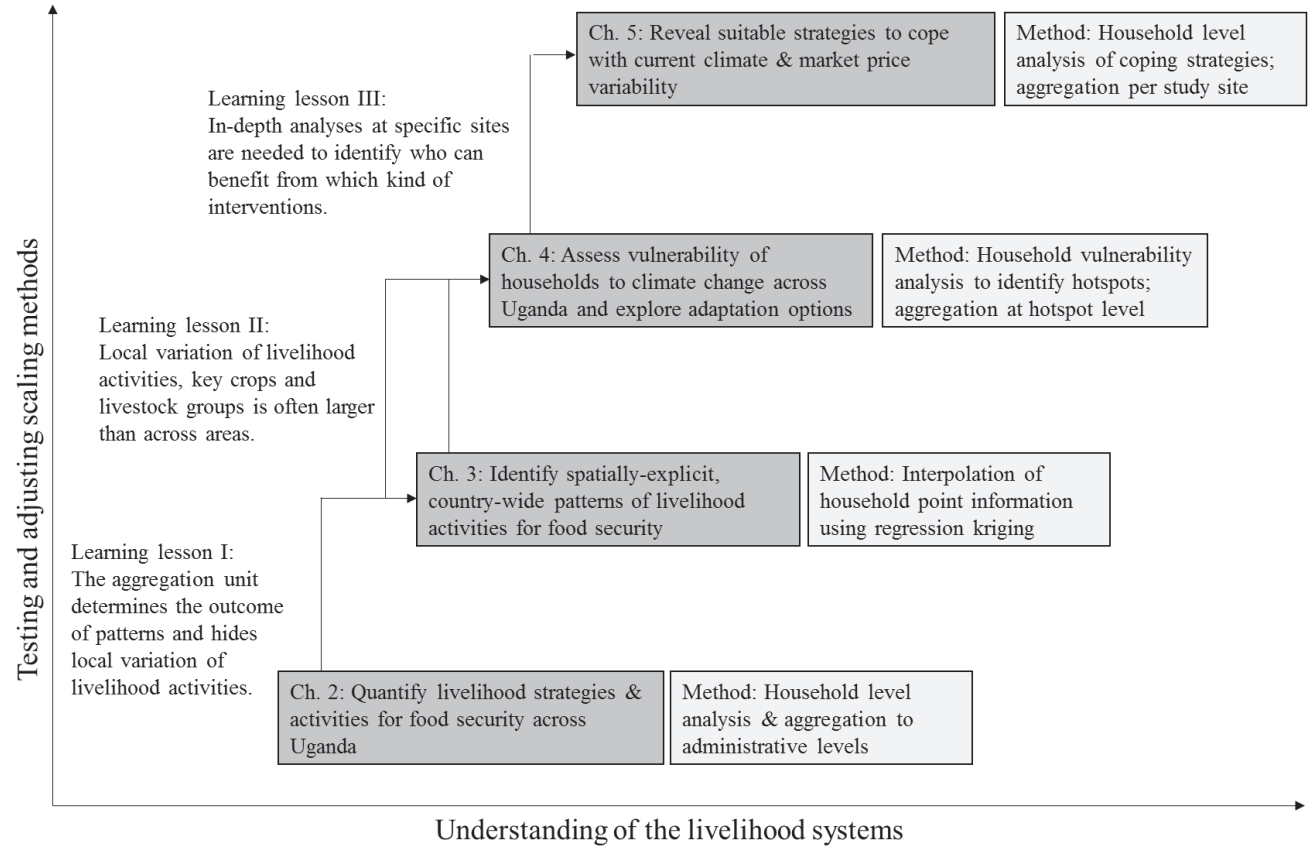

Fig 6.1 Summary of methods and learning lessons and how they influenced the following chapters (explanation in text)

In the course of testing and adjusting methods for using micro-level information, results showed that an approach that preserves information on the local heterogeneity in assessments at broader scales may improve the targeting of interventions, thereby supporting Hypothesis I. This will be illustrated in the rest of this section.

In Chapter 2 we analysed country-wide patterns of food availability and contributing livelihood strategies by aggregating household information to different administrative levels. Overall, results of food availability resembled observations from other studies (e.g. FANTA-2 2010; UBOS 2013) lending credibility to the analysis. But our approach had two major limitations: First, the LSMS-ISA survey was designed to be representative at national and regional levels and not at the district and livelihood zone levels. In that way our outcomes on these two lower levels were not representative for the population living within the aggregation units. Ideally, for such analyses below the regional level the LSMS-ISA data should be linked to census data to regain representativeness (Elbers et al. 2003). Second, aggregation to any level introduces a source of statistical bias (also called the modifiable areal unit problem, MAUP, Openshaw and Taylor (1979)) and the aggregation unit determines the outcome. To define the 'right' aggregation unit is a major challenge. While administrative levels are the levels at which decisions are made by policy makers, they are an artificial construct for variables like food 
availability or livelihood characteristics, which may be driven more by biophysical and socioeconomic characteristics than by administrative units. For that reason, studies often define livelihood or food security zones (e.g. FEWS NET and CFSVA), which may introduce bias themselves: The decision on which information is used to define such zones can influence the outcomes per zone. We approached these challenges by using different administrative and conceptual aggregation levels (national, regional, district and FEWS livelihood zone levels) and comparing the resulting patterns. Nevertheless, aggregation to a higher level always risks to hide local variability between nearby households and results in information losses (learning lesson I), which can affect decision making. For example, by identifying interventions based on aggregated (averaged) information, households with livelihood activities that are minor in their area may be disadvantaged.

Knowing about these limitations we were interested in preserving the local variability in our analyses at higher levels. To do so, we used a geostatistical approach (regression kriging) that interpolated household point information to identify country-wide patterns (Chapter 3). For many indicators the variability on short distance $(<10 \mathrm{~km})$ was much larger than across areas (learning lesson II). This was valid for food availability, for overarching livelihood activities as well as for contributions of livestock types and of key crops like maize, beans and cassava. These results suggest that information on the local heterogeneity in livelihood activities of households should be considered in decision making at higher levels (Hypothesis I).

We used the acquired knowledge from Chapters 2 and 3 to explore the potential of micro-level information in country-wide vulnerability and adaptation assessments (Chapter 4). Since aggregation to levels not matching household level variability introduced (statistical) bias and spatial interpolation hardly showed any large-scale pattern, we first analysed and mapped country-wide vulnerability at the household level (i.e. without scaling). Climate change scenarios were linked to the household level analysis to calculate potential impacts on crop production and household vulnerability. In this way we identified hotspots where more households were vulnerable to climate change. For these hotspots scenarios on climate change adaptation options were assessed to identify hotspot specific groups of potentially suitable interventions. To better understand for whom the different adaptation options are useful in which context, these assessments need to be linked to in-depth analyses (i.e. by using surveys with higher density of observations on small scale) within the hotspots (learning lesson III). This was done for two sites located within the hotspots in Rakai and Nwoya districts (Chapter 5) by identifying which current coping strategies worked for which households. 


\subsubsection{Methodological assumptions and limitations and suggestions for improvement}

This thesis is based on two underlying methodological assumptions, which influenced the overall outcomes. These assumptions were a) Existing (cross-country) household survey data can be used to identify food security and livelihood patterns and to assess household vulnerability to climate change. b) To assess the importance of livelihood strategies for food security of rural households, food security can be approximated by household food availability. I reflect critically on these two assumptions below.

\section{a) Household survey data can be used to identify wealth and livelihood patterns}

Household surveys were the source of micro-level information and the core of our analyses. Household surveys are a common tool for generating insight into rural communities (Christiaensen 2017), but suffer from diverse sources of error. Measurement errors can be introduced during design of survey and sampling, training of enumerators, and data collection and management, among others (Fraval et al. 2018b). In recent years researchers became increasingly aware of the different sources of measurement error and many systematic assessments have been conducted to determine the impact on data quality (Abay et al. 2018; Fraval et al. 2018b; Gibson et al. 2015; Zezza et al. 2016). Against this background the question arises if and how potential measurement errors may have affected our overall conclusions.

Fraval et al. (2018b) assessed the LSMS-ISA data of Uganda and revealed that $90 \%$ of the reported maize yields and $84 \%$ of reported maize prices were within credible bounds. Household head age, household size and to a lesser extent land owned and livestock holding showed consistency over time. Of lowest credibility were the composite indicators food selfsufficiency and food availability, which tended to propagate measurement errors from its contributing variables such as household composition, crop and livestock production, prices and off-farm income. These composite variables were generally sensitive to measurement errors. Lobell et al. (2018) compared self-reported yields with crop cutting measures and showed that respondents tended to overestimate yields. Such discrepancies in the LSMS-ISA data that we used probably caused some of the unrealistic results observed in the food availability analysis (see Chapter 2 Supplementary materials S2.1: Some households have crop consumptions of more than double the daily required kilocalories, suggesting overreporting or overestimation of production. Other households have food availability $<2,500 \mathrm{kcal} \mathrm{cap}^{-1} \mathrm{day}^{-1}$, quantities from which they could not live, suggesting underreporting or underestimation of production/ income). Validation of the quality of the LSMS-ISA data is difficult, but these results demonstrate that the food availability framework is sensitive to measurement errors (Fraval et al. 2018b). Against this background, the exact numbers per household should be treated with care. However, we gain confidence on overall patterns observed in the food 
availability analysis when comparing our results with those of similar analyses that use different data sources but obtain similar results (e.g. Frelat et al. 2016; Ritzema et al. 2017; Chapter 5).

Household survey tools have been subject to continuous improvement in survey design (e.g. regarding the length of questionnaires and recall periods, the use of standard indicators and of proxies), training of enumerators and data management (e.g. using electronic survey data entry). Given the growing abundance of alternative techniques such as high resolution remote sensing, mobile phones and GPS data (Abay et al. 2018; Lobell et al. 2018), triangulation of household survey data will become increasingly feasible in the future and should be used to further improve data quality. In addition, detailed information on a smaller subset of households (from those that keep records) can help to improve confidence on data quality and to triangulate and calibrate information of larger samples (e.g. the two-method measurement design, Little and Rhemtulla (2013).

\section{b) Household food security can be approximated by household food availability}

The food availability indicator (FA) by Frelat et al. (2016) was used to approximate food security in this study. Assumptions specific to the FA framework were addressed in the General Introduction (Chapter 1). Here, I critically reflect on whether the assumption that FA can be used to approximate food security is valid.

Food availability is only one of the four pillars of food security. The others are food access, utilisation and stability (FAO 2009). While households may have enough food available, dietary diversity of the food can be low due to limited access (e.g. as observed for Western Uganda in Chapter 2 comparing findings to UBOS (2013)). Also intra-annual (the stability pillar) and intra-household (the utilisation pillar) of food security can vary despite enough food being available on average over the year or at household level. Yet, food availability has shown to be an important indicator to approximate food security of rural households (Feleke et al. 2005). Indeed, triangulation of FA with two indicators of food access, the household dietary diversity score (HDDS) and the Household Food Insecurity Access Scale (HFIAS), showed that FA correlated with HDDS and HFIAS up to 5,000 $\mathrm{kcal} \mathrm{cap}^{-1}$ day $^{-1}$, while with larger FA this correlation disappeared (Hammond et al. 2016). Own comparisons of FA with HDDS for a bad month (i.e. the month of the year when a household is least food secure) and HFIAS for the data collected in Rakai and Nwoya similarly revealed a linkage between these indicators (Fig 6.2). However, despite these linkages between food availability and other components of food security, we will always need a suite of indicators if we want to capture a holistic picture of a complex, multi-dimensional concept such as food security (Carletto et al. 2013). Therefore, I propose to link FA to other dimensions of food security, wealth and vulnerability when aiming at targeting interventions for rural households. This can be done by including food security 
indicators that address other dimensions of food security (food access, utilisation and stability) such as the HDDS and HFIAS. In this way we can obtain a better picture on how livelihood activities link to food security as a whole and which interventions can work where and for whom.

To identify important livelihood activities for household food availability (as was in the focus of this study), FA has shown to be a useful concept (see for example the results in Chapter 2). By directly linking (agricultural) livelihood activities to food availability in a simple way, FA is a powerful tool to compare households across sites and countries with minimal data input. Rather than interpreting absolute FA values per household, the focus of analysis should be at the relative contributions of activities across households of different food availability.

a)

Comparing HFIAS categories and FA

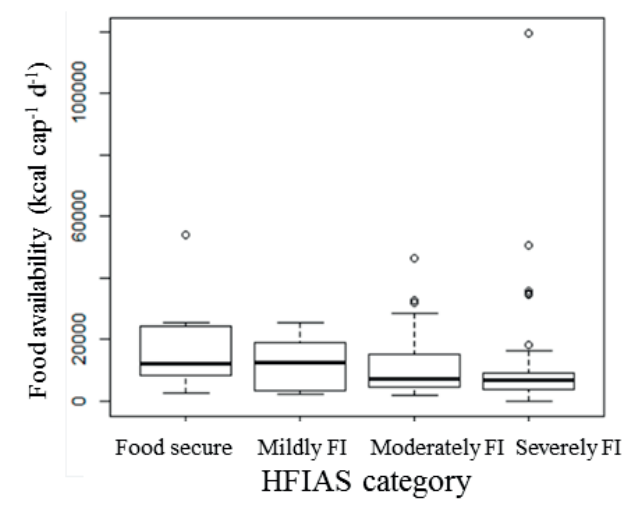

b)

Comparing HDDS score for bad month and FA

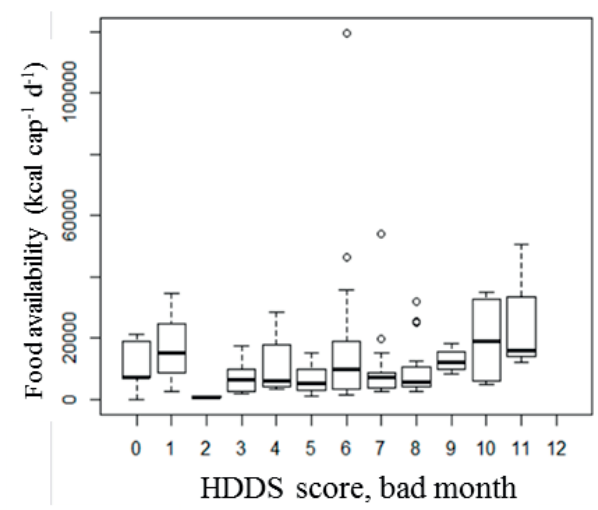

Fig 6.2 Comparison of food availability (FA) to a) HFIAS and b) HDDS scores for Rakai and Nwoya (data from Chapter 5). FI= food insecure. A bad month was understood as the month of the year when a household is least food secure and was based on interviewee perception. The HDDS ranges from 0 to 12, where 12 is the most diverse diet in which all 12 food groups that the HDDS addresses are eaten at least weakly

Besides these two major assumptions, another limitation, particularly for Chapters 2 to 4 , is that I only considered a snapshot in time (a 12 months period in 2010/11), while we know that rural household livelihoods and food security are highly dynamic and can change rapidly (Fraval et al. 2018a; Hammond et al. submitted). While it was beyond the scope of this research, I recommend for future research to add the temporal dimension to this kind of analyses to improve our understanding on patterns of change and consistency in food security, livelihood strategies and vulnerability across Uganda and other sub-Saharan African countries. 


\subsubsection{Comparing our approaches with existing initiatives on sub-national food security assessments}

Here, I explore in how far major existing initiatives to target interventions for food security and vulnerability at sub-national levels currently account for the key findings and learning lessons identified in 6.2.1. Plenty of initiatives exist that assess food security patterns at sub-national level to inform policy makers and development agencies for targeting interventions both for chronic and acute food insecurity. I assess three major ones that are contrasting in their approach: The Global Information and Early Warning System (GIEWS) of the $\mathrm{FAO}^{8}$, the Famine Early Warning Systems Network (FEWS NET) of USAID ${ }^{9}$, and the Comprehensive Food Security and Vulnerability Analysis (CFSVA) of the vulnerability and mapping methodology (VAM) of the World Food Programme ${ }^{10}$.

GIEWS was established in response to the food crisis in the early 1970s. It combines satellitebased information on land use with data on agricultural statistics, livestock, markets and weather to identify weather-related problems that could impact food security at international, national and subnational levels (Fritz et al. 2019; FAO 2019). GIEWS uses an Agricultural Stress Index, which is generated every ten days, to detect hotspot areas where crops may be affected by water stress (Fritz et al. 2019). It is a macro-level approach with limited connection to the lower (e.g. household) levels. It is a useful tool for food security assessments at the national level and above. However, it has limited power for within-country assessments of smallholder farming systems as analyses are based on country cereal balance sheets rather than taking the diverse characteristics of the farming population within a country into account.

FEWS NET was developed in response to the 1984/85 famine in Ethiopia and Sudan, where lack of timely information and interventions resulted in widespread famine (Funk and Verdin 2010). The tool combines macro-level and micro-level information aiming at forecasting acute food insecurity at sub-national levels by assessing vulnerability of livelihoods to climate, price or political shocks. Although not the focus of the tool, it is also able to monitor underlying causes of chronic food insecurity (Jones et al. 2013). Basis of the assessment is a household economy analysis for understanding local livelihood characteristics per predefined livelihood zone and household type (FEWS NET 2019). Scenario development is used to forecast acute food insecurity in different areas of a country at different points in time and regular monitoring (publishing monthly reports) enables to identify region- and time-specific threats to food security. FEWS NET uses the Integrated Food Security Phase Classification (IPC) system to identify and communicate acute food insecurity thereby providing a comprehensive picture on

\footnotetext{
${ }^{8} \mathrm{http}: / / \mathrm{www}$. fao.org/giews/en

${ }^{9} \mathrm{http}: / / \mathrm{www}$. fews.net

${ }^{10} \mathrm{https}$ //www.wfp.org/food-security/assessments/comprehensive-food-security-vulnerability-analysis
} 
food security (FEWS NET 2019; Jones et al. 2013). However, FEWS NET is a top-down oriented approach relying on predefined aggregation units (livelihood zones) and household types determined by local and national experts (FEWS NET 2019) thereby depending on the quality and accuracy of the expert knowledge. In this way it risks to overlook local diversities and households with marginal activities in an area (learning lesson II). With the purpose of early warning of famines as a result of major (regional) shocks FEWS NET targets regions rather than households. Thus while it is a suitable tool for early warning, it risks to overlook food insecure households in regions that do not stand out as critical in their assessment.

Both GIEWS and FEWS NET base their information of crop production and area on local experts (Fritz et al. 2019), whereas our approaches provide household-specific, quantitative information that helps to assess vulnerability and adaptation options for different households. GIEWS and FEWSNET are dynamic approaches providing frequent forecasts (every 10 days; monthly and timely alerts during emergency, Fritz et al. (2019)) and strongly focus on emergency support. Our approaches are retrospective, based on collected data of previous years and focused on non-crisis interventions.

CFSVA is part of the vulnerability and mapping methodology (VAM) and, contrasting to the previous two initiatives, aims at providing in-depth information on food security and vulnerability at the household level under non-crisis conditions ('baseline') (Gibson 2012, p. 448). CFSVA is grounded in the Food and Nutrition Security Conceptual Framework com bining UNICEF's Nutrition Fram ework an the (DFID) Sustainable Livelihoods Framework (WFP 2009). It provides information on the political, socio-economic and agroecological context, on markets, livelihoods and coping strategies and aims at identifying the root causes of food insecurity and vulnerability. Secondary data analyses support the household survey sampling and implementation. For example, a food security zoning is established based on homogeneous patterns of macro-level causes of food security in a country (WFP 2009), but the guidelines also give the option to use existing agroecological or FEWS livelihood zoning. Sampling of household data is based on these zones. However, the implementation leaves room for adjustment, for example in the Ugandan example regions were used instead of food security zones and the LSMS survey was the basis of the analysis instead of establishing an own 'CFSVA survey' (UBOS 2013). The food consum ption score (FSC) is at the core of the food security assessment, but the CFSVA makes use of 13 food security modules to get a comprehensive picture on the food security status of households (WFP 2009; Jones et al. 2013). CFSVA is a labour-intensive tool that combines macro- and micro-level information, while micro-level information is at the core of this initiative. The combination of the Sustainable Livelihoods Framework with a comprehensive food security analysis using micro-level information makes this initiative a strong bottom-up, micro-level information based 
approach with the potential to be linked with our approaches. In this way our approaches could be enriched by a comprehensive food security and vulnerability analysis, while CFSVA could benefit from our approaches that quantify livelihood activities for food security and that preserve local variability at higher levels.

\subsubsection{A stepwise approach for using micro-level information in multi-level interventions planning}

We know that rural households in sub-Saharan Africa are highly heterogeneous and need to be addressed with contextualised interventions (Descheemaeker et al. 2016b; Giller et al. 2011). And yet, currently existing initiatives to target food security often use aggregated or expertbased approaches such as livelihood zoning or household typology that inform decisions on zooming in (6.2.3). The results of Chapter 3 show that food security (here addressed by food availability) and related livelihood activities are more locally than large-scale driven (6.2.1). Early aggregation and top-down approaches risk to overlook the large local variability of livelihood activities and food security. Using a bottom-up approach with micro-level information as data source is an underused but promising approach that enables to preserve this local variability in the analyses at broader scales. Such an approach contributes to interventions planning by considering the large diversity of households and can improve the effectiveness and uptake potential of interventions.

Based on Chapters 2 to 5, I developed a micro-level information based stepwise approach for sub-national interventions planning. This approach can strengthen initiatives like FEWS NET that aim at improving the targeting of food security interventions for both regions and households under different scenarios (Fig 6.3). Step 1 aims at disentangling livelihood diversity at the household level by using cross-country agricultural household surveys (such as the LSMS-ISA). Per household the importance of different livelihood activities and components like key crops and livestock groups for a household's incom e and/ or food security is analysed. The conceptual framework for food availability and livelihood activities by Frelat et al. (2016) can be used as a basis. However, I recommend to link the food availability indicator (FA) to a suite of other food security indicators, e.g. the ones used in CFSVA or RHoMIS (WFP 2009; Jones et al. 2013; Hammond et al. 2016), to obtain a holistic picture of food security and vulnerability of households. Jones et al. (2013) provide questions to guide indicator selection depending on the purpose of the study. 
INPUT

OUTPUT

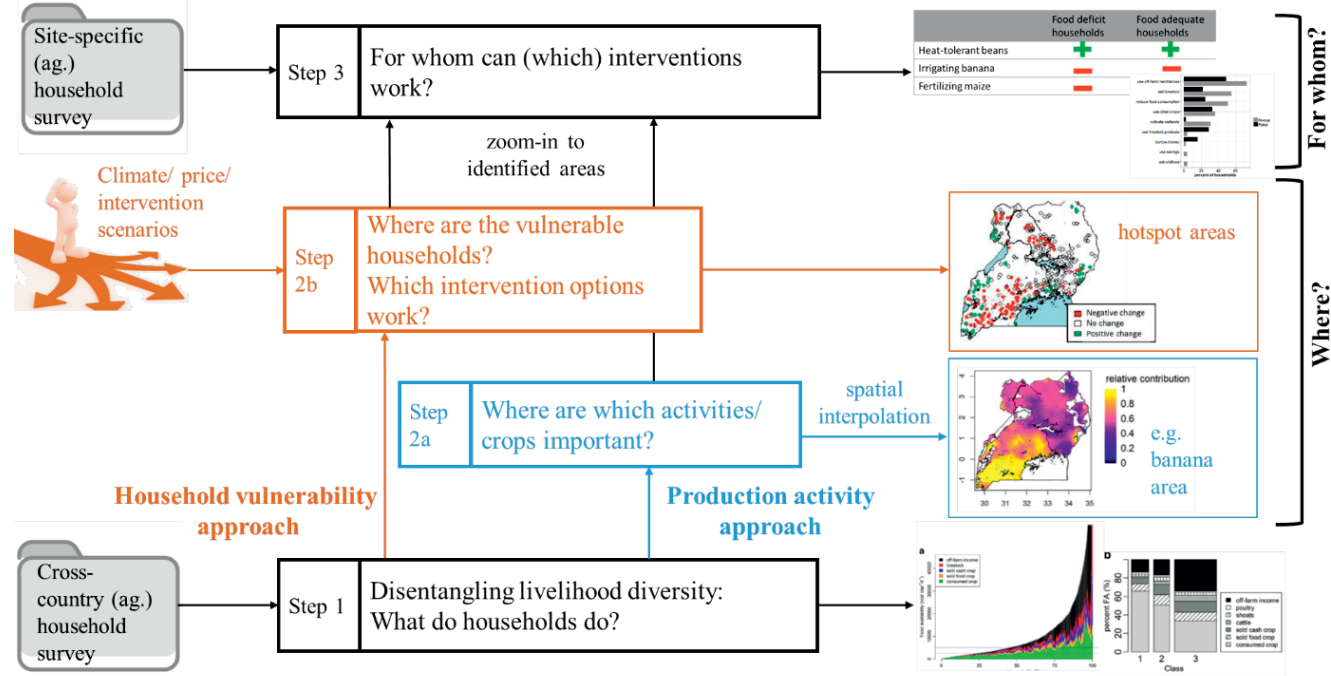

Fig 6.3 Stepwise approach using micro-level information for planning of interventions for household food security and vulnerability from national to sub-national levels. Ag. = agricultural

Step 2 aims at identifying areas (where) of households with similar production activities ('production activity approach', 2a), or of households that are vulnerable to particular events (e.g. related to clim ate change or m arket shocks, 'household vulnerabliity approach', 2b). The production activity approach aims at targeting smallholders by agricultural commodity and is relevant for questions like 'Where should we target interventions to boost national $\mathrm{m}$ aize production?'. A spatial interpolation approach similar to the one developed in Chapter 3 can be applied to identify core areas for commodity-based interventions. While we used a beta regression model, more sophisticated approaches exist using machine learning (Jean et al. 2016), spline interpolation that has shown to create better poverty maps than geo-statistical interpolation (Wong et al. 2018) or a combination of spatial interpolation models to produce better maps (Hengl et al. 2017). The household vulnerability approach aims at targeting vulnerable households and is relevant for questions like 'Where should we target interventions to help the food insecure households?' or 'Where are the households that are m ost vulnerable to tem perature increase and which adaptation options work for them ?'. Scenarioson climate, price, demography or political impacts can be used to identify hotspot areas of vulnerability. Scenarios on agricultural and non-agricultural intervention programmes can be applied to identify groups of interventions potentially suitable for different hotspots and different households. This was demonstrated for crop-related vulnerability to climate change and adaptation options in Chapter 4, but the approach presented there can be adjusted for scenarios on other agricultural and non-agricultural interventions that can be linked to the household livelihood activities (see below for an example on livestock). 
In Step 3, independent of whether the production activity or the household vulnerability approach is used, areas to zoom in for in-depth analyses are selected to identify for whom which of the previously identified interventions would work. Zoomed-in areas are based on outcomes from Step 2 where a commodity is important or where hotspots of vulnerable households are located. Site-specific household surveys can be used that provide a larger sample size at small scale than the cross-country surveys to address questions regarding the potential of different households to benefit from interventions and the capacity to adopt them. For this step additional information on the household wealth and asset base (e.g. by using the Sustainable Livelihood Fram ework, Scoones (1998)) should be included as those can influence a household's capacity to adapt and to adopt certain practices (Descheemaeker et al. 2016a).

This stepwise micro-level information based approach is relevant for rural farming households in the sub-Saharan African context. Despite some limitations (it does not identify big enterprises; it does not look at interactions between households and dynamics across years) it has the capacity to explore different questions on impacts from climate change, market shocks, population growth or a combination and on potential intervention options for food security (Table 6.1). This approach is exemplified for question 4 and discussed for question 6. 
Table 6.1 Example questions and how they could be answered with the stepwise approach

\section{Question}

1 Who would benefit from improved off-farm income options?

2 What would be the effect of crop insurances?

3 Who would be affected by a price decline of a major staple crop?

$4 \quad$ Who and which regions would be affected by climate change impacts on livestock?

5 Who would benefit from introducing improved cattle breeds?

6 Who and which regions would be affected by climate change impacts on off-farm income?

7 Who and which regions would be affected by cumulative effects of climate change on crops, livestock and off-farm income?

8 Who and which regions would be affected by population growth?

\section{Entry point in stepwise} approach

1) Household analysis

1) Household crop analysis

1) Household crop analysis

1) Household livestock analysis

2b) spatial scenarios on temperature and rainfall changes

1) Household livestock analysis 2a) spatial interpolation

1) Household analysis 2b) spatial scenarios on temperature and rainfall changes

1) Household analysis

2b) spatial scenarios on temperature and rainfall changes

1) Household crop analysis
Adjustments in stepwise approach

- off-farm income value (e.g. $+10 \%)$

- Add a crop-specific monetary compensation related to production loss

- Adjust market price for major staple crop(s) (e.g. 50\% decline)

- Identify climate suitability ranges for livestock (feed)

- Distinguish improved and local breeds

- Distinguish improved and local breeds in relation to production

- Identify types of off-farm income

- Quantify their relation to climate shocks (e.g. as suitabilities)

- Combine the crop suitability approach (Chapter 4) with \#4 and \#6

- Calculate effects of declining farm size on crop production

Who and which regions are affected by climate change impacts on livestock?

Mixed crop-livestock systems are an important form of agriculture in sub-Saharan Africa. While climate change impacts on the crop component have been at the focus of many impact assessments, knowledge gaps are still large regarding the effects of climate change on the livestock component (Descheemaeker et al. 2018; Weindl et al. 2015; Williams et al. 2018). It is important to better understand climate change impacts on livestock because of a) the multiple purposes that livestock have for these rural households such as production, insurance, financing, manure and traction, and b) the expected shift from arable farmers to livestock keepers in many areas where crop production becomes increasingly risky (Descheemaeker et al. 2018; Moll 2005; Jones and Thornton 2009). Livestock can be affected by climate change for example through heat stress, pests and diseases and the availability and quality of feed and water 
resources (Thornton et al. 2009b). Feed resources can include grass from rangelands, fodder crops, crop residues and concentrates (Valbuena et al. 2015).

Our stepwise micro-level information based approach enables assessment of potential impacts of climate change on livestock at the household level, for example by linking temperature and rainfall changes to potential effects on feed sources for livestock production. I demonstrate this for cattle and the feed sources grassland, fodder crops and crop residues in a simple example applying Step 2b (Fig 6.3). Assuming that feed systems differed across Uganda depending on agroecological conditions, I split Uganda into three zones (Table 6.2): I) Dry areas with annual rainfall $<900 \mathrm{~mm}$, in which grassland and crop residues are the main feed sources. II) Areas with annual rainfall of 900 to $1,300 \mathrm{~mm}$, in which grassland and crop residues are still most important, but fodder crops play an increasing role. III) Humid areas with $>1,300 \mathrm{~mm}$ annual rainfall and zero grazing systems in which fodder crops play a key role. While this zoning is based on annual rainfall, in reality the presence of grassland probably also depends on population densities, which should be included in more sophisticated analyses.

Table 6.2 Characteristics of the three zones to assess climate change impacts on the livestock component

\begin{tabular}{lrrr} 
& Zone 1 & Zone 2 & Zone 3 \\
\hline Rainfall mm year ${ }^{-1}$ & $<900$ & $900-1,300$ & $>1,300$ \\
Contribution of feed sources (\%) & & & \\
Grassland & 50 & 40 & 0 \\
Fodder crop & 0 & 20 & 60 \\
Crop residues & 50 & 40 & 40 \\
\hline
\end{tabular}

To assess climate change impacts I analysed changes in feed suitability in relation to temperature and rainfall changes. Grassland was represented by African foxtail (Cenchrus ciliaris), which has a broad temperature and rainfall range. Fodder crops were represented by Napier grass (Pennisetum purpureum), which requires higher annual rainfall than African foxtail (FAO 2007). Climate change impacts on crop residues were addressed based on suitability change of the key crops in a household. For this the figures on household level crop suitability from Chapter 4 were used. Following the same method as applied in Chapter 4 (section 4.2), suitability was also calculated for Napier grass and African foxtail under current and future climate conditions (future climate: $3{ }^{\circ} \mathrm{C}$ increase and $10 \%$ rainfall decline, uniformly across the country and for each month of the year). Overall feed suitability was then calculated by linking the spatially-explicit suitabilities of Napier grass, African foxtail, and crop residues (via household level crop suitability) to their zone-specific feed shares. Cattle suitability was assumed to be linked to feed suitability in a 1:1 relation. Household level livestock suitability was identified by linking cattle suitability to the contributions of cattle to the livestock component of food availability. Household level suitability subsequently linked household level 
livestock suitability to the contribution of livestock to food availability and included the contributions of crops and off-farm income to food availability as constants. Differences in household level suitabilities between future and current climate were identified per household. The calculations are explained in detail in Supplementary materials S6.1. The resulting hotspot maps of household level (livestock) suitability change (Fig 6.4) indicate where households may be most vulnerable to climate change due to larger dependence on cattle production and related climate change impacts on the feed sources.
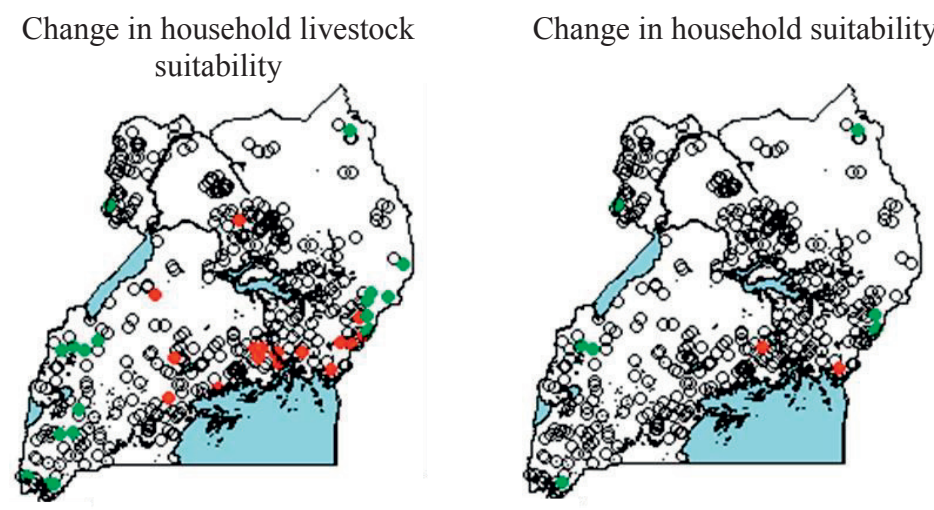

$\square$ negative change
$\square$ no change
$\square$ positive change

Fig 6.4 Changes in household level livestock suitability and household level suitability (for explanation see Chapter 4, section 4.2.4 and Supplementary materials S6.1) under a climate change scenario $\left(3^{\circ} \mathrm{C}\right.$ increase and $10 \%$ rainfall decline) compared with the current climate. These maps are based on simple examples to demonstrate the capacity of the approach described in Fig 6.3 and have not been validated

This simple example ignores other important climate impacts on livestock such as heat stress and feed quality change resulting in underestimations of overall vulnerability. Our calculations could be improved when knowledge gaps on the feed types (including dominating grassland species across Uganda) and their contributions to overall livestock fodder across Uganda are filled. In addition, climate change effects on feed sources need to be translated to effects on livestock (e.g. by using a conversion factor derived from process-based model approaches, Descheemaeker et al. (2018)). Despite these shortcomings this example demonstrated the capacity of the approach to include not only the crop component but also the livestock component of mixed crop-livestock systems allowing to approximate a 'wholefarm' perspective. 
Who and which regions are affected by climate change impacts on off-farm income?

Off-farm employment has been identified as an important livelihood strategy for food security (Chapter 2). It can also be an important strategy to cope with climate and other shocks (Chapter 5). The contribution of off-farm income to the rural economy in developing countries has been increasing steadily in the recent past (Amare and Waibel 2015; Davis et al. 2010; Barrett et al. 2001). But how is off-farm employment itself affected by climate shocks? The type of off-farm activity determines whether it is (directly or indirectly) affected by climate variability or shocks or can serve as a coping strategy. While agricultural wage is directly affected by climate variability, non-agricultural wage and self-employment may be indirectly affected by climate change. For example, in an area where many households earn most of their income from agriculture, a climate shock can result in many households being unable to use locally offered services. Still, non-agricultural wage and self-employment have shown to be an important source of income to cope with climate variability, while they are often less accessible to the poorest and most vulnerable (Amare and Waibel 2015).

Information on different types of off-farm income (e.g. agricultural wage, non-agricultural wage, self-employment) available in the LSMS-ISA dataset can be used to further break down livelihood activities for food security in Step 1 (Fig 6.3). Subsequently, we can identify where households depend on these different types of off-farm activities in Uganda (Step 2a) or where households may be most vulnerable to climate shocks due to their reliance on agricultural wage (Step 2b). Climate change impacts on agricultural wage activities could be approximated by identifying changes in crop (and livestock) suitabilities in a location. On-farm suitability changes could then be translated to changes in agricultural wage activities, for example by using a conversion factor. A major challenge in this approach is to determine a sensible conversion factor. Another challenge is that this approach cannot incorporate potential feedback loops. For example, changes in the supply of agricultural commodities can affect prices of these commodities and thus influence how vulnerable these households are. The strength of this approach is to identify where potentially vulnerable households are located. To quantify the magnitude of effects (i.e. how vulnerable are they?), in-depth and probably more data-intensive analyses are needed that address such feedback loops. 


\subsection{Lessons learnt from the Ugandan case study - What works where and for whom?}

\subsubsection{Increasingly understanding the livelihood systems in Uganda}

As illustrated in Fig 6.1, Chapters 2 to 5 have increasingly contributed to understanding livelihood systems in the Ugandan context from understanding livelihood strategies and activities for food availability (Chapter 2) to analysing the spatial context of these activities (Chapter 3) to identifying households and cropping systems vulnerable to climate change scenarios (Chapter 4) to exploring household capacities to adapt to changes under current climate and price variability (Chapter 5).

Livelihood strategies varied with household food availability in Uganda (Chapter 2). From small to large food availability major livelihood strategies changed from subsistence-oriented on-farm activities (consumption of own crops) to market-oriented on-farm activities (selling food crops, selling cash crops) to off-farm income generation. Similarly, the role of livestock changed along with food availability from small livestock and small ruminants being more important for households with smaller food availability to large livestock (especially cattle) being more important as food availability increased. Staple crops like maize, cassava and sorghum were more important for households with smaller food availability and coffee, Uganda's m ajor cash crop, was m ore im poant when food availability was larger, although these patterns differed per region (Fig 2.7 and 2.8).

Local variability in food availability and livelihood activities was often overriding large-scale differences (Chapter 3), with the two exceptions for highland banana and sorghum, two crops that showed stronger spatial patterns due to their predominance in geospatially restricted farming systems (e.g. highland banana in the humid highlands and sorghum in the dry northeast of Uganda). It was surprising that local diversity of almost all activities overruled large-scale patterns in a country like Uganda with such contrasting farming systems from humid highlands to dry savannah.

Assessments on vulnerability to climate change and adaptation options indicated that despite this local diversity hotspots of vulnerable households could be identified in the north and (central) southwest of Uganda (Chapter 4). While in the northern hotspots temperature determined vulnerability, rainfall was constraining in the (central) southwest of Uganda. Subsequently, adaptation options related to temperature (heat stress) and water conservation were identified for the most relevant crops for the four hotspots. However, which adaptation 
options are suitable for which households in those different hotspots also depends on a household's capacity to cope and adapt.

In a zoomed-in analysis in Chapter 5 we revealed that under current climate and price variability the application rate of ex-ante coping strategies of households (mostly related to climate variability) was often low and characterised by low levels of investment. This demonstrated that households tended to react to shocks rather than to take preventive action. While the production of key crops in good, normal and bad seasons fluctuated greatly for all households independent of their wealth characteristics, those households that had the means could buffer from crop production losses by selling livestock or using off-farm income. But especially the poorest in the community had few means to cope with crop production fluctuations and shocks because they lacked access and resources leaving them with the only option of eating less.

I hypothesised that livelihood activities for food security differed across Uganda in relation to agroecological conditions. This would allow to identify target areas for groups of interventions and to assess for which households what kinds of interventions are suitable in these target areas. The results of Chapters 4 and 5 indicated that a two-level approach of interventions planning (first per hotspot, then per household (type) within a hotspot) is feasible, supporting Hypothesis II. However, the results of Chapter 3 showed that livelihood activities for food security did not differ in relation to agroecological conditions, but local variability was often overriding largescale differences, thereby partly rejecting Hypothesis II. This suggests that current approaches that use regional characteristics rather than household characteristics to (pre-)define interventions, need to be revised and more attention must be drawn to the local diversity.

\subsubsection{We need to draw more attention to the for whom rather than to the where}

In current approaches for interventions planning we often find that regional (rather than household) characteristics predefine which interventions should be targeted at sub-national level. When asking the question: 'Which interventions work where and for whom ?', I claim that more attention needs to be drawn to the 'for whom' than to the 'where' than is currently done. Below I elaborate on three examples to support my claim.

\section{Example 1: Targeting food insecure households, not food insecure areas.}

Identifying and targeting food insecure areas is based on the assumption that poor and food insecure communities are clustered, for example through 'spiłbver effects' between neighbouring areas (Hyman et al. 2005). When aggregating household food availability to subnational levels, proportionally more food deficit households lived in northeastern Uganda than 
in most of the rest of the country (UBOS 2013; Chapter 2) supporting this assumption. We assumed that this was related to the low agricultural potential and remoteness of that region a drought-prone region, which has received a lot of attention from food aid programmes (e.g. FEWS NET). However, when interpolating point information on food availability across Uganda using the same data these regional patterns are overridden by large(r) local variability (Chapter 3). These results suggest that food insecure households can be found everywhere in Uganda. This matches findings from other studies (e.g. Ritzema et al. 2017; Elbers et al. 2004; Chapter 5), who observed that within-site variability is large at different locations. Against this background the question arises whether food security interventions should be based on identifying regions with larger prevalence of food insecure households at all. Such an approach has advantages for governments to distribute development support (Elbers et al. 2007) and is useful for targeting food aid for situations of acute food insecurity from regionally experienced shocks. However, it will probably not be enough for addressing chronic food insecurity on national level. Targeting based on regional characteristics of food insecurity risks to overlook food insecure households who live in areas where large proportions of households are food adequate or have food surpluses. Instead, policy information tools need to take into account the variability at the local (household) level and identify suitable intervention strategies based on the local diversity rather than on characteristics of the overall farming system or of aggregation units.

Example 2: Focusing on the 'right' crops for the 'right' households.

Besides sorghum, highland banana contribution to the crop part of food availability showed the strongest spatial structure among all interpolated variables (Chapter 3). However, highland banana contribution also had substantial variability at the local level indicating that even in areas where the majority of households cultivated highland banana, it was not the most important crop for every household. In fact, Fig 2.8 shows that the food deficient households in Western Uganda, the area where highland banana was especially dominant (Fig 3.3), depended less on highland banana for their living than the food adequate and food surplus households. Instead, cassava and maize were more important staple crops for the food deficient households. Therefore, the diversity of crops that the food insecure households depend on is relevant to consider when planning food security interventions, even if the area is dominated by highland banana. Interventions aiming at food security need to focus more on the target group (for whom) than only on the location characteristics (where). This is currently not always the case. Uganda's Agriculture Sector Strategic Plan (ASSP), which aim s at developing the agricultural sector for wealth creation and poverty reduction (Government of Uganda 2016), prioritises commodities (such as highland banana, one of the main agricultural commodities for the domestic market) for ten agricultural zones. Agricultural zone IX, located in the highland 
banana area in Western Uganda, prioritises banana, while other crops that may be relevant for the less food secure like cassava, are missing. The stepwise approach presented in section 6.2 could inform such decisions on allocation of research and extension service per agricultural commodity to better target rural farm households.

Example 3: Contextualised research can link adaptation options to potential barriers of adoption.

Our results support findings by others concluding that contextualised research is important for identifying who can benefit from which interventions (Chapter 5; Descheemaeker et al. 2016b; Vanlauwe et al. 2016). While the LSMS-ISA data helped to identify potentially suitable adaptation options for households vulnerable to climate change (Chapter 4), findings from indepth contextualised analyses suggest that the households most in need may not be able to realise these adaptation options (Chapter 5). It seems that in many cases households have no resources to implement such adaptation options and rely on social protection programmes (Hidrobo et al. 2018; Tirivayi et al. 2016). The capacity of such households to adopt these practices is often constrained by limited access to resources, weak institutional settings, poor market infrastructure and lack of supporting organisations and community awareness, to name a few (Descheemaeker et al. 2016a; Thornton et al. 2018). These constraints may explain why the adoption of adaptation options has been so low in the past decade (Thornton et al. 2018). It is important to better understand the different barriers to adoption and to include them in the impact studies (for example through contextualised research), which otherwise tend to overestimate the potential impact of adaptation options (Descheemaeker et al. 2016a; Lipper et al. 2014). In addition, there is a need to better understand how the context can be modified to provide an 'enabling environm ent' for strengthening adaptive capacity of rural households and thus enabling adoption of adaptation options (Thornton et al. 2018).

\subsection{Concluding remarks}

In this thesis I used micro-level information to identify within-country patterns of livelihood strategies and food security and to assess climate change vulnerability of rural households in sub-Saharan Africa. Micro-level information is relevant for accounting for the local diversity of households, but is an underused source for the planning of food security interventions at national and sub-national levels. My results showed that local variability of household livelihood activities and food security overrules large-scale patterns. Yet, often decisions for planning interventions for food security and climate change adaptation are based on top-down approaches using aggregated food security maps, livelihood zones or agricultural zones derived 
by national experts. These approaches risk to overlook households that are food insecure but live in areas not designated for food security interventions. They also tend to overlook households that live in regions dominated by certain crops while obtaining their food and income primarily from other crops. My findings show that there is a need to shift the focus from macro-level information to micro-level information based approaches. Such micro-level information approaches need to preserve the information on local heterogeneity of livelihood activities and food security in analyses at national and sub-national levels. A next step needs to address how the local diversity should be considered in policy decision making, which is usually based on administrative units (see Elbers et al. 2007 for discussion of an example from poverty research).

Smallholder farmers produce most of the food for their country, but are often most food insecure themselves. Therefore, food security must be addressed at two levels. National level food security focusing on domestic food production can be addressed by groups of interventions for specific target areas depending on agroecological conditions and farming systems. By contrast, household level food security must be addressed through interventions directly focusing at the households that are food insecure. Since food insecure households tend to be present in all farming systems, in-depth analyses are needed to identify which interventions can work where and for whom. The approach that I developed in this thesis (section 6.2.4) allows a fine-grained analysis to detect the food insecure and propose interventions tailored to their context, but also to target areas and households for interventions aiming at national food security. A question for future research is how this approach can be linked to datasets with a higher resolution (e.g. census data) to improve information on local variability of livelihood strategies for food security. The use of panel datasets is a good means to gain knowledge on the spatiotemporal dynamics behind these livelihood strategies.

The most food insecure households often lack resources to adopt interventions that could help them to cope with (expected) shocks or to increase food security. Instead, households often react to shocks based on the resources they have available making them vulnerable to dropping into poverty and food insecurity, especially after repeated shocks. Research aiming at identifying interventions for food security and climate change adaptation needs to address existing barriers of adoption and assess how an 'enabling environm ent' can be created to facilitate adoption of interventions.

We aspire for a world without hunger. I started this thesis with figures on current trends in food security in sub-Saharan Africa and these were sobering. Climate change, conflicts and population growth are said to have contributed to an increasing number of food insecure persons on this subcontinent in the past years. Meanwhile sub-Saharan Africa's population continues to 
rapidly increase and the growth rate is not expected to slow down any time soon (Gerland et al. 2014). For example Uganda, the case study country of this thesis, is facing one of the fastest growth rates in the region $(3.3 \%)$, while its population is one of the youngest (half of the population $<15$ years old) suggesting that the growth rates will continue to increase. To feed a growing population in the light of other pressing challenges, such as climate change, urbanisation, resource degradation and competition for food and non-food products, requires more food to be produced. Smallholder farming is still the driving engine of food production in sub-Saharan Africa. Crop yields are often low suggesting a large potential to increase productivity on African soils. However, without interventions that account for the local diversity of household livelihoods and context specific enabling conditions, many efforts will not reach their full potential. The approach introduced in this chapter can investigate such intervention options under different scenarios of future change at (sub-)national levels thereby contributing to answering the question of how to achieve zero hunger by 2030 in the context of sub-Saharan Africa. 


\section{Supplementary materials of Chapter 6}

S6.1 Calculations household level suitability for livestock

\subsection{Calculations of suitability of Napier grass and African foxtail}

See Ecocrop model descriptions in section 2.2.4.

\subsection{Calculating feed suitability per household}

HHFeedSuit $_{j}=\sum_{i}\left(\right.$ FeedSuit $_{i, j} \times$ FeedContr $\left._{i, j}\right)$

Where HHFeedSuit H $_{j}$ : Household level feed suitability of household $j$; FeedSuit $t_{i, j}$ : suitability of feed crop $i$ (Napier grass, African foxtail or crop residues ${ }^{11}$ ) at the location of household $j ;$ FeedContr $_{i, j}$ : contribution of feed crop $i$ to overall cattle feed of household $j$.

\subsection{Calculating household level livestock suitability per household:}

HHLvstSuit $_{j}=$ HHFeedSuit $_{j} \times$ Contr $_{\text {cattle }, j}+1 \times$ Contr $_{\text {other livestock }, j}$

Where HHLvstSuit, ${ }_{j}$ : Household level livestock suitability of household $j$; Contr cattle,$j$ : contribution of cattle to the livestock production of FA of household $j$; Contr $r_{\text {other livestock, }, j}$ : contribution of other livestock to the livestock production of FA.

\subsection{Calculating household level suitability per household:}

HHSuit $_{j}=$ HHLvstSuit $_{j} \times$ Contr $_{\text {livestock }, j}+1 \times$ Contr $_{\text {other activities }, j}$

Where HHSuit, ${ }_{j}$ : Household level suitability of household $j$; Contr livestock,,$j_{j}$ : contribution of livestock production to FA of household $j$; Contr $_{\text {other activities }, j}$ : contribution of other activities to FA.

1.5 Calculating change in household level suitabilities per household:

$$
\begin{aligned}
& \text { HHLvstSuitChange }_{j}=\left(\text { HHLvstSuit }_{f u-c l, j}-\text { HHLvstSuit }_{c u-c l, j}\right) \\
& \text { HHSuitChange }_{j}=\left(\text { HHSuit }_{f u-c l, j}-\text { HHSuit }_{c u-c l, j}\right)
\end{aligned}
$$

Where HHLvstSuitChange $e_{j}$ : Change of household level livestock suitability of household $j$; HHSuitChange $_{j}$ : Change of household level suitability of household $j$.

\footnotetext{
${ }^{11}$ For crop residues household level crop suitability HHCropSuit from Chapter 4 was used.
} 



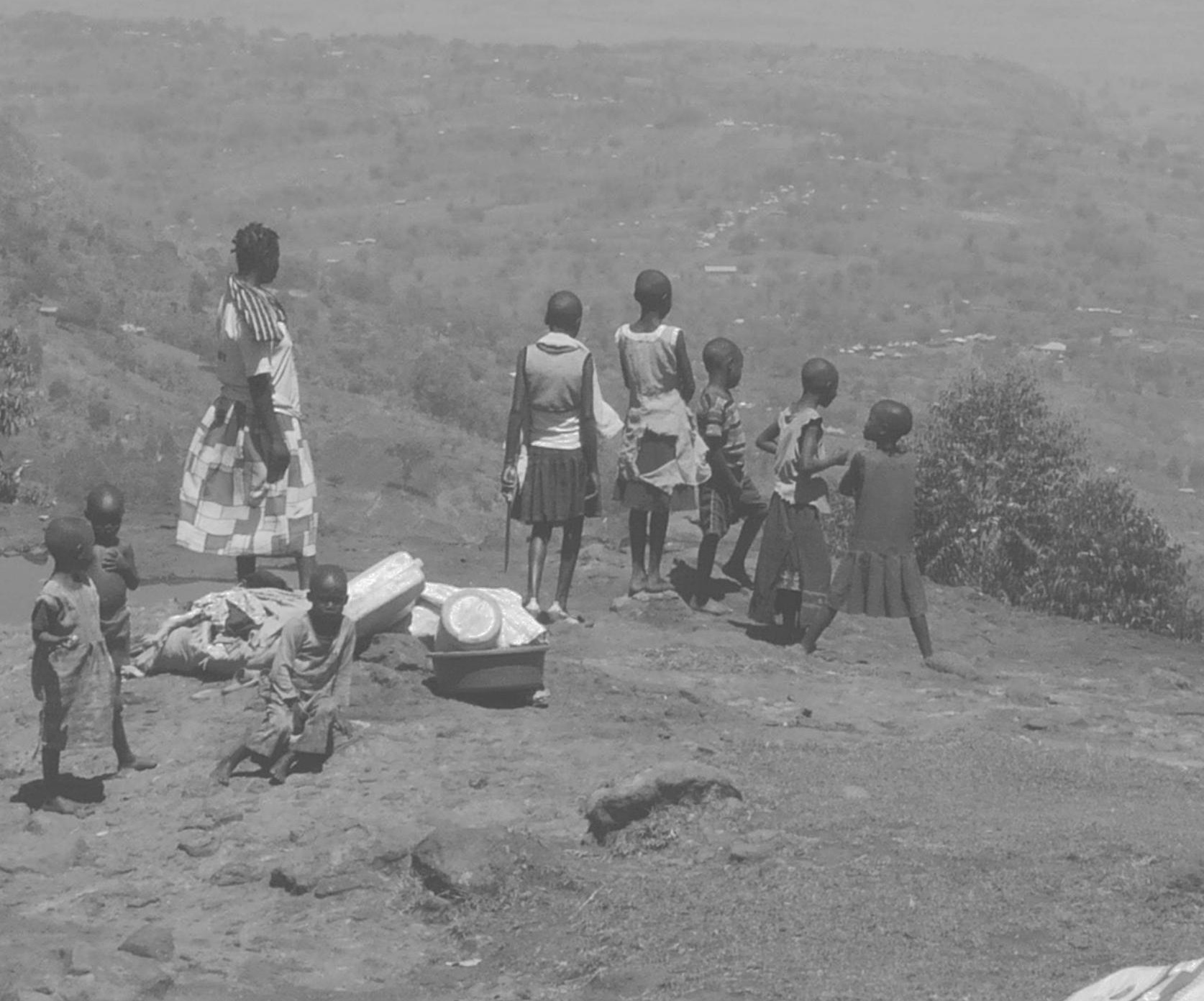




\section{Bibliography}

Abay, K. A., Abate, G. T., Barrett, C. B., and Bernard, T. (2018). Correlated Non-Classical Measurement Errors, 'Second Best' Policy Inference and the Inverse Size-Productivity Relationship in Agriculture. IFPRI Discussion Paper 1710. Washington, D.C.: International Food Policy Research Institute (IFPRI).

Adhikari, U., Nejadhashemi, A. P., and Woznicki, S. A. (2015). Climate change and eastern Africa: a review of impact on major crops. Food and Energy Security, 4(2), 110-132, doi:10.1002/fes3.61.

Affognon, H., Mutlingi, C., Sanginga, P., and Borgemeister, C. (2015). Unpacking Postharvest Losses in Sub-Saharan Africa: A Meta-Analysis. World Development, 66, 49-68, doi:10.1016/j.worlddev.2014.08.002.

Agrawal, A., and Perrin, N. (2008). Climate adaptation, local institutions and rural livelihoods. IFRI Working Paper, Wo8I-6: International Forestry Resources and Institutions Program, University of Michigan.

Alemayehu, A., and Bewket, W. (2017). Smallholder farmers' coping and adaptation strategies to climate change and variability in the central highlands of Ethiopia. Local Environment, 22(7), 825-839, doi:10.1080/13549839.2017.1290058.

Alemayehu, A., and Bewket, W. (2016). Local climate variability and crop production in the central highlands of Ethiopia. Environmental Development, 19, 36-48, doi:10.1016/j.envdev.2016.06.002.

Amadou, H., Dossa, L. H., Lompo, D. J. P., Abdulkadir, A., and Schlecht, E. (2012). A comparison between urban livestock production strategies in Burkina Faso, Mali and Nigeria in West Africa. Tropical Animal Health and Production, 44(7), 1631-1642, doi:10.1007/s11250-012-0118-0.

Amare, M., and Waibel, H. (2015). Climate Variability, Shocks and Non-farm Employment: Evidence from Rural Household in Northeast Thailand. Proceedings "Schriften der Gesellschaft für Wirtschafts- und Sozialwissenschaften des Landbaues e.V.”, 50, 261719.

Anderman, T. L., Remans, R., Wood, S. A., DeRosa, K., and DeFries, R. S. (2014). Synergies and tradeoffs between cash crop production and food security: a case study in rural Ghana. Food Security, 6(4), 541-554, doi:10.1007/s12571-014-0360-6.

Antwi-Agyei, P., Stringer, L. C., and Dougill, A. J. (2014). Livelihood adaptations to climate variability: insights from farming households in Ghana. Regional Environmental Change, 14(4), 1615-1626, doi:10.1007/s10113-014-0597-9.

Asare-Kyei, D., Renaud, F. G., Kloos, J., Walz, Y., and Rhyner, J. (2017). Development and validation of risk profiles of West African rural communities facing multiple natural hazards. PLoS ONE, 12(3), doi:10.1371/journal.pone.0171921. 
Barrett, C. B. (2008). Smallholder market participation: Concepts and evidence from eastern and southern Africa. Food Policy, 33(4), 299-317, doi:10.1016/j.foodpol.2007.10.005.

Barrett, C. B., Reardon, T., and Webb, P. (2001). Nonfarm income diversification and household livelihood strategies in rural Africa: concepts, dynamics, and policy implications. Food Policy, 26(4), 315-331, doi:10.1016/s0306-9192(01)00014-8.

Bashir, M. K., and Schilizzi, S. (2013). Determinants of rural household food security: a comparative analysis of African and Asian studies. Journal of the Science of Food and Agriculture, 93, 1251-1258, doi:10.1002/jsfa.6038.

Batello, C., Wade, L., Cox, S., Pogna, N., Bozzini, A., and Choptiany, J. Perennial Crops for Food Security: Proceedings of the FAO Expert Workshop. FAO Expert Workshop, Rome, 28-30 August 2013: Food and Agriculture Organization of the United Nations (FAO).

Beekman, G., and Meijerink, G. (2010). Reducing Food Price Variability in Sub-Saharan Africa. (pp. 96). The Hague, the Netherlands: LEI - Wageningen Univerity and Research.

Below, T., Artner, A., Siebert, R., and Sieber, S. (2010). Microlevel practices to adapt to climate change for African small-scale farmers: A review of selected literature. IFPRI Discussion Paper 00953. Washington: International Food Policy Research Institute (IFPRI).

Berman, R., Quinn, C., and Paavola, J. (2015). Identifying drivers of household coping strategies to multiple climatic hazards in Western Uganda: implications for adapting to future climate change. Climate and Development, 7(1), 71-84, doi:10.1080/17565529.2014.902355.

Biermann, F., Abbott, K., Andresen, S., Bäckstrand, K., Bernstein, S., Betsill, M. M., et al. (2012). Navigating the Anthropocene: Improving Earth System Governance. Science, 335(6074), 1306-1307, doi:10.1126/science.1217255.

Boudreau, T. (1998). The Food Economy Approach: a framework for understanding rural livelihoods. In Relief and Rehabilitation Network (Ed.), RRN Network Paper (Vol. 26). London: Overseas Development Institute.

Browne, S., and Glaeser, L. (2010). Livelihood Mapping and Zoning Exercise: Uganda. The Famine Early Warning System Network (FEWS NET).

Bryan, E., Ringler, C., Okoba, B., Roncoli, C., Silvestri, S., and Herrero, M. (2013). Adapting agriculture to climate change in Kenya: Household strategies and determinants. Journal of Environmental Management, 114, 26-35, doi:10.1016/j.jenvman.2012.10.036.

Bunn, C. (2015). Modeling the climate change impacts on global coffee production. HumboldtUniversität zu Berlin, Lebenswissenschaftliche Fakultät, Berlin, doi: 10.18452/17349.

Burke, M., Bergquist, L. F., and Miguel, E. (2017). Selling low and buying high: An arbitrage puzzle in Kenyan villages. Working Paper.

Burnham, K. P., and Anderson, D. R. (2002). Model Selection and Multimodel Inference - A Practical Information-Theoretic Approach (2nd ed.). New York: Springer. 
Carletto, C., Gourlay, S., Murray, S., and Zezza, A. (2017). Cheaper, Faster, and More Than Good Enough: Is GPS the New Gold Standard in Land Area Measurement? Survey Research Methods, 11(3), 235-265, doi:10.18148/srm/2017.v11i3.6791.

Carletto, G., Ruel, M., Winters, P., and Zezza, A. (2015). Farm-Level Pathways to Improved Nutritional Status: Introduction to the Special Issue. Journal of Development Studies, 51(8), 945-957, doi:10.1080/00220388.2015.1018908.

Carletto, C., Zezza, A., and Banerjee, R. (2013). Towards better measurement of household food security: Harmonizing indicators and the role of household surveys. Global Food Security-Agriculture Policy Economics and Environment, 2(1), 30-40, doi:10.1016/j.gfs.2012.11.006.

Christiaensen, L. (2017). Agriculture in Africa - Telling myths from facts: A synthesis. Food Policy, 67, 1-11, doi:10.1016/j.foodpol.2017.02.002.

CIAT (2009). Developing Beans that Can Beat the Heat. Cali, Colombia: International Center for Tropical Agriculture (CIAT).

Clay, N., and King, B. (2019). Sm allholders' uneven capacities to adapt to clim ate change am id Africa's 'green revolution': Case study of Rwanda's crop intensification program . World Development, 116, 1-14, doi:10.1016/j.worlddev.2018.11.022.

Cooper, P. J. M., and Coe, R. (2011). Assessing and addressing climate-induced risk in subSaharan rainfed agriculture foreword to a special issue of experimental agriculture. Experimental Agriculture, 47(2), 179-184, doi:10.1017/s0014479711000019.

Cooper, P. J. M., Dimes, J., Rao, K. P. C., Shapiro, B., Shiferaw, B., and Twomlow, S. (2008). Coping better with current climatic variability in the rain-fed farming systems of subSaharan Africa: An essential first step in adapting to future climate change? Agriculture Ecosystems and Environment, 126(1-2), 24-35, doi:10.1016/j.agee.2008.01.007.

Cooper, S. J., and Wheeler, T. (2017). Rural household vulnerability to climate risk in Uganda. Regional Environmental Change, 17(3), 649-663, doi:10.1007/s10113-016-1049-5.

Daniels, L., and Minot, N. (2015). Is Poverty Reduction Over-Stated in Uganda? Evidence from Alternative Poverty Measures. Social Indicators Research, 121(1), 115-133, doi:10.1007/s11205-014-0637-3.

Davis, B., Winters, P., Carletto, G., Covarrubias, K., Quinones, E. J., Zezza, A., et al. (2010). A Cross-Country Comparison of Rural Income Generating Activities. World Development, 38(1), 48-63, doi:10.1016/j.worlddev.2009.01.003.

de Haen, H., Klasen, S., and Qaim, M. (2011). What do we really know? Metrics for food insecurity and undernutrition. Food Policy, 36(6), 760-769, doi:10.1016/j.foodpol.2011.08.003.

Descheemaeker, K., Zijlstra, M., Masikati, P., Crespo, O., and Homann-Kee Tui, S. (2018). Effects of climate change and adaptation on the livestock component of mixed farming 
systems: A modelling study from semi-arid Zimbabwe. Agricultural Systems, 159, 282-295, doi:10.1016/j.agsy.2017.05.004.

Descheemaeker, K., Oosting, S. J., Tui, S. H. K., Masikati, P., Falconnier, G. N., and Giller, K. E. (2016a). Climate change adaptation and mitigation in smallholder crop-livestock systems in sub-Saharan Africa: a call for integrated impact assessments. Regional Environmental Change, 16(8), 2331-2343, doi:10.1007/s10113-016-0957-8.

Descheemaeker, K., Ronner, E., Ollenburger, M., Franke, A. C., Klapwijk, C. J., Falconnier, G. N., et al. (2016b). Which options fit best? Operationalizing the socio-ecological niche concept. Experimental Agriculture, doi:10.1017/s001447971600048x.

Desiere, S., and Jolliffe, D. (2018). Land productivity and plot size: Is measurement error driving the inverse relationship? Journal of Development Economics, 130, 84-98, doi:10.1016/j.jdeveco.2017.10.002.

Deuter, P., White, N., and Putland, D. (2011). Critical (temperature) thresholds and climate change impacts/adaptation in horticulture. Queensland: AgriScience Queensland.

Deutsch, C. V., and Journel, A. G. (1998). GSLIB Geostatistical Software Library and User's Guide (2ed.). New York: Oxford University Press.

Dillon, A., McGee, K., and Oseni, G. (2015). Agricultural Production, Dietary Diversity and Climate Variability. The Journal of Development Studies, 51(8), 976-955, doi:10.1080/00220388.2015.1018902.

Dormann, C. F., Elith, J., Bacher, S., Buchmann, C., Carl, G., Carre, G., et al. (2013). Collinearity: a review of methods to deal with it and a simulation study evaluating their performance. Ecography, 36(1), 27-46, doi:10.1111/j.1600-0587.2012.07348.x.

Elbers, C., Fujii, T., Lanjouw, P., Ozler, B., and Yin, W. (2007). Poverty alleviation through geographic targeting: How much does disaggregation help? Journal of Development Economics, 83(1), 198-213, doi:10.1016/j.jdeveco.2006.02.001.

Elbers, C., Lanjouw, P. F., Mistiaen, J. A., Ozler, B., and Simler, K. (2004). On the unequal inequality of poor communities. World Bank Economic Review, 18(3), 401-421, doi:10.1093/wber/lhh046.

Elbers, C., Lanjouw, J. O., and Lanjouw, P. (2003). Micro-level estimation of poverty and inequality. Econometrica, 71(1), 355-364, doi:10.1111/1468-0262.00399.

ESRI (2011). ArcGIS Desktop: Release 10. Redlands, California: Environmental Systems Research Institute.

FANTA-2 (2010). The Analysis of the Nutrition Situation in Uganda. Food and Nutrition Technical Assistance II Project (FANTA-2). Washington DC: USAID.

FAO (2019). GIEWS - The Global Information and Early Warning System on Food and Agriculture. http://www.fao.org/ES/giews/english/giews_en.pdf. Accessed 12 Jan 2019.

FAO (2018). FAOSTAT - Uganda. http://www.fao.org/faostat/en/\#country/226. Accessed 24 Jan 2019. 
FAO (2016a). The FAO Hunger Map 2015. http://www.fao.org/hunger/en/. Accessed 13 Sep 2016.

FAO (2016b). Uganda Country Indicators. http://faostat.fao.org/beta/en/\#country/226. Accessed 25 Oct 2016.

FAO (2015). Country Fact Sheet on Food and Agriculture Policy Trends - Country situation and role of agriculture - Uganda. Rome: Food and Agriculture Organization of the United Nations.

FAO (2014). The State of Food and Agriculture: Innovation in Family Farming. Rome: Food and Agriculture Organization of the United Nations.

FAO (2009). Declaration of the World Summit on Food Security. Rome: Food and Agriculture Organization of the United Nations.

FAO (2008). An Introduction to the Basic Concepts of Food Security. Food Security Information for Action - Practical Guides. Rome: Food and Agriculture Organization of the United Nations.

FAO (2001). Human Energy Requirements. Food and Nutrition Technical Report. Rome: Food and Agriculture Organization of the United Nations.

FAO, IFAD, UNICEF, WFP, and WHO (2018). The State of Food Security and Nutrition in the World 2018. Building climate resilience for food security and nutrition. Rome: Food and Agriculture Organization of the United Nations.

Farrow, A., Larrea, C., Hyman, G., and Lema, G. (2005). Exploring the spatial variation of food poverty in Ecuador. Food Policy, 30(5-6), 510-531, doi:10.1016/j.foodpol.2005.09.005.

Feleke, S. T., Kilmer, R. L., and Gladwin, C. H. (2005). Determinants of food security in Southern Ethiopia at the household level. Agricultural Economics, 33, 351-363, doi:10.1111/j.1574-0864.2005.00074.x.

Ferrari, S. L. P., and Cribari-Neto, F. (2004). Beta regression for modelling rates and $\begin{array}{llll}\text { proportions. Journal of Applied } & \text { Statistics, 31, }\end{array}$ doi:10.1080/0266476042000214501.

FEWS NET (2019). FEWS NET - Famine Early Warning Systems Network. http://www.fews.net/. Accessed 12 Jan 2019.

FEWS NET (2013). Uganda Livelihood Zone Map. http://fews.net/eastafrica/uganda/livelihood-zone-map/december-2013. Accessed 12 Jan 2019.

FEWS NET (2010). Livelihood Mapping and Zoning Exercise: Uganda - A special Report by the Famine Early Warning System Network (FEWS NET).

Fick, S. E., and Hijmans, R. J. (2017). WorldClim 2: New 1-km spatial resolution climate surfaces for global land areas. International Journal of Climatology, doi:10.1002/joc.5086.

Fisher, M., and Lewin, P. A. (2013). Household, community, and policy determinants of food insecurity in rural Malawi. Development Southern Africa, 30(4-5), 451-467, doi:10.1080/0376835x.2013.830966. 
Franke, A. C., van den Brand, G. J., \& Giller, K. E. (2014). Which farmers benefit most from sustainable intensification? An ex-ante impact assessment of expanding grain legume production in Malawi. European Journal of Agronomy, 58, 28-38, doi:10.1016/j.eja.2014.04.002.

Fraval, S., Hammond, J., Lannerstad, M., Oosting, S. J., Sayula, G., Teufel, N., et al. (2018a). Livelihoods and food security in an urban linked, high potential region of Tanzania: Changes over a three year period. Agricultural Systems, 160, 87-95, doi: 10.1016/j.agsy.2017.10.013.

Fraval, S., Hammond, J., Wichern, J., Oosting, S. J., de Boer, I. J. M., Teufel, N., et al. (2018b). Making the most of imperfect data: a critical evaluation of standard information collected in cross-sectional farm household surveys. Experimental Agriculture, doi:10.1017/S0014479718000388.

Fraval, S., Hammond, J., Ayantunde, A., de Boer, I. J. M., Bogard, J., Bosire, C., et al. (submitted a). Nutritional gaps of rural households in east and west Africa: prevalence and determinants based on rapid indicators. submitted to Global Food Security.

Fraval, S., Yameogo, V., Ayantunde, A., Hammond, J., De Boer, I. J. M., Oosting, S. J., et al. (submitted b). Pathways to food security in rural Burkina Faso: the importance of consumption of home-produced food versus purchased food. submitted to Food Security.

Frelat, R., Lopez-Ridaura, S., Giller, K. E., Herrero, M., Douxchamps, S., Djurfeldt, A. A., et al. (2016). Drivers of household food availability in sub-Saharan Africa based on big data from small farms. Proceedings of the National Academy of Sciences of the United States of America, 113(2), 458-463, doi:10.1073/pnas.1518384112.

Fritz, S., See, L., Bayas, J. C. L., Waldner, F., Jacques, D., Becker-Reshef, I., et al. (2019). A comparison of global agricultural monitoring systems and current gaps. Agricultural Systems, 168, 258-272, doi: 10.1016/j.agsy.2018.05.010.

Funk, C., and Verdin, J. P. (2010). Real-time decision support systems: the famine early warning system network. In Mekonnen, G., and Faisal, H. (Eds.), Satellite Rainfall Applications for Surface Hydrology. Netherlands: Springer.

Funk, C., Dettinger, M. D., Michaelsen, J. C., Verdin, J. P., Brown, M. E., Barlow, M., et al. (2008). Warming of the Indian Ocean threatens eastern and southern African food security but could be mitigated by agricultural development. Proceedings of the National Academy of Sciences of the United States of America, 105(32), 11081-11086, doi:10.1073/pnas.0708196105.

Gbegbelegbe, S., Serem, J., Stirling, C., Kyazze, F., Radeny, M., Misiko, M., et al. (2018). Smallholder farmers in eastern Africa and climate change: a review of risks and adaptation options with implications for future adaptation programmes. Climate and Development, 10(4), 289-306, doi:10.1080/17565529.2017.1374236. 
Gerland, P., Raftery, A. E., Sevcikova, H., Li, N., Gu, D. A., Spoorenberg, T., et al. (2014). World population stabilization unlikely this century. Science, 346(6206), 234-237, doi:10.1126/science. 1257469 .

Gibson, J., Beegle, K., De Weerdt, J., and Friedman, J. (2015). What does Variation in Survey Design Reveal about the Nature of Measurement Errors in Household Consumption? Oxford Bulletin of Economics and Statistics, 77(3), 466-474, doi:10.1111/obes.12066.

Gibson, M. (2012). The feeding of nation - Redefining food security for the 21 st century. United States: CRC Press.

Gilbert, C. L., Christiaensen, L., and J., K. (2017). Food price seasonality in Africa: Measurement and extent. Food Policy, 67, 119-132, doi:10.1016/j.foodpol.2016.09.016.

Giller, K. E. (2012). No silver bullets for African soil problems. Nature, 485, 41, doi:10.1038/485041c.

Giller, K. E., Tittonell, P., Rufino, M. C., van Wijk, M. T., Zingore, S., Mapfumo, P., et al. (2011). Communicating complexity: Integrated assessment of trade-offs concerning soil fertility management within African farming systems to support innovation and development. Agricultural Systems, 104(2), 191-203, doi:10.1016/j.agsy.2010.07.002.

Godfray, H. C. J., Beddington, J. R., Crute, I. R., Haddad, L., Lawrence, D., Muir, J. F., et al. (2010). Food Security: The Challenge of Feeding 9 Billion People. Science, 327(5967), 812818, doi:10.1126/science.1185383.

Govereh, J., and Jayne, T. S. (2003). Cash cropping and food crop productivity: synergies or trade-offs? Agricultural Economics, 28(1), 39-50, doi:10.1111/j.15740862.2003.tb00133.x.

Government of Uganda (2016). Agriculture Sector Strategic Plan 2015/16 - 2019/20 - Draft. Kampala: Ministry of Agriculture, Animal Industry and Fisheries.

Government of Uganda (2015). Economic Assessment of the Impacts of Climate Change in Uganda, Final Study Report. Kampala: Ministry of Water and Environment, Climate Change Department.

Government of Uganda (2004). Bankable Investment Project Profile Livestock Development Project. Support to NEPAD-CAADP Implementation, TCP/UGA/2910 (I), Vol. III. Kampala.

Grillo, J., and Holt, J. (2009). Application of the Livelihood Zone Maps and Profiles for Food Security Analysis and Early Warning - Guidance for Famine Early Warning Systems Network (FEWS NET) Representatives and Partners. USAID FEWS NET.

Haggblade, S., Hazell, P., and Reardon, T. (2010). The Rural Non-farm Economy: Prospects for Growth and Poverty Reduction. World Development, 38(10), 1429-1441, doi:10.1016/j.worlddev.2009.06.008. 
Hammond, J., Pagella, T., Fraval, S., Wichern, J., Teufel, N., Kihoro, E., et al. (submitted). Smallholder Poverty Dynamics in East Africa: Intensification and Off-farm Incomes. Submitted to Nature Sustainability.

Hammond, J., Fraval, S., van Etten, J., Suchini, J. G., Mercado, L., Pagella, T., et al. (2016). The Rural Household Multi-Indicator Survey (RHoMIS) for rapid characterisation of households to inform Climate Smart Agriculture interventions: description and applications in East Africa and Central America. Agricultural Systems, doi:10.1016/j.agsy.2016.05.003. Harris, D., and Orr, A. (2014). Is rainfed agriculture really a pathway from poverty? Agricultural Systems, 123, 84-96, doi:10.1016/j.agsy.2013.09.005.

HarvestChoice (2015). Length of Growing Period (mean, days, 1960-1995). Washington, D.C. and St. Paul, Minnesota: International Food Policy Research Institute, and University of Minnesota.

Helgeson, J., Dietz, S., and Hochrainer, S. (2013). Vulnerability to weather disasters: The choice of coping strategies in rural Uganda. Ecology and Society, 18(2), 2, doi:10.5751/ES05390-180202.

Henderson, B., Cacho, O. J., Thornton, P. K., Van Wijk, M. T., and Herrero, M. (2018). The economic potential of residue management and fertilizer use to address climate change impacts on mixed smallholder farmers in Burkina Faso. Agricultural Systems, 167, 195 205, doi:10.1016/j.agsy.2018.09.012.

Hengl, T., Mendes de Jesus, J., Heuvelink, G. B. M., Ruiperez Gonzalez, M., Kilibarda, M., Blagotic, A., et al. (2017). SoilGrid250m: Global gridded soil information based on machine learning. PLoS ONE, 12(2), 1-40, doi:10.1371/journal.pone.0169748.

Herrero, M., Thornton, P. K., Power, B., Bogard, J. R., Remans, R., Fritz, S., et al. (2017). Farming and the geography of nutrient production for human use: a transdisciplinary analysis. The Lancet Planetary Health, 1(1), e33-e42, doi:10.1016/S2542-5196(17)300074.

Herrero, M., Thornton, P. K., Bernues, A., Baltenweck, I., Vervoort, J., de Steeg, J. V., et al. (2014). Exploring future changes in smallholder farming systems by linking socioeconomic scenarios with regional and household models. Global Environmental ChangeHuman and Policy Dimensions, 24, 165-182, doi:10.1016/j.gloenvcha.2013.12.008.

Herrero, M., Thornton, P. K., Notenbaert, A. M., Wood, S., Msangi, S., Freeman, H. A., et al. (2010). Smart Investments in Sustainable Food Production: Revisiting Mixed CropLivestock Systems. Science, 327(5967), 822-825, doi:10.1126/science.1183725.

Hidrobo, M., Hoddinott, J., Kumar, N., and Olivier, M. (2018). Social Protection, Food Security, and Asset Formation. World Development, 101, 88-103, doi:10.1016/j.worlddev.2017.08.014. 
Hijmans, R. J., Phillips, S., Leathwick, J., and Elith, J. (2017). R Package 'Dismo' - Species Distribution Modeling. https://cran.r-project.org/web/packages/dismo/dismo.pdf. Accessed 8 Feb 2019.

Hijmans, R. J., Cameron, S. E., Parra, J. L., Jones, P. G., and Javis, A. (2005). Very high resolution interpolated climate surfaces for global land areas. International Journal of Climatology, 25, 1965-1978, doi:10.1002/joc.1276.

Hjelm, L., Mathiassen, A., and Wadhwa, A. (2016). Measuring Poverty for Food Security Analysis: Consumption- Versus Asset-Based Approaches. Food and Nutrition Bulletin, 37(3), 275-289, doi:10.1177/0379572116653509.

Holden, S., Shiferaw, B., and Pender, J. (2001). Market Imperfections and Land Productivity in the Ethiopian Highlands. Journal of Agricultural Economics, 52(3), 53-70, doi:10.1111/j.1477-9552.2001.tb00938.x.

Hyman, G., Larrea, C., and Farrow, A. (2005). Methods, results and policy implications of poverty and food security mapping assessments. Food Policy, 30(5-6), 453-460, doi:10.1016/j.foodpol.2005.10.003.

Jaramillo, J., Muchugu, E., Vega, F. E., Davis, A., Borgemeister, C., and Chabi-Olaye, A. (2011). Some Like It Hot: The Influence and Implications of Climate Change on Coffee Berry Borer (Hypothenemus hampei) and Coffee Production in East Africa. PLoS ONE, 6(9), doi:10.1371/journal.pone.0024528.

Jarvis, A., Guevara, E., Reuter, H. I., and Nelson, A. D. (2008). Hole-Filled SRTM for the Globe. (Version 4 ed.) CGIAR Consortium for Spatial Information.

Jarvis, A., Ramirez-Villegas, J., Campo, B. V. H., and Navarro-Racines, C. (2012). Is Cassava the Answer to African Climate Change Adaptation? Tropical Plant Biology, 5(1), 9-29, doi:10.1007/s12042-012-9096-7.

Jassogne, L., Van Asten, P. J. A., Wanyama, I., and Baret, P. V. (2013a). Perceptions and outlook on intercropping coffee with banana as an opportunity for smallholder coffee farmers in Uganda. International Journal of Agricultural Sustainability, 11(2), 144-158.

Jassogne, L., Laederach, P., and van Asten, P. (2013b). The impact of climate change on coffee in Uganda - Lessons from a case study in the Rwenzori Mountains. In Oxfam (Ed.), Oxfam Research Reports. Oxford, UK.

Jayne, T. S., Chamberlin, J., and Headey, D. D. (2014). Land pressures, the evolution of farming systems, and development strategies in Africa: A synthesis. Food Policy, 48, 1-17, doi:10.1016/j.foodpol.2014.05.014.

Jayne, T. S., Mather, D., and Mghenyi, E. (2006). Smallholder farming under increasingly difficult circumstances: Policy and public investment priorities for Africa. MSU International Development Working Paper (Vol. 86). East Lansing, Michigan: Michigan State University. 
Jean, N., Burke, M., Xie, M., Davis, W. M., Lobell, D. B., and Ermon, S. (2016). Combining satellite imagery and machine learning to predict poverty. Science, 353(6301), 790-794, doi:10.1126/science.aaf7894.

Johnson, N. L., Kotz, S., and Balakrishnan, N. (1994). 14: Lognormal Distributions. In Continuous univariate distributions (2 ed., Vol. 1, Wiley Series in Probability and Mathematical Statistics: Applied Probability and Statistics). New York: John Wiley and Sons.

Jones, A. D., Ngure, F. M., Pelto, G., and Young, S. L. (2013). What Are We Assessing When We Measure Food Security? A Compendium and Review of Current Metrics. Advances in Nutrition, 4(5), 481-505, doi:10.3945/an.113.004119.

Jones, L., Jaspars, S., Pavanello, S., Ludi, E., Slater, R., Arnall, A., et al. (2010). Responding to climate change: Exploring how disaster risk reduction, social protection and livelihoods approaches promote features of adaptive capacity. Working Paper 319. London: Overseas Development Institute.

Jones, P. G., and Thornton, P. K. (2009). Croppers to livestock keepers: livelihood transitions to 2050 in Africa due to climate change. Environmental Science and Policy, 12(4), 427-437, doi:10.1016/j.envsci.2008.08.006.

Joy, E. J. M., Ander, E. L., Young, S. D., Black, C. R., Watts, M. J., Chilimba, A. D. C., et al. (2014). Dietary mineral supplies in Africa. Physiologia plantarum, 151(3), 208-229, doi:10.1111/ppl.12144.

Kakande, M. (2010). Poverty monitoring. In F. Kuteesa, E. Tumusiime-Mutebile, A. Whitworth, and T. Williamson (Eds.), Uganda's economic reforms: Insider accounts. Oxford: Oxford University Press.

Kalanda-Joshua, M., Ngongondo, C., Chipeta, L., and Mpembeka, F. (2011). Integrating indigenous knowledge with conventional science: Enhancing localised climate and weather forecasts in Nessa, Mulanje, Malawi. Physics and Chemistry of the Earth, 36(14-15), 9961003, doi:10.1016/j.pce.2011.08.001.

Kaminski, J., and Christiaensen, L. (2014). Post-harvest loss in sub-Saharan Africa what do farmers say? Global Food Security-Agriculture Policy Economics and Environment, 3(34), 149-158, doi:10.1016/j.gfs.2014.10.002.

Kates, R. W., Travis, W. R., and Wilbanks, T. J. (2012). Transformational adaptation when incremental adaptations to climate change are insufficient. Proceedings of the National Academy of Sciences of the United States of America, 109(19), 7156-7161, doi:10.1073/pnas.1115521109.

Kikoyo, D. A., and Nobert, J. (2016). Assessment of impact of climate change and adaptation strategies on maize production in Uganda. Physics and Chemistry of the Earth, 93, 37-45, doi:10.1016/j.pce.2015.09.005.

Kikulwe, E. (2017). Post-harvest losses of banana in Uganda. Bioversity-Uganda. 
Kilic, T., Winters, P., and Carletto, C. (2015). Gender and agriculture in sub-Saharan Africa: introduction to the special issue. Agricultural Economics, 46(3), 281-284, doi:10.1111/agec.12165.

Komarek, A. M., and Ahmadi-Esfahani, F. Z. (2011). Impacts of price and productivity changes on banana-growing households in Uganda. Agricultural Economics, 42, 141-151, doi:10.1111/j.1574-0862.2011.00558.x.

Kotir, J. H. (2011). Climate change and variability in Sub-Saharan Africa: a review of current and future trends and impacts on agriculture and food security. Environment, Development and Sustainability, 13(3), 587-605, doi:10.1007/s10668-010-9278-0.

Kristjanson, P., Neufeldt, H., Gassner, A., Mango, J., Kyazze, F. B., Desta, S., et al. (2012). Are food insecure smallholder households making changes in their farming practices? Evidence from East Africa. Food Security, 4(3), 381-397, doi:10.1007/s12571-012-0194-z.

Kristjanson, P., Mango, N., Krishna, A., Radeny, M., and Johnson, N. (2010). Understanding poverty dynamics in Kenya. Journal of International Development, 22(7), 978-996, doi:10.1002/jid.1598.

Kuteesa, F., Tumusiime-Mutebile, E., Whitworth, A., and William son, T. (2010). Uganda's economic reforms. Insider accounts. Oxford: Oxford University Press.

Kyazze, F., and Kristjanson, P. (2011). Summary of Baseline Household Survey Results: Rakai District, South Central Uganda. Copenhagen, Denmark.

Leliveld, A., Dietz, T., Foeken, D., and Klaver, W. (2013). Agricultural dynamics and food security trends in Uganda. In Developmental Regimes in Africa (DRA) Project ASC-AFCA Collaborative Research Group (Ed.), Agro-Food Clusters in Africa (AFCA), (Vol. 2013ASC-2). London/ Leiden.

Leonardo, W. J., Bijman, J., and Slingerland, M. A. (2015). The Windmill Approach Combining transaction cost economics and farming systems theory to analyse farmer participation in value chains. Outlook on Agriculture, 44(3), 207-214, doi:10.5367/oa.2015.0212.

Lipper, L., Thornton, P., Campbell, B. M., Baedeker, T., Braimoh, A., Bwalya, M., et al. (2014). Climate-smart agriculture for food security. Nature Climate Change, 4, 1068, doi:10.1038/nclimate2437.

Little, T. D., and Rhemtulla, M. (2013). Planned Missing Data Designs for Developmental Researchers. Child Development Perspectives, 7(4), 199-204, doi:10.1111/cdep.12043.

Lobell, D. B., Azzari, G., Marshall, B., Gourlay, S., Jin, Z., Kilic, T., et al. (2018). Eyes in the sky, boots on the ground : assessing satellite- and ground-based approaches to crop yield measurement and analysis in Uganda. (Vol. Policy Research working paper no. WPS 8374). Washington, D.C.: World Bank Group. 
Lobell, D. B., Burke, M. B., Tebaldi, C., Mastrandrea, M. D., Falcon, W. P., and Naylor, R. L. (2008). Prioritizing climate change adaptation needs for food security in 2030. Science, 319(5863), 607-610, doi:10.1126/science.1152339.

Loison, S. A. (2015). Rural Livelihood Diversification in Sub-Saharan Africa: A Literature Review. Journal of Development Studies, 51(9), 1125-1138, doi:10.1080/00220388.2015.1046445.

Lyon, B., and DeWitt, D. G. (2012). A recent and abrupt decline in the East African long rains. Geophysical Research Letters, 39, doi:10.1029/2011g1050337.

MAAIF (2010). Agriculture for Food and Income Security - Agriculture Sector Development Strategy and Investment Plan: 2010/11 - 2014/15. Entebbe, Uganda: Republic of Uganda Ministry of Agriculture, Animal Industry and Fisheries (MAAIF).

Maidment, R. I., Allan, R. P., and Black, E. (2015). Recent observed and simulated changes in precipitation over Africa. Geophysical Research Letters, 42(19), 8155-8164, doi:10.1002/2015g1065765.

Mango, N., Zamasiya, B., Makate, C., Nyikahadzoi, K., and Siziba, S. (2014). Factors influencing household food security among smallholder farmers in the Mudzi district of Zimbabwe. Development Southern Africa, 31(4), 625-640, doi:10.1080/0376835x.2014.911694.

Manners, R., and van Etten, J. (2018). Are agricultural researchers working on the right crops to enable food and nutrition security under future climates? Global Environmental Change, 53, 182-194, doi:10.1016/j.gloenvcha.2018.09.010.

Map Library (2019): Map Library. www.maplibrary.org. Accessed 8 Feb 2019

Martiniello, G. (2013). Food Sovereignty as a Weapon of the Weak? Rethinking the Food Question in Uganda. Third World Quarterly, 36(3), 508-525.

Mathiassen, A., and Hollema, S. (2014). What is the effect of physical activity level on food consumption, energy deficiency, and dietary diversity? Food and Nutrition Bulletin, 35(3), 351-360.

Matsumoto, T., Kijima, Y., and Yamano, T. (2006). The role of local nonfarm activities and migration in reducing poverty: evidence from Ethiopia, Kenya, and Uganda. Agricultural Economics, 35(3), 449-458, doi:10.1111/j.1574-0862.2006.00190.x.

McMaster, D. N. (1962). A subsistence Geography of Uganda. The world land use survey. Occasional papers no. 2. Bude, Cornwall, England: Geographical Publications Limited.

McSweeney, C., New, M., and Lizcano, G. (2010). The UNDP Climate Change Country Profiles Improving the accessibility of Observed and Projected Climate Information for Studies of Climate Change in Developing Countries. Bullet American Meteorological Society, 91(2), 157-166, doi:10.1175/2009BAMS2826.1. 
Moll, H. A. J. (2005). Costs and benefits of livestock systems and the role of market and nonmarket relationships. Agricultural Economics, 32(2), 181-193, doi:10.1111/j.01695150.2005.00210.x.

Mubiru, D. N., Komutunga, E., Agona, A., Apok, A., and Ngara, T. (2012). Characterising agrometeorological climate risks and uncertainties: Crop production in Uganda. South African Journal of Science, 108(3-4), 108-118, doi:10.4102/sajs.v108i3/4.470.

Mulinde, C., Majaliwa, J. G. M., Twesigomwe, E., and Egeru, A. (2016). Chapter XI: Meteorological drought occurrence and severity in Uganda. In B. R. Nakileza, Y. Bamutaze, and P. Mukwaya (Eds.), Disasters and Climate Resilience in Uganda: Processes, Knowledge and Practices: UNDP.

Müller, C., Cramer, W., Hare, W. L., and Lotze-Campen, H. (2011). Climate change risks for African agriculture. Proceedings of the National Academy of Sciences of the United States of America, 108(11), 4313-4315, doi:10.1073/pnas.1015078108.

Muthoni, F. K., Odongo, V. O., Ochieng, J., Mugalavai, E. M., Mourice, S. K., HoescheZeledon, I., et al. (2018). Long-term spatial-temporal trends and variability of rainfall over Eastern and Southern Africa. Theoretical and Applied Climatology, doi:10.1007/s00704018-2712-1.

Mwebaze, S. M. N. (1999). Country Pasture/Forage Resource Profiles - UGANDA. http://www.fao.org/ag/agp/agpc/doc/counprof/uganda/uganda.htm\#3. Accessed 25 Oct 2016.

Mwongera, C., Shikuku, K., Twyman, J., Winowiecki, L., Ampaire, E., Koningstein, M., et al. (2014). Rapid Rural Appraisal Report of Northern Uganda. International Center for Tropical Agriculture (CIAT), CGIAR Research Program on Climate Change, Agriculture and Food Security (CCAFS).

Mwungu, C., Mwongera, C., Shikuku, K., Nyakundi, F., Twyman, J., Winowiecki, L., et al. (2017). Survey data of intra-household decision making and smallholder agricultural production in Northern Uganda and Southern Tanzania. Data Brief, 14, 302-306, doi:10.1016/j.dib.2017.07.040.

Nelson, A. (2008). Estimated travel time to the nearest city of 50,000 or more people in year 2000. http://forobs.jrc.ec.europa.eu/products/gam/ Accessed 18 Sep 2015.

Nelson, A., Rogers, D., and Robinson, T. (2012). Poverty Mapping in Uganda - Extrapolating household expenditure data using environmental data and regression techniques. FAO Animal Production and Health Working Paper (Vol. 9). Rome: Food and Agriculture Organization of the United Nations.

Niang, I., Ruppel, O. C., Abdrabo, M. A., Essel, A., Lennard, C., Padgham, J., et al. (2014). Africa. In V. R. Barros, C. B. Field, D. J. Dokken, M. D. Mastrandrea, K. J. Mach, T. E. Bilir, et al. (Eds.), Climate Change: Impacts, Adaptation, and Vulnerability. Part B: Regional Aspects. Contribution of Working Group II to the Fifth Assessment Report of the 
Intergovernmental Panel on Climate Change (pp. 1199-1265). Cambridge, UK and New York, NY, USA: Cambridge University Press.

Nsubuga, F. W., and Rautenbach, H. (2018). Climate change and variability: a review of what is known and ought to be known for Uganda. International Journal of Climate Change Strategies and Management, 10(5), 752-771, doi:10.1108/ijccsm-04-2017-0090.

Nsubuga, F. W., Olwoch, J. M., and Rautenbach, H. (2014). Variability properties of daily and monthly observed near-surface temperatures in Uganda: 1960-2008. International Journal of Climatology, 34(2), 303-314, doi:10.1002/joc.3686.

Ojiem, J. O., Ridder, N. d., Vanlauwe, B., \& Giller, K. E. (2006). Socio-ecological niche: A conceptual framework for integration of legumes in smallholder farming systems. International Journal of Agricultural Sustainability, 4(1), 79-93.

Oluoko-Odingo, A. A. (2011). Vulnerability and Adaptation to Food Insecurity and Poverty in Kenya. Annals of the Association of American Geographers, 101(1), 1-20, doi:10.1080/00045608.2010.532739.

Ongoma, V., Chen, H. S., Gao, C. J., Nyongesa, A. M., and Polong, F. (2018). Future changes in climate extremes over Equatorial East Africa based on CMIP5 multimodel ensemble. Natural Hazards, 90(2), 901-920, doi:10.1007/s11069-017-3079-9.

Openshaw, S., and Taylor, P. (1979). A million or so correlation coefficients: three experiments on the modifiable areal unit problem. Statistical Applications in the Spatial Sciences, 21, 127-144.

Oppenheimer, M., Campos, R. W., Birkmann, J., Luber, G., O'Neill, B., and Takahashi, K. (2014). Emergent risks and key vulnerabilities. In C. B. Field, V. R. Barros, D. J. Dokken, K. J. Mach, M. D. Mastrandrea, T. E. Bilir, et al. (Eds.), Climate Change 2014: Impacts, Adaptation, and Vulnerability. Part A: Global and Sectoral Aspects. Contribution of Working Group II to the Fifth Assessment Report of the Intergovernmental Panel on Climate Change (pp. 1039-1099). Cambridge, United Kingdom and New York, NY, USA: Cambridge University Press.

Ospina, R., and Ferrari, S. L. P. (2010). Inflated beta distributions. Statistical Papers, 51, 111 126, doi:10.1007/s00362-008-0125-4.

Ospina, R., and Ferrari, S. L. P. (2012). A general class of zero-or-one inflated beta regression models. Computational Statistics and Data Analysis, 56(6), 1609-1623, doi:10.1016/j.csda.2011.10.005.

Palacios-Lopez, A., Christiaensen, L., and Kilic, T. (2017). How much of the labor in African agriculture is provided by women? Food Policy, 67, 52-63. doi: 10.1016/j.foodpol.2016.09.017.

Panda, A., Sharma, U., Ninan, K. N., and Patt, A. (2013). Adaptive capacity contributing to improved agricultural productivity at the household level: Empirical findings highlighting 
the importance of crop insurance. Global Environmental Change-Human and Policy Dimensions, 23(4), 782-790, doi:10.1016/j.gloenvcha.2013.03.002.

Patricola, C. M., and Cook, K. H. (2011). Sub-Saharan Northern African climate at the end of the twenty-first century: forcing factors and climate change processes. Climate Dynamics, 37(5), 1165-1188, doi:10.1007/s00382-010-0907-y.

Pauline, N., Vogel, C., Grab, S., and Liwenga, E. (2016). Smallholder farmers in the Great Ruaha River sub-Basin of Tanzania: coping or adapting to rainfall variability? Climate and Development, 9(3), doi:10.1080/17565529.2016.1184607.

Pender, J., Jagger, P., Nkonya, E., and Sserunkuuma, D. (2004). Development pathways and land management in Uganda. World Development, 32(5), 767-792, doi:10.1016/j.worlddev.2003.11.003.

Pokhriyal, N., and Jacques, D. C. (2017). Combining disparate data sources for improved poverty prediction and mapping. Proceedings of the National Academy of Sciences of the United States of America, 114(46), E9783-E9792, doi:10.1073/pnas.1700319114.

R Development Core Team (2008). R: A language and environment for statistical computing. Vienna: R Foundation for Statistical Computing.

Ramirez-Villegas, J., Jarvis, A., and Laederach, P. (2013). Empirical approaches for assessing impacts of climate change on agriculture: The EcoCrop model and a case study with grain sorghum. Agricultural and Forest Meteorology, 170, 67-78, doi:10.1016/j.agrformet.2011.09.005.

Reardon, T., Berdegué, J., Barrett, C. B., and Stamoulis, K. (2006). Household Income Diversification into Rural Nonfarm Activities. In S. Haggblade, P. Hazell, and T. Reardon (Eds.), Transforming the Rural Nonfarm Economy. Baltimore: John Hopkins University Press.

Rehm, S., and Espig, G. (1991). The Cultivated Plants of the Tropics and Subtropics. Stuttgart, Germany: Verlag Josef Margraf.

Rigby, B., and Stasinopoulos, M. (2010). A flexible regression approach using GAMLSS in R. Short course in GAMLSS given at the University of Lancaster. https://pdfs.semanticscholar.org/ed3d/f96aa477d6454d5737403a5aab751ccd9315.pdf.

Accessed 8 Feb 2019.

Ritzema, R. S., Frelat, R., Douxchamps, S., Silvestri, S., Rufino, M. C., Herrero, M., et al. (2017). Is production intensification likely to make farm households food-adequate? A simple food availability analysis across smallholder farming systems from East and West Africa. Food Security, 9(1), 115-131, doi: 10.1007/s12571-016-0638-y.

Robinson, T., Emwanu, T., and Rogers, D. (2007). Environmental Approaches to Poverty Mapping: an example from Uganda. Information Development, 23(2/3), 205-215, doi:10.1177/0266666907079077. 
Rojas, O., Vrieling, A., and Rembold, F. (2011). Assessing drought probability for agricultural areas in Africa with coarse resolution remote sensing imagery. Remote Sensing of Environment, 115(2), 343-352, doi:10.1016/j.rse.2010.09.006.

Rosenthal, D. M., and Ort, D. R. (2012). Examining Cassava's Potential to Enhance Food Security Under Climate Change. Tropical Plant Biology, 5(1), 30-38, doi:10.1007/s12042011-9086-1.

Rowhani, P., Lobell, D. B., Linderman, M., and Ramankutty, N. (2011). Climate variability and crop production in Tanzania. Agricultural and Forest Meteorology, 151(4), 449-460, doi:10.1016/j.agrformet.2010.12.002.

Ruel-Bergeron, J. C., Stevens, G. A., Sugimoto, J. D., Roos, F. F., Ezzati, M., Black, R. E., et al. (2015). Global Update and Trends of Hidden Hunger, 1995-2011: The Hidden Hunger Index. PLoS ONE, 10(12), e0143497-e0143497, doi:10.1371/journal.pone.0143497.

Rufino, M. C., Quiros, C., Boureima, M., Desta, S., Douxchamps, S., Herrero, M., et al. (2013a). Developing generic tools for characterizing agricultural systems for climate and global change studies (IMPACTlite - phase 2). Report to CCAFS. Copenhagen, Denmark: CGIAR Research Program on Climate Change, Agriculture and Food Security (CCAFS).

Rufino, M. C., Thornton, P. K., Ng'ang'a, S. K., Mutie, I., Jones, P. G., van Wijk, M. T., et al. (2013b). Transitions in agro-pastoralist systems of East Africa: Impacts on food security and poverty. Agriculture Ecosystems and Environment, 179, 215-230, doi:10.1016/j.agee.2013.08.019.

Saint Ville, A. S., Hickey, G. M., Locher, U., and Phillip, L. E. (2016). Exploring the role of social capital in influencing knowledge flows and innovation in smallholder farming communities in the Caribbean. Food Security, 8, 535-549, doi:10.1007/s12571-016-0581y.

Samberg, L. H., Gerber, J. S., Ramankutty, N., Herrero, M., and West, P. C. (2016). Subnational distribution of average farm size and smallholder contributions to global food production. Environmental Research Letters, 11(12), 124010, doi:10.1088/1748-9326/11/12/124010.

Sánchez, B., Rasmussen, A., and Porter, J. R. (2014). Temperatures and the growth and development of maize and rice: a review. Global Change Biology, 20(2), 408-417, doi:10.1111/gcb.12389.

Schlenker, W., and Lobell, D. B. (2010). Robust negative impacts of climate change on African agriculture. Environmental Research Letters, 5(1), 8, doi:10.1088/1748-9326/5/1/014010.

Schneider, S. H., Semenov, S., Patwardhan, A., Burton, I., Magadza, C. H. D., Oppenheimer, M., et al. (2007). Assessing key vulnerabilities and the risk from climate change. In M. L. Parry, O. F. Canziani, J. P. Palutikof, P. J. van der Linden, and C. E. Hanson (Eds.), Climate Change 2007: Impacts, Adaptation and Vulnerability. Contribution of Working Group II to the Fourth Assessment Report of the Intergovernmental Panel on Climate Change (pp. 779810). Cambridge, UK: Cambridge Univ. Press. 
Scoones, I. (1998). Sustainable Rural Livelihoods: A Framework for Analysis. IDS Working Paper 72. Brighton, UK: Institute of Development Studies.

Sempiira, J. E., Katimbo, A., Mugisa, D. J., and Kisaalita, W. S. (2017). Ghee-making in the cattle corridor of Uganda. African Journal of Food, Agriculture, Nutrition and Development, 17(1), 11771-11786, doi:10.18697/ajfand.77.16000.

Sheahan, M., and Barrett, C. B. (2017). Ten striking facts about agricultural input use in SubSaharan Africa. Food Policy, 67, 12-25, doi:10.1016/j.foodpol.2016.09.010.

Shongwe, M. E., van Oldenborgh, G. J., van den Hurk, B., and van Aalst, M. (2011). Projected Changes in Mean and Extreme Precipitation in Africa under Global Warming. Part II: East Africa. Journal of Climate, 24(14), 3718-3733, doi:10.1175/2010jcli2883.1.

Silvestri, S., Douxchamps, S., Kristjanson, P., Förch, W., Radeny, M., Mutie, I., et al. (2015). Households and food security: lessons from food secure households in East Africa. Agriculture and Food Security, 4(23), doi:10.1186/s40066-015-0042-4.

Smith, L., Alderman, H., and Aduayom, D. (2006). Food Insecurity in Sub-Saharan Africa: New Estimates from Household Expenditure Surveys. (Vol. Research Report 146). Washington, D.C.: International Food Policy Research Institute (IFPRI).

Stasinopoulos, D. M., and Rigby, B. A. (2007). Generalized additive models for location scale and shape (GAMLSS) in Journal of Statistical Software, 23(7), doi:10.18637/jss.v023.i07.

Taulya, G., Van Asten, P., Leffelaar, P. A., and Giller, K. E. (2014). Phenological development of East African highland banana involves trade-offs between physiological age and chronological age. European Journal of Agronomy, 60, 41-53, doi:10.1016/j.eja.2014.07.006.

Taulya, G. (2013). East African highland bananas (Musa spp. AAA-EA) 'worry' m ore about potassium deficiency than drought stress. Field Crops Research, 151, 45-55, doi: 10.1016/j.fcr.2013.07.010.

The World Bank (2018). GINI index (World Bank estimate). https://data.worldbank.org/indicator/SI.POV.GINI?year_high_desc=false. Accessed 22 Oct 2018.

The World Bank (2016a). Country Programs: Uganda. http://econ.worldbank.org/WBSITE/EXTERNAL/EXTDEC/EXTRESEARCH/EXTLSM S/0,,contentMDK:23635524 pagePK:64168445 piPK:64168309 theSitePK:3358997,00. html. Accessed 2 Apr 2017.

The World Bank (2016b). GDP growth (annual \%) - World Bank national accounts data, and OECD National Accounts data files. http://data.worldbank.org/indicator/NY.GDP.MKTP.KD.ZG. Accessed 25 Oct 2016.

The World Bank (2016c). Living Standards Measurement Study - Datasets - Uganda National Panel Survey. http://go.worldbank.org/FS2M7AYE00. Accessed 9 Sep 2016. 
The World Bank (2012). Uganda- National Panel Survey 2009-10. http://microdata.worldbank.org/index.php/catalog/1001/studydescription\#page=sampling\&tab=study-desc. Accessed 23 Jul 2018.

The World Bank (2009). AFRICA REGION - Making development climate resilient: a world bank strategy for sub-Saharan Africa. Washington DC: World Bank.

Thomas, D. S. G., Twyman, C., Osbahr, H., and Hewitson, B. (2007). Adaptation to climate change and variability: farmer responses to intra-seasonal precipitation trends in South Africa. Climatic Change, 83(3), 301-322, doi:10.1007/s10584-006-9205-4.

Thompson, D. K. (2016). Map East Africa - Uganda Shapefiles. http://mapeastafrica.com/countries/east-africa-shapefiles/uganda-shapefiles/. Accessed 26 Oct 2016.

Thornton, P. K., Kristjanson, P., Förch, W., Barahona, C., Cramer, L., and Pradhan, S. (2018). Is agricultural adaptation to global change in lower-income countries on track to meet the future food production challenge? Global Environmental Change, 52, 37-48, doi: 10.1016/j.gloenvcha.2018.06.003.

Thornton, P. K., and Herrero, M. (2015). Adapting to climate change in the mixed crop and livestock farming systems in sub-Saharan Africa. Nature Climate Change, 5(9), 830-836, doi:10.1038/nclimate2754.

Thornton, P. K., and Cramer, L. (2012). Impacts of climate change on the agricultural and aquatic system s and natural resources within the CGIAR's m andate. Working Paper No. 23. Copenhagen, Denmark: CGIAR Research Program on Climate Change, Agriculture and Food Security (CCAFS).

Thornton, P. K., Jones, P. G., Ericksen, P. J., and Challinor, A. J. (2011). Agriculture and food systems in sub-Saharan Africa in a 4 degrees C+ world. Philosophical Transactions of the Royal Society a-Mathematical Physical and Engineering Sciences, 369(1934), 117-136, doi:10.1098/rsta.2010.0246.

Thornton, P. K., Jones, P. G., Alagarswamy, G., Andresen, J., and Herrero, M. (2010). Adapting to climate change: Agricultural system and household impacts in East Africa. Agricultural Systems, 103(2), 73-82, doi:10.1016/j.agsy.2009.09.003.

Thornton, P. K., Jones, P. G., Alagarswamy, G., and Andresen, J. (2009a). Spatial variation of crop yield response to climate change in East Africa. Global Environmental Change-Human and Policy Dimensions, 19(1), 54-65, doi:10.1016/j.gloenvcha.2008.08.005.

Thornton, P. K., van de Steeg, J., Notenbaert, A., and Herrero, M. (2009b). The impacts of climate change on livestock and livestock systems in developing countries: A review of what we know and what we need to know. Agricultural Systems, 101(3), 113-127, doi: 10.1016/j.agsy.2009.05.002. 
Tirivayi, N., Knowles, M., and Davis, B. (2016). The interaction between social protection and agriculture: A review of evidence. Global Food Security-Agriculture Policy Economics and Environment, 10, 52-62, doi:10.1016/j.gfs.2016.08.004.

Tittonell, P., and Giller, K. E. (2013). When yield gaps are poverty traps: The paradigm of ecological intensification in African smallholder agriculture. Field Crops Research, 143, 7690, doi:10.1016/j.fcr.2012.10.007.

Traore, B., Descheemaeker, K., van Wijk, M. T., Corbeels, M., Supit, I., and Giller, K. E. (2017). Modelling cereal crops to assess future climate risk for family food self-sufficiency in southern Mali. Field Crops Research, 201, 133-145, doi:10.1016/j.fcr.2016.11.002.

Traore, B., van Wijk, M., Descheemaeker, K., Corbeels, M., Rufino, M., and Giller, K. (2015). Climate variability and change in Southern Mali: Learning from farmer perception and onfarm trials. Experimental Agriculture, 51(4), 615-634, doi:10.1017/S0014479714000507.

Tusiime, H. A., Renard, R., and Smets, L. (2013). Food aid and household food security in a conflict situation: Empirical evidence from Northern Uganda. Food Policy, 43, 14-22, doi:10.1016/j.foodpol.2013.07.005.

UBOS (2016). The National Population and Housing Census 2014 - Main Report. Kampala: Uganda Bureau of Statistics (UBOS).

UBOS (2013). Comprehensive Food Security And Vulnerability Analysis (CFSVA) Uganda. Kampala: Uganda Bureau of Statistics (UBOS).

UBOS (2012). District Boundaries Uganda 2010. Kampala: Uganda Bureau of Statistics (UBOS).

UBOS (2011). The Uganda National Panel Survey (UNPS) 2010/11 - Basic Information Document. Kampala: Uganda Bureau of Statistics (UBOS).

UBOS (2010a). Uganda National Household Survey, 2009/2010. Socio-Economic Module. Kampala: Uganda Bureau of Statistics (UBOS).

UBOS (2010b). The Uganda National Panel Survey (UNPS) 2009/10 - Basic Information Document. Kampala: Uganda Bureau of Statistics (UBOS).

UBOS (2007). Uganda National Household Survey 2005/2006 - Report on the Agricultural Module. Kampala: Uganda Bureau of Statistics (UBOS).

Uganda Law Reform Commission (2005). The National Agricultural Research Act 2005. Kampala.

UNCTAD (2015). Commodities and Development Report 2015: Smallholder Farmers and Sustainable Commodity Development UNCTAD/SUC/2014/5. Paper presented at the United Nations Conference on Trade and Development, Geneva, Switzerland.

UNGA (2015). Transforming Our World: The 2030 Agenda for Sustainable Development. Draft resolution referred to the United Nations summit for the adoption of the post-2015 development agenda by the General Assembly at its sixty-ninth session. 
United Nations (1998). Principles and Recommendations for Population and Housing Censuses, Revision 1. (Vol. Series M). New York: United Nations.

United Nations DESA (2017). World Population Prospects: The 2017 Revision. New York: United Nations, Department of Economic and Social Affairs, Population Division 2017.

Unks, R. R., King, E. G., Nelson, D. R., Wachira, N. P., and German, L. A. (2019). Constraints, multiple stressors, and stratified adaptation: Pastoralist livelihood vulnerability in a semiarid wildlife conservation context in Central Kenya. Global Environmental Change, 54, 124-134, doi: 10.1016/j.gloenvcha.2018.11.013.

Valbuena, D., Tui, S. H.-K., Erenstein, O., Teufel, N., Duncan, A., Abdoulaye, T., et al. (2015). Identifying determinants, pressures and trade-offs of crop residue use in mixed smallholder farms in Sub-Saharan Africa and South Asia. Agricultural Systems, 134, 107-118, doi: 10.1016/j.agsy.2014.05.013.

Valdivia, C., Seth, A., Gilles, J. L., Garcia, M., Jimenez, E., Cusicanqui, J., et al. (2010). Adapting to Climate Change in Andean Ecosystems: Landscapes, Capitals, and Perceptions Shaping Rural Livelihood Strategies and Linking Knowledge Systems. Annals of the Association of American Geographers, 100(4), 818-834, doi:10.1080/00045608.2010.500198.

van Asten, P. J. A., Fermont, A. M., and Taulya, G. (2011). Drought is a major yield loss factor for rainfed East African highland banana. Agricultural Water Management, 98(4), 541-552, doi:10.1016/j.agwat.2010.10.005.

van Wijk, M. T. (2014). From global economic modelling to household level analyses of food security and sustainability: How big is the gap and can we bridge it? Food Policy, 49, 378388, doi:10.1016/j.foodpol.2014.10.003.

Vanlauwe, B., Coe, R. I. C., and Giller, K. E. (2016). Beyond averages: New approaches to understand heterogeneity and risk of technology success or failure in smallholder farming. Experimental Agriculture, 1-23, doi:10.1017/S0014479716000193.

Vermeulen, S. J., Dinesh, D., Howden, S. M., Cramer, L., and Thornton, P. K. (2018). Transformation in Practice: A Review of Empirical Cases of Transformational Adaptation in Agriculture Under Climate Change. Frontiers in Sustainable Food Systems, 2(65), doi:10.3389/fsufs.2018.00065.

Vermeulen, S. J., Aggarwal, P. K., Ainslie, A., Angelone, C., Campbell, B. M., Challinor, A. J., et al. (2012). Options for support to agriculture and food security under climate change. Environmental Science and Policy, 15(1), 136-144, doi:10.1016/j.envsci.2011.09.003.

von Grember, K., Bernstein, J., Patterson, F., Sonntag, A., Klaus, L. M., Fahlbusch, J., et al. (2018). Global Hunger Index - Forced Migration and Hunger. Dublin/ Bonn: Welthungerhilfe. 
Waha, K., van Wijk, M. T., Fritz, S., See, L., Thornton, P. K., Wichern, J., et al. (2018). Agricultural diversification as an important strategy for achieving food security in Africa. Global Change Biology, 24(8), 3390-3400, doi:10.1111/gcb.14158.

Waha, K., Müller, C., Bondeau, A., Dietrich, J. P., Kurukulasuriya, P., Heinke, J., et al. (2013). Adaptation to climate change through the choice of cropping system and sowing date in sub-Saharan Africa. Global Environmental Change-Human and Policy Dimensions, 23(1), 130-143, doi:10.1016/j.gloenvcha.2012.11.001.

Wairegi, L. W. I., and van Asten, P. J. A. (2010). The agronomic and economic benefits of fertilizer and mulch use in highland banana systems in Uganda. Agricultural Systems, 103(8), 543-550, doi:10.1016/j.agsy.2010.06.002.

Weindl, I., Lotze-Campen, H., Popp, A., Müller, C., Havlík, P., Herrero, M., et al. (2015). Livestock in a changing climate: production system transitions as an adaptation strategy for agriculture. Environmental Research Letters, 10(9), 094021, doi:10.1088/17489326/10/9/094021.

WFP (2009). Comprehensive Food Security and Vulnerability Analysis - Guidelines. Rome: World Food Programme (WFP).

Wichern, J., Descheemaeker, K., Hammond, J., Giller, K. E., and Van Wijk, M. T. (submitted). Production variability and coping strategies of Ugandan smallholders in the face of climate variability and market shocks. Submitted to Climate and Development.

Wichern, J., van Heerwaarden, J., de Bruin, S., Descheemaeker, K., Van Asten, P. J. A., and Giller, K. E. (2018). Using household survey data to identify large-scale food security patterns across Uganda. PLoS ONE, 13(12), doi:10.1371/journal.pone.0208714.

Wichern, J., Van Wijk, M. T., Descheemaeker, K., Frelat, R., Van Asten, P. J. A., and Giller, K. E. (2017). Food Availability and Farming Strategies among Rural Households across Uganda. Food Security, 9(6), 1385-1403, doi:10.1007/s12571-017-0732-9.

Williams, P. A., Crespo, O., Abu, M., and Simpson, N. P. (2018). A systematic review of how vulnerability of smallholder agricultural systems to changing climate is assessed in Africa. Environmental Research Letters, 13(10), 19, doi:10.1088/1748-9326/aae026.

Williams, A. P., Funk, C., Michaelsen, J., Rauscher, S. A., Robertson, I., Wils, T. H. G., et al. (2012). Recent summer precipitation trends in the Greater Horn of Africa and the emerging role of Indian Ocean sea surface temperature. Climate Dynamics, 39(9-10), 2307-2328, doi:10.1007/s00382-011-1222-y.

Wisner, B., Blaikie, P., Cannon, T., and Davis, I. (1994). At Risk - Natural hazards, people's vulnerability and disasters (2nd Edition). London, U.K.: ROUTLEDGE.

Wong, K. L. M., Brady, O. J., Campbell, O. M. R., and Benova, L. (2018). Comparison of spatial interpolation methods to create high-resolution poverty maps for low- and middleincome countries. Journal of the Royal Society Interface, 15(147), doi:10.1098/rsif.2018.0252. 
WorldPop (2016). WorldPop. http://www.worldpop.org.uk/. Accessed 26 Oct 2016.

WorldPop (2015). 2010 Estimates of Total Number of People Per Grid Square Across the World, with National Totals Adjusted to Match UN Population Division Estimates. Unpublished.

World Population Review (2018). Uganda Population 2019. http://worldpopulationreview.com/countries/uganda-population/. Accessed 24 Jan 2019.

Wortmann, C. S., and Eledu, C. A. (1999). Uganda's agroecological zones: A guide for planners and policy makers. Kampala: International Center of Tropical Agriculture (CIAT).

Wossen, T., Berger, T., Haile, M. G., and Troost, C. (2018). Impacts of climate variability and food price volatility on household income and food security of farm households in East and West Africa. Agricultural Systems, 163, 7-15, doi:10.1016/j.agsy.2017.02.006.

WRI (2009). Waterbodies in Uganda. Uganda GIS data. Washington: World Resource Institute. You, L., Wood-Sichra, U., Fritz, S., Guo, Z., See, L., and Koo, J. (2017). Spatial Production Allocation Model (SPAM) 2005 v3.2.

Zezza, A., Federighi, G., Kalilou, A. A., and Hiernaux, P. (2016). Milking the data: Measuring milk off-take in extensive livestock systems. Experimental evidence from Niger. Food Policy, 59, 174-186, doi:10.1016/j.foodpol.2016.01.005. 
Undernourishment and food insecurity have risen in sub-Saharan Africa in recent years. This makes it more difficult to achieve Sustainable Development Goal 2: Zero Hunger. Rural households are particularly vulnerable to food insecurity because they obtain a substantial part of their living from rain-fed agriculture. These households farm on small land areas and are sensitive to climate and market variability. They will be even more challenged to become food secure under future trends of population growth and climate change. At the same time these households are often the main agricultural producers in their country and are therefore important agents for national level food security.

To achieve zero hunger in an environment where climate change is an increasing challenge for smallholder farming, agricultural interventions are needed that target the rural households that are most at risk of being food insecure and vulnerable. A key challenge is to identify which interventions work in which regions and for which households. Blanket recommendations are often ineffective and poorly adopted. Instead, approaches are needed that provide guidance on how the large diversity of households can be considered for interventions planning at subnational and national levels. Current models for targeting agricultural development for food security often use top-down approaches (for example macro-economic models) that risk to insufficiently account for the diversity of households. Bottom-up approaches that use microlevel information such as household survey data often only go up to the community or landscape level. Since food security and vulnerability tend to be locally driven with large variation at small scale, approaches are needed that can analyse country-wide patterns while preserving information on local variability.

This thesis explored how micro-level information from household survey data collected country-wide could be used for planning of interventions. The corresponding research aim was to understand within-country patterns of livelihood strategies in relation to food security and vulnerability to climate change of rural households in sub-Saharan Africa. Two research questions addressed this research aim:

1. How can micro-level information be used for planning interventions for food security and reducing vulnerability of rural households at national and sub-national levels?

2. How do livelihood activities for food security and vulnerability to climate change differ across a country and what are the implications for interventions planning? 
Uganda was used as a case study because of the importance of agriculture for national food security and for rural livelihoods, and because of the diverse farming systems, which will be affected by climate change in different ways. Household survey data were the source of microlevel information. A cross-country household dataset from the World Bank Living Standard Measurement Survey - Integrated Surveys on Agriculture (LSMS-ISA) from 2010/11 was used in Chapters 2 to 4. For Chapter 5 I used household data that I collected from two sites contrasting in their agroecological setting. Food security was approximated using a food availability indicator that quantifies the contribution of on- and off-farm livelihood activities to household food availability.

Research question 1: How can micro-level information be used for planning interventions for food security and reducing vulnerability of rural households at national and sub-national levels?

LSMS-ISA data were used to 1) aggregate household level information to higher (administrative) levels (Chapter 2), 2) spatially interpolate household point information (Chapter 3) and 3) identify hotspots of household vulnerability before aggregation (Chapter 4). In Chapter 2, country-wide patterns of food availability and contributing livelihood activities were identified through aggregating household information to district, FEWS livelihood zone, regional and national levels. Major limitations were that aggregation of household data was hiding local variability between nearby households and introduced statistical bias, and that LSMS-ISA data were not representative at district and livelihood zone levels. In Chapter 3, we quantified local variability using a geostatistical approach (regression kriging) to interpolate household information and determine country-wide patterns of livelihood activities and food availability. For many indicators, including food availability and overarching livelihood activities, the variability on short distance $(<10 \mathrm{~km})$ was much larger than across areas. This suggests that information on the local heterogeneity in livelihood activities should inform decision making at broader scales. In Chapter 4, we mapped country-wide household vulnerability without aggregation or interpolation by simply assessing vulnerability at household level. This way we identified hotspot areas of household vulnerability by investigating exposure and sensitivity to climate change at the household level for different climate change scenarios. Adaptation options were assessed per hotspot area to identify location-specific groups of potentially suitable interventions. An in-depth analysis for two sites (Chapter 5) was conducted to identify which current coping strategies worked for which households.

Results showed that local variability of livelihood activities and food security overruled largescale patterns. Still, decisions for planning interventions for food security and climate change 
adaptation are often based on top-down approaches. Therefore, I proposed a three-step approach (Chapter 6) for using micro-level information for multi-level interventions planning. The first step in the approach disentangles livelihood diversity (Step 1) using cross-country household survey data. Step 2 locates important production activities (Pathway 2a) or vulnerable households (Pathway 2b). The production activity pathway identifies areas of key livelihood activities in a country, which is useful for targeting interventions aimed at stimulating national level food security. Pathway $2 \mathrm{~b}$ locates vulnerable households and enables to assess the suitability of adaptation options. Lastly, Step 3 uses site-specific household surveys to assess which interventions are useful for which groups of households in the local context. This approach can contribute to interventions planning by considering the large diversity of households and potentially improving the effectiveness and uptake of interventions.

Research question 2: How do livelihood activities for food security and vulnerability to climate change differ across Uganda and what are the implications for interventions planning?

Uganda's rural households followed diverse livelihood strategies, which differed across the regions and with the degree of household food availability (Chapter 2). They changed from subsistence-oriented on-farm activities to market-oriented on-farm and off-farm activities as household food availability increased. Households with greater food availability tended to diversify their on-farm and off-farm activities, thus spreading the risk. In areas with good market access and infrastructure, cash crops were an important strategy contributing to household food availability. In areas with poor infrastructure and less favourable agroecological conditions, off-farm income played a more important role. Most staple crops were more important for the households with insufficient food availability, while East African highland banana was identified to be one of the key crops for income generation in western and central Uganda and most important for households with surplus food availability. The diversity of livelihood strategies must be considered when targeting interventions. Holistic livelihood interventions, including access to off-farm activities, are needed to improve household food availability.

Spatial interpolation of household information revealed that local variability in food availability and livelihood activities was often larger than variability across larger areas (Chapter 3). Spatial predictability was strongest for indicators for which environmental gradients determined their distribution, such as highland banana or sorghum contribution to the crop part of food availability. In contrast, indicators of crops that were more ubiquitously present across agroecological zones showed large local variation, which often overruled patterns at large scale (for example the contribution of maize to the crop part of food availability). Interventions that 
aim to target the poor must recognise the large diversity in livelihood activities within any given area, which often overrides the variability between regions.

Assessments of vulnerability to climate change and adaptation options (Chapter 4) indicated that despite this local diversity hotspot areas of vulnerable households could be identified. About $30 \%$ of the households in the hotspot areas in (central) southwest Uganda were vulnerable to a combination of $3^{\circ} \mathrm{C}$ temperature increase and $10 \%$ rainfall decline through declining suitability for several key crops. In contrast only $10 \%$ of the households in the hotspot areas in northern Uganda were negatively affected and this was mainly related to a decline in suitability of common beans. Households that depended on common beans and lived at lower elevations in West Nile and central north were vulnerable to a 2 to $3^{\circ} \mathrm{C}$ temperature increase, while households located at higher elevations (above 1,100-2,000 m.a.s.l. depending on the crop) benefitted. Options for adaptation to increasing temperatures were most suitable in northern Uganda, while drought-related adaptation options were more suitable in the southwest.

An in-depth analysis at two sites in northern and central southwest Uganda (Chapter 5) revealed that few ex-ante coping strategies were applied under current climate and price variability. Such coping strategies mostly required little financial investment such as switching crops, which was common for households with more land available. Households tended to react to shocks rather than taking preventive action. Although most common ex-post coping strategies were to use off-farm income or selling livestock, these strategies were not feasible for $25-50 \%$ of the sample population. Especially the poorest lack resources to cope with crop production fluctuations and shocks. Results suggest that limited resources can prevent households from adapting to climate change, even when adaptation options are useful from an agronomic perspective (Chapter 4).

Current top-down approaches that do not consider local diversity of livelihood strategies and food security run the risk of overlooking households that are food insecure but live in areas not designated for food security interventions (Chapter 6). In-depth, contextualised research is needed to understand local barriers to adoption, so that adaptation options can be tailored to local contexts and underpinned by enabling policies and institutional arrangements.

In conclusion, there is a need for using micro-level approaches for interventions planning at the (sub-)national level that target food security and climate change adaptation in sub-Saharan Africa. The local diversity of rural households and the dual role that these households play for household and national level food security requires approaches that preserve local information at higher levels. These approaches can assess scenarios of future change and thereby contribute to identify pathways to achieve zero hunger by 2030 in sub-Saharan Africa. 


\section{Zusammenfassung}

Unterernährung und Ernährungsunsicherheit in Subsahara-Afrika haben in den vergangenen Jahren zugenommen. Dies stellt eine zunehmende Herausforderung dar, das zweite globale Ziel für nachhaltige Entwicklung ,Kein Hunger‘ (Sustainable Developm ent Goal 2: Den Hunger beenden, Ernährungssicherheit und eine bessere Ernährung erreichen und eine nachhaltige Landwirtschaft fördern') zu erreichen. Insbesondere Haushalte im ländlichen Raum sind anfällig für Ernährungsunsicherheit, da sie einen wesentlichen Teil ihrer Nahrungsmittel und ihres Einkommens aus Regenfeldbau beziehen. Diese Haushalte verfügen oftmals nur über kleine Ländereien und sind anfällig für klimatische und marktbedingte Schwankungen. Zunehmendes Bevölkerungswachstum und der Klimawandel stellen für diese Kleinbauern eine große Herausforderung für ihre Ernährungssicherheit dar. Gleichzeitig sind diese Haushalte oft die wichtigsten landwirtschaftlichen Produzenten in ihrem Land und damit auch wichtige Akteure für die nationale Ernährungssicherung.

Um das Ziel ,Kein Hunger ' in einem Umfeld zu erreichen, in dem die Unbilden des Klimawandels eine zunehmende Herausforderung für Kleinbauern darstellt, sind landwirtschaftliche Maßnahmen erforderlich, die auf die ländlichen Haushalte abzielen, die am anfälligsten für Ernährungsunsicherheit sind. Eine wesentliche Herausforderung ist es, geeignete Maßnahmen für die große Vielfalt an Regionen und Haushalten zu identifizieren. Pauschale Empfehlungen sind oftmals ineffektiv und werden oft schlecht angenommen. Stattdessen sind Ansätze erforderlich, die Anhaltspunkte dafür liefern, wie die große Vielfalt der Haushalte für die Planung von Maßnahmen auf nationalen und subnationalen Ebenen berücksichtigt werden kann. Derzeitige Modelle zur Planung landwirtschaftlicher Entwicklung für Ernährungssicherheit sind häufig Top-down-Ansätze (zum Beispiel makroökonomische Modelle), die die Vielfalt an Haushalten unzureichend berücksichtigen könnten. Bottom-upAnsätze, die Informationen auf Mikroebene verwenden (zum Beispiel Haushaltserhebungen), berücksichtigen hingegen oftmals nur Prozesse auf lokaler, Gemeinde- oder Landschaftsebene. Ernährungssicherheit und Vulnerabilität gegenüber Klimawandelfolgen werden oftmals auf lokaler Ebene beeinflusst und weisen große Variabilität auf kleinstem Raum auf. Daher sind Ansätze notwendig, die landesweite Muster analysieren können und gleichzeitig Informationen über lokale Variabilität bewahren.

Die vorliegende Arbeit untersucht wie Informationen auf Mikroebene anhand von Daten aus landesweiten Haushaltserhebungen für Maßnahmenplanungen verwendet werden können. Das Forschungsziel war es zu verstehen wie Strategien zur Sicherung des Lebensunterhalts (,Lebensunterhaltsstrategien') ländlicher Haushalte in Subsahara-Afrika in Bezug auf 
Ernährungssicherung und Reduzierung der Anfälligkeit gegenüber dem Klimawandel variieren und inwieweit sie landesweite Muster aufweisen. Hieraus ergaben sich zwei Forschungsfragen:

1. Wie können Informationen auf Mikroebene in der Planung von Maßnahmen zur Ernährungssicherung und Reduzierung der Anfälligkeit ländlicher Haushalte auf nationaler und sub-nationaler Ebene verwendet werden?

2. Wie unterscheiden sich Haushaltaktivitäten zur Sicherung des Lebensunterhalts (,Lebensunterhaltsaktivitäten') in Bezug auf Ernährungssicherung und die Reduzierung der Anfälligkeit gegenüber dem Klimawandel landesweit und welche Schlussfolgerungen resultieren daraus für die Planung von Maßnahmen?

Uganda wurde als Fallstudie gewählt, da kleinbäuerliche Landwirtschaft eine zentrale Rolle für die nationale Ernährungssicherheit und für den ländlichen Lebensunterhalt spielt. Zudem besitzt Uganda eine hohe Diversität landwirtschaftlicher Anbausysteme, die auf unterschiedliche Weise vom Klimawandel betroffen sind. Für die Untersuchung wurden Daten aus Haushaltserhebungen als Informationsquelle verwendet. Für Kapitel 2 bis 4 wurde ein landesweiter Haushaltsdatensatz der Weltbank (World Bank Living Standard Measurement Survey - Integrated Surveys on Agriculture, LSMS-ISA) von 2010/11 verwendet. Als Datenquelle in Kapitel 5 dienten eigene Haushaltserhebungen an zwei Standorten mit unterschiedlichen agroökologischen Eigenschaften. Die Ernährungssicherheit wurde durch einen Indikator für die Nahrungsmittelverfügbarkeit abgeschätzt. Dabei wurde der relative Beitrag von landwirtschaftlichen und nichtlandwirtschaftlichen Tätigkeiten zur Nahrungsmittelverfügbarkeit eines Haushaltes quantifiziert.

Forschungsfrage 1: Wie können Informationen auf Mikroebene in der Planung von Maßnahmen zur Ernährungssicherung und Reduzierung der Anfälligkeit ländlicher Haushalte auf nationaler und sub-nationaler Ebene verwendet werden?

LSMS-ISA Daten wurden verwendet, um (1) Haushaltsinformationen auf höheren (administrativen) Ebenen zu aggregieren (Kapitel 2), (2) Haushaltsinformationen räumlich zu interpolieren (Kapitel 3) und (3) Schwerpunkte von Haushaltsanfälligkeiten zum Klimawandel zu identifizieren (Kapitel 4). In Kapitel 2 wurden landesweite Muster von Nahrungsmittelverfügbarkeit und beitragenden Lebensunterhaltsaktivitäten identifiziert, indem Haushaltsinformationen auf Bezirks-, ,FEWS-Livelihood-zone'-, Regional- und Nationalebene aggregiert wurden. Wesentliche Einschränkungen dieses Ansatzes waren, dass die Aggregierung von Haushaltdaten die lokale Variabilität zwischen nahegelegenen Haushalten verdeckte, einen statistischen Verzerrungseffekt einführte, und dass LSMS-ISA Daten auf Bezirks- und Livelihood-zone-Ebenen nicht repräsentativ waren. In Kapitel 3 wurde die lokale 
Variabilität mit einem geostatistischen Ansatz quantifiziert (Regressionskriging), um Haushaltinformationen $\mathrm{zu}$ interpolieren und landesweite Muster von Lebensunterhaltsaktivitäten und von Nahrungsmittelverfügbarkeit zu bestimmen. Für viele Indikatoren, Nahrungsmittelverfügbarkeit und übergeordnete Lebensunterhaltsaktivitäten eingeschlossen, war die Variabilität auf kurzer Distanz $(<10 \mathrm{~km})$ erheblich größer als flächenübergreifend. Dies deutet darauf hin, dass Informationen über die lokale Heterogenität von Lebensunterhaltsaktivitäten in Entscheidungsprozessen auf höheren Ebenen berücksichtigt werden sollten. In Kapitel 4 wurde die Anfälligkeit ländlicher Haushalte zu klimatischen Veränderungen landesweit abgebildet, ohne zu aggregieren oder zu interpolieren. Durch die Untersuchung von Exposition und Sensitivität von Haushalten gegenüber dem Klimawandel für verschiedene Klimawandelszenarien konnten Schwerpunktgebiete anfälliger Haushalte identifiziert werden. Anpassungsoptionen wurden für jedes Schwerpunktgebiet bewertet, um standortspezifische potentiell geeignete Maßnahmen zu identifizieren. Eine detaillierte Analyse an zwei Standorten (Kapitel 5) wurde durchgeführt, um zu verstehen, welche derzeitigen Bewältigungsstrategien für welche Haushalte funktionieren.

Die Ergebnisse zeigten, dass die lokale Variabilität von Lebensunterhaltsaktivitäten zur Ernährungssicherung groß angelegte Muster außer Kraft setzte. Dennoch basieren die Entscheidungen über die Planung von Maßnahmen zur Ernährungssicherheit und Anpassung an den Klimawandel oft auf Top-down-Ansätzen. Aus diesem Grund wird hier ein dreistufiger Ansatz vorgeschlagen, wie Informationen auf Mikroebene zur Planung von Maßnahmen auf mehreren Ebenen verwendet werden könnten (Kapitel 6). Im ersten Schritt wird die Diversität von Lebensunterhaltsstrategien durch landesweite Haushaltserhebungen entwirrt. In Schritt 2 werden wichtige Produktionsaktivitäten (Stufe 2a) oder Klimawandel-gefährdete Haushalte (Stufe 2b) lokalisiert. Stufe $2 \mathrm{a}$ identifiziert Gebiete mit landwirtschaftlichen Schlüsselaktivitäten zur Ernährungssicherung eines Landes. Dies ist für die Festlegung von Maßnahmen zur Förderung der nationalen Ernährungssicherheit von Nutzen. Stufe 2b lokalisiert gefährdete Haushalte und ermöglicht es die Eignung von Anpassungsmaßnahmen zu beurteilen. Stufe 3 verwendet schließlich standortspezifische Haushaltserhebungen, um zu bewerten, welche Maßnahmen für welche Haushaltsgruppe im lokalen Kontext sinnvoll sein könnten. Dieser mehrstufige Ansatz kann einen Beitrag zur Planung von Maßnahmen leisten, indem er die große Diversität an Haushalten berücksichtigt und dadurch das Potential hat, die Effektivität und die Umsetzbarkeit von Maßnahmen zu verbessern.

Forschungsfrage 2: Wie unterscheiden sich Haushaltaktivitäten zur Sicherung des Lebensunterhalts (,Lebensunterhaltsaktivitäten') in Bezug auf Ernährungssicherung und die Reduzierung der Anfälligkeit gegenüber dem Klimawandel landesweit und welche Schlussfolgerungen resultieren daraus für die Planung von Maßnahmen? 
Ugandas ländliche Haushalte nutzen unterschiedliche Lebensunterhaltsstrategien, die sich sowohl zwischen und innerhalb der Regionen als auch in Abhängigkeit zum Status eines Haushaltes an Nahrungsmittelverfügbarkeit unterscheiden (Kapitel 2). Von geringer zu großer Nahrungsmittelverfügbarkeit verändern sich die Lebensunterhaltsstrategien von subsistenzorientierter Landwirtschaft $\mathrm{zu}$ einer Kombination aus marktorientierter Landwirtschaft und nichtlandwirtschaftlichen Aktivitäten. Haushalte mit größerer Nahrungsmittelverfügbarkeit weisen in der Tendenz eine größere Diversität landwirtschaftlicher und nichtlandwirtschaftlicher Aktivitäten auf, welches ihr Risiko verringert. In Gebieten mit gutem Marktzugang und guter Infrastruktur sind der Anbau von Marktfrüchten eine wichtige Strategie zur Verbesserung der Nahrungsmittelverfügbarkeit auf Haushaltsebene. Demgegenüber sind nichtlandwirtschaftliche Aktivitäten in Gebieten mit schlechter Infrastruktur und suboptimalen agroökologischen Bedingungen von größerer Bedeutung. Der Anbau von Grundnahrungsmitteln war für Haushalte mit unzureichender Nahrungsmittelverfügbarkeit wichtiger. Matoke (East African Highland banana), das ein Grundnahrungsmittel in Uganda darstellt, wurde in West- und Zentraluganda hingegen als eine bedeutende Marktfrucht zur Einkommensgenerierung identifiziert und war am wichtigsten für Haushalte mit hoher Nahrungsmittelverfügbarkeit. Diese Vielfalt an Lebensunterhaltsstrategien muss in der Interventionsplanung berücksichtigt werden. Ganzheitliche Maßnahmen zur Sicherung des Lebensunterhalts, einschließlich des Zugangs zu Aktivitäten außerhalb der Landwirtschaft, sind erforderlich, um die Nahrungsmittelverfügbarkeit für Haushalte zu verbessern.

Die räumliche Interpolation von Haushaltsinformationen ergab, dass die lokale Variabilität der Nahrungsmittelverfügbarkeit und der Lebensunterhaltsaktivitäten im Vergleich zu großräumigen Unterschieden oft überwiegt. Die räumliche Vorhersagbarkeit war für Indikatoren am stärksten, für die Umweltfaktoren die räumliche Verteilung von Kulturpflanzen bestimmte. Dies war der Fall für den Beitrag von Matoke und Sorghum zur Nahrungsmittelverfügbarkeit eines Haushalts. Im Gegensatz dazu zeigten Indikatoren von Pflanzen, die in diversen agroökologischen Zonen vorkommen, größere lokale Variabilität, welche oft großflächige Muster überlagerte (zum Beispiel bei Mais). Interventionen, die auf die Ärmsten abzielen, müssen die Vielfalt der Aktivitäten zur Sicherung des Lebensunterhalts innerhalb eines Gebietes berücksichtigen, da diese häufig die Variabilität zwischen Gebieten überlagert.

Die Bewertungen der Anfälligkeit gegenüber Klimawandel und der Anpassungsmöglichkeiten (Kapitel 4) zeigten, dass trotz der lokalen Vielfalt an Lebensunterhaltsaktivitäten, Schwerpunktgebiete gefährdeter Haushalte identifiziert werden können. Etwa 30\% der 
Haushalte in den Schwerpunktgebieten in (Zentral-)Südwestuganda sind bei einer Kombination von $3^{\circ} \mathrm{C}$ Temperaturanstieg und 10\% Rückgang des monatlichen Niederschlags gefährdet, da in Folge der Klimaveränderung die Erträge bedeutender Kulturpflanzen sinken können. Im Gegensatz hierzu sind nur 10\% der Haushalte in den Schwerpunktgebieten im Norden Ugandas negativ betroffen, welches hauptsächlich daran liegt, dass der Anbau von Bohnen schwieriger wird. Haushalte, die einen wesentlichen Teil ihres Lebensunterhalts durch Bohnenanbau generieren und in geringen Höhen in West Nile und Zentralnorduganda leben, sind bei einem Temperaturanstieg von 2 bis $3^{\circ} \mathrm{C}$ gefährdet. Haushalte in höheren Gebieten (1.000 bis $2.000 \mathrm{~m}$ ü.N.N, abhängig von der Kulturpflanze) profitierten hingegen vom Temperaturanstieg. Anpassungsmöglichkeiten der Landwirtschaft an steigende Temperaturen, sind in Norduganda am besten möglich, während im Südwesten Anpassungsstrategien an Trockenphasen mit Dürreereignissen relevant sind.

Eine detaillierte Analyse an zwei Standorten im Norden und Zentralsüdwesten von Uganda (Kapitel 5) zeigte auf, dass unter derzeitiger Klima- und Preisvariabilität die Anwendungsrate von Ex-ante-Bewältigungsstrategien oft niedrig und durch niedrige Investitionen gekennzeichnet ist. Dieses Ergebnis zeigt, dass Haushalte tendenziell eher auf Schocks reagierten, anstatt vorsorgend zu handeln. Die zwei am häufigsten vorkommenden Ex-postBewältigungsstrategien waren nichtlandwirtschaftliche Einkommensquellen zu nutzen oder Nutztiere zu verkaufen. Diese Strategien wären jedoch für 25-50\% der befragten Bevölkerung nicht umsetzbar. Vor allem den Ärmsten fehlte es an Ressourcen, um mit Schwankungen und Schocks in der Pflanzenproduktion umzugehen. Die Ergebnisse deuten darauf hin, dass mangelnde Ressourcen die Umsetzung von Anpassungsoptionen verhindern könnten (Kapitel 5), selbst wenn sie aus agronomischer Perspektive nützlich wären (Kapitel 4).

Derzeitige Top-down-Ansätze, die die lokale Vielfalt von Lebensunterhaltsstrategien zur Ernährungssicherheit nicht berücksichtigen, laufen Gefahr, dass Haushalte übersehen werden, die mangelnde Ernährungssicherheit aufweisen, aber in einem Gebiet liegen, das nicht für Maßnahmen zur Ernährungssicherheit vorgesehen ist (Kapitel 6). Es bedarf eingehender, kontextualisierter Forschung, um die lokalen Hindernisse für die Übernahme von Anpassungsmaßnahmen zu verstehen, sodass potenziell geeignete Anpassungsoptionen auf den lokalen Kontext zugeschnitten werden können und mit befähigenden Richtlinien und institutionellen Anordnungen untermauert werden.

In der Maßnahmenplanung zur Förderung der Ernährungssicherung und Anpassung an den Klimawandel in Subsahara-Afrika auf (sub-)nationaler Ebene bedarf es vermehrter Ansätze, die Informationen auf Mikro-Ebene verwenden. Die lokale Vielfalt ländlicher Haushalte und ihrer Lebensunterhaltsstrategien und die duale Rolle, die diese Haushalte für ihre eigene und 
die Ernährungssicherheit auf nationaler Ebene spielen, erfordern Ansätze, die diese lokalen Informationen auf höheren Ebenen bewahren. Mit diesen Ansätzen können dann Szenarien für zukünftige Veränderungen evaluiert werden und damit dazu beitragen, Wege aufzuzeigen, wie das Ziel ,Kein Hunger' bis 2030 in Subsahara-Afrika erreicht werden kann. 


\section{Acknowledgements}

This work would not have been possible without the huge scientific, organisational and emotional support of many, many people. Most of all I want to thank the farmers across Uganda, who spent their valuable time with me and shared a small part of their lives with me.

To my promotor, Ken Giller, thank you for giving me the opportunity to be a part of your chair group and for believing in my ability to do a $\mathrm{PhD}$ in the field of agronomy, in which I was (and still am a bit of) an alien. Thank you for your challenging questions and for admitting that you also do not necessarily know the answers to those questions. Thank you for always having an open door and for your excitement about my work (and maps, even when they were really poor).

To my co-promotor, Katrien Descheemaeker, thank you for illuminating me when our team was running away with ideas that I did not grasp and for grounding us when we were flying away with too abstract ideas. Thank you for always being clear on how to phrase things and for being critical of $m$ y writing. Thank you also for the 'non-scientific' and em otional support and your interest in how I was doing as a person. We had a really nice time in Nwoya together and I learned a lot from you, including how to be critical during farmer surveys and that - with the right equipment - one can get a freshly brewed morning coffee everywhere.

To my other co-promotor, Mark van Wijk, thank you for believing that I could do this $\mathrm{PhD}$ despite my lack of modelling (and programming) skills. Thank you for the many emergency skypes and for always helping me to find the way out of the (data) forest. Thank you also for your Dutch directness and the sometimes very picturesque descriptions of my work (I remember a comment that my writing was like eating dry oat meal...). Even though I may not always have valued it right away, your directness and pragmatism greatly contributed to getting me to where I am today - on the podium of the Aula defending my $\mathrm{PhD}$ thesis.

I am grateful for the support and contributions from my other co-authors. Romain Frelat, thank you for sharing your scripts and for helping me with the figures in Chapter 2. Piet, thank you for your support on Chapters 2 and 3 and for connecting my results to the larger context of Ugandan agriculture and policy making. Joost van Heerwaarden, thank you for your critical eye on my statistics, my writing, my research questions and even on my general $\mathrm{PhD}$ ideas. Discussions with you could feel like taking an exam at times, but always contributed to better outcomes. Apologies for having been a bit pushy at times when I wanted to get things done while you were still looking for the perfect approach to the problem. And thank you for all the fun talks we had in between the statistics. Thank you also to Sytze de Bruin for your support 
on my Chapter 3, for having thought along with me on what the best geostatistical approach could be for my problem at a stage when I barely knew what geostatistics actually was. Jim Hammond greatly supported me in the design of my survey in Chapter 5, in the technicalities to get the survey running and in the training of enumerators for the RHoMIS survey in Rakai. Thank you for your fast responses and evening shifts to get the survey running. Thank you also, Peter Ebanyat and Godfrey Taulya, for your support with Chapter 4, your critical feedback and for sharing your local knowledge on Uganda's cropping system s. Peter, you also helped m e during my stay in Uganda in 2015 and 2016 to get into contact with different experts and you took me with you to the field. Thank you very much for your support!

I've shared offices, coffee and lunch breaks, drinks, frustration and success with m anypeople in Wageningen. Thank you to my PPS colleagues for the past years together: Esther, Lotte W., Travis, Comfort, Linda, Keiji, Ashenafi, Jiska, Ilse, Lotte K., Beyene, João, Juliana G., Eva H., Eva T., Marieke, Wytze, Wim, Greta, Petra, Merel, Juliana T., Tom, Pytrik, Maja, Gerrie, Mezegebu, Hanna, Anne, Samuel, Edouard, Guillaume, Mary, Marloes, Mink, Marcel, Bert R., Bert J., Aart, Joy, Dennis, Na, Martin, Alex-Jan, Renske and many more. Thank you also to Charlotte, Ria, Linda and Karen for all your support. Thank you, Kamran, for collecting and analysing data for my project in Nwoya and Christiana, for working on the data of my chapter 5. Uta, thank you for all the endless conversations we had about ups and downs in the life of a $\mathrm{PhD}$ and as a young mother, and about anything else. Simon, thank you for the interesting discussions we had about food security, research and working in Africa and much more - I really enjoyed them and hope there'll be $\mathrm{m}$ ore to com eThank you everyone from the PE\&RC $\mathrm{PhD}$ council with whom I spent time in meetings and PE\&RC events and also thank you to Claudius and Lennart for the good support of the graduate school and the fun PhD weekends.

My stay in Uganda was greatly supported by IITA, I especially thank Piet, Laurence, Edidah, Millie, Judith and Christopher for their huge support. I had a great time at the IITA student house in Kampala with Ben, Onno, Marleen, Laurie, Mariëtte, Theresa, Mandy, Tim, Siobhán, Vincent and many others. Thanks for the coffees, the in-depth conversations and the 'retreats' to Kabira. Especially Mariola and Simon, Alejandra and Maya - thank you for making Kampala feel like a second home to me and for your friendship!

Field work itself was only a success because of my dedicated field teams: Isaac in Mbale, Lawrence Kirangwa, Sylivia, Lydia and Peninnah in Rakai, and Sunday and Walter in Nwoya. 
You all worked so hard for this project and I am very grateful for that. Thank you Sunday and Walter for the great time at Murchison Falls and during my stay in Nwoya. Thank you also to Ken, my driver: There is no such thing as an unpassable road - you always drove us safely and made every field trip feel like a safari! Thank you Kelvin, for help arranging my stay in Nwoya!

Gertjan, thank you for inspiring me to do a PhD. Eike, thanks for making me apply to this position.

I am also very grateful to the members of the committee for having taken the time to read and critically evaluate my thesis and for participating in my defence.

Thank you to my wonderful friends (Miriam and Dane, Markus, Sarisha, Jantje, Bonnie, Liesbeth, Neeltje, Marike and many more) for awesome Canadian-German breakfasts, for listening ears, for sharing the fun and the pain of $\mathrm{PhD}$ life, for having been there when my life was tough, for 'retreat' weekends to get distance from the $\mathrm{PhD}$, for dinners, for coffees for BBQs on the beach, and for making me feel at home here in the Netherlands.

Finally, I would like to thank my family. Mieke and Ibele for taking care of Lykka when I was finalising my PhD. Babe and Make Mnisi, Sindy, Tse and Mfihlo, for welcoming me like your own daughter and sister and for teaching me so much about Swazi rural livelihood and smallholder farming - Ngiyabonga! Florian for regularily taking me out of my comfort zone, which encouraged me to make decisions that brought me to where and who I am today. Mama and Papa, thank you for your unconditional love and endless support in finding my way in life, for having given me the wings to fly and the roots to come back to. Thank you, Mama, for having been there whenever I needed you and to prepare me to find my way after you had to leave. Ramon, thank you for all your love and support, for always putting things into perspective, for your endless confidence in me and your indestructible optimism for life. And for all the dinners cooked while I tried to finish my PhD. Finally, Lykka, thank you for bringing so much joy into our lives and for showing us what really matters in life. 


\section{About the author}

Jannike Wichern was born on 15 March 1986 in Bremen, Germany. She grew up in a small village in Northern Germany surrounded by cows, sheep and horses. Her primary school playmate brought her into contact with northern German dairy and potato production systems. However, nature and far-away places and cultures fascinated her more than the local production of food. After completing high school she moved to Swaziland to work with the Lutheran Church. It was while living with a Swazi family that she realised how crucial smallholder food production and access to

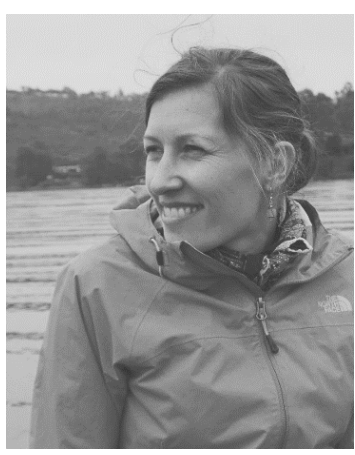
water and land is for food and living security of many people in the world. The scarcity of water that she and her Swazi family experienced made her decide to study Environmental and Resources Management at Brandenburg Technical University in Cottbus, Germany in 2006.

After receiving her Bachelor's degree in 2009, Jannike worked as a project coordinator for corporate sustainability and international networking at GUTcert $\mathrm{GmbH}$ in Berlin. Although she enjoyed her tasks and the travelling, helping companies save money was not fulfilling. Reminding herself of her experiences in Swaziland she decided to study Transnational water management at the Radboud University Nijmegen (The Netherlands) and the University Duisburg-Essen (Germany) in 2011. Jannike was most interested in the management of water scarcity and did her internship at Alterra Wageningen UR on quantifying water consumption for smallholder irrigation in Limpopo, leading her back to Southern Africa. This project brought her into contact with research on smallholder agricultural systems in Africa.

After her graduation in 2013, she worked at the Institute for Science, Innovation and Society (ISIS) at Radboud University Nijmegen as a junior researcher. She liked the combination of indepth research and hands-on consultation work within the project, which encouraged her to do a PhD. In May 2014 she started her PhD at the Plant Production Systems Group in Wageningen University as part of the project 'Policy Action for Clim ate Change Adaptation (PACCA)' of the CGIAR research program on Climate Change, Agriculture and Food Security (CCAFS). The topic of food security of rural households in a spatial context in sub-Saharan Africa fascinated.

After her $\mathrm{PhD}$ graduation Jannike will fulfil a longstanding wish of travelling together with her family for several months through Australia and New Zealand following her passion of exploring nature and far-away places. Returning in autumn 2019, she will look for opportunities to combine her research skills on smallholder livelihoods with her experience in consultancy and project coordination. 


\section{Publications}

\section{Scientific publications}

Wichern J, van Heerwaarden J, de Bruin S, Descheemaeker K, van Asten PJA, Giller KE, van Wijk MT (2018): Using household survey data to identify large-scale food security patterns across Uganda. PLoS ONE 13(12):e0208714. DOI: https://doi.org/10.1371/journal.pone.0208714.

Fraval S, Hammond J, Wichern J, Oosting SJ, de Boer IJM, Teufel N, Lannerstad M, Waha K, Pagella T, Rostenstock TS, Giller KE, Herrero M, Harris D, van Wijk MT (2018): Making the most of imperfect data: a critical evaluation of standard information collected in cross-sectional farm household surveys. Experimental Agriculture 55(2):230-250. DOI: https://doi.org/10.1017/S0014479718000388.

Waha K, van Wijk MT, Fritz S, See L, Thornton PK, Wichern J, Herrero M (2018): Agricultural diversification as an important strategy for achieving food security in Africa. Global Change Biology. DOI: https://doi.org/10.1111/gcb.14158.

Wichern J, van Wijk MT, Descheemaeker K, Frelat R, van Asten PJA, Giller KE (2017): Variability of Food Availability and Livelihood Strategies among Rural Households across Uganda. Food Security 9(6):1385-1403. DOI: https://doi.org/10.1007/s12571-017-0732-9.

Descheemaeker K, Ronner E, Ollenburger M, Franke AC, Klapwijk CJ, Falconnier GN, Wichern J, Giller KE (2016): Which options fit best? Operationalizing the socio-ecological niche concept. Experimental Agriculture 1: 1-22. DOI: https://doi.org/10.1017/S001447971600048X.

Wichern J, Wichern F, Joergensen RG (2006): Impact of salinity on soil microbial communities and the decomposition of maize in acidic soils. Geoderma 137: 100-108. DOI: https://doi.org/10.1016/j.geoderma.2006.08.001.

\section{Submitted manuscripts}

Wichern J, Descheemaeker K, Giller KE, Ebanyat P, Taulya G, van Wijk MT (submitted): Vulnerability and adaptation options to climate change for rural livelihoods - a countrywide analysis for Uganda. Agricultural Systems.

Wichern J, Descheemaeker K, Hammond J, Giller KE, van Wijk MT (submitted): Production variability and coping strategies for climate and price variability of smallholder farmers in Uganda. Climate \& Development. 
Hammond J, Pagella T, Fraval S, Wichern J, Teufel N, Kihoro E, Herrero M, Rosenstock T, van Wijk MT (submitted): The rapidly changing socio-economic landscape of smallholder farming in rural East Africa: insights for sustainable development.

\section{Conference proceedings}

Wichern J, van Wijk ME, Descheemaeker K, Giller KE (2017): Bringing food availability to scale: Mapping livelihood strategies for household food availability across Uganda. In: Impacts World 2017, October 11-13, 2017, Potsdam, Germany.

Wichern J, van Wijk MT, Descheemaeker K, van Heerwaarden J, Frelat R, Giller KE (2016): What Works Where for Whom - Identifying Farm Household Strategies for Food Security Across Uganda. In: Tropentag 2016, September 19-21, 2016, Vienna, Austria.

Wichern J, Descheemaeker K, van Wijk MT, Giller KE (2015): Food Security Patterns at Farm Household Level: Key Drivers and Options for Climate-Smart Agricultural Interventions. In: 3rd Global Science Conference "Clim ateSm art Agriculture 2015” March 1618, 2015, Montpellier, France.

Wichern J, Biemelt D, Grünewald U (2010): Analyse und Bewertung von Einflüssen auf den Wasserhaushalt von Seen auf eiszeitlichen Hochflächen des Ostbrandenburger Heide- und Seengebietes. In: Aktuelle Probleme im Wasserhaushalt von Nordostdeutschland: Trends, Ursachen, Lösungen, April 22-23, 2010, GFZ, Potsdam, Germany. 


\section{PE\&RC Training and Education Statement}

With the training and education activities listed below the $\mathrm{PhD}$ candidate has complied with the requirements set by the C.T. de Wit Graduate School for Production Ecology and Resource Conservation (PE\&RC) which comprises of a minimum total of 32 ECTS (= 22 weeks of activities)

\section{Review of literature (4.5 ECTS)}

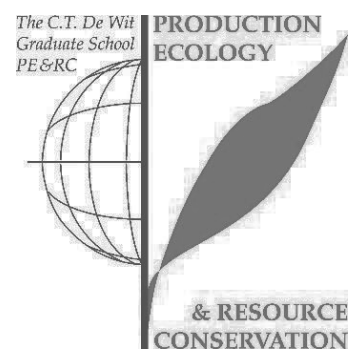

- Food security in the context of Sub-Saharan Africa rural livelihoods (2014)

\section{Writing of project proposal (4.5 ECTS)}

- Food security in a changing world: the effects of climate-smart agricultural practices on food security at different scales considering natural resource constraints and future trends

\section{Post-graduate courses (4.2 ECTS)}

- Introduction to R; PE\&RC (2014)

- Bayesian statistics; PE\&RC (2015)

- Geostatistics; PE\&RC (2015)

- Uncertainty propagation in spatial environmental modelling; PE\&EC (2016)

\section{Laboratory training and working visits (4.5 ECTS)}

- How do Uganda's sm allholder farm ers react to weather and price variability; International Institute of Tropical Agriculture (IITA) (2016)

- Changes of farming systems in Rakai, revisiting ImpactLite farmers after 5 years; IITA, International Livestock Research Institute (ILRI) (2017)

\section{Invited review of (unpublished) journal manuscript (2 ECTS)}

- Springer Plus: poverty and water access in agro-pastoral systems of the "cattle corridor" in Uganda (2016)

- Environmental, Development and Sustainability: crop switching as an adaptation strategy to climate change, case study Ethiopia (2017)

Deficiency, refresh, brush-up courses (3 ECTS)

- Quantitative analysis of land use systems (2015)

\section{Competence strengthening / skills courses (2.1 ECTS)}

- Scientific writing; Wageningen In’to Languages (2016)

- Career assessment; WGS (2018)

\section{PE\&RC Annual meetings, seminars and the PE\&RC weekend (3 ECTS)}

- PE\&RC First years PhD weekend (2014)

- Symposium: remotely sensed spatio-temporal dynamics of vegetation (2014)

- PE\&RC Midterm weekend (2015)

- PE\&RC Day (2016)

- Wageningen PhD symposium (2017)

- PE\&RC Last year weekend (2017)

- PE\&RC Day (2017) 
Discussion groups / local seminars / other scientific meetings (7.5 ECTS)

- Discussion group Sustainable Intensification of Agricultural Systems (SIAS) (20142016)

- WaCasa meetings (2014-2018)

- R-Discussion group meeting; Wageningen UR (2015, 2018)

- $\quad$ IITA Lunch meetings; Kampala, Uganda (2015-2016)

- Spatial targeting agricultural sustainable intensification investment workshop; Arusha (2016)

International symposia, workshops and conferences (5.7 ECTS)

- Third Global Science Conference on Climate-Smart Agriculture; poster presentation; Montpellier, France (2015)

- Tropentag; poster presentation; Vienna, Austria (2016)

- Impacts World Conference; oral presentation; Potsdam, Germany (2017)

\section{Lecturing / Supervision of practicals / tutorials (1.2 ECTS)}

- Food security course (2016)

- Quantitative analysis of land use systems (2017)

\section{Supervision of MSc students (6 ECTS)}

- Household food availability under weather variability and coping strategies of Uganda's farm households

- Natural resource use as a coping strategy for weather variability in Northern Uganda 

The research described in this thesis was financially supported by the CGIAR Programme on Climate Change, Agriculture and Food Security (CCAFS) and by the Plant Production Systems Group of Wageningen University \& Research.

The views expressed in this thesis cannot be taken to reflect the official opinions of these organisations.

Financial support from Wageningen University for printing this thesis is gratefully acknowledged.

Cover design by Jannike Wichern and Dennis Hendriks

Cover images by Jannike Wichern and Kamran Taherkhani, Mosaic by XXLPIX GmbH

Printed by ProefschriftMaken, www.proefschriftmaken.nl 

